\title{
CULTURAL REPRESENTATION OF NEW ZEALAND'S \\ LANDSCAPES IN THE FILMS OF \\ THE LORD OF THE RINGS \\ AND ITS IMPLICATIONS FOR TOURISM
}

by

Daniela Susann Carl

\author{
A thesis \\ submitted to the Victoria University of Wellington \\ in fulfilment of the \\ requirements for the degree of \\ Masters of Science \\ in Geography
}


Filmic images influence how we see the world and filmic tourists visit places to experience the image they have seen on the screen. New Zealand is an example of a destination that has embraced the relationship between film and tourism. Through its box-office success and the associated tourist promotions, The Lord of the Rings (TLotR) film trilogy has exposed New Zealand's landscapes to a global audience of potential travellers.

This study analyses the landscape portrayal in the first and second film of TLotR and filmic tourists' experiences of these landscapes. As with many other film tourism destinations, the screen locations are a mix of real landscapes, film sets, and digital enhancements. Thus, the tourist will not necessarily be able to experience the landscapes of the films. This results in implications regarding the sustainability of film tourism and tourism management.

The study employed an overall interpretive approach to analyse the landscape portrayal in the films and filmic tourists' experiences. Triangulation was used to reveal iconic landscapes of the films. Empirical research was undertaken with three tourism operators offering TLotR themed products: a half-day tour of the Hobbiton location in Matamata, a half-day jeep safari tour around Queenstown, and a multi-day tour of 'New Zealand as Middle-earth' for TLotR enthusiasts. Filmic tourists' experiences of former TLotR film sites are explored in these case studies.

The cultural landscapes portrayed in the films are a combination of actors' performances, narratives in the plot, film sets and digitally generated images. New Zealand's landscapes were used as geography, metaphor and spectacle as part of the narrative. This study determined that Hobbiton, Rivendell and Edoras were the three main iconic landscapes of the films. The findings show that the more perfect the representation of hyper-reality in the tours, the higher the satisfaction and the more enhanced the tourist experience. Filmic tourists desire to step into the film set and to be part of the film when re-enacting film scenes. In addition, guides integrate stories about the challenge of filmmaking or behind-the-scenes' anecdotes, which served to enhance the fascination and 'authenticity' of the experience.

There is still a need for more information and support to ensure high quality interpretation and guiding given the importance of these aspects in mediating tourist experience and informing resultant levels of satisfaction. By better understanding how filmic tourists experience these cultural landscapes, tourism operators and destination marketers can better meet expectations, thereby expanding the beneficial effects of film tourism on destinations. 
When I came to New Zealand, two years ago, I fulfilled my life's dream. However, as it is with dreams, one realises the risk of disappointment is high. Not in my case though. My expectations were very high but were easily exceeded by New Zealand's beauty and its people. I will always treasure my time here, and a piece of my heart will definitely remain in the 'Kiwi Country'. I would like to thank the many people who made this thesis possible through their support and encouragement.

Very special thanks to my supervisors Sara Kindon (Victoria University of Wellington - School of Earth Sciences) and Dr Karen Smith (Victoria University of Wellington - Tourism Management School) who helped me to develop my ideas, gave me guidance and always constructive criticism and encouragement when needed, but otherwise left it up to me.

I would also like to extend my thanks to the three case study operators who gave me the opportunity to undertake my research. Thanks for uncomplicated cooperation to: Rings Scenic Tours in Matamata, particularly Russell Alexander, Henry Horne, and the guides Wara and Amber; Vic James of Red Carpet Tours; Helen Jansen of Nomad Safari in Queenstown, and the Safaris of the Rings tour guides Mike, Jack, Tony, David, and Richard.

In addition, many thanks to tourism operators who were happy to give time for an interview: Chris Morrisey of Mountain Air, Mount Ruapehu; Jason Bragg of Wellington Rover Tours, Wellington; Les Cain of 4x4 NZ Ltd, Geraldine; Anne-Marie Forsyth of Tourmasters South Pacific NZ Ltd, Auckland; Barbara Swan of Heliworks Queenstown Helicopters, Queenstown; and Peter Davis of Dart Stables, Glenorchy. Furthermore, thanks to Sue Whiting of the Visitor Information Centre in Matamata and David Kennedy of Destination Queenstown. Helpful information was also provided by the staff in the Visitor Information Centres of Turangi, Whakapapa, Otaki, Wellington, Nelson, Christchurch, Geraldine, Lake Pukaki, Queenstown and Te Anau.

Moreover, thanks to all the participating filmic tourists in the chosen case study tours, for spending time completing the questionnaire or answering interview questions.

Thanks to the School of Earth Sciences at Victoria University for providing office facilities and something like 'home'. Morna Matangi-Want and Marita Basabas, the administration heroes in the school, always gave fast help when needed. 
Thanks to the tutors of the Student Learning Support Service who helped me at so many stages of this thesis as well as with my studies the previous year: special thanks to Ann Pocock and Deb Laurs.

Helpful information was also provided by academics from outside VUW, such as Glen Croy of the School of Tourism and Hospitality at the Waiariki Institute of Technology in Rotorua, and Richard Mitchell and Anna Carr both in the Department of Tourism at the University of Otago in Dunedin.

Thanks to Caroline Roughneen for re-awaking my hidden SPSS knowledge; Anke Timmermann for her help with the map data; Dr Ulrike Hardenbicker for her support, and Jo Spratt for proof-reading. Sláinte and thanks to Ann-Marie Carroll. Thanks also for their support to my officemates Ed Challies and Anton Griffith.

I would also like to thank the people who I have met during my stay in New Zealand who made me think and in some cases I became friends with. Thanks for keeping in contact, your encouragements and understanding to Angelika 'Angel' Pott and Paul Schneider.

Thanks to my former officemate Julie Smyth for the coffee breaks, the distraction of work and your attitude.

Cheers, for excellent feed, accommodation, encouragement, non-superficial conversations, proof-reading and company to procrastinate to Michelle Bird and Alastair Hancock.

'Ein GROSSES DANKESCHÖN' to friends of mine in Germany for being so loyal over the last two years: Marén 'El Shalom' Schorch, Judith Hübner, Vicky Roegels, Jasmin Altinok, Kerstin 'Hutzel' Berls, and Anja Liedtke.

I am deeply in dept to my family who made this thesis and my stay in New Zealand possible through financial support, encouragements, and their understanding. Thanks a lot for your faith in me! Ohne Eure Unterstützung wäre diese Arbeit nicht möglich gewesen. Von tiefstem Herzen Danke für Euer Vertrauen! 
Abstract

Acknowledgement:

Table of Contents

List of Figures

List of Tables

List of Boxes

List of Maps

List of Pictures

List of Appendices

1.1 Introduction

1.2 Rationale

1.3 Research Aims/ Questions and Objectives

1.4 Theoretical Framework

1.5 Research Methodology and Methods

1.6 Case Studies

1.7 Thesis Structure

2.1 Introduction

$2.2 \quad$ Case Study Approach

2.3 Theoretical Framework

2.4 Research Methodologies

2.5 Questionnaire Survey

2.5.1 Questionnaire Design 10

2.5.2 Data Collection 13

2.5.3 Sample Size and Distribution $\quad 14$

2.5.4 Data Analysis $\quad 15$

2.5.5 Ethical Issues 16

2.5.6 Limitations 16

2.6 Semi -Structured Interviews 17

2.6.1 Semi-Structured Interview Design 17

$\begin{array}{ll}\text { 2.6.2 Data Collection } & 18\end{array}$

2.6.3 Sample Size and Distribution $\quad 18$ 
2.6.4 Data Analysis 18

2.6.5 Ethical Issues 19

2.6.6 Limitations 19

$\begin{array}{lll}2.7 & \text { Research Diary } & 19\end{array}$

2.8 Textual Analysis of Landscape in the Films of The Lord of the Rings 20

2.8.1 Limitations 21

$\begin{array}{lll}2.9 & 22\end{array}$

Chapter Threes Cultural Geography and Film 23

$\begin{array}{lll}3.1 & \text { Introduction } & 23\end{array}$

3.2 Culture and Cultural Geography 23

3.2.1 Landscape Studies 24

3.2.2 Cultural Geography and Film 25

3.2.3 Cultural Representation in Film 28

$\begin{array}{lll}3.3 & \text { Film as Medium } & 30\end{array}$

3.3.1 Landscape in Film/Filmed Landscape 31

3.3.2 Reading Landscape in Film 33

3.3.3 New Zealand's Landscape in Film 35

3.3.4 The Films of The Lord of the Rings 36

$\begin{array}{lll}3.4 & 36\end{array}$

Chapter Fours Film Tourism 39

$\begin{array}{lll}4.1 & 39\end{array}$

4.2 The Tourist Experience: Motivations, Expectations and Satisfaction 39

4.3 Film as Destination Promotion 42

$4.4 \quad$ Film-induced Tourism and Filmic Tourists 44

4.4.1 Film and Travel as Form of Escape 44

4.4.2 Hyper-Reality 46

4.4.3 Authenticity, Myth Creation and Film Tourism 46

4.4.4 Filmic Tourists' Experiences 48

4.5 Film Tourism induced by the Films of The Lord of the Rings 50

$\begin{array}{lll}4.6 & & 53\end{array}$

Chapter Fives Findings and Discussions Landscape portrayal in The Lord of the Rings films 55

$5.1 \quad$ Introduction $\quad 55$

5.2 Middle-earth as a Concept and Myth 55

5.3 Landscape Portrayal in The Lord of the Rings Films 61 
5.3.1 Landscape and Place in the $1^{\text {st }}$ Film- The Fellowship of the Ring 61

5.3.2 Landscape and Place in the $2^{\text {nd }}$ Film- The Two Towers 70

5.3.3 Symbolic Landscapes $\quad 76$

$\begin{array}{lll}5.7 & \text { Chapter Summary } & 78\end{array}$

$\begin{array}{lll}\text { Chapter sixs } & \text { Findings and Discussions Film Tourism }\end{array}$

$\begin{array}{llr}6.1 & \text { Introduction } & 80\end{array}$

$\begin{array}{lll}6.2 & \text { Case Studies } & 80\end{array}$

6.2.1 Matamata: Case Study Rings Scenic Tours 82

6.2.2 Queenstown 90

6.2.2.1 Case Study Safari of the Rings 96

6.2.3 Case Study Red Carpet Tours 100

6.3 Other Film Site Locations and Tourism Operators 103

6.3.1 Tongariro National Park 103

6.3.2 Otaki 104

6.3.3 Wellington 104

6.3.4 Canterbury 105

6.3.5 Central Otago 106

6.3.6 Tourmasters South Pacific NZ Ltd 106

$\begin{array}{ll}6.4 & 107\end{array}$

$6.5 \quad$ The Lord of the Rings Filmic Tourists 115

$\begin{array}{lll}6.6 & 119\end{array}$

Chapter sevens Findings and Discussions Filmic Tourists' Experiences

121

$\begin{array}{lll}7.1 & \text { Introduction } & 121\end{array}$

7.2 Iconic Landscapes and Filmic Tourists' Experiences 121

$\begin{array}{lll}7.3 & 130\end{array}$

7.4 Filmic Tourists' Experiences of The Lord of the Rings Film Sites 135

7.4.1 Fulfilment of Expectations 136

7.4.2 Tour Satisfaction 142

7.4.3 Impact of Film Watching on the Experience 146

$\begin{array}{lll}7.5 & \text { Chapter Summary } & 147\end{array}$

Chapter Eights Final Discussion and Recommendations

149

$\begin{array}{llr}8.1 & 149\end{array}$

$\begin{array}{lll}8.2 & \text { Research Evaluation } & 149\end{array}$

$\begin{array}{llr}8.3 & \text { Findings } & 150\end{array}$ 
8.3.1 Representation of New Zealand's Landscapes in the Films

8.3.2 Filmic Tourists' Experiences 151

8.3.3 Iconic Landscapes 154

8.3.4 Implications 155

8.4 Discussion and Conclusion 159

8.5 Film Tourism Management Recommendations 161

8.6 Suggestions for Further Research 164

$\begin{array}{ll}\text { Bibliography } & 165\end{array}$ 
Figure 6.1ı Information sources of respondents Rings Scenic Tours 88

Figure 6.2z Information sources of respondents Safari of the Rings 99

Figure 6.33 Country of origin of all respondents 107

Figure 6.48 Country of origin of respondents within each case study 108

Figure 6.5s Gender representation within each case study 109

Figure 6.63 Age groups within each case study and total proportion 110

Figure 6.78 Main purpose/motivation of all respondents to visit NZ

Figure 6.88 Importance of The Lord of the Rings films to visit NZ of

Safari of the Rings respondents

Figure 6.98 Previous visit to NZ

Figure 6.10: Plans to revisit NZ

Figure 6.11 Length of stay in NZ of all respondents

Figure 6.12s Travelling companions of all respondents

Figure 6.13: Frequency of watching the $1^{\text {st }}$ and $2^{\text {nd }}$ films per case study group 116

Figure 7.1s Similarities of NZ's landscape and Middle-earth

Figure 7.28 Perceived similarities between NZ's landscape and Middle-earth 133

Figure 7.3: Fulfilment of expectations (half-day tour experiences)

Figure 7.48 Fulfilment of expectations (multi-day tour experience)

Figure 7.5? Satisfaction with tour experience (half-day tour experiences)

Figure 7.68 Satisfaction with tour experience (multi-day tour experience)

145

\section{List of Tables}

Table 6.13 Comparison length of stay per case study group and TRCNZ results

Table 7.18 Landscapes in the $1^{\text {st }}$ and $2^{\text {nd }}$ films - comparison of the iconic value 
Box 2.18 Objective two related questions

Box 2.28 Objective three related questions

Box 2.38 Objective four related questions

Box 3.1ః Geography in film

\section{Box 4.18}

An experimental model of the influence of major motion pictures in tourism (an excerpt) $\quad 49$

Box 6.1ః Comments against improvement 90

$\begin{array}{ll}\text { Box 6.28 Red Carpet Tours itinerary } & 101\end{array}$

Box 8.1ః Reasons for expectation fulfilment/disappointment 153

$\begin{array}{ll}\text { Box 8.28 Reasons for tour satisfaction } & 154\end{array}$

\section{List of Maps}

Map 4.1ః Film NZ: Studio NZ/ Home of Middle-earth promotional map 51

Map 5.1s Middle-earth 56

Map 5.28 Physical and plant geography of Middle-earth 50

$\begin{array}{ll}\text { Map 5.38 Political geography of Middle-earth } & 60\end{array}$

Map 6.1ః Case study locations and itinerary of Red Carpet Tours 81

Map 6.28 Map of former Hobbiton film set 85

Map 6.33 Location of Deer Park Heights 94

Map 6.48 Other former film sites visited or planned to visit by respondents 118

\section{List of Pictures}

$\begin{array}{lc}\text { Picture 5.1ః The Shire (film image) } & 62\end{array}$

Pieture 5.28 Isengard after nature was destroyed (film image) 65

Picture 5.32 Backdrop of Isengard 65

$\begin{array}{ll}\text { Picture 5.42 Rivendell (film image) } & 66\end{array}$

Picture 5.5s Edoras - guarded entrance of the Golden Hall (film image) 74

\section{Picture 6.18}

Visitor Information Centre Matamata: Rings Scenic Tours merchandising articles 83

Picture 6.28 Guide using picture boards for demonstration 86

$\begin{array}{ll}\text { Picture 6.38 Guide using picture boards for demonstration } & 86\end{array}$

Picture 6.48 Glenorchy Air pamphlet (size changed) - Trilogytrail 92

Picture 6.5ః Glenorchy Air pamphlet (size changed) - Trilogytrail 92 
Pieture 6.68 Air Fiordland pamphlet (size changed) - Wings over the Rings 94

Pieture 6.78 Air Fiordland pamphlet (size changed) - Wings over the Rings 94

Picture 6.83 Deer Park Heights sign to The Lord of the Rings (LOR) former film site 95

Picture 6.92 Deer Park Heights sign to The Lord of the Rings former film site 95

\section{Picture 7.18}

Edoras- Éowyn standing in front of the Golden Hall overlooking Edoras (film image) 125

Picture 7.28 Tourism New Zealand advertisement 125

Picture 7.38 Hobbits hiding from Black Rider (film image) 126

$\begin{array}{ll}\text { Picture 7.48 Hobbit holiday } & 127\end{array}$

$\begin{array}{ll}\text { Picture 7.58 The Argonath/Pillars of the Kings (film image) } & 128\end{array}$

$\begin{array}{ll}\text { Pieture 7.68 Kawarau River - Backdrop for The Argonath } & 128\end{array}$

$\begin{array}{ll}\text { Pieture 7.7ః Rohan refugees (film image) } & 128\end{array}$

$\begin{array}{ll}\text { Pieture 7.88 Mountain tarn on Deer Park Heights/Queenstown } & 128\end{array}$

Picture 7.98

Tourism New Zealand - Marketing of New Zealand as Home of Middle-earth 131

List of Appendices

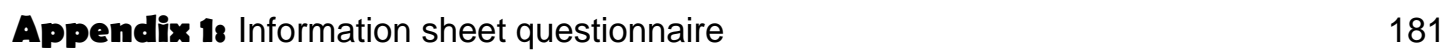

$\begin{array}{ll}\text { Appendix 28 Questionnaire } & 182\end{array}$

$\begin{array}{ll}\text { Appendix 3z Information sheet interviews (filmic tourists) } & 188\end{array}$

$\begin{array}{ll}\text { Appendix 48 Consent form interviews (filmic tourists) } & 189\end{array}$

Appendix 58

Information sheet interviews (tourism operators \& Visitor Information Centre staff) $\quad 190$

Appendix 68

Consent form interviews (tourism operators \& Visitor Information Centre staff) 191

Appendix $7 \mathbf{8} 1^{\text {st }}$ film- plot summary of landscapes 192

Appendix 8z $2^{\text {nd }}$ film- plot summary of landscapes 194

Appendix 9: Plot summaries $1^{\text {st }}$ and $2^{\text {nd }}$ films of The Lord of the Rings 196

Appendix 10: Rings Scenic Tours pamphlet 199

Appendix 11: Safari of the Rings pamphlet 200

Appendix 12: Rings Scenic Tours postcards 202

Appendix 13: Iconic landscapes named by respondents 203

Appendix 14: Explanations of similarities of NZ and Middle-earth (question 4) 204 Appendix 15,

Adjectives describing landscapes in the films and the real landscapes (question 2 and 5) 208 
Appendix 16: Specifications of expectations by respondents (question 6)

Appendix 17: Specifications for tour satisfaction by respondents (question 9) 


\section{$1.1 \quad$ Introduction}

The success of the first two films in the trilogy The Lord of the Rings exposed New Zealand's landscape as portrayed as Middle-earth, to a huge global audience of potential tourists. These two films, along with the media coverage identifying New Zealand as the place of filming, reached 200 million viewers and readers worldwide (Tourism New Zealand 2003a).

The films are based on J.R.R. Tolkien's tale of good versus evil and a journey to rescue Middle-earth, a fantasy world, from destruction. Brook (2001: 1), even called it "a great travel book". The book provides detailed descriptions of landscapes, supported through maps. However, when Tolkien wrote the books on which the films are based, he had a mixture of real and fantastic landscapes in mind, not New Zealand, where he had never been (Brook 2001; National Geographic 2001).

Before the successful films by New Zealand director Peter Jackson, New Zealand was known for its natural beauty and diversity, its efforts in cultural harmony between the two main races (Māori and Pakeha), its anti-nuclear politics, and its role in introducing voting rights to women before any other country.

It was in the global context of a political environment filled with fear of terrorist attacks when the first film was released (December 2001). The films, as well as numerous reports about the country that provided the backdrop for filming, portrayed New Zealand as a peaceful paradise, still off the beaten tourist track. In times of tourism stagnation all over the world, New Zealand tourist numbers increased by 3.8 per cent in 2001/2002 (Tourism New Zealand 2002a). However, this increase has not only been due to the successful The Lord of the Rings films but reflects a combination of factors.

For many recent travellers to New Zealand, the films of The Lord of the Rings may have provided the final stimulus to visit the country. One study showed that "about 69 per cent of potential visitors said they were motivated to visit New Zealand as a result of the films" (Coventry 2003: 2). On the other hand, it has to be acknowledged that it also takes time for a film to create tourist demand, particularly to an expensive long-haul destination such as New Zealand.

As "New Zealand has become the embodiment of Middle-earth to millions of moviegoers and J.R.R. Tolkien fans the world over" (Brodie 2002: 98) New Zealand's 
tourism industry has high hopes for film tourism. For that reason, New Zealand has been promoted as the Home of Middle-earth or even as Middle-earth (Air New Zealand 2003; Tourism New Zealand 2002b). In particular, the New Zealand Tourism Board's consumer webpage (www.purenz.com), has aligned itself with the film trilogy. The webpage offers filmic tourists an interactive map of New Zealand with the locations of the films in the shape of a travel guide (Tourism New Zealand 2003b: 19). Furthermore, Air New Zealand has labelled itself the Airline to Middle-earth and is, in this sense, the biggest flying billboard in the world. This promotion campaign includes three Boeings with pictures of each part of the trilogy on the outside, carrying the tourism promotion all over the world.

Despite the faith of the New Zealand Tourism Board in these films, the impact of films on tourism is hard to measure. That said, research done elsewhere by scholars shows a relationship between successful films and TV programmes, and increases in tourist numbers in the featured destinations. Moreover, these scholars have shown in particular, that underdeveloped tourist destinations can benefit from film-related tourism (for example Riley and Van Doren 1992; Tooke and Baker 1996; Stewart 1997).

In the case of New Zealand and The Lord of the Rings, tourists are obviously interested in visiting destinations featured in the films, and tourism enterprises have already reacted to this demand. Nationwide operating tours have been set up and locally based tourism operators are integrating The Lord of the Rings former film sites in their existing tours or designing new products exclusively focused on the portrayed locations.

The growing desire of people to visit featured locations can also be seen in the success of lan Brodie's Lord of the Rings Location Guidebook (2002; 2003), which includes a multi-day itinerary to the locations portrayed in the films. In addition, Tourism New Zealand web pages (2003c) offer a variety of self-driving routes for filmic tourists to the featured locations of the films. Furthermore, Te Papa in Wellington has been the host of a very successful exhibition about the films. Nearly 200,000 people visited this exhibition between December 2002 and the Easter weekend 2003 (Tourism New Zealand 2003d). In this exhibition the props and costumes were presented like archaeological findings of an ancient society. After leaving Te Papa the exhibition embarked on a tour across Europe, the United States, Australia and Asia (Te Papa 2002).

This thesis will use The Lord of the Rings as a case study to reflect how a nation's landscape, as portrayed in film, is reinterpreted for the purposes of tourism. Moreover, it will investigate how tourists experience New Zealand's landscapes and 
whether this is related to their viewing of the films of The Lord of the Rings. The films were released over a period of three years between 2001 and 2003. Due to the timeframe of the study, it has not been possible to include the third film of the trilogy in any analysis. The focus of this research is on the first two films of the trilogy - The Fellowship of the Ring and The Two Towers.

\section{$1.2 \quad$ Rationale}

Film, as well as the whole area of popular culture, remains neglected in the field of cultural geography. In contrast, geographers have tended to study 'more sophisticated' and 'elitist' cultural aspects such as literature (Tuan 1978; Pocock 1981; Herendeen 1986), although a few geographers have also considered popular culture from a geographic perspective (Burgess and Gold 1985; Wall 2000).

With reference to film, a knowledge gap is present and, in particular, there is a lack of film case studies in cultural geographers' research. Existing film tourism research is limited to the USA, Europe and Australia. Gaps in academic tourism research exist, furthermore, in case studies done on filmic tourists' experience of former film sites. Therefore, this study will contribute to further understanding of the role played by the representation of landscapes in films, in particular in the films of The Lord of the Rings, and their relationship with tourists' landscape experiences.

As a human geographer, with interests in cultural aspects of both geography and tourism, the researcher believes that geography, more than any other academic discipline, is able to affiliate issues associated with landscape, culture, tourism and film. Furthermore, her own interest in the topic is related to being a geographer, a tourist of sorts and, of course, a moviegoer who watched the first film of the trilogy overseas before arriving in New Zealand, and the second film after having been here for almost a year. These personal experiences made her realise that viewing the films made a significant difference in the way she perceived New Zealand's landscapes.

The importance of this study for New Zealand is that the tourism industry is promoting New Zealand as the Home of Middle-earth (Tourism New Zealand 2002b). For that reason, this study will contribute to an understanding of how tourists experience former film locations in New Zealand. A better understanding of filmic tourists' experiences, and the implications for local tourism bodies and tourism operators, is essential for future planning and the sustainability of film tourism.

The outcome of this research will be of interest to the national tourism board, regional tourism bodies in the regions portrayed in the films of The Lord of the Rings, 
and tourism operators offering The Lord of the Rings themed products. In addition, an intended audience is academics in cultural geography and tourism studies.

\subsection{Research Aims/ Questions and Objectives}

The aim of this study is to answer the following research questions.

- How are New Zealand's landscapes portrayed in the films of The Lord of the Rings?

- How do filmic tourists experience these landscapes and how are these experiences informed by tourists' previous viewing of the films of The Lord of the Rings?

- What are the implications of the landscape portrayal for film tourism in the selected locations and for New Zealand more generally?

To answer these questions the research was based on the following four objectives:

Objective 1: Analyse how New Zealand's landscapes are portrayed in the films of The Lord of the Rings;

Objective 2: Evaluate how filmic tourists experience the landscapes of New Zealand and how their experiences are related to The Lord of the Rings films;

Objective 3: Determine landscapes shown in the films which have a potential to attract filmic tourists and act as icons; and

Objective 4: Discuss the implications for The Lord of the Rings film tourism and New Zealand more generally.

\section{4}

\section{Theoretical Framework}

Media research in geography has taken two main epistemological approaches: the American behavioural approach, and the European, particularly the UK, poststructural approach. The first view focuses on the effects of mass media upon an individual's attitudes as well as their behaviour. This approach is also influenced by cognitive psychology. The European/UK approach is concerned more with the construction of meaning, politics, and cultural aspects through media. The researchers involved in this second approach focus on post-structuralism, semiotics, and Marxism as their epistemological framework (Burgess and Gold 1985).

Due to the nature of this study that combines textual analysis and interpretation of the landscape portrayal in the films, as well as empirical tourism research none of the above mentioned epistemologies was seen as appropriate to provide satisfying results. For the purpose of this research an overall interpretive approach, set in the 
theoretical framework of social constructionism, was chosen for the analysis of the films and the findings of the survey/interviews.

\section{$1.5 \quad$ Research Methodology and Methods}

Within this research, a mixed-method approach was adopted that combines quantitative and qualitative research instruments. More precisely, film analysis and interpretation was used to reveal how New Zealand's landscapes were portrayed in the films. A questionnaire survey of filmic tourists explored their experiences of landscapes featured in the films of The Lord of the Rings. Semi-structured interviews conducted with filmic tourists teased out more qualitative information about the experience. The results of these interviews gave closer insights as well as made the results of the questionnaire 'richer' through quotations.

Furthermore, semi-structured interviews were conducted with tourism enterprises that offer tours The Lord of the Rings themed products as well as with staff in local Visitor Information Centres. The intention was, as with the survey questionnaire, to explore their experiences with filmic tourists. This provided more insight into the context of film tourism and future implications in New Zealand. Finally, the researcher's own responses to the research process were recorded in a research diary. The employed methods are further clarified in chapter two.

\section{$1.6 \quad$ Case Studies}

The trilogy was filmed at about 150 locations between Waikato and Fiordland (Tourism New Zealand 2002c: 8). However, the extent of this study could not take all those film sites into account. For the tourism research three case studies have been chosen. The first case study is located at Matamata in the Waikato region. Although not a former tourism destination, a very successful half-day tour Rings Scenic Tours was set up by the owners of the farm near Matamata where filming took place. The second case study is located in Queenstown where a well-established off-road jeep tour operator, Nomad Safari, offers two half-day Safari of the Rings tours. These two products were designed after the potential of The Lord of the Rings film tourism was noticed. Both tours include a number of former film sites in the Queenstown region. Beside these locally based and operating companies, Red Carpet Tours was chosen for a survey with participants on a multi-day film location tour. All three companies and their products are further explained in chapter six. 
This thesis is structured in eight chapters. Chapter two outlines the research methods employed and their use in answering the research questions. The case study approach is explained in detail and the research is situated within the theoretical framework. In addition, the methods used, such as questionnaire survey, semistructured interviews, research diary, and textual analysis of film, are covered.

Chapters three and four are devoted to literature reviews and reveal gaps in existing research. Chapter three reviews literature concerned with the cultural representation of landscapes, particularly in film. More precisely, it reviews existing literature on cultural geography with regard to landscape studies, cultural geography and film, and the cultural representation in film. The second section of chapter three deals with film as a medium, including literature on landscape in film and filmed landscape, approaches to read landscapes, New Zealand's landscapes in film portrayals, and the film portrayal of The Lord of the Rings.

The fourth chapter examines research done on tourism, particularly film tourism. It gives a brief overview of aspects of the tourist experience, such as motivation, expectation and satisfaction. Literature concerned with film as a promotional instrument for destinations is reviewed before moving on to film-induced tourism and filmic tourists. This section teases out several factors. These are: similarities between watching a film, and travel, as forms of escapism; the theory of hyper-reality that can be employed for filmic tourists' experiences; and authenticity and myth-creation for the purpose of film tourism. The existing literature on filmic tourists' experiences is also examined. Finally, chapter four introduces film tourism induced by the films of The Lord of the Rings.

Chapter five provides an introduction to Tolkien's work and his created fantasy world Middle-earth, which includes interpretations of possible messages interwoven in the story. The chapter also discusses the landscape portrayal and symbolic landscapes used in the first and second film of the trilogy.

Chapter six presents the findings and some discussion on the research conducted with filmic tourists and operators. It gives a detailed description of the three case study tourism operators and their The Lord of the Rings products. In addition, other former film sites of The Lord of the Rings films, and tourism operators using the film sites, are shown. An overview of the tourism research sample is given and The Lord of the Rings filmic tourists are described.

Chapter seven presents and discusses the iconic landscapes found through triangulation. The marketing of New Zealand as Home of Middle-earth or even Middle-earth is discussed combined with results of the survey. The final section of 
chapter seven presents the results, with discussion, of the filmic tourists' experiences of The Lord of the Rings products and how their experience was informed by watching the films.

The final chapter of this thesis, chapter eight discusses the implications of the results, draws some final conclusions, and makes recommendations for film tourism management and further research in the field. 


\section{Chapter two}

Methodology

\section{1}

Introduction

This chapter outlines the methods chosen for this research. More precisely, the case study approach is explained. The research is also set in a theoretical framework and the applicability of this framework is explained.

This research used a mixed-method approach combining qualitative and quantitative research of filmic tourists' experiences, and analysis and interpretation of the landscapes within the first two films of The Lord of the Rings. The research instruments of questionnaire survey, semi-structured interviews and research diary are explained. Along with this, the interpretive approach employed for reading film as text is elucidated. Triangulation was used to combine findings of the film analysis and information conducted through the questionnaire survey and semi-structured interviews to reveal the iconic landscapes of both films.

\section{2}

\section{Case Study Approach}

In academic research, case studies are "chosen when a rich descriptive real life holistic account is required that offers insights and illuminated meanings which may in turn become tentative hypotheses for further research" (Burns 1998: 385). In research on film tourism (see chapter four) case studies have been used to describe the phenomenon of film tourism and to develop theories based on the findings. The present research uses the first and second film of The Lord of the Rings as a film case study. In conjunction with this, three tourism operators ("Rings Scenic Tours", "Safari of the Rings" and Red Carpet Tours) were chosen to represent examples of the range of The Lord of the Rings products that have been developed and to conduct a survey/ interviews with filmic tourists. These operators all have newly designed products based on The Lord of the Rings films. More detailed information on the chosen operators is presented in chapter six.

\section{$2.3 \quad$ Theoretical Framework}

This research is set in the theoretical framework of social constructionism and interpretive axiomatic perspectives. In both frameworks it is believed that there is "no single, objective reality or truth which can be discovered" (Clarke 2001: 33). In social constructionism knowledge is seen as "always relative to its social setting (there are 
no absolutes), and the outcome of an active process of fabrication rather than the discovery of a reality pre-existent and fully" (Barnes 2000: 748).

In interpretativist tradition subjective methods are employed to understand the social world that is observed (Potter 1996). The researcher's own interpretation is combined within the methods. Interpretativists argue that the social world has "multiple, subjective realities" (Clarke 2001: 33). Interpretive methods are often criticised as lacking validity and reliability, particularly the idea that interpretations are purely subjective. However, from a qualitative perspective, the "multiplicity of interpretation is seen as strength [and] the role of human interpretation is highlighted, not ignored" (Potter 1996: 44).

Within this research quantitative and qualitative approaches are combined. It can be argued that quantitative and interpretivist methods, in their pure form, are incompatible. However, in contemporary social research mixing methods within the same study is common, and pluralism wanted (Clarke 2001).

The combination of quantitative and qualitative methods can provide perspectives at the 'macro' as well as the 'micro' level. As quantitative research aims to produce factual data from which generalisations can be made, information gained by qualitative research "can be used to illustrate, explain and add depth to the findings of quantitative research", through its exploration of meanings (Clarke 2001: 33).

This research focuses also on how filmic tourists construct meaning from viewing the films and what kinds of meanings. In this sense filmic tourists are semioticians who read the landscapes for signs familiar from the film portrayal (Urry 2002).

\section{$2.4 \quad$ Research Methodologies}

Research methodologies "are perspectives on research; they set out a vision for what research is and how it should be conducted" (Potter 1996: 50); in this sense "methods are tools - techniques of data gathering, techniques of analysis, and techniques of writing" (ibid). In other words, "methodologies are the blueprints; methods are the tools" (Potter 1996: 65).

When choosing a methodology the goal is to find a 'blueprint' that is best for a particular topic and thus, will be most appropriate to obtain answers to the research question(s) (Fitzpatrick et al. 1998). For the purpose of this research a mixed-method approach was used to gather and interpret findings through different lenses, thereby gaining deeper insights. 
There were two main ways the data was obtained. Firstly, in a quantitative way, using a questionnaire to gain information about filmic tourists who participated in a tour with "Rings Scenic Tours", "Safari of the Rings", and Red Carpet Tours. However, the design of the survey also integrated open-ended questions, which are more common in qualitative research. Filmic tourists who did not participate in an organised tour were contacted on former film sites as well as in hostels where the researcher stayed. These conversations about their experiences were informal. Secondly, qualitative research methods like textual analysis and semi-structured interviews with tourists and tourism operators were applied.

By using mixed-methods the strength of qualitative and quantitative approaches are combined because "both approaches are needed, since no one methodology can answer all questions and provide insight on all issues" (Burns 1998: 11).

\subsection{Questionnaire Survey}

A self-administered questionnaire, which included closed and open-ended questions as well as scaled questions, was chosen for the purpose of this research. A survey has the advantages of being relatively cheap to administer and a large sample size can be achieved. In addition, such a survey can also guarantee anonymity. Beside these strengths, however, disadvantages are abundant such as the usually low response rate, incomplete responses, superficiality, misinterpretation of questions and no room for freedom to expression (Burns 1998). To lessen these disadvantages and to make the results richer, open-ended questions also gave respondents an opportunity to give reasons for their choices.

A self-administered questionnaire was chosen as it is the most effective way to include a group of people at one place at the same time. This is most appropriate when taking into account a group of 30 people participating in the same tour.

\subsubsection{Questionnaire Design}

When designing the questionnaire questions needed to be easily understandable, particularly for non-native English speakers. Furthermore, the completion process could not be too time intensive. This was necessary as respondents of the two halfday tour experiences only had 10-15 minutes to complete the questionnaire. Respondents of Red Carpet Tours had no time constraint due to the fact that completed questionnaires were returned by mail.

An information sheet (Appendix 1) was designed and attached to the front of the questionnaire providing information on the study and contact details. The questionnaire (Appendix 2) comprised 20 questions of which the more complex, 
open-ended questions are located at the beginning. This is in contrast to common questionnaires that contain warm-up questions, usually concerned with demographics, at the beginning. This procedure was chosen to get participants' interest quickly. Respondents are most motivated at the beginning of a survey and thus more likely to give detailed answers. The less interesting demographic questions, that can be completed quickly, were located at the end of the survey. This meant the 'quick' questions were at the end and could be easily answered, particularly important when taking time constraints into account.

The questionnaire was structured in four sections. Section A (questions 1-4) dealt with the viewing of the films. Section B (questions 5-12) was based on the actual experience of the real landscapes as well as the tour experience. Questions in section $C$ (questions 13-19) focused on travel patterns of the filmic tourists. The final section $D$ (question 20) requested personal information about the tourist, such as country of origin, sex and age. A space for comments and suggestions was provided at the end of the questionnaire.

\section{Objective-related questions}

Within the questionnaire, 12 questions, either closed or open-ended, were designed to answer the objectives of this research. In detail, the second objective to evaluate how tourists experience the landscapes of New Zealand and how their experiences are related to The Lord of the Rings films, was answered by integrating six questions as shown in Box 2.1 into the survey.

Box 2.1: Objective two related questions

Question 1: Have you watched the film(s) of The Lord of the Rings?

Question 2: In your opinion which three words best describe the landscapes shown in the film(s) of The Lord of the Rings?

Question 4: On a scale of 1-5, please tell me how much you relate New Zealand's landscape to Middle-earth?

Question 5: Which three words best describe the actual landscapes of the former film location you have visited?

Question 6: Were the film locations/ landscapes you have visited as you expected them to be?

Question 9: Overall, how satisfied are you with this tour experience here? 
Question 1, 6 and 9 were combined and statistically analysed as described in section 2.5.4 in order to reveal whether there is a relation between the frequency of watching the films and filmic tourists' experiences.

The third objective: to determine landscapes shown in the films which have a potential to attract filmic tourists and act as icons, was answered through the questions listed in the box below (Box 2.2).

Box 2.2: Objective three related questions

Question 3: Which locations/ landscapes do you remember best from the film(s) of The Lord of the Rings?

Question 10: Have you been to other film locations of The Lord of the Rings?

Question 11: Are you planning to visit other film locations of The Lord of the Rings?

The final and fourth objective: to discuss the implications for The Lord of the Rings film tourism and New Zealand more generally was answered by including the following questions (Box 2.3).

Box 2.3: Objective four related questions

Question 9: Overall, how satisfied are you with this tour experience here?

Question 10: Have you been to other film locations of The Lord of the Rings?

Question 11: Are you planning to visit other film locations of The Lord of the Rings?

Question 12: Would you like facilities for The Lord of the Rings film tourism to be improved in any way?

Question 13: What was the main motivation to visit New Zealand?

Question 14: How important was the fact that The Lord of the Rings was filmed in New Zealand for your decision to come here?

\section{Pilot study}

When conducting a survey, it is appropriate and beneficial to pre-test the questionnaire in a pilot. This is to ensure that the formulated questions will provide the needed information. A questionnaire pilot was carried out with participants of the 
June group of the Red Carpet Tours. The outcomes resulted in a number of changes, such as in question 7 where it was appropriate to ask more specifically for an Internet address because all participants mentioned that they found information about this tour online. Question 12 was added to reveal whether visitors want facilities for The Lord of the Rings film tourism to be improved. Question 16 was also added to ask whether visitors are planning to come back to New Zealand in the future to reveal how sustainable their experience was. And finally, due to children under 20 participating in the pilot, the age group was divided into 'under 16' and '16-20 years' of age.

Due the fact that participants of the pilot were predominantly fans who had watched the films several times and therefore were very familiar with portrayed locations in the films, research done in Matamata showed that visitors who are not so familiar with the films had difficulties in completing question 2, 3 and 5 . Thus, the formulation was further clarified. In detail, in questions 2 and 5 a note was added requesting the participants to use adjectives to describe the landscapes. The former question 3: Which locations/ landscapes do you relate to the films of The Lord of the Rings? was changed to: Which locations/ landscapes do you remember best from the films of The Lord of the Rings?.

In question 7, lan Brodie's The Lord of the Rings Location Guide Book (2002) was added as an information source. In question 11, it was asked whether visitors were planning to visit other film locations. Beside the 'yes' and 'no' option, 'possibly' was added. Finally, question 14 was added inquiring as to what importance the fact that The Lord of the Rings was filmed in New Zealand played in tourists' decision to come here.

Logistical problems made it impossible to add these changes in the survey conducted in Matamata with Rings Scenic Tours. However, it was possible to include the changes in questions 2, 3, 5, 7, 11, and 14 in the Queenstown survey with Safari of the Rings' participants.

\subsubsection{Data Collection}

An on-site survey with a self-administered questionnaire was used and participants completed this questionnaire after they had been to the former film sites. To achieve a good response rate, the researcher personally handed out the questionnaires and collected them after the tours of Rings Scenic Tours in Matamata and Safari of the Rings in Queenstown. An exception was one group of Nomad Safaris' Safari of the Rings, where the questionnaires were handed out and collected by the tour guide. The tourists on the Red Carpet Tours were also contacted differently. 
In Matamata, visitors were contacted when entering the tour van or bus in front of the local Visitor Information Centre. This was the point of pick up and drop off for the tour. When handing out the questionnaires the request was to complete the questionnaire on the way back after visiting the former film site. The questionnaires were then collected after the tour. This procedure was carried out twice a day at 12:30 pm and 3:00 pm between $27^{\text {th }}$ July and $3^{\text {rd }}$ August 2003. The number of participants depended on demand by tourists attending each day.

In the case of Nomad Safaris' Safari of the Rings tours, it was not possible to hand out the questionnaires before the tour due to the lack of a fixed pick up point. Thus, the researcher joined the tour and, during the tea break, after two thirds of the tour, the questionnaires were handed out. This process was adopted for convenience of the tourists who were able to fill out the questionnaires outside the vehicle. The completed questionnaires were collected before the tour continued. Research within Safari of the Rings tours was conducted between $26^{\text {th }}$ August and $1^{\text {st }}$ September 2003 on morning tours (8:00 am and 8:30 am) as well as on afternoon tours (1:30 $\mathrm{pm})$.

Due to the different nature and the tight timeframe of the Red Carpet Tours, it was impossible to have personal contact with tourists. Therefore, tour guides of Red Carpet Tours handed out the questionnaire survey at the end of the tour and filmic tourists returned them in provided, pre-stamped envelopes. Only participants of the June (01.06.03 - 12.06.03) and the July (28.7.03 - 09.08.03) Red Carpet Tours could be included in the research because the August and September tours were cancelled due to lack of demand.

\subsubsection{Sample Size and Distribution}

When gaining information on a specific group of people, it is not usually possible, nor necessary to consult the entire group $(\mathrm{N})$. In addition, it is in most of cases impossible to define $\mathrm{N}$ by a specific number. In relation to the just developing The Lord of the Rings film tourism, it is hard to define $\mathrm{N}$, or the size of a sample $\mathrm{n}$ that may provide a good representation of $\mathrm{N}$. Only a low number of filmic tourists at the study sites could be reached due to the fact that the research timeframe fell into the tourism off-peak season.

The population $\mathrm{N}$ in this research was defined as all filmic tourists visiting the former film sites of The Lord of the Rings on an organised tour in New Zealand. The sample $\mathrm{n}$ in this research consists of 132 completed questionnaires. 73.5 per cent of the surveys were conducted within Rings Scenic Tours in Matamata ( $n=97), 14.4$ per cent within Safari of the Rings tours in Queenstown ( $n=19)$, and 12.1 per cent of the 
questionnaires were collected within two Red Carpet Tours $(n=16)$. These visitor surveys were carried out during winter 2003, between June and September.

The response rate for each of the three case studies varied due to different circumstances of carrying out the survey. 71.4 per cent of the Red Carpet Tours' respondents completed questionnaires. This represents the lowest response rate within the present research. A possible explanation is the lack of personal contact between the researcher and the respondents because the tour guides carried out the questionnaire. Furthermore, respondents had to return the completed questionnaire by mail, which may have been bothersome to some.

In the case of Rings Scenic Tours the response rate accounted for 89.7 per cent. This higher number is due to personal contact while handing out the survey and the knowledge that the researcher was to collect it again after the tour was finished. On the other hand, two aspects lessened the response rate. Firstly, on site, a second researcher from La Trobe University of Melbourne was conducting interviews and some respondents might have felt 'over researched'. In addition, there were a high number of groups, either families or couples (see chapter six), that participated in the tours. When approaching groups, reactions like "my wife can answer these questions for me" came up. The researcher tried to approach these unwilling tourists but only in some cases could she convince them to participate.

The most successful response rate of 100 per cent was with the Safari of the Rings tours. In this case, the researcher participated on the tours where the survey was conducted. A personal relation was able to be established in conversations, mainly started by the guides, about the research and this integrated the participants of the tour into the survey. Thus, the embarrassment and threat of losing face by declining the survey might have been too high. Also a greater understanding of the researcher and the study would make people want to help.

Overall, an average response rate of 87 per cent is a highly satisfying result, which reflects the filmic tourists' excitement about their visit to the former film locations and their desire to share their experience.

\subsubsection{Data Analysis}

Prior to data input and analysis, the questionnaire was coded. Providing categories, e.g. multiple-choice questions to choose from, does the coding for closed questions. Open-ended questions required a categorisation of answers. These categories were designed after reading completed questionnaires. 
The data obtained from the questionnaires were transferred into an EXCEL spreadsheet and analysed using the statistical program EXCEL. When data were coded and entered into the EXCEL spreadsheet, accuracy was checked.

To answer the second research objective the data from questions 1, 6 and 9 were transferred to the statistical program SPSS, uncompleted responses deleted and statistical tests conducted. Data was set in cross tabulation tables to display an existing relationship between the categorical variables of: i) frequency the films were watched, and ii) indicated expectations and satisfaction of respondents. Chi-square tests were carried out to determine if the relationship between the cross-tabulated variables was significant or not. In addition, regression was used to reveal whether factors, such as frequency of watching the films and expectations, influenced respondents' evaluation of the tour satisfaction level.

\subsubsection{Ethical Issues}

The visitor survey raised no ethical issues as it was conducted anonymously. Participants received an information sheet (Appendix 1), which provided an explanation of the research project and gave contact details of the researcher as well as of her supervisors. Before survey and interviews were conducted, the content of the questionnaire, together with the semi-structured interviews, went through the ethics approval of the Human Ethics Committee at Victoria University of Wellington. The approval for this research was given on 13.06.2003.

\subsubsection{Limitations}

Limitations of this research have to be acknowledged. These are related to the small sample size and the unequal sample size of each case study. The physical distance between the researcher's residence (Wellington) and the main case study locations in Matamata and Queenstown, time and financial constraints, and the tourism offseason led to the mentioned limitations. Moreover, open-ended questions might have been disadvantageous for people with difficulties in expressing themselves, e.g. children and non-native English speakers. Another limitation of the questionnaire was the integration of changes as well as new questions in the different stages of the research. There may also be errors associated with inputting the data into the EXCEL spreadsheet. The assumption of this research is, however, that although these limitations exist, the influences are acceptable and have only limited effects on the analysis of the data and the conclusions drawn from the results. 


\section{6}

\section{Semi-Structured Interviews}

To gain a closer insight into tourists' experiences of the landscapes as featured in The Lord of the Rings films, the method of semi-structured interviews was used. This interview method was seen as the most appropriate due to the flexibility involved, meaning additional questions could be asked as well as issues explored in depth. People are also more willing to talk then write. This is important when conducting research with non-native English speaking respondents. Furthermore, a face-to-face situation leads to an increase in motivation of respondents to answer questions (Burns 1998). In addition, the researcher, herself a non-native English speaker, found a semi-structured interview procedure more comfortable.

Semi-structured interviews were chosen to structure the questions. This was needed due to time constraints, particularly in the case of interviews conducted with filmic tourists.

Interviews with filmic tourists were conducted at both locally based case studies in Matamata and Queenstown. In addition, semi-structured interviews with tourism enterprises that offer The Lord of the Rings themed tours, as well as staff in Visitor Information Centres around New Zealand were conducted to reveal their experiences with film tourism and filmic tourists. This provided more insight into the context of film tourism and its sustainability in New Zealand, which would address the fourth objective.

\subsubsection{Semi-structured Interview Design}

The questions in the tourist interviews intended to tease out the general trends identified by the questionnaire. In detail, the semi-structured interviews with filmic tourists covered four issues: the film experience; New Zealand as a destination and its relation to the films; the New Zealand experience; the evaluation of the tour; and the film tourism infrastructure. A pilot of these tourist interviews was undertaken in Wellington at a former film site at Mount Victoria.

The interviews with tourism operators and local tourism bodies were structured according to four topics: the history of the company and their The Lord of the Rings product; the product itself; experiences with filmic tourists; and future plans. A pretest was undertaken with Anne-Marie Forsyth from Tourmasters South Pacific NZ Ltd.

In both cases, the interview questions and structure were seen as appropriate and no changes were made after the pilots. 


\subsubsection{Data Collection}

Semi-structured interviews with tourists in the Matamata case study were conducted after filmic tourists returned from the tour. In the Queenstown case study, tourists were recruited during the tea break while other group participants completed the questionnaires. These interviews took between 10 to 15 minutes time.

Interviews with tourism operators were mainly conducted in the office of the particular company. In three cases, Dart Stables in Glenorchy, Rover Tours in Wellington, and 4x4 New Zealand Ltd. in Geraldine, other locations were used. In the first case this was a café in Queenstown, for the second the Visitor Information Centre in Wellington and in the latter, the private home of the owner of the company. The interviews with tourism operators and tourism officials varied between 10 to 45 minutes in time.

\subsubsection{Sample Size and Distribution}

Overall, seven interviews with filmic tourists were conducted with participants of Rings Scenic Tours in Matamata (three interviews) and Safari of the Rings in Queenstown (four interviews).

Interviews with tourism operators were conducted with enterprises in Matamata, Tongariro National Park, Wellington, Geraldine, Queenstown and Glenorchy. Tourmasters South Pacific NZ Ltd and Red Carpet Tours answered the interview questions via e-mail. Visitor Information Centres staff were interviewed in Matamata and Queenstown. The researcher also visited a number of other Visitor Information Centres, such as in Whakapapa/ Tongariro National Park, Otaki, Wellington, Christchurch, Geraldine, and Alexandra, to research how helpful staff are when filmic tourists would need advice, as well as to get an overview of what is offered in relation to The Lord of the Rings in these centres. Overall, 12 interviews were conducted with film tourism operators and local tourism bodies.

It was not possible to obtain research from tourists at all the above-mentioned enterprises. This was due to the lack of agreement of operators, availability of tourists, and financial and time constraints.

\subsubsection{Data Analysis}

Interviews conducted with tourists as well as with tourism operators were taperecorded. Then the interviewees' answers were coded. 'Coding is intended to make the analysis [of interviews] more systematic and to build upon interpretation through a series of stages, avoiding the temptation of jumping to premature conclusion" (Jackson 2001: 202). Coding meant that special words or sentences that came up 
several times in the context of a particular question were highlighted. These words lead to the formation of categories. The results of the interviews with tourists were used to deepen understanding as well as to make the results of the questionnaire 'richer' through quotations.

\subsubsection{Ethical Issues}

In the case of interviewed filmic tourists, an information sheet (Appendix 3 ) and a consent form (Appendix 4) was necessary that informed the participant about his/her right to withdraw from the interview as well as withhold any information without giving any reasons. By signing the consent form the participant agreed to the procedure of a taped interview and that the information given may be used for publications. However, participants were assured that their identity would remain confidential.

In contrast, anonymity was impossible to guarantee to tourism enterprises and staff in local Visitor Information Centres. These participants were informed about this issue, as well as the intention of the research project, with an information sheet (Appendix 5). Also here, a consent form (Appendix 6), which had to be signed was handed out and collected again. In one case, concerns were raised about answering a question related to sensitive business information. This question asked about the numbers of filmic tourists who had undertaking the tour at the time the research was conducted. In this case it was agreed to leave this question out.

\subsubsection{Limitations}

The limitations of the semi-structured interviews were mainly the limited time available. In addition, as with the questionnaire, non-native English speaking respondents might have had difficulties expressing themselves in the more openended questions.

On the other hand, there were also disadvantages of interviewing, such as the time involved, cost of audiotapes, and the limited number of respondents that could be interviewed at a time.

\section{$2.7 \quad$ Research Diary}

While conducting fieldwork, a research diary was used to record the researcher's own response to the research process, the experience of the former film landscapes, problems that the researcher faced during the fieldwork, notes on sampled tours, participant observations, the environment the survey and interviews were conducted in, and finally the tourism infrastructure at the locations of the former film sites. The approach of a research diary, also combining general field notes, was chosen to 
provide means of placing information in context when analysing and interpreting data.

\section{$2.8 \quad$ Textual Analysis of the Landscapes in the Films of The Lord of the Rings}

Geographers have always tried to understand landscapes. They look at either how physical processes have formed the landscape they observe, or how human beings change the landscape they live in. Human geographers and, in particular, cultural geographers view landscapes as an outcome of ways of thinking about a place (LeHéron 2002). This includes the analysis of the meaning of landscapes. This section describes the methods employed to obtain, analyse and interpret the meanings of landscapes as portrayed in The Lord of the Rings films one and two.

Scholars within cultural geography have developed ways of reading landscapes as texts (for example Cosgrove and Daniels 1988; Duncan and Duncan 1988; Duncan 1990; Barnes and Duncan 1992; Aiken 1997). Specifically, the films in this research were analysed by looking at how landscapes were presented, and how different types of landscapes were used to describe different people/creatures and their habitats in the films. This process is based on the new landscape school within cultural geography that emphasises the way landscapes are represented in texts, art or maps. Analysing the films in this way is important because visitors might have specific expectations and perceptions associated with these landscapes.

An interpretive approach was used to read the films as a text to analyse the portrayal of New Zealand's landscapes in The Lord of the Rings films. This method attempted to answer the first objective of this research: to analyse how New Zealand's landscapes are portrayed in the films of The Lord of the Rings.

Firstly, a plot summary of the landscapes portrayed in the first and second film of The Lord of the Rings was conducted. This was done by viewing the films, analysing the duration of time a particular scene was on screen, at which location within Middle-earth this scene was set, and in which real New Zealand landscape this scene was filmed. This method was used to find out how long a location within Middle-earth was on screen as this was thought to influence how the scene or landscape stayed in the viewers' memory. These results were compared to the survey and interview results collected from tourists themselves. Plot summary tables of the landscapes are attached in Appendices 7 and 8.

The third objective in this research, to determine which landscapes shown in the films have potential to attract filmic tourists and act as icons, is also partly answered with a film analysis. The focus is based on the approach of Riley et al. 
(1998) and classifies landscapes, along with film locations, according to their value as icons. Riley et al. (1998: 924) see an icon as "extraordinary or captivating (...) which viewers attach to a location shown in the movie". They go on to argue that:

By using the word 'icon', it is implied that a movie's symbolic content, a single event, a favourite performer, a location's physical feature, or a theme can represent all that is popular and compelling about a movie. Icons, abstract or tangible, become the focal point for visitation and the associated location is tangible evidence to the icon (ibid).

Often films have more than one icon for one, or a range of, locations (Riley et al. 1998). In the case of the films of The Lord of the Rings, the iconic attraction is the variety of natural scenery/landscapes used in the films. The task for this research was to examine which scenes were significant and could be seen as icons in their own right. The textual analysis focuses on the significance of a scene as defined either by screen time in the films, or whether it contained a crucial event or special feature, of the film. It was assumed that images portrayed in such significant scenes might stay in the memory of the tourists currently visiting The Lord of the Rings film sites, and affect their experiences and travel patterns.

Within the survey filmic tourists were asked what they thought could be seen as iconic landscapes of the films. The researcher's interpretation of iconic landscapes then was compared to tourists' view of these landscapes. In addition, tourists were asked to name other film locations of The Lord of the Rings, which they had previously visited, as well as whether they were planing to visit other locations while staying in New Zealand. These were again compared to the outcome of the examined iconic landscapes. This process is called triangulation.

Triangulation was employed to answer the third objective and can be defined as "the use of two or more methods of data collection" (Burns 1998: 324). In other words different angles are used to get results. Triangulation in combining qualitative and quantitative methods can strengthen the argument of the researcher. However, triangulation can also disprove arguments when different data sources used lead to different conclusions or are incomparable.

\subsubsection{Limitations}

The method of interpretation within textual analysis is subjective and influenced by various factors. However, this is perceived as strength within qualitative research (Potter 1996). The interpretation is based on the researcher's personal knowledge, cultural background, experiences, and position. Therefore, various people may arrive 
at different interpretations. It was realised that there are many other ways of reading and interpreting the featured landscapes. The researcher's interpretation was combined with information gathered from respondents in the sampled The Lord of the Rings tours, tour guides and the researcher's observation during fieldwork on the particular locations.

\section{$2.9 \quad$ Chapter Summary}

This chapter clarified the theoretical framework of social constructionism and interpretativist tradition the research is set in. A mixed-method approach, which combines quantitative and qualitative methods was used for the conduct of the research. In contemporary social research it is common to employ both quantitative and qualitative methods to add depth to survey findings and to reveal deeper meanings.

A case study approach, based on the first and the second film of The Lord of the Rings and three tourism operators, was employed. The three tourism operators all offer The Lord of the Rings themed products. These case studies explore filmic tourists' experiences of former The Lord of the Rings film landscapes, through the use of a survey and semi-structured interviews.

The study employed an overall interpretive approach to analyse the landscape portrayal in the films. Triangulation by combining findings of the interpretation of the films and the naming by respondents within the survey/interviews was used to reveal iconic landscapes of the films. Furthermore, semi-structured interviews with film tourism operators and local tourism bodies in the former film site were conducted to reveal their experience with film tourism and filmic tourists.

Limitations of the methods employed in this research were identified which are mainly concerned with the small and unequal sample size respectively and the study design.

The next chapter reviews existing literature and research done on film in the field of cultural geography. 


\section{Chapter three}

\section{1}

Introduction

Landscape within cultural geography studies is a vital and essential concept. Geographers have studied landscape through a variety of approaches and in a variety of contexts. Lately cultural geographers have also begun researching landscape in film. This chapter explores the relationship between cultural geography and film. It gives an overview of ways that landscape in general, and landscape in film in particular, can be analysed, interpreted and understood.

This chapter is divided into two sections. The first section shows how new ideas about landscape have influenced cultural geography and what aspects of culture are examined by scholars. Moreover, it discusses geographers' research in film and cultural representation in film.

The second section deals with film as a medium and discourse, as well as how film is influencing the way landscape is portrayed. Furthermore, approaches that can be specifically used to read and analyse landscape in film are discussed. The final two parts of this section briefly discuss how New Zealand's landscapes are portrayed in film, and give an insight into the films of The Lord of the Rings. Finally, the findings are concluded in the chapter summary.

\subsection{Culture and Cultural Geography}

Before turning to cultural geography it is appropriate to define the term culture. Hall (2002: 2), an anthropologist, acknowledges culture as "one of the most difficult concepts in human and social sciences and there are many different ways of defining it". Cosgrove (1994b: 116), a human geographer, stated similarly and adds that culture is "one of the most complex yet important concepts in the social sciences". A definition by Williams (1982:13) clarifies that culture is "the signifying system through which necessarily a social order is communicated, reproduced, experienced, and explored". Duncan (1990) refers to culture and cultural products as texts, which can be read in multiple ways. This approach to reading culture as texts is always related to the "politics of interpretation" (Duncan 1990: 16). McDowell's (1994) definition of culture is adopted for the purpose of this research. According to her culture is: 
a set of ideas, customs and beliefs that shape people's actions and their production of material artefacts [e.g. literature, philosophy, music, paintings, film], including the landscape and the built environment. Culture is socially defined and social determined. Cultural ideas are expressed and challenge these sets of ideas and values, which are themselves temporally and spatially specific (ibid: 148).

These ideas lead to cultural geography as a field within human geography that is concerned with human culture, both material and non- material and how this is related to the environment in which human beings live (Cosgrove 1994a). Cultural geographers are doing research in a variety of areas ranging from "analysis of everyday objects, views of nature in art or film to studies of the meaning of landscape and social construction of place-based identities" (Mc Dowell 1994: 146). This spectrum is continuously expanding due to the fact that "geography is everywhere" and culture is wherever people are (Cosgrove 1989: 118).

With the new cultural emphasis in geography, human geographers have examined a variety of fields of cultural aspects, such as literature (Tuan 1978; Pocock 1981; Herendeen 1986; Mallory and Simpson-Housley 1987), art and photography (Pringle 1988; Seamon 1990; Tuan 1990). Moreover, they have researched forms of mass media such as newspapers (Burgess 1985), travel literature (Zube and Kennedy 1990; Duncan and Gregory 1999), advertisements (Sack 1992), music (Ford 1971; Ford and Henderson 1974; Curtis 1976; Jarvis 1985; Gill 1993; Carney 1994; Leyshon, Matless and Revill 1995; Valentine 1995; Wall 2000), television (Brooker-Gross 1985; Gould and Lyew-Ayee 1985; Youngs 1985; Burgess 1987; Higson 1987; Adams 1992), and film (Manvell 1956; Zonn 1984; Jenkins 1990; Aitken 1991; Aitken and Zonn 1993, 1994a; Gold, Haigh and Jenkins 1993; Rose 1994; Lukinbeal 1995). However, film is still a relatively small field of research within cultural geography.

\subsubsection{Landscape Studies}

Geography is without a doubt the study of landscapes. This includes either aspects of physical, cultural, natural or imaginary landscape or a combination of these.

Interpretation of landscapes within cultural geography is based in the traditional American school of cultural geography, which was mainly influenced and dominated by Carl Sauer and his fellows at the Berkeley University. The main focus of Sauer's school was on the "material elements of culture and their representation in landscape" (Jackson 1995: 10). In his most influential essay The Morphology of 
Landscape, Sauer (1925: 46) states that "culture is the agent, the natural area is the medium, the cultural landscape is the result".

The lack of involvement of human aspects within this approach of analysising cultural landscapes led to new attempts to fill this gap. In particular in Britain, perhaps due to less influence from Sauer's landscape school, a new cultural geography emerged. Influential representatives of this approach are Cosgrove and Daniels. In their collection of essays The Iconography of Landscape (1988) Cosgrove and Daniels argue that "a landscape is a cultural image, a pictorial way of representing, structuring or symbolising surroundings" (ibid: 1). These new cultural geographers see landscape as a medium, which conveys meanings and therefore can be read and interpreted as text. Jay (1986: 182) stresses that "what is seen is not a given, objective reality open to an innocent eye, but an epistemologic field construct as much linguistically as visually". The method of regarding meanings as text that can be read, goes back to linguistic structuralism and post-structuralism.

Text and landscape can be interpreted due to shared similarities, such as foreand background, and different points of view which are incorporated in their narrative as well as layers filled with meaning in which we can shift (Duncan and Duncan 1988). In addition, both, text and landscape retain meanings. Thus, they are intertextual, represent our world, our society and the culture we live in. To understand this inter-textuality we have to decode these meanings of landscapes "in order to reveal the deeper processes that have made them and upon which the symbolic method rests" (Robertson and Richards 2003: 5).

\subsubsection{Cultural Geography and Film}

For cultural geographers, the importance of film, as a research object, is its ability to create and sustain stereotypes, its ability to form interactions between people, places and landscapes, and its ability to influence social identity (Burgess and Gold 1985; Aitken and Zonn 1994a; Lukinbeal 1995). In this context landscape can also be seen as a kind of stereotype.

Geographers, in particular, can use film to gain certain information. As Lukinbeal (1995: 5) acknowledges:

Film offers geographers a realm of information which combines multiple perspective[s], imagination, art, objective and subjective qualities, geographical information and geographical imagination. Films may also provide one way to explore personal and cultural perceptions and attitudes towards landscapes. 
Film is a part of contemporary popular culture and forms an integral element of our leisure activities. If something or somebody is popular then (s)he/it is "widely favoured" or "well-liked" (Jackson 1995: 76). Popular culture is associated with a culture for the masses, in contrast to high culture, which is seen as related to an elite (Burgess and Gold 1985; Jackson 1995). This implies that popular culture carries a negative undertone and might be a reason why it has been neglected in cultural geography research for such a long time. Recently, however, scholars have turned to aspects of popular culture such as film.

Aitken and Zonn (1994b: 5) call the geography of film an "embryonic research area". On the other hand, cultural geographers have researched film since the mid 1980 s in the context of how it can influence our construction of geographical imaginations. There are three notable collections of essays concerned with geographical aspects in film.

The first, edited by Burgess and Gold (1985), Geography, the Media, and Popular Culture, is an attempt to connect geographical research on media by British and American scholars. As with other fields of geographical research there are obviously different epistemological and methodological approaches between British and Northern American schools. British scholars primarily focus on the relationship between media and other forms of culture and politics. Their preferred epistemological approaches and methods are grounded in structuralism and semiotics. In contrast, Northern American scholars are more concerned with the implications of media on attitudes and behaviour of people. Therefore, their employed epistemologies and methods are based on phenomenology, behaviouralism, social and cognitive psychology.

Place Image in Media, edited by Zonn (1990a), consists of essays written by American scholars who emphasise on aspects of cultural geography, landscape studies, and studies of perception and behaviour. The intention is to determine how media produces meanings and how place is represented. Thus, these scholars consider four different elements of a communication model in their analysis: "(1) the medium and its associated image; (2) the place being portrayed; (3) the perceiver of the image, known as the audience; and (4) the individual or collection of individuals who created the image" (Zonn 1990b: 3). According to Aitken and Zonn (1994b: 10), the intention of this essay collection was to "provide an understanding of the processes through which information is conveyed by various media, with a specific focus on representations of place".

Thirdly, Place, Power, Situation, and Spectacle, edited by Aitken and Zonn (1994a), is the first book by geographers focusing exclusively on cinematic 
representations. The scholars within the book focus on filmic representation and how its impact can shape "social, cultural, and environmental experiences" (Aitken and Zonn 1994b: 5). Their essays are presented in three distinct parts. Part one is concerned with theory in geographical film research, followed by essays focusing on how film influences people and places. Essays in the final part deal with aspects of how film can be used to give us, the audience, an understanding of our place in the world in which we live.

In addition to these books, a selection of essays by cultural geographers are concerned with aspects of film and geography, such as Burgess (1987), Nicholson (1991), Wright (1993), Rose (1994), Lukinbeal (1995), Kennedy and Lukinbeal (1997), and LeHéron (2002).

Burgess (1987) examined landscapes portrayed in film and television as well as how geographers can read these landscapes. Her employed methods were grounded in British geographers' tradition of semiology.

The relationship between our perception of environment, gained through cinema and television, and the reality of these landscapes is a focus of Nicholson's (1991) paper Images of Reality. He looked, in particular, at examples of film and television productions made in Scotland and how these have impacted on a kind of pilgrimage to the locations, and the location itself.

In his article, The Real River That Runs Through It: Montana's Imperilled Blackfoot, Wright (1993: 18) studied the impacts of the 'geographical myth' in the film The River Runs Through It. The story of the film was set on a particular river in Montana but all scenes were filmed on other rivers far distant from this location. Moviegoers were so fascinated by the scenery that they wanted to live in Montana along the river, which led to an enormous boom in real estate.

Rose (1994) examined two films made by community groups in the East End of London in the 1970s. The chosen films portrayed how these groups see and experience their surroundings, the place where they live. Thus, her analysis was concerned with cultural politics and the representation of the post-modern western city in film.

In addition to the above work, there is an ongoing critique of bipolar models of methods and epistemologies used by geographers when studying film. Kennedy and Lukinbeal (1997) have addressed this concern and tried to find a holistic approach to geographic research on film. Their answer is transactionalism but they also acknowledge: 
geographic research on film should not seek one unifying theory, but rather move into a multiplicity of scales and combine different theoretical frameworks in creative new ways (ibid: 47 ).

Finally, there are two theses worthy of mention here. The first one, A Geography in Film, A Geography of Film by Lukinbeal (1995), is concerned with models that are used to analyse the relationship between geography and film. Secondly, Le Héron (2002) researched landscape in film and film landscape as an attempt to translate place, using a variety of films that portray New Zealand's landscapes.

However, except for Nicholson's essay (1991) to some extent, none of these volumes of work by geographers are concerned with the specific link between cultural representation of landscape in film and its implications for tourism. This is where the present research will add to existing knowledge.

\subsubsection{Cultural Representation in Film}

An image, a portrayal or a depiction can be a representation of something. Aitken and Zonn (1994b: 6) define it as follows:

To represent is to portray clearly before the mind, to give back to society an image of itself, or to act a part or a role. Representation is, of course, one of the oldest functions of art and theatre. Among other things, representation reinforces a set of societal structures that help individuals to make sense of surroundings that are otherwise chaotic and random, and to define and locate themselves with respect to those surroundings.

Therefore, a representation is a function of culture and as mentioned earlier, culture is concerned with "shared meanings" (Hall 2002: 1). Meanings in turn are dependant on language, which makes it possible to approach, and understand, but also to create culture (Barnes and Duncan 1992). How something, such as landscape in film, is represented can be read as a cultural text. Post-structuralists argue that "the way we gain an understanding of the factors that shape our lives is to deconstruct the multiple messages being conveyed to us by the objects we encounter" (Kitchin and Tate 2000: 22). Foucault (1972), one of the most influential post-structuralists, points out that how something is represented is always influenced by people's knowledge and beliefs. Therefore, representations can impact on people's lives in political, social and economic contexts.

In fact, we are surrounded by visual representations of places in daily life. This depicted place can be familiar to us, like the town we live in, or totally unfamiliar. 
Images of places that are familiar to us will not change our perception much when we watch these representations. Representations in film can be close to reality. However, we have to bear in mind that what we see is only a representation, a picture of which we see 24 frames per second when watching a film. A representation can change our perception of place, reinforce, or complement it. We are more likely to accept new images of places with which we are less familiar (Zonn 1990a).

Moreover, we are surrounded by cameras, which are recording representations of place. There is a camera at the VUW campus; every bank and even pedestrian zones are filmed around the clock for security reasons. These cameras portray ongoing changes in the lives of people and whole societies. Representations are acting as a kind of 'back coupling' process, which means that changes are recorded and at the same time these recordings (i.e. films) are influencing and changing our lives. In addition, the old photo album has been replaced by the collection of videotapes, which show us moments of holiday trips, weddings, or birthday parties. We record in moving visual form to tell the story of our lives.

Questions that occur are: What is real and what is staged? Is the staged perhaps real to the same degree as the real is staged? Since the invention of moving pictures Western culture, particularly, has been influenced by visual images. If we watch a film we can assume that what is portrayed is not reality. However, filmmakers do not make it easy for the audience to be sure about this. Everything that we see in film is staged and highly subjective, always depending on the intention and perception of the filmmaker; how (s)he chooses to film the scene and what to depict. We might think a documentary is a portrayal of real life. For example, Peter Jackson's film Forgotten Silver (1995) makes viewers believe the story of a forgotten New Zealand film pioneer. In a documentary style, Jackson makes a sensational discovery of the first film document ever made in the world, which was filmed by Colin McKenzie, the protagonist of Jackson's film. Jackson is able to present the story in such a convincing documentary style and technique that it is easy to believe. Chapple (1995: 26) even called the film "New Zealand's biggest-ever hoax".

Thus, visual images manipulate reality and we are fooled into thinking that seeing is believing. Amazing technical advances in the process of filmmaking make it even more complex for us, the audience, to perceive an accurate sense of place or ourselves in the world. Representations in film also influence how we see the world around us. Denzin (1991) states that filmic representations and images are even felt as lived experience. This implies three things: 
First, reality becomes a staged, social production. Second, the real is judged against its staged, cinematic counterpoint. Third, the metaphor of the dramaturgical (theatre as life) society becomes the transactional reality (Aitken and Zonn 1994b: 7).

In addition, Nicholson (1991) argues about the impact of film (and television) on our geographic imagination. He says that:

For many of us, a perception of geography, of place, of the relation between our immediate surroundings and the world at large, is conditioned primarily through films and television (1991: 29).

In this research context, the present work seeks to find out how the New Zealand landscape is represented, what the messages are in the films of The Lord of the Rings, and the possible impact these representations have on tourists' experience of the 'real' New Zealand landscape.

\subsection{Film as a Medium}

Simply speaking, film is nothing more than a series of images in motion, pictures on celluloid shone through by strong light. It combines a specific language in a complex form of storytelling, which heavily relies on visual representation (Sadovichikoff and Macdonald 1997). This particular language is based on concepts and analytical terms of psychoanalysis, semiology and linguistic approaches (Burgess 1997). Film uses not only its own language to present meanings but also is a discourse. Film is an inter-textual medium that articulates other cultural texts when it is producing and communicating meanings. These meanings are in return dependent on the cultural background of viewers and the historical context in which they are watching.

For example, the German film Sonnenallee (1999) shows an exaggerated and humorous insight into everyday life of a group of teenagers in East Berlin in the 1970s. It is not a true story. Unfortunately, due to a lack of background knowledge as well as interest by West Germans, the intention of the director Leander Haussmann could not get through. The researcher realised herself when watching the film in both East and West Germany that different cultural and historical backgrounds, as well as knowledge, led to a different experience of the film. People in the East were disappointed because their history was portrayed in a humorous way. In contrast, West Germans left the cinema with comments like: "They had fun there. I am surprised". The meaning of this film will also be differently understood and experienced in different cultures, for example, if a Malay, Nigerian or Finn is 
watching. In addition, another historical background might influence obtained meanings, for example, the generation which was born in Germany post-1989.

"A film is difficult to explain because it is easy to understand" (Metz cited in Goldberg 2000: 1). The methods of interpretation of visual images are as broad as film is multidimensional in meanings. They range from content analysis, audience studies, psychoanalysis, and compositional interpretation, to semiology and discourse analysis (Rose 2001). However, none of these methods can be used as a universal approach. We have to consider that each of these has strengths to answer particular questions as well as weaknesses.

Film as a medium is special because it uses specific elements to transfer meanings. The most important element is the structure of the narrative, which can be divided into story and plot. The story refers to all events that are presented in a film. The plot, in return, refers to how these events are ordered and arranged in film (Prince 2001). Moreover, the mise-en-scène, which incorporates how something is filmed and what is filmed, "includes lighting, costumes, sets, the quality of the acting, and other shapes and characters in the scene" (Corrigan 1998: 45). In postproduction, messages of a film can be influenced and even totally changed in the process of editing or montage of the frames, as well as with the addition of special visual effects. Furthermore, the influence of sound and music in transporting or suggesting moods and emotions should not be underestimated.

Similar elements are integrated in films that we see on television. So what makes watching a film in cinema such a special experience? Beyond doubt, it is the atmosphere in the cinema that differs from sitting in a comfy position on a couch in one's living room. In a cinema, we sit in the dark, concentrating and paying full attention in front of a huge screen. The pictures on screen, and the sound, are of high quality and give us this special experience (Ellis 1991).

\subsubsection{Landscape in Film/Filmed Landscape}

"Landscape is a medium. Film is a medium for landscape" (LeHéron 2001: 39). Landscapes in film have a crucial function to "accommodate action and spectacle" (Aitken and Zonn 1994b: 17) and to make the narrative believable and more authentic. In particular, American geographers (Aitken and Zonn 1994b; Hopkins 1994; Lukinbeal 1995) distinguish between geography in film and geography of film. When looking at landscape in film/filmed landscape, the concept of geography in film can be used to categorise the way landscape is portrayed and integrated. Aitken and Zonn (1994b: 17) indicate that "place [landscape] become spectacle, a signifier of the film's subject, [and] a metaphor for the state of mind of the protagonist". In the 
context of landscape portrayed in film (geography in film), Lukinbeal (1995) places landscape/place as part of the narrative in film, as Box 3.1 clarifies. He distinguishes place in the narrative of a film as place as space, geography, metaphor, and spectacle. Place in this context can also be seen as a kind of landscape.

Box 3.1: Geography in film

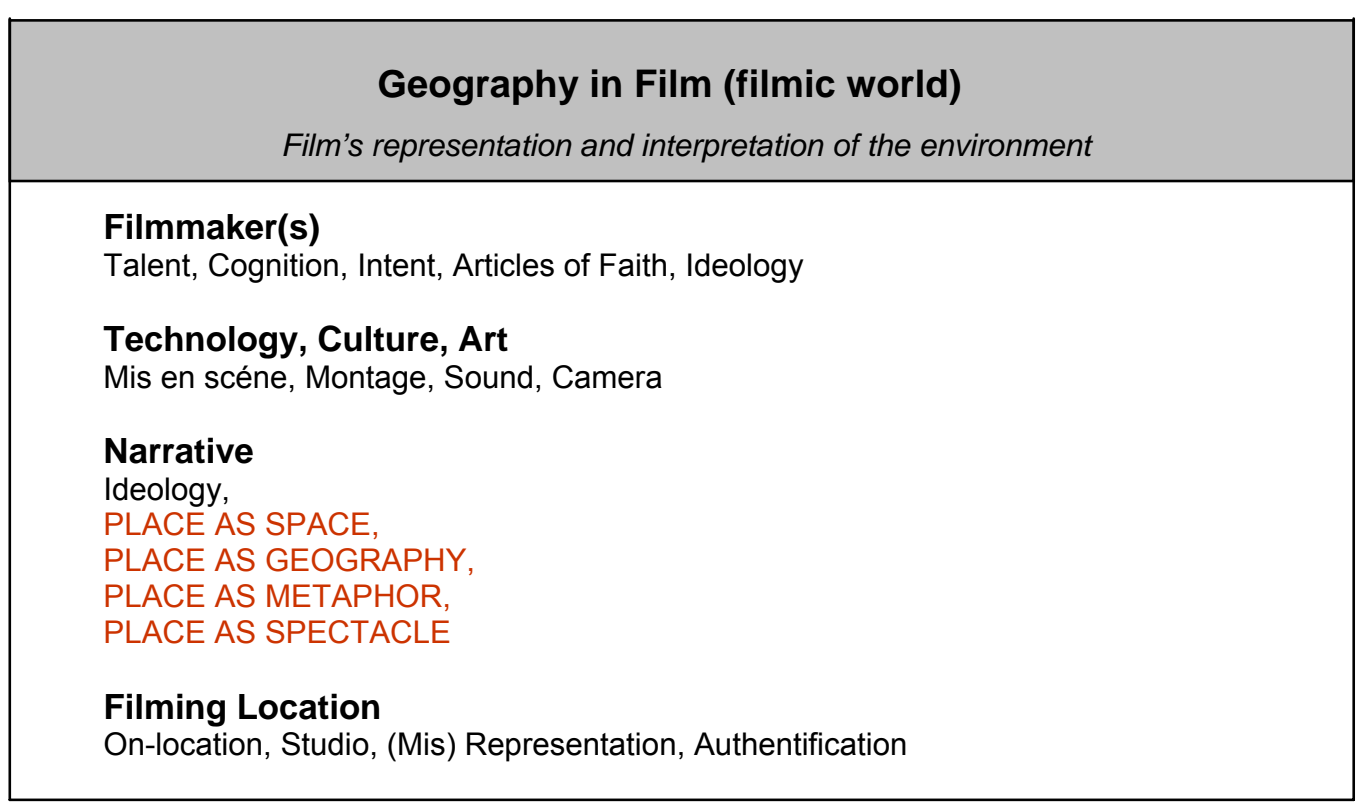

Source: adapted and modified after Lukinbeal 1995: 56

The use of landscape (place) as space in film means that action happens in landscape but landscape is not more than background to the plot. This refers to LeHéron's (2002: 109) view that "landscape processes and forces are not important in the story". For example, in the New Zealand film Goodbye Pork Pie (1981), the protagonists travel through New Zealand from Northland down to Invercargill when hiding from the police. However, here, the landscape is never more than something in the background of the story and the portrayed relationships are the centre of the film.

Landscape (place) as geography, in contrast, portrays a specific landscape, which can be recognised. This means the story takes place in this landscape and "transforms place [landscape] into narrative space" (Lukinbeal 1995: 68). The depicted landscape embraces the action in it. This concept is also related to what LeHéron calls "landscape-dominated films" (2001: 128). The films of The Lord of the Rings are examples of this category. Here, landscape is a character, which is actively participating in the narrative of the film.

Furthermore, landscape (place) as metaphor through which "the filmmaker(s) can appropriate ideology and meaning to place [landscape]" can be distinguished 
(Lukinbeal 1995: 69). More specifically, the way landscape is portrayed in film can emphasise the story or how the protagonist develops, his/her "state of mind" (Aitken and Zonn 1994b: 17). For example, Kennedy (1994) clarifies in her analysis of the film Lawrence of Arabia (1962) the change of the protagonist as the story develops. To enforce this development, the film director David Lean portrayed the landscape, predominantly the desert, in different ways.

Finally, landscape (place) as spectacle can provide two different aspects: "a spectacle of beauty or a spectacle because it generates curiosity and interest" (Lukinbeal 1995: 69). Higson (1984: 3) points out that:

The spectator [is] confronted by an image which is so fascinating that it seems complete; no longer the sense of something lacking; voyeurism blocked in a moment of fetishism.

\subsubsection{Reading Landscape in Film}

Landscape is a highly visual concept and "a way of seeing the world" (Cosgrove 1984: 13). As landscapes, in general, are inter-textual formations, the same can be said for landscapes in film.

When reading landscapes in film, it is important to distinguish between the landscape prior to filming and the 'product' that we view in the film. Therefore, different layers of meanings, texts and symbols have to be acknowledged as well as the intention of the filmmaker to translate landscape into film; all of which can alter the pre-filmed landscape. In detail, we need to consider how and why the landscape was transformed. This leads to the mise-en-scène (in which way the image was shot and what was chosen to be the image in film), montage, sound and the narrative structure in which the landscape is portrayed.

LeHéron (2002: 97) suggests three ways to analyse landscapes in film. These are "the opening and closing sequences", the "treatment of genetic place within film", and thirdly "the impact of traditional framing modes" (ibid). Furthermore, landscape in film can be analysed and interpreted by approaching iconography, a widely used inter-textual method in cultural geography. Iconography is "the description and interpretation of visual images in order to disclose and interpret their hidden or symbolic meanings" (Cosgrove 2000: 366). Thus, landscapes can be seen as an accumulation of culturally produced meanings. Cosgrove (ibid) argues that:

The iconographic method seeks to address these meanings through describing the form, composition and content of such representations, disclosing their symbolism, and interpreting the significances and implications of that symbolism by re-immersing landscapes into their social and historical contexts. 
Kennedy and Lukinbeal (1997) recommend transactionalism as a holistic approach to geographic research on film. Transactionalism is grounded within cognitive psychology, which "recognizes the link between physical environment and social systems by placing humans as an integral part of the environment, rather than an object in it" (ibid: 36). Transactionalism, as a research method, was also favoured by other American scholars such as Zonn (1984, 1985, 1990b) and Aitken (1991). Both these scholars researched transactions within film as well as between filmmakers and the audience.

When analysing landscapes in film we must bear in mind that film uses a specific kind of language to articulate meanings. Thus, semiotics (also known as semiology), which is strongly employed in linguistics, can be approached as a method of analysis. Rose (2001: 69) points out that "semiology offers a very full box of analytical tools for taking an image apart and tracing how it works in relation to broader systems of meaning". One of these tools, and doubtless the most important within semiology, is the sign. A sign can be a form of language as well as a "social and cultural product" (Aitken 1997: 205). Within semiology, signs consist of two components: "the signifier [the sound image] and the signified [the mental concept to which it refers - the object in reality]" (Burgess 1987: 3). Furthermore, Burgess (ibid: 5 ) suggests a structuring in "paradigmatic or vertical axis" and "syntagmatic or horizontal axis" cases. Both, she argues, "are key elements in representations of landscapes in film and television (ibid). According to Rose (2001: 99), however, semiology is limited due its "focus on the image itself and (...) little attention paid to audiencing and $(\ldots)$ reflexivity".

The last approach to analysing film, and landscapes in film, that requires mention here, is discourse analysis. The term discourse is grounded in Foucault's volumes of work. Discourse "is a particular knowledge about the world which shapes how the world is understood and how things are done in it" (Rose 2001: 136). In this context, both geography and film can be seen as a discourse, which uses a specific language to produce knowledge. Discourse can be expressed in a variety of structures. This means that inter-textuality is essential to consider discourse (ibid). Foucault stated (1977: 27) that "power produces knowledge" and in return knowledge implies power. Furthermore, whoever exercises the power also has the knowledge and therefore the truth (Rose 2001). In conclusion, discourse analysis can be used to discover how "images construct specific views of the social world" (ibid: 140) as well as in which inter-textual context an image is rooted. Discourse analysis is concerned with power relations, which are expressed in visual images (ibid: 161). 


\subsubsection{New Zealand's Landscape in Film}

New Zealand with its natural beauty and landscape diversity enables filmmakers to find nearly any film landscape that might be needed. Thus, the variety of landscapes that exist leads to multiple ways in which New Zealand's landscapes are portrayed in film.

Roughly, three ways of landscape portrayal can be differentiated. First and very common, particularly by non-New Zealand filmmakers, is the use of New Zealand's landscapes to reproduce landscapes from other parts of the world such as

"Italian lake district, American north west, Scottish highlands and lakes, Norwegian fiords, badlands in Nevada, Kansas heartland, coastline of Maine, Big Sur, Korea, Ireland and Ancient Greece" (Film New Zealand 1999: 21).

Film New Zealand argues strongly that filmmakers coming to New Zealand can save costs because expensive film sets to recreate particular landscapes are not necessary. A recent example of such a film project is The Last Samurai (2004). This film profits from the similarities in the shape of Mount Taranaki and Mount Fuji in Japan.

Second, New Zealand's landscapes are integrated in the portrayal of the country and its people, usually through films made by New Zealand filmmakers. New Zealand filmmakers portray their country as New Zealanders see themselves and their national identity (LeHéron 2002; Conrich and Woods 2000). Within this category belong films in which landscape strongly contributes to the film and particularly its narrative such as Utu (1982), The Piano (1992), and The Price of Milk (2000).

The third method of landscape portrayal, again popular with non-New Zealand filmmakers, is the trend to represent New Zealand as a pastoral paradise, "a place faraway in space and time" (LeHéron 2002: 13). Here, the portrayal of New Zealand's landscapes contributes to the "experience of otherness" (Jones 1999: 24) for nonNew Zealand audiences. New Zealand, as a country and a nation, is represented as a place that was spared of the negative aspects of most modern western societies. This is confirmed in Jones' (1999: 5) study of New Zealand film and its perception in Germany when he quotes Lindsay Shelton of the New Zealand Film Commission by saying that "many German people look upon New Zealand as an idyllic paradise where there are none of the problems which they face in everyday life in Europe".

In addition to these different approaches in landscape portrayal, it must be borne in mind that as with everything that is socially constructed, and landscape obviously is, the way landscapes are portrayed depends on the cultural norms and values dominating the society producing them. In the case of New Zealand, these 
norms and values are associated with majority Pakeha/ European culture, although lately a number of successful films made by Māori filmmakers and on Māori aspects have been released. The most recent example of the latter is Whale Rider (2003). However, it can be argued, that such films are seldom more than exotic film festival successes and the 'mainstream' and million dollar box-office films remain dominated by European and American style films.

\subsubsection{The Films of The Lord of the Rings}

With the production of the trilogy The Lord of the Rings, "the biggest cinema production ever undertaken in the Southern hemisphere" (Beattie 1998: 1), New Zealand's landscapes have been constructed and portrayed as somehow fairytalelike and "Tolkienesque" (Wright 2000: 52). It is debatable whether the films of The Lord of the Rings fit easily into the category of 'New Zealand film' (i.e. films which display a "strong New Zealand flavour" (Cairns and Martin 1994: ix)) as a high level of financial support was provided by the American film company New Line Cinema. That said, the trilogy is a New Zealand product as pre-production, production and post-production took place there.

Peter Jackson, a New Zealander and the director of the films of The Lord of the Rings, had the vision that New Zealand was the right place to unveil Tolkien's fantasy world and created this modern myth. The filming took place over 18 months in a variety of New Zealand's most spectacular and remote locations. This variety of New Zealand's landscapes provides "all the needed locations: from the Shire to Rivendell, the Misty Mountains to Mordor- it's all here out on our doorstep" (Jackson in Williams 1998: 1).

Tolkien's trilogy was originally set in a mystical medieval England or a northern European imaginary landscape. Due to his rich and detailed description of the landscape of Middle-earth, it was argued that the story could never be visually represented. The major problem in this context was to find appropriate locations to film as there are no landscapes left that are not transformed by civilisation in the U.K. (McKellen 2002). It is quite ironic therefore that the films are set in New Zealand when the required landscapes have to represent a European 'dark age'.

\subsection{Chapter Summary}

This chapter has addressed the variety of fields of research by geographers, in particular, the recent re-emphasis on culture. However, for a long time research was only focused on the more elite aspects of culture, such as literature or paintings; geographers neglected aspects of popular culture like film. 
Studies of cultural landscape in geography have their roots in Sauer's Berkeley School. However, particularly in the United Kingdom, scholars started to focus on aspects that appreciate humans and their impact on landscape. These new ideas and approaches within cultural geography recognised not only aspects of human culture and landscape, but also the different meanings and inter-textuality of landscape. Landscape is increasingly seen as text, which can be read and interpreted.

For nearly 20 years now, cultural geographers have being researching a variety of fields concerned with geography and film. However, the discipline seems to be divided in methods and approaches with two main branches - the British and the American influenced schools. There is great debate between researchers as to whose approach is best.

The chapter has discussed how influential visual cultural representation can be. It is such an important part of our daily life that we are often confused as to whether something is real or merely staged. Film is a cultural representation, which can be seen as a contemporary witness. Film is also a way 'Western' societies view the world and therefore it transplants their geographical imaginations onto the screen when using frames and symbols. When watching a film, we see the world with the eyes of the filmmaker; his/her vision of the world. These visual images seem to be more real than our fantasy images when reading a book, because all the other people (in the cinema) see the same images. Therefore, we perceive images on screen to be more real.

This chapter discussed how a recognisable landscape portrayal in film can make the story more believable and realistic. Landscape can even be seen as a character in film, which acts and changes as the story develops. Landscape in film, as part of the narrative, can be categorized in landscape as space, geography, metaphor or spectacle. Landscape in films can be analysed and read by employing a variety of approaches and methods, such as iconography, transactionalism, semiotics or discourse analysis. This study employs Lukinbeal's (1995) concept of landscapes in films as geography, metaphor and spectacle.

This chapter has also explored the idea that New Zealand's landscapes are portrayed in a range of ways. In some films the landscape plays an active role within the narrative. On the other hand, there are also films that use New Zealand's landscapes only in the background of the main story as an inactive actor. New Zealand, because of its diversity of landscapes, has been used to host many films where the story is not set in New Zealand. 
The following chapter, chapter four, reviews literature concerned with aspects of the tourist experience, particularly the experience of filmic tourists, and the links between film and film tourism. 


\subsection{Introduction}

The relationship between successful films or TV programmes, and increases in tourist numbers in the featured destinations, is shown in a variety of academic research. However, researched case studies are limited to the USA, Europe and Australia.

This chapter reviews literature concerned with the tourists' experiences and the relationship between film and tourism. The review reveals gaps in academic research. It also gives examples of how regional or national tourism bodies use images created in film as a promotional instrument for destinations. Case studies of film tourism destinations are reviewed to give a better understanding of tourism induced by film(s).

Literature on the experience of filmic tourists at former film sites is presented. In addition, the similarities of experiencing a film, and travel, as escapism are discussed. As film is based on simulations but, on the other hand, experienced as real when visiting former film sites, the concept of hyper-reality can be employed. Therefore this is briefly clarified in this chapter. Following this the literature is reviewed in relation to authenticity and myth-creation in tourism, particularly film tourism. However, aspects covered in this review are complex fields in themselves and can only be touched upon here.

Moreover, this chapter focuses on film tourism in New Zealand induced by The Lord of the Rings films. The chapter is finally summarised in the last section.

The Tourist Experience: Motivations, Expectations and Satisfaction

The tourist experience is the culmination of a given experience which a tourist forms when they are visiting and spending time in a given tourist location. The experience one forms is a complex amalgam of individual perception and image of a locality and the products consumed which can be influenced by individual, environmental, situational and personality-related factors as well as the degree of communication with other people (Page et al. 2001: 412). 
The aspects Page et al. (2001) mention form the highly complex picture of tourist experience, which integrates visitors' motivations, expectations and evaluations of their trip satisfaction. Ryan (2002: 35) observes:

The context, meanings and experiences of tourism can vary from holiday to holiday, from tourist to tourist. To talk of the 'tourist experience' seems to imply a homogeneity which, in reality, is not always present. Rather, it can be argued that tourists experience competing motives and thus tensions exist between needs that might be, to a greater or lesser extent, mutually incompatible.

However, understanding how tourists experience a destination is a major challenge for the tourism industry in order to create satisfying holiday products and maintain benefits of tourism through repeated visitations or recommendations made to others.

\section{Motivations}

Reasons why tourists travel to a particular destination can be highly complex and might be due to a number of reasons. In general, it can be said that an individual travels to satisfy a personal desire. In other words, if a tourist's perception of a destination matches with their personal needs (s)he is motivated to visit the location (Holloway 2002).

In tourism literature, tourists' motivations are roughly classified as sociopsychological motives (push factors), such as the desire to experience something different or enhance the ego. These push factors also integrate recreational aspects. On the other side are cultural motives (pull factors) that lead to the choice of a particular destination (Crompton 1979; Schmidhauser 1989; Shaw and Williams 2002).

Iso-Ahola (1982), and Mannel and Iso-Ahola (1987) refer to seeking and escaping as motivations for tourism. In their model it is argued that a tourist is escaping personal or interpersonal environments to seek personal or interpersonal awards. Thus, the experience is the reward of the travel, and provides the very basis of tourism. Taylor (1998: 1) coming from an anthropological point of view, expresses a similar theory grounded in Bakhtin's (1981) Exotopy in which a tourist desires to leave the familiar place labelled as home "to come to contact with some other, and to return with some sign of gain reflecting the experience". Urry (1990: 3) notes that:

The tourist gaze is directed to features of landscape (...) which separate them off from everyday experience. Such aspects are viewed because they are taken to be some sense out of the ordinary. 


\section{Expectations}

The way tourists experience landscapes or places in general depends to a high degree on their expectations (Pocock 1992; Suvantola 2002). These expectations are often created by information such as prior images and beliefs. Suvantola (2002: 99) states that:

(...) an image created [e.g. in films] and enforced by sufficiently powerful markers and sustained by the travel industry, defines a destination more than any realities of the place.

Consequently, visitors' expectations may not always be realistic. This is particularly the case when little is known about the destination, or inaccurate perceptions have been built up, for example, through tourism promotional images or again through films.

Expectations are also highly subjective. This is, for example, obvious in different preferences of tourist environments. One tourist might prefer what Urry (2002: 150) calls the "collective tourist gaze", which could be, for example, a busy beach like the Copacabana in Rio de Janeiro, Brazil. For others, such a busy beach would be a terrifying experience. This tourist type would prefer the "romantic gaze" as Urry calls it (ibid). Page et al. (2001: 413) suggest that:

"an individual's ability to tolerate the behaviour of other people, level of use, the social situation and the context of the activity are all important determinants of the tourist experience" [because it is directly impacting on tourist satisfaction].

\section{Satisfaction}

Tourism literature on motivation argues that the tourist is motivated by escape or pull factors to satisfy a need and, likewise, to gain a rewarding experience. If this is achieved a tourist will have a satisfying holiday/trip experience. A definition by Pizam et al. (1978: 315) describes tourist satisfaction as "the result of the interaction between a tourist's experience at a destination area and the expectations he/she had about that destination". Ryan (1995) argues that a satisfying experience is achieved when the expectations and experience correspond. Definitions might vary, however, the main core is always that "satisfaction is a post-consumption evaluative judgement" (Westbrook and Oliver 1991 cited in Kozak 2001: 304).

The level of satisfaction also depends on tourists' feelings of well-being. "Those [tourists] who feel good are those who are satisfied because they have a preponderance of positive experience in their lives and in their holiday" (Ryan 2002: $55)$. Beside such mental attitudes it is also argued that the more experienced a 
tourist in travelling, the greater the level of satisfaction (s)he can gain from a holiday experience (Page et al. 2001).

Furthermore, there are, beside the holiday destination or performance by the tourism industry, related mechanisms that are beyond any influence such as climate, traffic, noise and pollution that also impact on the satisfaction of a holiday experience (ibid). Taking these impacts on tourists' satisfaction into account, it is not surprising that literature acknowledges the complexity of measuring tourists' satisfaction (Mannell 1989).

\subsection{Film as Destination Promotion}

A filmmaker does not in the first instance, intend to create a tourist gaze when choosing film locations. (S)he is choosing a site predominately to set the film's story in context or to use the landscape to support the plot. However, film(s) can act as a destination promotion instrument due to the length of exposure of a destination's image, which provides a connection and identification with it. Film as a promotional instrument is an easily accessible medium with the ability to reach a broad group of people in a non-sale environment. The effect of destination promotion is also enhanced through repeated film releases, for example on video, DVD, or TV (Croy and Walker 2003).

Regional and national film commissions encourage film directors to use their locations. These efforts often go hand in hand with national and regional tourism board's marketing strategies.

A representation in successful box office film(s) is used to create a brand for a country. Two good examples are Scotland with historic genre films like Braveheart, Rob Roy or Highlander, or Australia and the Crocodile Dundee films. The same has been done recently in New Zealand with the film trilogy of The Lord of the Rings, as is clarified further in section 4.5 .

As film is part of popular culture it has an impact on a mass audience by publicising and promoting consumable items. Consumable items are not only goods and services but also experiences and images (Mansvelt 1999). This includes places and landscapes. Urry (1990: 3) clarifies the influence, in the context of tourism, when he states that:

Places are chosen to be gazed upon because there is an anticipation (...). Such anticipation is constructed and sustained through a variety of non-tourist practices, such as film, TV, literature, (...) which construct and reinforce that gaze. 
Urry (1990), and Riley and Van Doren (1992) argue that such aspects of popular culture influence people and their travel patterns.

Film has the ability to reach a large audience and to influence many people with shown images and knowledge (Butler 1990). This is crucial when taking the high costs of tourism advertising into account. Riley and Van Doren (1992: 267) note that:

"recognition gained from motion picture films can be substantial and the recouped value through increased tourism, when compared with paid advertising promotions, is worthwhile".

The image-making process of a destination is a main requirement of the tourism industry (Ryan 1997). The image created and the perception this results in, influence tourists' travel decision-making processes. Middleton and Clarke (2001: 126) state that "destination images are not necessarily grounded in experience or facts but they are always powerful motivators in leisure travel and tourism". The hyper-real or staged image, portrayed in film(s), may not match with reality. Thus, tourism bodies responsible for the destination marketing "must be aware of the images created by authors [and filmmakers] and manage them accordingly" (Hilty 1996: 195) to provide a satisfying tourist experience. Hilty (ibid) continues to suggest that destination marketing bodies should "prepare visitors for what they are about to see" and achieve "a balance of realism and romanticism" when a destination's connection with a film is used for marketing.

Tourism research and experiences at former film locations have shown that films increase the awareness of a destination and awaken the desire to experience the places portrayed in film(s). In detail, scholars like Riley and Van Doren (1992) have studied how films promote tourism in a destination. Riley and Van Doren (ibid) analysed tourist numbers at former film sites in the USA, such as Rayburn Country, Georgia where the film Deliverance was filmed and Fort Hays/ Kansas where Dances with Wolves was portrayed; as well as films in Australia, particularly Crocodile Dundee.Their research showed that films can act as hallmark events and pull factors.

Croy and Walker (2003) showed how film(s) could be used for imaging and branding a destination with particular regards to Australia. Film and its impact on a destination's image have been assessed by Kim and Richardson (2003). Their study focused on how the images in film can influence viewers' perceptions of a place. Films used in this study were Before Sunrise, which was filmed in Vienna, and Groundhog Day, filmed in a small town in Pennsylvania.

How the tourist gaze impacts on former film locations was researched by Riley et al. (1998). In their research, ten former film sites in the USA were analysed 
according to the change/increase in visitor numbers. Beeton (2001) used a case study approach to analyse how the ABC television series Sea Change changed the visitor profile in Barwon Heads, Victoria, Australia. O'Connor (2001) examined the socio-cultural impacts of the television series Ballykissangel on the Irish village of Avoca in County Wicklow.

Thus, it becomes clear that case study research in film tourism located outside the USA, Europe and Australia is still neglected and this is where this research will add a new dimension by focusing on New Zealand and The Lord of the Rings.

\subsection{Film-induced Tourism and Filmic Tourists}

Filmic tourists are inspired to travel by film(s) (Riley et al. 1998). Therefore, film tourism is based on film-featured locations, as well as on filmic tourists' demands to visit these locations. Thus, in tourism induced by a film, the portrayed locations act as tourist attractions. The landscapes experienced when watching a film can lead to a film tourism gaze in which filmic tourists consume the familiar signs and symbols previously watched in the film(s), in an environment that dislocates and relocates the films narrative.

Film also familiarizes an audience with places (Kim and Richardson 2003). Due to exposure of tourist attractions through film, potential tourists can gather information and knowledge about a destination (Riley and Van Doren 1992). This familiarisation process with a destination increases the chances that people might travel to it. This is due to fewer risks anticipated with limited information. In this sense New Zealand, as a long haul destination that is time and cost intensive to travel to, can benefit from film.

Riley and Van Doren (1992: 269) conclude that three criteria of a successful film are crucial to induce film tourism: "uniqueness, status or timely significance". They argue that "if a film has these qualities it will magnify the tourism potential of a destination" (ibid) and thus possibly create a gaze by filmic tourists as occurred in, for example, Wyoming's Devils Tower National Monument, where visitor numbers increased by 74 per cent after the film Close Encounters of the Third Kind was released (ibid).

\subsubsection{Film and Travel as Form of Escape}

Leisure activities, like watching a film as well as travelling, are used as a way to escape. Both provide an opportunity of temporary relief from facing the real world with its challenges, problems and commitments. The tourism industry deals with dreams and desires, and so does film. 
When experiencing a film, particularly in the cinema, we separate ourselves from reality, due to the atmosphere in a darkened room surrounded by sound and facing a big screen (Turner 1988). We plunge into a fantasy world in between the imaginary and the real. This occurs despite the knowledge that film images are nothing more than a number of pictures; a representation of something that may not even exist in reality. However, in a good film we get involved in the story, empathise with the actor(s) and see the world with their eyes. In this way the image becomes a world of its own and, in a way, real. The power of the story binds us in the so-called diagetic reality, which is the fictional space created by telling the story and therefore, a space in which to escape while watching a film (O'Brien 2003; Hickethier 1993). Turner (1988: 110-111) points out that the "blurring of the boundaries between the imaginary and the real is at the heart of the cinema experience".

The desire to travel is often driven by a need to escape familiar environments to reach and experience something different. The tourism industry capitalises on this desire by promoting destinations as places to escape to (Rojek 1993), such as the tropical paradise or places with exotic cultures. The important similarity is that the destination appears to be different from home and so the tourist is not reminded of all the attachments the home has. As Taylor puts it:

the creation of myths and fantasy surrounding travel to distant land (...) [is] often accompanying the apprehension of physical distances in a romantic heightening of perceived difference (1998: 1).

The tourism industry creates "new escape areas organized around spectacle and sensation" (Rojek 1993: 136). Rojek (ibid) categorised these under four themes. The first theme involves black spots, also known as Dark Tourism, based on grave sites such as Ground Zero in New York or the cemetery Père Lachaise in Paris. Second are heritage sites, focusing on historical events or the life of former times. This achieved either with actors performing or tableaux, such as laser simulations, audio or model animations. Examples are the National Wallace Monument near Stirling, Scotland in which a 'talking head', simulated by lasers, tells the story of the national hero William Wallace (Scottish Tourist Board 2003), or the Plimoth Plantation in Massachusetts, in which actors, costumed and even talking in $17^{\text {th }}$ century dialects, perform their daily tasks as settlers of 1627 would have done (Plimoth Plantation 2004). Literary landscapes, the third theme, are created around an authors' life or places in which (s)he set the novel. Particularly in the UK, a large number of tourism destinations are using the connection to an author, characters, and places the story was set in for the purpose of tourism. Two examples are 
Thomas Hardy Country in Wessex and Catherine Cookson Country in Tyneside. Theme parks are the fourth category of created escape areas. Theme parks are closed leisure areas based around created attractions. This can be, as in the case of Disney World and Disney Land, around film/cartoon characters and historical or fantasy landscapes.

Film tourism can be added to Rojek's list of created tourism escape areas, as it is also based upon simulation, spectacle and sensation of constructed visitor attractions. Film tourism also offers temporary escape from everyday life's reality. The filmic tourist, searching for what was portrayed in film, is, thus, travelling in hyper-reality (Eco 1986).

\subsubsection{Hyper-Reality}

The gaze on themed tourist areas, for example by using on author's characters or films, is what Eco (1986) calls travel in hyper-reality. These places seem to be "more real than the original, hyper-real" (Urry 2002: 131). Hyper-reality is a post-modernism concept that was introduced by Baudrillard. He defines it as "the generation by models of a real without origin or original" (Baudrillard 1983: 2). To him today's society is conquered by advertisements, mass media and simulated leisure and spectacle (Rojek 1990).

Hyper-reality as a concept can especially be employed for tourism to media portrayed places. Couldry (1998: 94) argues that:

Television and film locations are apparently perfect examples of Baudrillard's theory of 'hyperreality': 'simulacra' in which 'model' and 'reality' are hopelessly confused in a world where access to unmediated reality is impossible.

For film tourism, Eco's (1986: 7) statement is highly relevant when he says "the 'completely real' [actual landscape] becomes identified with the 'completely fake' [film portrayal of landscape]. Absolute unreality is offered as real presence".

Scholars (for example Rojek 1990, Urry 2002) concerned with tourism and hyper-reality argue that new tourism entertainment forms are based upon "simulation, spectacle, impact and sensation" (Eco 1986: 7). These unrealities are then presented and experienced as reality. When watching a film the fiction is often accepted as fact although we know that it is not more than a representation of something or a fantasy world, like a matrix.

\subsubsection{Authenticity, Myth Creation and Film Tourism}

Tourism, as a leisure activity, is highly based on myths and fantasies. In this sense, "the creation of unreal images is essential for many tourists seeking to escape the 
blandness of home and work routines" (Ryan 1997: 202). In literature it is argued that the search for authenticity and myths is a product of modern western societies, which are lacking authenticity (for example Selwyn 1996; Urry 2002). The "non-modern [is] viewed as authentic, and the modern world [is] viewed as inauthentic" (Meethan 2001: 90). Meethan (ibid: 95) continues and defines authenticity as "a constructed value or set of values, (...) [which] cannot be accounted for without considering the social and material context in which it is located".

Academics, particularly in the social sciences, have ongoing controversies about authenticity in tourism. It is argued that tourists are searching for authenticity "even though the result might be a staged authenticity" (Pocock 1992: 236). Boorstin's critical voice labels the "tourist world as one of pseudo-events and inauthentic experiences" (cited in Pocock 1992: 236). Thus, tourists prefer the reproduced or staged image rather than the reality (Boorstin 1972).

If tourists desire the "ultimate fake" (Sterry 1998: 370), and this is what provides a satisfying experience, is it not justifiable to capitalise on this desire and create a synthetic cultural heritage for enjoyment and entertainment (Lickorish 1991; Sterry 1998)? On the other hand, what can be called authentic in today's world in which history is "replaced with simulations of the past" (Rojek 1993: 166) and cultural authenticity is lost to pure tourist entertainment (Cohen 1996)?

Some tourists are aware of these 'cheating' techniques used by the tourism industry. Urry calls this particular type of tourist 'post-tourist' as (s)he "knows that there is no authentic tourist experience, that there are merely a series of games or texts that can be played" (Urry 2002: 12). Cohen and Taylor (1976: 118) agree when saying:

Tourists even when searching for authenticity are capable of ironically commenting on their disappointment in not finding it: they see through the staged authenticity of the tourists setting and laugh about it.

For MacCannell (1976) tourism is a quest for authenticity. To him, in the context of tourism's authenticity there are front and back regions. The front region is where host and guest can meet, for example in the hotel. This is what he labels as staged authenticity. The back region is reserved for the host where everyday life happens and thus generally not opened to experience for tourists. For some tourists the staged authenticity of the front region is what they expect to see and what gives a satisfying experience, but for others this might not be satisfying enough.

Cohen (1988) articulates this difference in demands as a typology. His argument is that for different types of tourists, authenticity is important to different 
degrees. His typology comprises four tourist types ranging from the existential tourist type who is highly alienated and authenticity is central, to the diversionary tourist type who has a low alienation level and authenticity is less important. The first tourist type is described as elitist or independent tourist and the latter as mass package tourist.

Wang (1999) defines authenticity in tourism using three categories. Firstly, the objective-related authenticity in which "the provenance of an artefact needs to be established", for example, in a museum (Meethan 2001: 94). Secondly, he describes constructive authenticity in which authenticity is defined by "beliefs, perspectives [and] power" (Wang 1999: 351). This constructive authenticity is based on "some form of symbolic value" for a particular culture or social group of people (Meethan 2001: 94). Filmic tourists can be placed in this category as they are obviously fans of a particular film which has a certain value to them. Wang's final type of authenticity is termed existential authenticity, which is related to personal experiences a tourist had, and which give meaning to the experience (ibid).

Film tourism provides excellent examples of the concepts of authenticity and myth creation when the "imaginary [is] being commodified as heritage for the purpose of tourism" (Meethan 2001: 99). As in the case of the Sterling region, or even the whole of Scotland, the film Braveheart enhanced the myth of the national hero William Wallace. Filmic tourists visit certain attractions to find historical places related to the story as well as to the film (Stewart 1997). Ironically, Braveheart's plot is only partly consistent with historical facts, and the filming was pronominally undertaken in Ireland and not at 'original' locations in the Sterling region (Croy and Walker 2003).

A second example is the Australian film Crocodile Dundee. The success of the two films internationally (released in 1986 and 1988) branded the whole nation and their outback lifestyle. Filmic tourists travel to Australia to experience the 'real' outback lifestyle as portrayed in the films even though they might just experience a staged authenticity of make believe.

\subsubsection{Filmic Tourists' Experiences}

It is the filmmakers' portrayal that creates the frame through which tourists experience former film sites. If the filmic tourist's experience matches with his/her expectations, an authentic experience is achieved (Pocock 1992). This occurs despite the fact that the experience is based on expectations built up when watching fictitiously staged landscapes in film(s).

Filmic tourists experience the landscapes previously portrayed in film not in the landscapes own right but in terms of the film they are associated with (Sterry 1998). 
The hyper-reality of the film becomes reality, as the former film sites are real, and can be recognised and actively experienced.

When reviewing literature on film tourism it becomes clear that academic research on filmic tourists' experiences is very much in its infancy. However, notable attempts that have been made in this research area are Mitchell's (1998) experimental model on filmic tourist experience, Aden et al.'s (1995) research on interpretive community formation at a former film site in lowa and Schofield's (1996) research on the experience of tourists participating in alternative film heritage tours in Manchester.

Mitchell (1998) developed an a-priori model (Box 4.1), which offers a framework for testing and understanding hyper-real tourism and, therefore filmic tourists' experiences. He argues with his hypothetical model that, if expectations are based on hyper-real images in film(s) and this mismatch with the actual experience, it will lead to a real experience that may result in dissatisfaction. On the other hand, an experience that matches with the hyper-real expectations would lead to a satisfying experience. His concept is graphically shown in Box 4.1. However, he also acknowledges that the model has not yet been verified by empirical research, which is emphasised.

Box 4.1: An experimental model of the influence of major motion pictures in tourism (an excerpt)

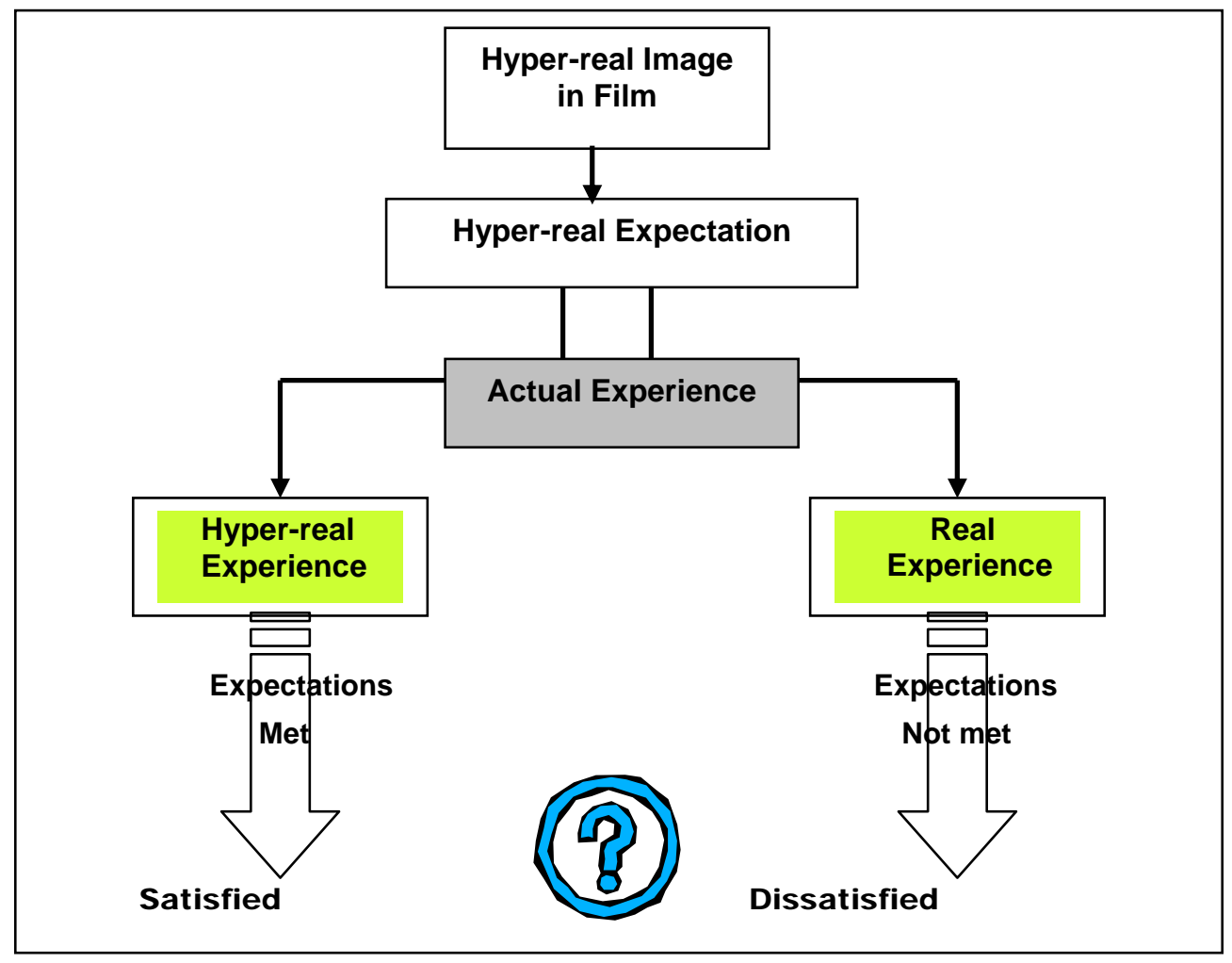

Source: adapted and modified after Mitchell 1998: 14 
Aden et al. (1995) analysed how filmic tourists formed interpretive communities to experience the former film site of the Field of Dreams in Dyersville, lowa. Their findings showed how watching the film resulted in reading and performing at the former film site by filmic tourists. More precisely, filmic tourists re-performed the action portrayed in the film. In so doing, these visitors "simultaneously produce and perform their own individualized texts [and] an interpretive community within which individuals can feel unique yet part of a larger congregation" is formed (Aden et al. 1995: 377).

Schofield (1996) researched the tourist experience on Manchester's Hollywood of the North film location tour. He concluded that:

the visitor's direct and indirect perceptual experience consist of a sequence of framed images from the window of an alternative media-themed heritage coach tour to the actual cinema screen, with the latter pervading, mediating and focusing the entire experience (ibid: 339 ).

Despite these studies, the lack of research evaluating the actual experience of filmic tourists at former film sites has to be acknowledged. The present research is an attempt to use findings from three case study film tourism products to provide a better understanding of how filmic tourists experience former film sites.

Furthermore, in the context of film tourism there is a lack of research on the motivating factors that cause people to become filmic tourists. This is despite the recognition that film can be used as an instrument to induce tourism to locations formerly featured in film (see for example Riley 1994; Tooke and Baker 1996; Croy and Walker 2003). Riley and Van Doren (1992) examined four motivations of people to become filmic tourists. These are the motivation of escape, which is in general, a main motivation in tourism; the pilgrimage; the nostalgia; and the search for untainted physical environments.

However, research is also needed to examine expectations and satisfaction levels of filmic tourists to better understand filmic tourists' experiences. This is where this research attempts to add to the knowledge gap.

\subsection{Film Tourism induced by the Films of The Lord of the Rings}

With the exposure of New Zealand's landscapes in these very successful films, moviegoers' awareness of New Zealand's potential as a travel destination increased. As Tourism New Zealand is aiming to promote the country as a tourist destination, the films are utilised as a promotional instrument to enforce the connection between 
the successful films and New Zealand as the place where they were filmed. Research recently undertaken by Tourism New Zealand (2003e) in Visitor Information Centres shows that 86 per cent of international visitors are aware before arriving that New Zealand is the place where the trilogy was filmed. The films are used to promote the country as the Home of Middle-earth or, as done by Air New Zealand, as Middle-earth (Tourism New Zealand 2002b; Air New Zealand 2003).

Aware of the positive effects of major film projects, during and particularly post production, the New Zealand government now offers tax breaks and other initiatives to attract film productions (Clark 2001). Film New Zealand is using the diversity of the landscape, as well as the filming infrastructure of The Lord of the Rings, to attract other film projects, to increase the awareness of New Zealand as a film location and "to broaden the view of what New Zealand offers as a visitor destination" (Film New Zealand 2001: 8). Film New Zealand created a map with a historical appearance to illustrate New Zealand as the home of Middle-earth (Map 4.1).These activities indicate how film and tourism industries can combine efforts to benefit.

Map 4.1: Film New Zealand: Studio New Zealand/ Home of Middle-earth promotional map

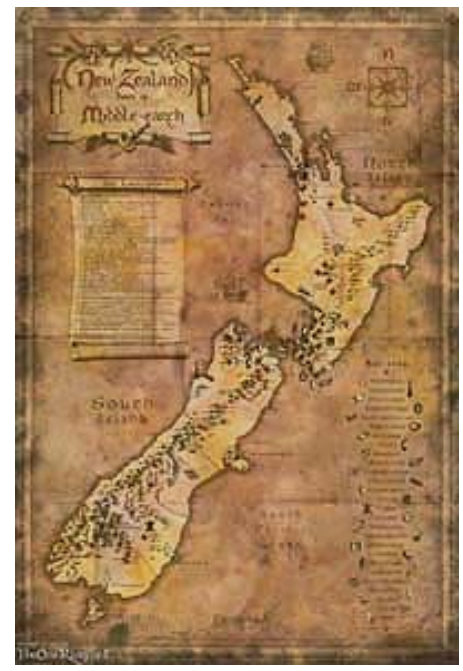

The map is divided in eight regions that show which locations were used for The Lord of the Rings films, their film infrastructure, as well as the local craftspeople in the particular region. Film New Zealand officials are confident that the map "will help tourism as well as the screen production industry" in New Zealand (Film New Zealand 2001: 10).

Source: Film New Zealand (2003)

The New Zealand Tourism Board estimates the value of the exposure of New Zealand in the first film of the trilogy to have a promotional value worth US $\$ 41,925,538$ (New Zealand Institute of Economic Research 2002). This means that the promotion could save over US $\$ 41$ million in costs and reach audiences that other promotion instruments may never reach.

Furthermore, in this context, New Zealand gained worldwide recognition when the Wellington-screened World Premiere of the third film was celebrated and 
broadcast through international media in December 2003. This media attention again reinforced the connection of the film trilogy and the country it was filmed in.

A study undertaken for the New Zealand Film Commission (New Zealand Institute of Economic Research 2002) on the lasting effects of The Lord of the Rings, expects an enhanced brand of New Zealand's tourism. In detail "significant effects on inbound tourism for New Zealand" are expected (ibid: 29). Another aspect in this context is that films are able to reach a larger audience than a conventional tourism promotion ever could (Walker 2001).

It may even be argued that New Zealand's tourism industry will benefit to the same extent Australia's did in their 1980s tourism boom. This was partly due to the successful Crocodile Dundee films. In New Zealand "The Frodo Economy", as the phenomenon is called, is booming (Huffstutter 2003: B5). It seems to be that everything related to New Zealand is 'trendy' and sells. In this manner, for example, designer outlets named as those where Liv Taylor, who acted as Arwen in the films, bought clothes are very successful in the USA now. Another example is a Wellington beauty therapist who experienced a wave of purchase orders after the actress used one of her products (Huffstutter 2003).

Little has been written on film tourism induced by The Lord of the Rings films in New Zealand. This is not surprising due to the short time since the release of the films, with the third and last part released in December 2003. Academic research done by Singh (2003) attempted to contribute to the knowledge on filmic tourists' motivation through a case study in Matamata (Hobbiton). He researched the motivations of filmic tourists to visit the former film site of Hobbiton, which has been portrayed (at the time the research was undertaken) in the first film of The Lord of the Rings film trilogy.

In the area of popular literature, Brodie (2002) has written The Lord of the Rings Location Guidebook, which includes a sixteen-day tour to the locations featured in the films. In Brodie's (2003) revised edition of the location guidebook, locations portrayed in all three films are included in a 23-day itinerary. The book also presents pictures of the landscapes as they were portrayed in the film and the same landscapes now, as tourists will find them. Also included is information on some locally operating tourism companies and their The Lord of the Rings themed tours.

The recently (October 2003) published The Rough Guide to The Lord of the Rings (Errigo 2003) gives information about the man (Tolkien) behind the story, the films, characters, Middle-earth and, most importantly in the context of film tourism, the locations portrayed in the films. The section on the former film locations gives information on what was filmed where and a general introduction to the particular 
region. Possibly due to the publication date in October 2003, the book has very limited information on organised tours at these sites.

Tourism New Zealand (2001a) is very positive about New Zealand's future as a film tourism destination due to film projects that have followed The Lord of the Rings. These film projects may continue to bring New Zealand landscapes to international attention as well as to further develop film tourism. However, the stories of these films as well as that of The Lord of the Rings are not based on New Zealand. Nevertheless, The Last Samurai (2004) in which Tom Cruise is starring, is an example where a whole region, Taranaki, is hopeful that this film project will bring benefits.

A film more related to New Zealand, and that raises hopes of tourism operators in the East Cape region, is the internationally awarded film Whale Rider (2003), which is based on a New Zealand story and location.

\section{6}

\section{Chapter Summary}

This chapter has given an overview of relevant research concerning film tourism and aspects related to the tourist experience. The chapter highlighted academic discussions around the complexity of aspects impacting on the tourist experience. The latter is influenced by motivations to travel, such as push and pull factors, or the escape-seeking dimension of travel. Furthermore, expectations influencing the tourist experience, and the degree to which the experience is satisfying, were discussed.

Film has the potential to act as a promotional instrument for destinations. This chapter discussed a number of examples of this along with previous studies. A film portrayal can even brand a whole country as in the case of Crocodile Dundee and Australia in the 1980s.

Chapter four also addressed similarities between watching a film and travel, as forms of temporary escape from everyday environments. This leads to the concept of hyper-reality in which it is argued that when watching a film, and then experiencing the portrayed landscapes, the boundaries of reality and unreality (hyper-reality in a film) are blurred. This in return impacts on filmic tourists' experiences of former film sites as shown in Mitchell's (1998) experimental model. This model proposed that only a hyper-real actual experience might provide a filmic tourist with a satisfying experience.

Furthermore, this chapter discussed academic arguments on authenticity, particularly in film tourism. Knowledge gaps on filmic tourists' experiences have been identified as well as the limitation of studies in the USA, Europe and Australia 
clarified. This research aims to add to existing knowledge and, through using a New Zealand case study, contribute to fill the gap in the case studies' geography.

In the context of The Lord of the Rings films, potential tourists are attracted to the landscapes where the films were set and are motivated to visit these places to experience them. If this is the case how do they experience the 'real' landscapes of New Zealand? Will they appreciate the landscapes that are 'left' or will they have unrealistic expectations due to the way the landscapes were portrayed in the films? These questions are what this research will explore.

The following chapter briefly discusses Tolkien's Middle-earth as a concept and myth. In addition, it deals with the analysis of the first and second films of The Lord of the Rings, discusses the manner in which New Zealand is portrayed, and the symbolism of landscapes used in the films. 


\section{Chapter five}

\section{1}

\section{Introduction}

Film is shaping our understanding of place and everyday life. This is also true for the understanding of New Zealand's landscapes as they are portrayed in the films of The Lord of the Rings.

In this chapter, are discussed Middle-earth as a concept and a myth created by Tolkien and interpreted by the filmmakers. The emphasis is on themes interwoven in the story and on the physical as well as the political geography of Middle-earth. Content analyses and interpretations of the first film: The Fellowship of the Ring and the second film: The Two Towers of the trilogy The Lord of the Rings are also provided. More precisely, it gives an interpretation of the landscapes portrayed and the symbolic landscapes used in the films. The chapter summary at the end concludes the chapter.

\subsection{Middle-earth as a Concept and Myth}

The story of The Lord of the Rings is about a quest to rescue a world and its people from evil forces and to resist the corruption of power. It is told in a fairytale manner with wizards; walking trees; mirrors that show the future; a magical ring; monsters and angel-like elves. When Tolkien wrote the books of The Lord of the Rings he invented Middle-earth (Map 5.1) with a diversity of landscapes and people/creatures. Through this he intended to create a mythology for England because in his opinion England unlike places like Norway lacked such a myth (National Geographic 2001). 


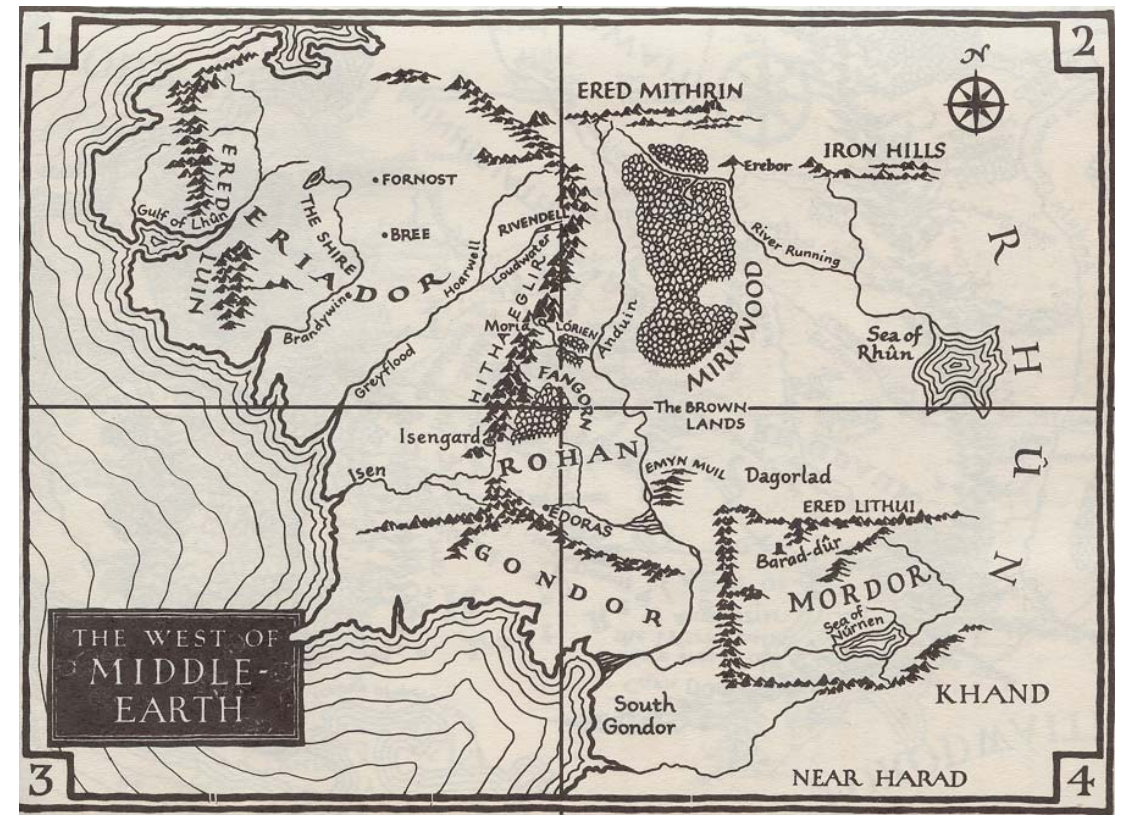

Source: Tolkien 1994: 1141

Since the making of The Lord of the Rings films, New Zealand has been branded and even redefined as Middle-earth or the Home of Middle-earth (Tourism New Zealand 2002b; Air New Zealand 2003). Such has been the 'success' of this branding, that recently some tourists visiting places where the film was made asked the Wellington Visitor Information Centre if The Lord of the Rings was based on a New Zealand myth (The Dominion Post 2003a). However, New Zealand due to its relatively recent non-Polynesian cultural history lacks such a myth, which these filmic tourists had obviously not realised.

As a "mythology illuminates (...) [people's] view of the world and their place in it" (Errigo 2003: 101), it is also a social construct. Shurmer-Smith and Hannam (1994: 61) discuss Lévi-Strauss' concept of constructed myths and state that such myths are:

self-evidently fantastical but also give full reign to the thinking capability of the society which generate them, exploring ideas to their point of illogicality, testing the power of opposition by creating crazy oppositional categories, pushing towards the possible-tothink with the impossible (socially or physically) to do.

A myth implies a concept of a utopian world. This world is, of course, somewhere else in place and in time. It is far in the future or long forgotten past.

Within Tolkien's fictional world of Middle-earth, several themes and messages are interwoven, and many scholars have analysed the books. Here, only some of the themes can be touched upon. 
The main theme obviously concerns good versus evil. However, the boundaries are blurred and 'good' people become evil when corrupted by power, particularly through the power of the ring. The evil the fellowship has to fight against is not only outside the group. The main enemy is within the members themselves whenever they are attracted by the power of the ring. The message is that nothing is ever black or white, nobody is totally good or totally evil; there is always a mixture of both in everyone and the challenge is to resist these temptations.

Another theme concerns creation versus destruction; in other words, respect for nature versus abuse of nature. The Lord of the Rings calls upon human beings to fight environmental degradation and deforestation. It questions the relationship humans have with nature. Tolkien's message is that people should live in greater harmony with nature. The 'good' people in the story, like the elves, appreciate nature in contrast to the evil forces, like Saruman, that want to destroy it. An element of war or apocalypse is also omnipresent in the story and some scholars interpret Sauron as metaphor of Hitler (for example Duriez 2001).

The ring has been interpreted as the machine that can enslave people and deprive them of their free will away or as metaphor of nuclear energy or the atomic bomb (for example Errigo 2003). By means of the metaphor the increasing technology in the world and whether we can maintain our essential humanity in such conditions is questioned. The worst-case scenario, a machine which churns out people (as Saruman practices with his underground uruk-hai breeding factory) stands in strong contrast to human nature.

Themes of loyalty, community and friendship are abundant even though ancient prejudices and enmity exist. Examples are the unlikely bond of friendship between the elf Legolas and the dwarf Gimli and Sam's loyalty to Frodo that can even overcome his fear of water at Path Galen at the end of the first film.

Endurance even when faith is tested, belief and resolve in the matter, are other themes. These characteristics are not limited to a common hero and even the smallest person can change the world. As Chance (cited in McNamara 2001: 4) interprets "Frodo is a little guy who is called upon to do heroic work against enormous evil. [This] (...) speaks to us because we're all little guys, we're all hobbits." However, Frodo would never have succeeded without the help of his friends, particularly Sam. Thus the message is that there is always hope and no one is alone. It does not matter if people are different, either in race or culture. When they share a common goal differences and prejudice fade away. Bonds of friendship make people strong and able to reach otherwise impossible goals. 
Interpretations of the story have changed over time depending on social conditions. For example in the 1960s, during the times of flower power and anti-war movements, The Lord of the Rings was seen as "an antiwar manifesto and endorsement of environmentalism" (McNamara 2001: 2). Later interpretations saw it as "a plea for racial tolerance and condemnation of Industrial Age" (ibid).

In today's context, industrialisation is no longer seen as a force of evil, which rules the world and takes individuality from humans. The interpretation as plea for racial tolerance should carefully be seen. Tolkien's distribution of good and evil, with good in the west and evil in the east and south relates to the politics of the time (1950s) when he wrote the books. The political landscape has changed since then. However, today's viewer might still perceive an element of current political controversy in the story. The fight against evil could be reinterpreted as a metaphor for the 'War against Terrorism'. The race portrayal in the books and films is debatable as well. The races are human like and particularly the elves could be said to symbolise the cultures of northern European races. In contrast, the evil races such as uruk-hais and orcs appear animal-like and of darker skin colour.

The ring could also be interpreted as a metaphor for globalisation. The inscription of the ring says "One ring to rule them all; one ring to find them; one ring to bring them all and in the darkness bind them" (Tolkien 1994: v).

It seems that The Lord of the Rings is also relevant in today's changing world and it can be interpreted in many ways. However, this is not the central purpose of this thesis.

\section{Physical geography of Middle-earth}

The story of The Lord of the Rings is set in the time of the so-called Dark Age in Europe. This corresponds with new age fantasy stories (Shurmer-Smith and Hannam 1994). It may reflect some familiar aspects of European history but as Porteous (1975: 33) points out:

(...) Tolkien's Lord of the Rings depicts a unique entity, a world in itself, with little or no reference to our own space and time dimensions. Middle-Earth has a chronology and a geography peculiar to itself $(\ldots)$. It is not a past of future extrapolation of modern western society, nor is it a dreamscape (...).

Tolkien's imaginary landscapes of Middle-earth as well as Jackson's translation to film is described and portrayed in such detail that it becomes realistic and believable. Easily distinguishable is the physical geography of Middle-earth. We get the broad landscapes as well as the specific landscapes, which are inhabited by 
particular races. Different political allies are described and there is a clear geographical separation between the forces.

The fellowship crosses a variety of landscapes on their quest. While the story unfolds it seems that the landscape also changes as part of the narrative. Even the protagonist, Frodo, appears to age within the plot.

In the first film we 'experience' the green hilly countryside of Hobbiton, which seems to be highly fertile for agricultural usage. From Hobbition the story moves eastwards to the mountain range the Misty Mountains, which forms a boundary due to the altitude and dimensions. Further east of the Misty Mountains, the River Anduin, also called the Great River, runs from north to south through Middle-earth. To the south and east of Middle-earth the landscape becomes rougher and unfriendlier. There is a wetland and swamp region, the Dead Marshes. Further south is Mordor, an active volcanic region that is enclosed on three sides by mountain ranges. The highest volcano is Mount Doom (Map 5.1).

In the course of the journey the vegetation changes from highly fertile farmlands of Hobbiton to the non-vegetated wasteland of Mordor and from light to dark landscapes. Map 5.2 clarifies the physical and plant geography of Middle-earth according to Tolkien's books.

Map 5.2: Physical and plant geography of Middle-earth

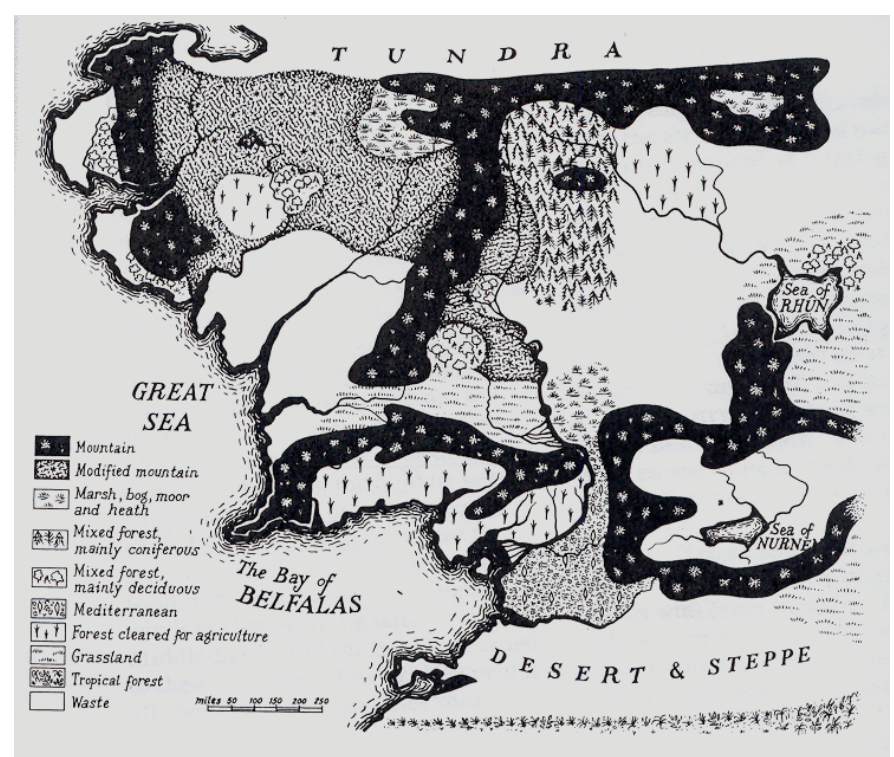

Source: Porteous 1975: 35 


\section{Political geography and power relations of Middle-earth}

When watching the films we get an idea of the distribution of good and evil forces of Middle-earth. Every race has its counterpart, either an evil or good equivalent. For example, the elves on the side of the 'good', have orcs as evil counterparts and men have the Black Riders or other men who were corrupted by evil.

The prologue in the first part gives background information about the history of the ring and the war against Sauron 2500 years prior to the main story. It becomes clear that there were always feelings of dislike between some of the 'good' people, for example between dwarves and elves. However, when faced with destruction by evil forces, they bond and fight together.

Roughly speaking, people who are living west of River Anduin belong to those classified as 'good', the forces of light. Exceptions are Saruman in Isengard, which is on the western edge of the Misty Mountains, as well as the creatures hiding in the mountain range. East and south of the river is the zone of evil forces, particularly of Mordor and its allies. The political geography of Middle-earth is clarified in Map 5.3.

Map 5.3: Political geography of Middle-earth

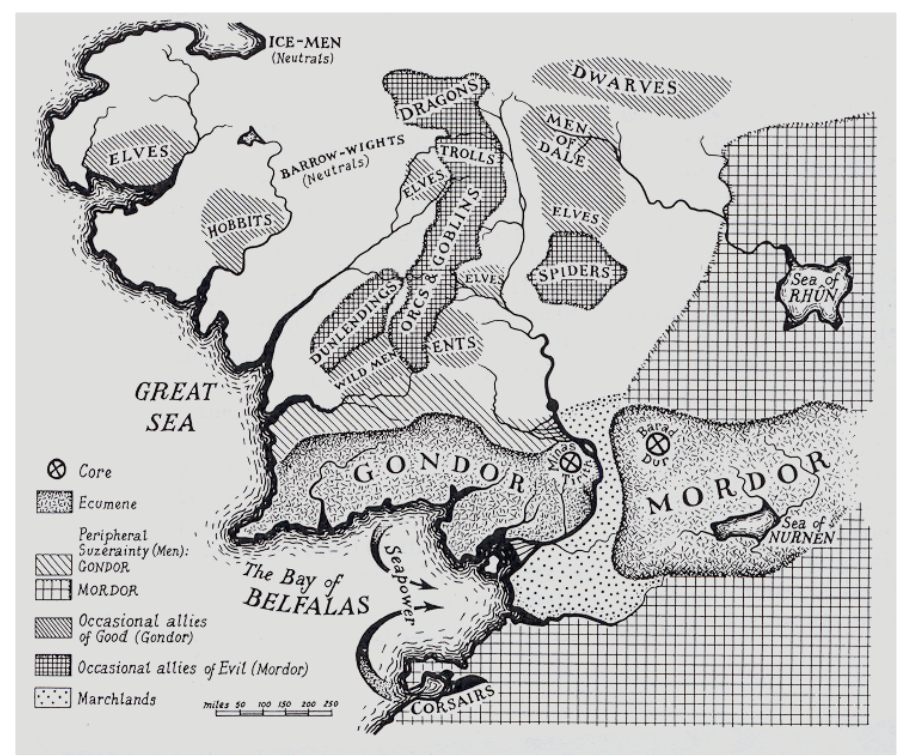

Source: Porteous 1975: 35

It could be argued that this distribution was not chosen by accident. When the books were published in the 1950s, the evil was seen in the east in form of the Eastern Block. On the other hand, the people of Harad, the southland, have amazing similarities to Arabic races. This is ironic in today's context and fits the 'war on terrorism' interpretation of the films. 


\subsection{Landscape Portrayal in The Lord of the Rings Films}

Plot summaries of the first film, The Fellowship of the Ring, and film two, The Two Towers, is given in Appendix 9. Appendixes 7 and 8 provide summaries of landscapes portrayed in both films in the form of tables. These tables give detailed information on the duration a particular landscape appeared on screen, give the name of this landscape/place within Middle-earth, and the main locations in New Zealand which were used in the film.

The following analysis and interpretation of landscapes portrayed in the first and second films of The Lord of the Rings were derived from watching the films and information given by tour guides of Rings Scenic Tours in Matamata and Safari of the Rings in Queenstown. In addition, secondary data were assembled from publications such as Brodie (2002; 2003), Errigo (2003), Tolkien and The Lord of the Rings themed lectures in 2003 at Victoria University of Wellington, and from Internet fan community pages.

\subsubsection{Landscape and Place in the $1^{\text {st }}$ Film- The Fellowship of the Ring}

"The world is changed. I feel it in the earth, I feel it in the water, and I smell it in the air" (Galadriel in The Fellowship of the Ring). During the first seconds of The Fellowship of the Rings we hear these words spoken over a darkened screen, first in Elvish and then repeated in English by Galadriel.

Thus begins the prologue and we are introduced to the pre-story of the one ring and its former owners. We are also introduced to the balance of power, the inhabitants and Middle-earth. The prologue draws the audience to the story that will follow and we are ready to enter Tolkien's epic fantasy adventure tale.

J.R.R. Tolkien wrote the books and created Middle-earth, an imaginary world with good and evil forces. Middle-earth provides a mixture of familiar landscapes, such as Hobbiton's English-inspired green hilly pasture, as well as fantastical landscapes, such as the dwelling places of the elves built around huge trees in Lothlórien or the underground labyrinths of Moria.

The contrast of good versus evil is also manifested in the landscape. Events of the plot are foreshadowed in the landscapes. For example, when a landscape is light, nature is healthy and respected by its inhabitants we can expect good forces. In contrast dark landscapes with a lifeless environment are inhabited by evil forces, such as orcs, cave trolls or Sauron who is the main personification of evil in the story.

In the first film of The Lord of the Rings the audience is introduced to a variety of landscapes and the people/creatures who inhabit these. Following the landscapes of Hobbiton and The Shire; Isengard; Bree; Rivendell; the Misty Mountains and 
Moria; Woods of Lothlórien and Caras Galadhan; Path Galen and Amon Hen; Mordor, and its inhabitants are described.

\section{Hobbiton and The Shire}

At the beginning of the first film, after the darkness of the war for the one ring within the prologue, the landscape within which Frodo is sitting seems to be from another world. He is sitting in an old light forest with a lush and flowering under-storey resting on an old tree. He is reading a book while he is waiting for Gandalf as we discover a minute later. The atmosphere of this first scene with its sunlight, twittering birds and healthy green environment is peaceful and the viewer feels reassured.

This first scene was filmed on the very same farm where The Shire set was created and filmed, near Matamata in the Hinuera Valley (see chapter six, section 6.2.1). In reality, the forest is a group of pines with almost no under-storey vegetation due to extensive sheep brows. Within post-production the landscape was modified in a way that the pine trees cannot easily be identified. In fact, they look more like old oak trees with flowering liverleaf underneath. This vegetation type is not native to New Zealand, but can be found in the English environments Tolkien had in mind when writing the books (Errigo 2003).

Frodo is waiting for Gandalf, a wizard and a good friend of Frodo and his uncle Bilbo Baggins. Gandalf is on his way to The Shire, a village within Hobbiton, where Frodo and Bilbo are living. The reason for his visit is Bilbo's $111^{\text {th }}$ birthday. Frodo joins Gandalf on his trap to The Shire. We learn that hobbits are short people, about half the height of Gandalf. In their conversation we learn that the common hobbit ignores the outside world. Hobbits could even be described as childlike and naive. Likewise, outside Hobbiton the existence of hobbits is largely ignored by the rest of the world.

Hobbits are peace loving and social people who like eating, partying, dancing, drinking and smoking. They are just ordinary people and not perfect at all. The intension of Tolkien, and likewise Peter Jackson, was to portray the hobbits as a kind of 'everyman' with strengths and weaknesses. Thus, we are more likely to identify ourselves with these 'anti-heroes'.

The Shire is depicted as an idyllic and peaceful place were the hobbits live in harmony. The hobbits work as farmers, craftsmen or gardeners. The Shire is situated in a hilly valley surrounded by fertile crop fields. In the centre of the valley is a lake on which the local mill and the pub are located (Picture 5.1). 
Picture 5.1: The Shire (film image)

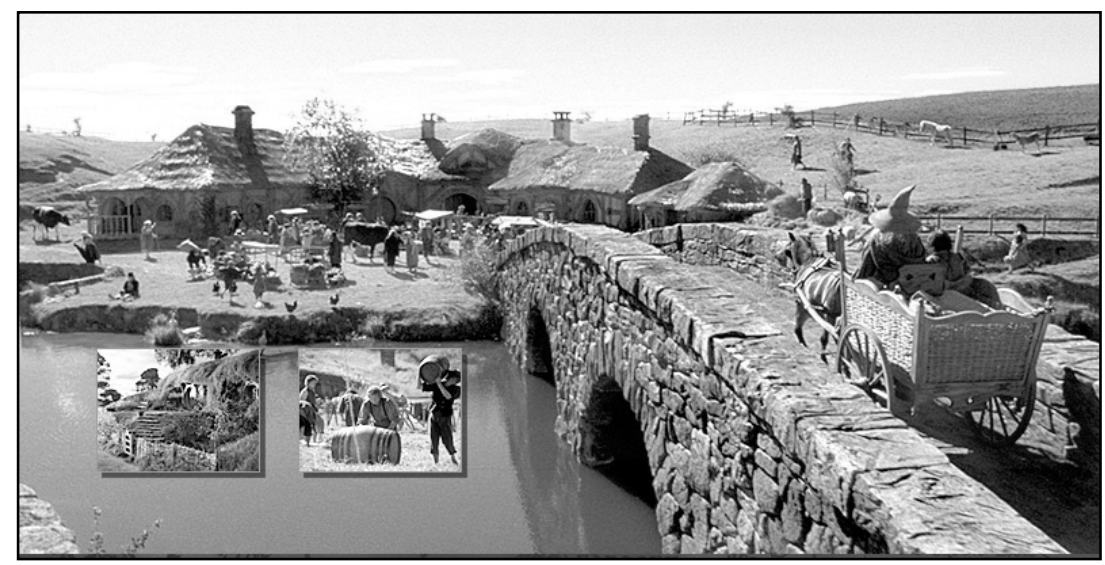

Source: Lord of the Rings Net (2004a)

The hobbits live in holes that are built into the hills and located around the lake. For the purpose of filming, 37 individual hobbit hole entrances were carved into the valley. Entrances are made of untreated timber and the false fronts were covered by polystyrene blocks to let them appear like stone. After filming, according to the contract between the farmer family and New Line Cinema, these entrances were to have been demolished. However, due to the weather conditions only half were destroyed (Rings Scenic Tours guides 2003). The remaining half is now one of the main attractions on Rings Scenic Tours (for further discussion see chapter six, section 6.2.1).

The Shire is portrayed in the film as fairytale-like and as having a homely atmosphere with treasured front gardens and smoking chimneys. These images, again, could be associated with old folk memories of somewhere in Europe. In fact the intention when designing The Shire was to create an old English style landscape, according to Tolkien's vision (Rings Scenic Tours guides 2003).

To make the landscape believable and more authentic, Peter Jackson's team constructed the village one year prior to filming so that the film sets aged a bit to make viewers believe that this landscape had existed forever. The green meadows of the sheep farm were divided in small paddocks and were sown with common European field crops, such as colza, sweet corn or sunflowers. The gardens of the hobbits were also planted with common European flowers.

In a former swamp, which was drained and filled with soil by the New Zealand army, vegetable gardens were designed and a party field created. The threats by common, but not native predators, such as possums and rats forced the production crew to inject the garden vegetables with hormones to resist these predators and 
secondly to make the plants look longer fresh and healthy (Rings Scenic Tours guides 2003).

Through detailed props the hobbit culture became believable. It created the illusion that hobbits actually lived 400 or 300 years ago somewhere in Europe. Their costumes were based on European fashion of earlier ages and this also created the illusion of authenticity.

The landscape of Hobbiton and The Shire, as portrayed in the film gives no hints that the film was actually made in New Zealand. Even the sheep in the film are not those commonly seen in New Zealand. In fact, although The Shire was filmed on a working sheep farm with up to 12,000 sheep the filmmakers imported sheep with black heads, which were more common in England in earlier periods (Rings Scenic Tours guides 2003).

Any natural feature that would betray a connection to New Zealand, such as native manuka shrubs, was masked or camouflaged. On the other hand, plants were imported to make the portrayal more convincing. For example, a cut 26 -tonne oak tree was brought to the valley in numbered pieces and then reconstructed. Imported artificial leaves were individually wired onto a dead tree. This jigsaw tree then became the tree overlooking Bag End, which is the home of Bilbo and Frodo in the film (ibid).

One reason, beside the perfect location of lake and party tree, for choosing the farm of the Alexander family in Hinuera Valley near Matamata was that there were hardly any obvious men-made structures. However, as common on farmland in New Zealand, there were typical number eight wire fences. For the purpose of filming these fences were transformed to make them look like old wooden fences. Power line poles were also masked to look like trees and in one instance like a windmill.

Within an iconic landscape Hobbiton was the setting of certain key scenes and its unique appearance is further discussed in chapter seven (section 7.2).

\section{Isengard}

We are introduced to Isengard when Gandalf visits his wizard colleague Saruman to obtain his advice about the ring. We learn that Saruman is a powerful wizard who lives in a tower named Orthanc in Isengard. Isengard is located in a valley, which is abundantly covered with an old dense forest. In the background we see the hill slopes of the Misty Mountains.

The backdrop for the scenes in Isengard was filmed in the Dart River Valley, near Glenorchy, southwest of Queenstown (Picture 5.3). The mountains and the 
valley in the film are real, but the tower and the forest were superimposed in postproduction.

The tower is portrayed as made of black rock or volcanic glass that seems hard and aggressive. This is in strong contrast to the beautiful lush forest which surrounds it. For viewers, it reinforces the sense that something ominous is about to happen. Later on, when it is clear that Saruman is collaborating with Sauron, who is the personification of evil, we see how Saruman spoils the nature of Isengard by transforming it into a dark and treeless place. Saruman destroys everything that is alive and beautiful in the landscape. The ground is split open and Saruman 'creates' an army of uruk-hais and weapons in underground caverns (Picture 5.2).

Picture 5.2: Isengard after nature was destroyed (film image)

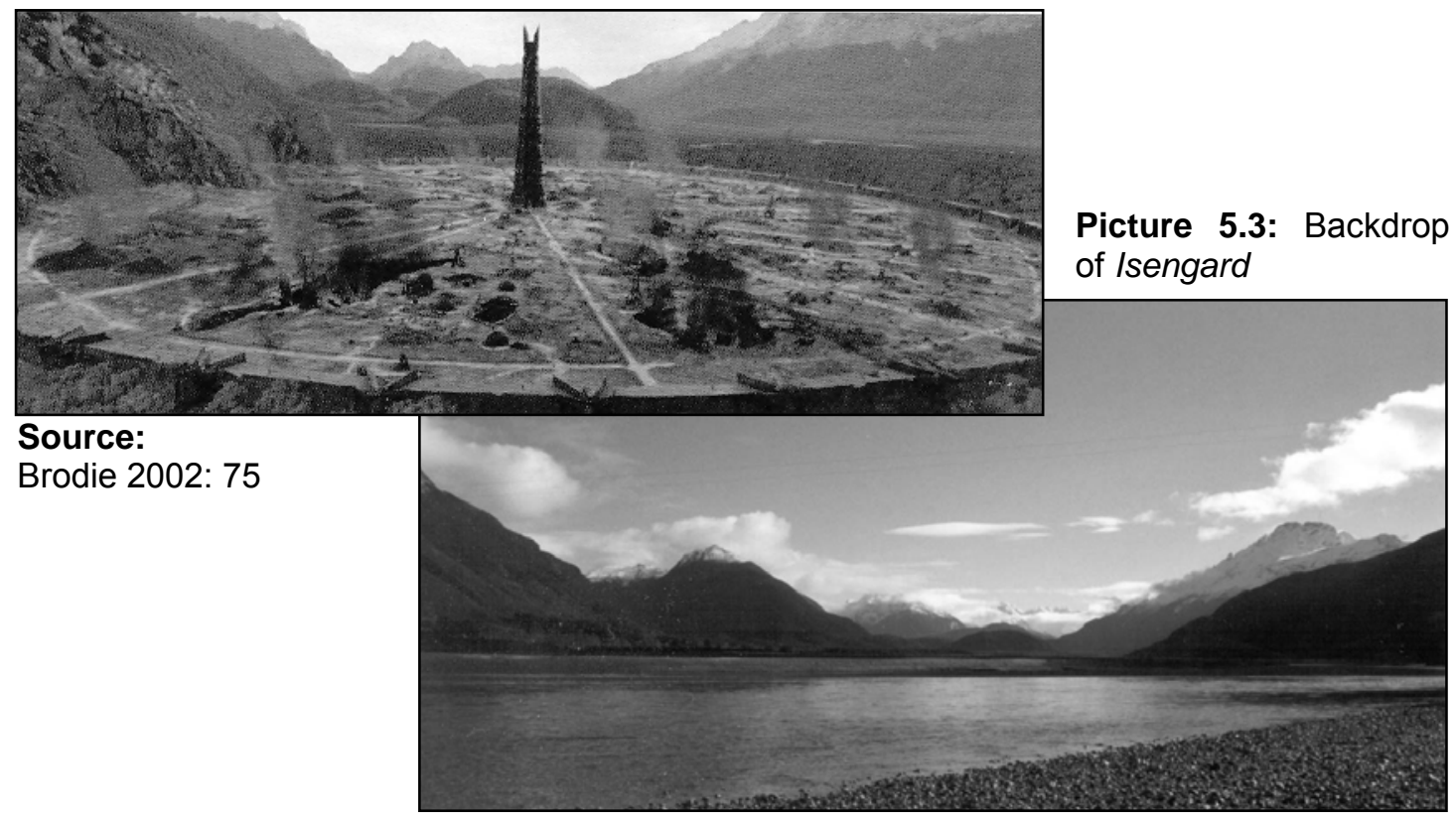

Source: The Author

The analyses of the scenes in Isengard found that the landscape of Isengard cannot be seen as having an extraordinary appearance or the plot containing a key scene within the story of the first film.

\section{$\underline{B r e e}$}

Bree first appears after the four hobbits, Sam, Frodo, Merry, and Pippin escape the Black Riders on a raft at Buckleberry. They arrive in Bree where the hobbits are supposed to reunite with Gandalf.

Bree is a town inhabited by men and is located east of The Shire. It contrasts with Hobbiton as a dark medieval-looking town with English styled half-timbered 
houses and narrow, muddy streets. A secure wall surrounds the town and a gatekeeper guards the entrance. When the gatekeeper looks through a special hobbit peephole we realise that hobbits use to come to this place. Even in the pub, The Prancing Pony Inn, the publican offers special hobbit sized beds. The town does not look friendly and inviting. Despite the pub offering special hobbits size beds, by contrast to the hobbit village everything else is huge, crude and hostile.

The scenes in Bree were filmed in a set built in an old Wellington navy base, Fort Dorset, as well as in an indoor set in Wellington. The appearance of the set is not extraordinary in a way that might interest filmic tourists. Within the story of the first film the scenes could not been seen as being key.

\section{Rivendell}

Before the group arrives in Rivendell, Frodo is fatally wounded after an attack by the Black Riders at the watchtower of Amon Sûl. Arwen, an elf, appears like a knight in shining armour. She carries Frodo to Rivendell knowing that only the medicine of elves can save his life. However, her efforts seem to be in vain and Frodo seems to be dying in Arwen's arms at the Ford of Bruinen.

The next scene is filled with warm sunlight, birds are twittering and water is splashing in the background. Frodo wakes up in Rivendell fully healed. There is a peaceful melancholic atmosphere in this beautiful lost valley of Rivendell. It seems to be a paradise. The architecture, influenced by Art Nouveau and Celtic design, imitates natural forms and shapes. Again with the addition of props the architecture looks familiar yet also unfamiliar (Picture 5.4). When designing Middle-earth for the films, WETA Workshop, aimed to produce different art work to represent each culture in each place, such as Rivendell (Taylor 2003).

Picture 5.4: Rivendell (film image)

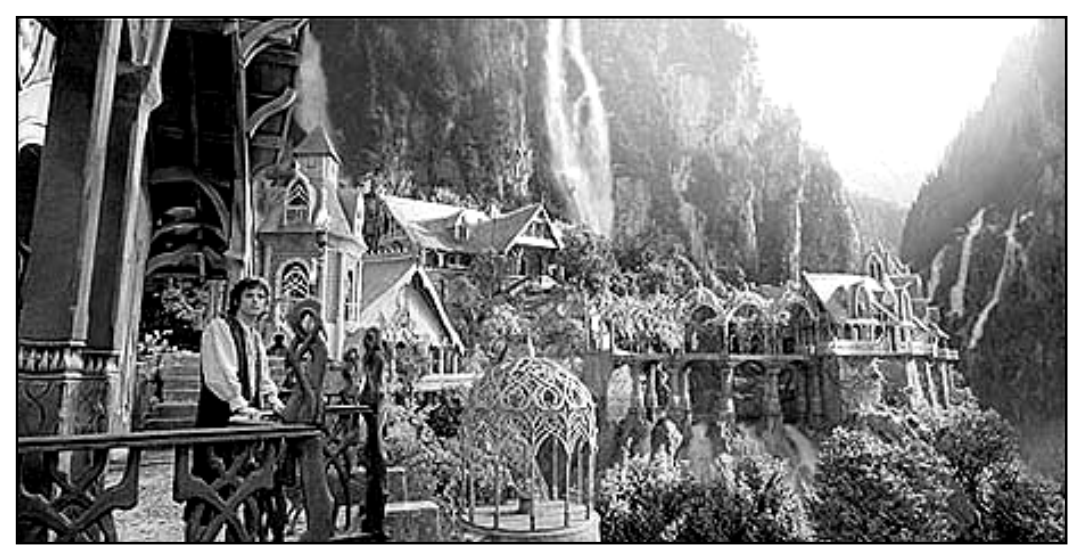

Source: Lord of the Rings Net (2004a) 
The overall design and architecture is very elegant even lyrical. Statues glorify the tall and elegant elves. The elves seem to be angelic and symbolise what is high and noble in human beings. They are very artistic, tall, elegant, and beautiful people who have a deep spiritual relationship with nature. However, we learn that elves can be dangerous, too. They are able to communicate via telepathy, are perfect archers and great warriors.

Elves are immortal and live in a stage of autumn, when the events of The Fellowship of the Ring take place and so they have assumed the colours of nature as well as their environment. Leaves are colourful which suggests the stage of autumn. Again this shows characteristics of a European autumn, because New Zealand native trees are green all year.

Rivendell is located on the foothills of the Misty Mountains in a steep valley with rivers and waterfalls. It is a place of knowledge and history. We see in Elron's house books and paintings of ancient wars. Rivendell is a refuge, not only for elves. Bilbo goes there to finish his book and, because it is a neutral place, the good people of Middle-earth gather there to debate the ring and their common future.

Most of the filming of Rivendell took place in Kaitoke Regional Park near Wellington. However, New Zealand is not recognisable in Rivendell's landscape. For the purpose of filming, a set was built up which was demolished immediately filming was completed. Artificial houses were built and a separate water system was created for the rivers. The impressive scenery of the steep valley and most of the dwelling places were digitally added in post-production. Thus, the former film set in Kaitoke Regional Park is currently hardly recognisable as Rivendell.

The portrayal of Rivendell has iconic status because it contains a key scene and has extraordinary appearance, which will be further discussed in chapter seven (section 7.2).

\section{Misty Mountains and Moria}

In the first film when the fellowship is crossing the Misty Mountains, Saruman evokes a snowstorm and avalanches. The only way the fellowship can continue its journey is to pass the mountains through the mines of Moria. Gandalf is worried because he knows of the danger in the mines. Instead of being a friendly place, as promised by Gimli, Moria turns out to be a tomb. Everywhere are bodies of those killed by orcs. Yet there is no going back. Outside the mine is a monstrous octopus that attacks the fellowship and blocks the way out of the mines.

Moria is an underground palace built by the dwarves in the central part of the Misty Mountains. The mines are a dark place comprising huge halls in different 
levels, long stairs, viaducts and tunnels. As if the darkness is not foreboding enough, everywhere are dead bodies and destroyed architecture as the remains of ancient battles.

The architectural features of the mines represent geometric forms with no round shapes. Moria occurs to be a dark labyrinth, a landscape of fear and death. Deep in the mines, orcs and a cave troll dwell. When it seems that all is lost and while the fellowship is surrounded by hundreds of orcs something more evil appears: the balrog, an evil fire creature that pulls Gandalf into the abyss.

The mines of Moria were totally studio based and digitally created to portray the immensity of the mines. Nothing like this can be found in the natural New Zealand landscape.

The content analysis did not reveal key scenes or extraordinary appearance of scenes set in the Misty Mountains. Also the landscape of the mines of Moria could not be seen as having extraordinary appearance. However, in Moria the key scene of Gandalf's fight with the balrog that he is loosing is set.

\section{Woods of Lothlórien and Caras Galadhan}

The remaining members of the fellowship escape out of the mines and into a nearby dense moss covered forest. The forest used for the film portrayal was found near Paradise, which is west of Glenorchy. Although the forests were naturally mossy, the filmmaker added more moss to cover the forest soil (Safari of the Rings guides 2003). In Tolkien's books, the woods were also known 'The golden woods of Lothlórien'. Thus, artificial golden leaves were added for filming.

We learn that an "elf witch of terrible power" inhabits these woods and "all who look upon her fall under her spell and they are never seen again" (Gimli in The Fellowship of the Ring). Immediately after Gimli the dwarf has spoken these words the members of the fellowship find themselves surrounded by arrowheads of elf warriors.

Gimli was referring to Galadriel and her armies. She and her people inhabit and guard the woods of Lothlórien where visitors are unwelcome. They have built a city within the forest, Caras Galadhan, which is made of filigree houses built around huge trees, and the houses are consistent and blend in with their natural surroundings. The city and the forest are bathed in misty blue light; the elves are singing to show their respect for the slain Gandalf. The atmosphere is surreal, almost dreamlike. Lothlórien with Caras Galadhan appears particularly extraordinary because of its design. 
The elves of Lothlórien seem to be more mystic and powerful than the ones of Rivendell. Galadriel communicates via telepathy and can look in the future with her mirror. The mirror confronts Frodo with terrible future prospects of a worst-case scenario. Evil forces invade The Shire and force the hobbits to work in chains in the mill, which is transformed in a factory. Despite this the scenes in Lothlórien do not contain key events for the first film of the trilogy.

The fellowship continues its journey down the River Anduin after being farewelled by Galadriel and her people. This scene was filmed in Fernside near Featherston in the Wairarapa. Due to the fact that this garden is in hotel property, interested tourists can only visit it if they are guests of the exclusive hotel where a single room costs NZ \$800 per night (Fernside 2003).

\section{Path Galen and Amon Hen}

After leaving Lothlórien the fellowship travels by boat down the River Anduin. They decide to stop at Path Galen to rest before crossing the river at nightfall. Legolas urges them not to stay at Path Galen. He feels something evil is drawing near in the forest. As we will learn later an army of uruk-hais and orcs which have been sent by Saruman to capture the hobbit ring bearer is close to the camp.

The members of the fellowship are preparing the camp when they realise that Frodo and Boromir are missing. Frodo is aimlessly wandering in the woods when Boromir finds him. An argument starts and Boromir tries to snatch the ring off Frodo. Frodo puts on the ring and escapes up the hill to Amon Hen, an ancient watchtower of the kingdom of Gondor. From there Frodo sees straight into the heart of Mordor and Sauron's eye at the top of the tower Barad-dûr. Moments later the uruk-hais reach the hilltop. Only because of Aragorn's help who has found him can Frodo, the ring bearer, escape. Frodo runs back to the camp and decides to leave the fellowship behind. He plans to continue by himself in his mission to destroy the ring. He regrets what has happened and the burden he has to carry.

However, his mind is made up and he leaves the shores in one of the boats. Sam who descended to the camp is trying to follow Frodo by running into the water. He has made a promise not to abandon Frodo and he will keep it even though he is not able to swim. Frodo rescues Sam and they continue their journey together.

The remaining fellows are fighting the uruk-hais. Boromir is killed and the hobbits Merry and Pippin are captured and taken away by the uruk-hais to Saruman. When Legolas, Gimli and Aragorn reach the camp again Frodo and Sam are landing on the opposite eastern banks of the river. The three decide not to follow Frodo and Sam. Instead they will pursue the uruk-hais and rescue Merry and Pippin. These 
events mark the breaking-up of the fellowship. Thus, the scenes set at Path Galen and Amon Hen are key within the story. However, the appearance of the landscapes was not seen as extraordinary.

Path Galen and Amon Hen were filmed at the Mavora Lakes and near Closeburn on Lake Wakatipu. The forest scenes were set in the beach forest in Paradise near Glenorchy. To suggest Amon Hen is the place of an ancient civilisation fragments of statures made of polystyrene were placed in the woods and on the hilltop.

\section{$\underline{\text { Mordor }}$}

Mordor appears in all films of the trilogy. It is presented as a dark place with active volcanoes with a river of lava from Mount Doom flowing through it. Mount Doom is where Sauron forged the ring of power and thus is also the only place where the ring can be destroyed.

We see deep caverns in which lava streams are flowing next to Sauron's fortress Barad-dûr. On top of this tower is an eye of fire that represents his power and destructiveness.

Mordor is completely bereft of vegetation and everywhere there seems to be fire and lava. Mordor is enclosed on three sides by a mountain range and can only be accessed through gates, which are strictly guarded. The whole place looks desolate and completely uninviting.

Scenes of Mordor were filmed in the Tongariro National Park in the centre of the North Island. The rugged landscape, which was formed by volcanic activity, was perfect for portraying Mordor. However, not only was Mount Doom added in postproduction but natural features were also digitally modified so as to make Mordor a place of fear and danger.

Within the first and second films Mordor does not have the key scenes and extraordinary appearance it assumes in the third film.

The landscapes which appear in the second film The Two Towers the Emyn Muil, Fangorn Forest, Isengard, Rohan and Edoras, Helms Deep, Dead Marshes, and Ithilien are now discussed.

\subsubsection{Landscape and Place in the $2^{\text {nd }}$ Film- The Two Towers}

The second film starts with a panoramic camera flight over the snow-capped Misty Mountains. The sun is rising. We hear Gandalf's voice in the background and see the fight of Gandalf and the balrog in the mines of Moria. Both fall into the abyss. This all 
proves to be a nightmare from which Frodo wakens drenched in sweat. We are back in the main narrative. The fellowship has broken into three groups and different storylines now unfold. Frodo and Sam meander in the Emyn Muil searching for their way to Mordor. Aragorn, Legolas and Gimli are hunting Saruman's orcs and urukhais that have captured the hobbits Merry and Pippin.

Thus, the second film is characterised by different plots which take place simultaneously at different places within Middle-earth. The film is also darker in mood as the journey gets closer to Mordor and Frodo struggles more against the evil power of the ring.

A number of new places are introduced, although only two new cultures. Firstly, Rohan with its capital Edoras and the fortress Helms Deep, and secondly Fangorn Forest, the home of the ents.

As the story becomes more perilous and dramatic the landscapes are similar portrayed to reinforce this development of the story. The Two Towers has more dramatic and 'aggressive' landscapes in contrast to the first film The Fellowship of the Ring with its beautiful and magical places such as Hobbiton, Rivendell and Lothlórien.

\section{Emyn Muil}

Frodo and Sam are lost in the labyrinth of rocks of the Emyn Muil highlands. Sam remarks: "This looks strangely familiar". To which Frodo replies: "It's because we've been here before. We're going in circles". Besides being lost they are also tracked by Gollum, who wants to steal his precious ring back. The hobbits pretend to be asleep when Gollum crawls down the cliff and attacks Frodo. The two hobbits can overpower him. A deal is made and Gollum promises to lead them out of the Emyn Muil to the Black Gate of Mordor.

The landscape of the Emyn Muil appears cold and unfriendly because of its bare and bleak cliffs, and its dingy lighting. There is hardly any vegetation. In the distance can be seen Mordor with the fire-breathing Mount Doom. This foreshadows what is to come. Sam remarks: "Mordor. The one place in Middle-earth we don't want to see any closer. And it's the one place we're trying to get to."

The landscape of the Tongariro National Park with its rough lava rocks was used to portrayal the Emyn Muil. The landscape of the Emyn Muil was not perceived as extraordinary and the plot did not contain key scenes. 


\section{Fangorn Forest}

The group of orcs and uruk-hai that captured Merry and Pippin at Amon Hen are resting at the edge of a dark forest. They start chopping wood for a fire when suddenly noises can be heard. Merry remembers an old folk tale about trees that could whisper and talk to each other and could even move.

A fight starts between the hungry orcs who want to eat the hobbits and the uruk-hais that have been ordered to bring the two unharmed to Saruman. While this conflict is taking place an army of horsemen of Rohan attacks the fighting groups. In the chaos the hobbits manage to escape to the nearby Fangorn Forest.

Fangorn Forest is ancient and full of secrets and memories and the basis for many tales. It is dense, dark, gloomy and foreboding. The air is close there as Gimli remarks to Aragorn and Legolas when they are searching for Merry and Pippin later in the story. There is hardly any daylight in the woods and no animals.

Fangorn Forest is the retreat of the ents: walking and talking trees. The ents are very old and slow speaking creatures who are known as 'tree-herders' or 'shepherds of the forest'. Merry and Pippin encounter the oldest of the ents, Treebeard.

The inside of Fangorn Forest was filmed in a studio set in which the actors were superimposed in post-production. The model was created out of real elements, such as 100 year old gorse, that is a pest in New Zealand, which was used for trunks and lower branches of the trees. Tea leaves from teabags was used to simulate the litter of a forest floor (Lord of the Rings Net 2004d).

Treebeard's was simulated by two means: firstly a 15-foot tall animated model was used to portrayal the action particularly that which interacted with the hobbits and, secondly, a digital model, particularly for the movement was used. Both models were then combined to achieve the desired effects (ibid).

Fangorn Forest is not based on any existing New Zealand landscape and, thus tourists wishing to visit natural locations cannot experience this because it was created on an indoor film set. The scenes in Fangorn Forest are key event within the narrative of the second film because the fellowship is reunited with the reborn and rejuvenated Gandalf. The film analysis, however, did not show extraordinary appearance of Fangorn Forest's landscape.

\section{Isengard}

As seen in the first film, Saruman destroyed the nature of Isengard. In the second film we see him evoke his crystal globe, the palantir, with which he is in communication with Sauron. He is praising his achievements when saying: 
The world is changing. Who now has the strength to stand against the armies of Isengard and Mordor? To stand against the might of Sauron and Saruman and the union of the two towers? Together, my Lord Sauron we shall rule this Middle-earth. The old world will burn in the fires of industry. The forests will fall. A new order will rise. We will drive the machine of war with the sword and the spear and the iron fists of the orc. We have only to remove those who oppose us (Saruman in The Two Towers).

While he is saying this we witness the destruction he wields and the creation of evil when a new uruk-hai, one of his brainless killing machines, is 'born' from the mud.

Later in the story of the second film we see the ents attacking Isengard and the valley with its underground factories is flooded. Saruman can only watch helplessly as his empire breaks apart.

Again, as with Isengard in the first film most of the landscape was computergenerated. The landscape of the Dart River valley (Picture 5.3) was used as the backdrop on which Isengard was superimposed. The scenes in Isengard as shown in the second film contain the key scene of the victory and thus destruction of Isengard by the ents. The appearance like the portrayal in the first film, was not seen as having extraordinary appearance.

\section{Rohan and Edoras}

We are introduced to the plains of Rohan when Aragorn, Gimli and Legolas are tracking the uruk-hai army that captured the hobbits Merry and Pippin by order of Saruman.

The landscape of Rohan comprises large plains of treeless grassland. We see on a plateau near a lake a peasant village that is attacked by wild men and orcs who were sent by Saruman. The village and its inhabitants are medieval in appearance. The colours are earthy browns and greens. Huts are thatched and livestock is running free.

The capital of Rohan is Edoras, situated in a valley and surrounded by the snow-capped White Mountains. Edoras is built on a mountain slope within the valley. A medieval city wall surrounds the town. The architecture and design can be described as Viking or Norman influenced (Picture 5.5). The people of Rohan of the higher social class are proud warriors and horsemen. The symbol of a horse is omnipresent in flags, wooden carvings or on helmets. The king of Rohan is Théoden and his palace is the Golden Hall, a rustic building with a thatched roof of golden colour. 
Picture: 5.5: Edoras- guarded entrance of the Golden Hall (film image)

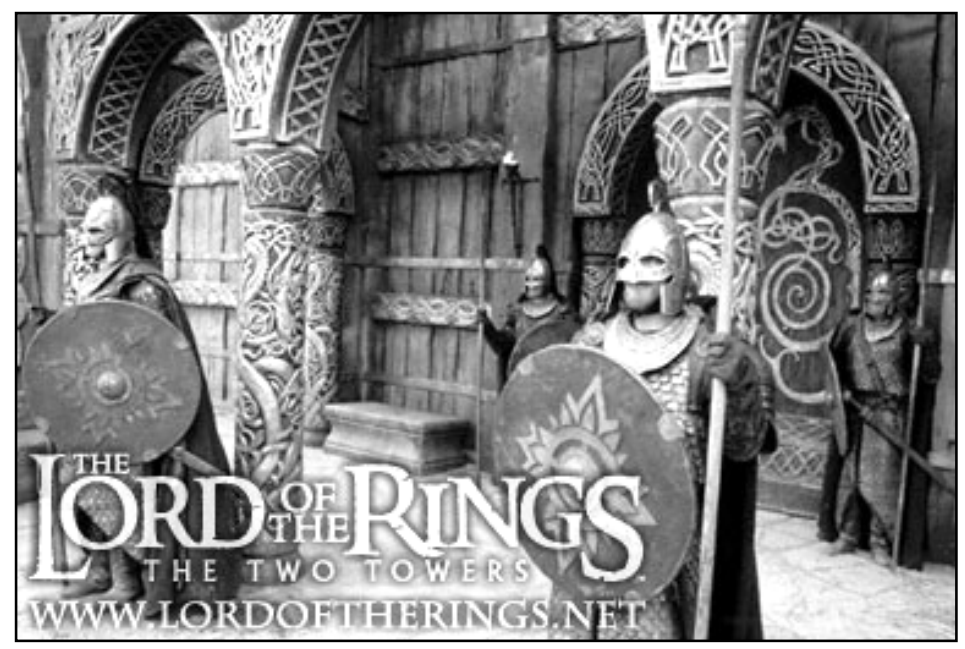

Source: Lord of the Rings Net (2004b)

When Legolas, Gimli, Aragorn and Gandalf arrive in Edoras they do not expect a warm welcome from the Rohirrims. They know that Saruman corrupted Grima Wormtongue, the king's advisor. King Théoden is weakened and blind to the encroachment of Saruman. Gandalf uses his power to free Théoden's mind from Saruman's influence. All of a sudden the appearance of the king as well as the atmosphere within the hall is transformed. The light and strength return in Edoras and hope is raised. The king slowly realising what had happened to him and is convinced that he must fight Saruman as he should have earlier. It is decided to retreat to Helms Deep, a fortress built on the White Mountains, to fight against the army that will be send by Saruman.

For the film a life-size set was built on Mount Sunday in the Rangitata Valley, 45 minutes drive from Methven. The construction of this remote film set took seven months. Once filming was completed the landscape was restored to its original state, which took another year (Lord of the Rings Net 2004b).

Edoras was seen as having extraordinary appearance as well as containing key scenes for the story, which will be explained more detailed in chapter seven (section 7.2).

\section{Helms Deep}

The people of Rohan flee to the supposedly impregnable fortress of Helms Deep which had been used for generations as a refuge in times of war. Women, children and older people are gathered in the more secure caverns that reach back into the mountain while above the last preparations for the battle are made.

Saruman's army of hundreds of thousands of highly armed uruk-hais reaches the fortress by nightfall. Their only purpose is to destroy the world of men. The 
situation seems to be hopeless for the people of Rohan. The uruk-hais have the superior force and are equipped with dynamite to destroy the strong walls of Helms Deep.

The battle rages throughout the night. When everything seems to be lost and uruk-hais are about to penetrate the fortress King Théoden decides to charge for a last time against the invaders. At the same time the sun is rising in the east and, true to Gandalf's promise that he will be back at this hour with help, Gandalf and an army of riders of Rohan attack the confused uruk-hais from the opposite hill. Minutes later the battle is won.

The scenes at Helms Deep are the climatic battle in the story so far and thus a key scene. For the film the fortress was partly built in a quarry in Lower Hutt near Wellington. After filming the set was demolished. The portrayal of Helms Deeps was not seen as having extraordinary appearance.

\section{Dead Marshes}

The Dead Marshes make their appearance when the narrative returns to the group of Frodo, Sam and their new guide Gollum. Gollum has promised to guide the two hobbits safely on a secure path, which is not known by orcs, through the swamp to the Black Gate of Mordor.

The Dead Marshes are an endless seemingly vast and soggy landscape stretching between the Emyn Muil and Mordor. The atmosphere is misty and eerie and gives an unsettling and foreboding hint of perilous things about to come. In the marshes little fires are burning and Sam observes: "There are dead things! Dead faces in the water". Gollum remarks that these elves, men and orcs are the remains from a great battle long ago.

Frodo disregards Gollum's warning not to follow the lights and is drawn to one of the faces in the water. As if in trance he falls into the water where greenish and ghostly faces of the dead are screaming and reaching for him. Gollum rescues Frodo by pulling him out of the water.

A large wetland near Te Anau was used as the backdrop for the portrayal of the marshes. Most of the filming, however, was done in Wellington on indoor and outdoor sets (Lord of the Rings Net 2004c). The landscape of the Dead Marshes was neither seen as having extraordinary appearance nor containing a key scene within the story of the second film. 
Ithilien

Frodo, Sam and Gollum decide to take another path to Mordor. They have realised that they cannot enter the Black Gate to Mordor without being caught. This leads them to Ithilien.

Ithilien belongs to Gondor and is located between the River Anduin and the western mountain range of Mordor. Ithilien is portrayed as bush and forestland. Here Faramir and his troops encounter the hobbits. They capture them under the mistaken impression that the hobbits are orc spies. Faramir takes both hobbits to his base at Henneth Annûn. He decides to bring Frodo, Sam, the later encountered Gollum, and the ring of power to his father in Gondor as this would change the fortune to the war that is happening there. The troops move to Osgiliath, which has already been destroyed by Mordor's armies. Faramir decides to release the hobbits and let them finish their mission.

The scenes at Ithilien were not seen as being key scene in the plot. In addition, the landscape was neither seen as being extraordinary.

\subsubsection{Symbolic Landscapes}

Symbolic landscapes, in particular imaginary ones, appeal to an audience's experience and knowledge (Shurmer-Smith and Hannam 1994). Viewers associate specific emotions with particular landscapes. In films symbolic landscapes are used to evoke specific emotions within the narrative. Porteous (1990) analysed the landscapes in Tolkien's books. However, his statements may apply also to the films when he comments that:

(...) the Good Lands are fertile rural areas, whereas cities are ambivalent, and mountains, deserts, and above all, forests are symbolic landscapes of terror and doom (Porteous 1990: 152).

Tolkien has created the story and landscapes of The Lord of the Rings from the perspective of the main protagonists, the hobbits. Therefore, the viewer of the films experiences the world with the eyes of the hobbits. Hobbits usually do not stay in dark forests, mountains, and caves. Accordingly they do not feel comfortable in these places and expect danger. In the films these landscapes are deliberately shown as foreboding and dangerous.

Following symbolic landscapes such as pasture and farmland; forest and bush; cave and mountain; river; wasteland and marshland and their use in the films are explained. 


\section{Pasture and Farmland}

The fertile rural areas in The Lord of the Rings are the 'good' lands. This relates to one of the main themes of the books about the need to appreciate and value nature. Hobbiton, as the countryside of Middle-earth, is an example of such a rural area. It is the place of people who live in accordance with nature. However, it is ironic that in reality the green hills of the landscape where Hobbiton was filmed are the result of deforestation. Early Māori and Pakeha burned down the bush in order to provide pastureland for sheep.

On the other hand, this 'green' landscape accords with an image that people from overseas associate with New Zealand, as a rural country with rolling hills and millions of sheep. This matches perfectly the tourism slogan of Tourism Waikato (2004) where Matamata and the former film set of Hobbiton are located that says: "Waikato...where the grass is greener".

However, it is worth noting that in many other New Zealand films (except perhaps The Price of Milk) pasture land is not seen as exciting enough to be filmed, and so it rarely appears.

\section{Forest and Bush}

As in many fantasy stories and fairytales, forests are landscapes representing fear; dark places where dangerous creatures dwell.

In the first film after its journey along the River Anduin the fellowship halts at Parth Galen. Legolas, the elf, has a foreboding feeling when he looks at the forest near the banks of the river. He says "A shadow and a threat is been growing in my mind. Something draws near. I can feel it". What he feels is an approaching army of uruk-hais sent by Saruman to hunt down the group.

In the second film Fangorn Forest is portrayed as an eerie place, the mere mention of whose name strikes fear in people's hearts. However, in The Lord of the Rings forests can also the refuge of benign forces like elves.

\section{Cave and Mountain}

In fairytales, secret and sinister creatures dwell in caves. In the first film of The Lord of the Rings, the abyss of the Misty Mountains is the refuge of the balrog, a demon of fire, as well as of the cave troll and orcs. All are malevolent creatures.

In the second film, the mountain range of the Emyn Muil is an unfriendly place which foreshadows what is about to come the nearer one gets to Mordor. In this landscape the hobbits realise that the more the journey becomes rougher the more Frodo becomes obsessed with the ring. 
$\underline{\text { River }}$

A river itself is not a landscape on its own because we always associate a river with its banks and other surroundings. To put it poetically, the water of a river is the "blood of the earth" (Porteous 1990: 75). However, as a river can also be associated with a journey it can also stand for dangers on a journey because of the unknown that is around the next bend. A river is associated with something new coming up, a change, a passage or an adventure. Often a film's narrative takes a significant turn whenever a river is shown. This is also the case in the films of The Lord of the Rings. The river is the main landscape feature when the fellowship leaves Galadriel and her people in Lothlórien as well as when the fellowship breaks into groups at Path Galen at the end of the first film.

In The Lord of the Rings the good people of Middle-earth, such as the elves of Rivendell and the hobbits in The Shire, live close to water. Water is equated with the good forces and life. In contrast, the dark forces associated with death avoid water.

The dark forces cannot resist the power of water. In the first film of the trilogy, the Black Riders have to halt when the hobbits escape on a raft at Buckleberry. In another scene Arwen is eluding from the Black Riders. She casts a spell on the river to transform it into a torrential flood which obstructs the passage, and block the path of the Black Riders at the Ford of Bruinen. Furthermore, when the ents attack Isengard, in the second film the valley of Isengard is flooded and Saruman's underground factory of evil is destroyed by the water.

\section{Wasteland and Marshland}

Wastelands suggest hopelessness and danger. There is nowhere to hide from enemies, as there is no vegetation or sign of life. This is the foretaste of the things that are going to come the closer one gets to Mordor, such as the Dead Marshes in the second film. The marshes are an eerie landscape where dead witnesses of an ancient battle are rotting in the water. Even the orcs avoid the paths through the swamp because they are in danger of following the wrong paths and getting lost.

\section{$5.4 \quad$ Chapter Summary}

This chapter discussed Middle-earth as a concept and myth with its interwoven themes such as good versus evil; creation versus destruction; elements of war, machine and industry; loyalty and friendship; and endurance. The physical geography of Middle-earth with its landscapes changing from green and lush to dark and lifeless was described. In addition, the chapter outlined the relationship of the various powers of Middle-earth among good and evil people/creatures and where 
they were located. The good people, the forces of light, live primarily west of the River Anduin. To the east and south of the river is the domain of the evil forces.

The film versions of The Lord of the Rings presented New Zealand as a place of elves and dwarves, terrifying creatures and little hairy hobbits, each inhabiting a specific landscape. New Zealand was used to portray the fairytale-like, place faraway in space and time where good is fighting against evil to rescue Middle-earth from destruction. Such a portrayal gives hardly any hint of the true cultural landscapes of New Zealand because many features had been camouflaged or modified through computer-generated images or the set design.

The first film, The Fellowship of the Ring, introduces us to the pre-story of the ring, the balance of power in Middle-earth and the landscapes of Hobbiton, Isengard, Rivendell, the Misty Mountains with the mines of Moria, Lothlórien, Path Galen and Amon Hen, and Mordor. Of these landscapes Hobbiton, Rivendell and Lothlórien were seen as being extraordinarily attractive. Key scenes in the first film were portrayed in Hobbiton, Rivendell, the mines of Moria and Path Galen/Amon Hen.

In the second film, The Two Towers, different plots occur simultaneously after the fellowship had split at the end of the first film. In contrast to the first film the landscapes become darker, more aggressive and dramatic because they foreshadow what is about to happen the closer the journey gets to Mordor. The audience is introduced to the landscapes of the Emyn Muil, Fangorn Forest, Rohan with its capital Edoras, the fortress Helms Deep, the Dead Marshes and Ithilien. Only Edoras has an unsual appearance. Key scenes take place in Fangorn Forest, Isengard, Edoras, and Helms Deep.

In both films symbolic landscapes are used as part of the plot to evoke certain feelings in the audience. Pasture and farmland are shown as 'good' lands whose inhabitants appreciate and are in harmony with nature. Forest and bush are shown as a symbol of hidden danger and doom. Cave and mountain are shown in similar terms because they are where evil creatures dwell. A river symbolises change and something new about to happen. Wastelands and marshlands are places, which symbolise hopelessness and danger.

The next chapter discusses findings of the empirical film tourism research. 


\subsection{Introduction}

This chapter presents parts of the findings of the film tourism research. Case study tourism operators and their The Lord of the Rings themed products are discussed as well as the film tourism infrastructure in Matamata and Queenstown. Other New Zealand film site locations, which provided backdrops for The Lord of the Rings films as well as operators are described. In addition, a wholesale package operator, Tourmasters South Pacific NZ Ltd, and its The Lord of the Rings themed products is explained.

An overview of the tourist sample is given, looking at the tourists' country of origin, gender, age, purpose of travel, first or repeated visitation, return plans, lengths of stay, and travelling companions. What makes a The Lord of the Rings filmic tourist is discussed afterwards through the examination of the frequency with which the films were watched and whether filmic tourists had experience of other former film location in New Zealand. Finally, the findings and discussions are concluded in the chapter summary.

\section{2}

Case Studies

Three case studies were chosen to conduct a survey and interviews with filmic tourists and to discuss The Lord of the Rings themed products. The first case study is of Rings Scenic Tours Ltd, which offers a tour to the former film set of Hobbiton, as portrayed in the first and third film. The tour is operating in the Waikato region, near Matamata (Map 6.1). Rings Scenic Tours Ltd offers a half-day product, which is called Rings Scenic Tours. The former film location of Hobbiton which the film tourism product focuses upon is the only place where remains of the film set can still be seen. In Appendix 10 the promotional pamphlet of the tour is presented.

The second case study tourism operator is Nomad Safaris in Queenstown (Map 6.1), which is offering jeep tours, particularly to gold-rush heritage sites. Restructuring and expanding of existing tours designed two half-day tour products called Safari of the Rings and they focus on a number of The Lord of the Rings former film sites in the Queenstown region. The special designed pamphlet for the tours is displayed in Appendix 11. 
Red Carpet Tours offers a 13-day coach tour, focussing on several of New Zealand's landscapes portrayed in the films of The Lord of the Rings. The tour starts in Auckland and finishes in Christchurch (see Box 6.1 for route). Map 6.1 shows the itinerary of Red Carpet Tours, of which the main destinations are highlighted with stars. The Lord of the Rings Internet fan page www.theonering.net is the main promotion tool whereby the product is marketing. Thus, these tours are specifically geared for The Lord of the Rings enthusiasts.

Map 6.1: Case study locations and itinerary of Red Carpet Tours

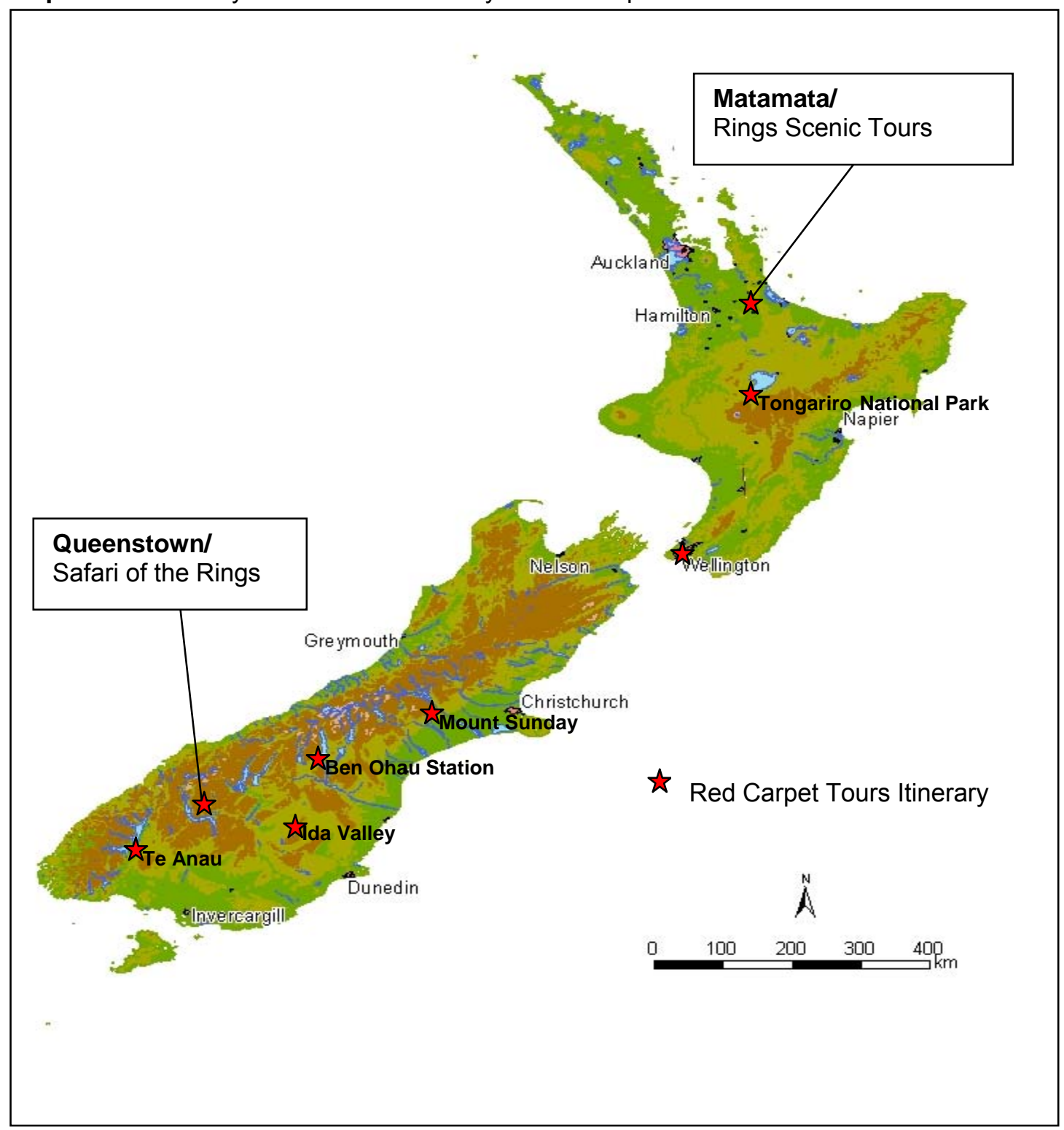

Map data source: adapted by the author from Maproom (2003)

Following, the three case study tourism enterprises, their products as well as tour specific results of the survey/interviews are presented and discussed. In the case of 
the two half-day tour experiences in Matamata and Queenstown the film tourism infrastructure is also discussed.

\subsubsection{Matamata: Case Study Rings Scenic Tours}

Matamata, a typical rural New Zealand town in the Waikato, is a two-hour drive from Auckland and one-hour from Rotorua. The population is about 12,000 people of which approximately 6,000 live in the town itself. The main industries are dairying, sheep farming and its awarded stud racehorses.

Before Rings Scenic Tours Ltd. started operating tours to the former film set of Hobbiton in December 2002, tourism did not play any great role in Matamata. In fact, the town was no more than a "toilet and takeaway stop" for travellers on State Highway 27 on their way to Auckland, Hamilton, Tauranga, Rotorua, or Taupo (Sue Whiting, Marketing Manager, Visitor Information Centre Matamata, pers. comm., 01.08.03).

However, tourist attractions in Matamata: include the Firth Tower, a heritage centre and museum, Opal Hot Springs, and the Wairere Fall. The latter is within a Department of Conservation (DOC) area. None of these attractions are exceptional by themselves and do not have the potential to attract great numbers of tourists, particularly those from overseas.

In the hidden Hinuera Valley a sheep farm, which is 15 minutes drive from the town centre, became the embodiment of Hobbiton which can be seen in the first and in the third film of The Lord of the Rings film trilogy. For the purpose of filming, 37 hobbit holes, flowering gardens, paddocks, a mill, a pub, and a double arch bridge were created to transform the valley into a visual approximation of Hobbiton as described in Tolkien's books and imagined by the filmmakers (see previous chapter section 5.3.1).

Jackson chose this farm to be the set of Hobbiton because it had the needed green rolling hills, the lake and the party tree. It was also remote and had few visible men-made structures.

Soon after information was released that scenes for The Lord of the Rings films had been shot on the farm, enquiries came from tourists who wanted to visit the film set (Russell Alexander, Managing Director of Rings Scenic Tours Ltd. and member of the Alexander family who owns the farm and the tourism enterprises, pers. comm., 01.08.03). Suddenly, the farming family had to deal with a completely new phenomenon: film tourism. 
Because the former film set is on the property of the Alexander family, visits are only allowed with consent from the family or on a Rings Scenic Tours. Thus, the family has the monopoly on this tourism product.

One problem in using the former film set for film tourism was the contract with New Line Cinema, the American production firm of the film trilogy. The contract specifies that the remains of the film set had to be demolished once filming was finished and the farmland returned to its natural state. This was partly done by the Alexander family and only disadvantageous weather conditions delayed further demolition. The result is that 17 hole entrance claddings remain. Yet, the former film set is still legally owned by New Line Cinema. According to Mr Alexander (2003), it took several letters until in August/September 2002 a final agreement was reached to use the former film set for a film tourism operation. Beside the permission to run a tour, the family is only allowed to maintain the holes but is not permitted to rebuild it or to transform the valley as it was portrayed in the films. Mr Alexander is still trying to obtain permission to rebuild the former film site but is so far unsuccessful.

Rings Scenic Tours Ltd estimates that 10 to 20 per cent of the visitors would appreciate it more if the set was rebuilt (Alexander 2003). The tour guides explain the situation to tourists and clarify that there is no option due to the contract. On the other hand, letters and Emails by tourists who enjoyed and appreciated the tour give support and encouragement. There are even people who have been on the tour two or three times.

Ring Scenic Tours is marketed as a brand and tourists can buy any imaginable item with the sign of the company on it. The Visitor Information Centre in Matamata presents these merchandising articles as indicated in the arrow in Picture 6.1. Since late August 2003 visitors can also send postcards from their Hobbiton experience to their loved ones (Appendix 12).

Picture 6.1: Visitor Information Centre Matamata with Rings Scenic Tours merchandising

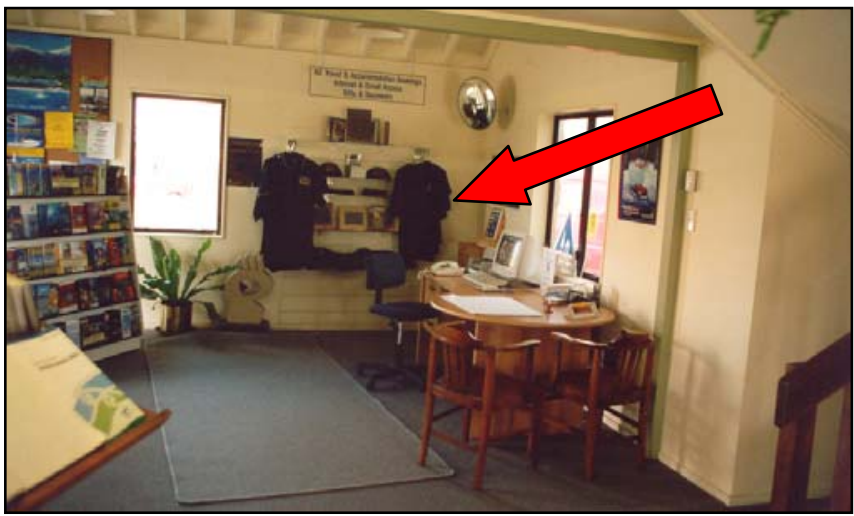
articles

Source: The author 
The tour operation started in December 2002 and in August, when this research was undertaken, more than 7,500 people had visited the remains of Hobbiton on a Rings Scenic Tour. A further 3,000 tourists were visitors on an inbound tour, such as Red Carpet Tours.

A ticket costs NZ $\$ 50$ for adults, NZ $\$ 25$ for children aged between 10-14 years. Children under 10 have free admission. This price seems high, particularly for domestic tourists and Matamata locals. According to Henry Horne (Marketing Manager of Rings Scenic Tours Ltd., pers. comm., 25.07.03), Tourism New Zealand suggested a ticket price of NZ \$80 for adults. Tourism New Zealand's justification for this price was to keep the quality of New Zealand as tourist destination high, particularly because of the buying power of tourists with strong American dollars or British pounds.

Some tourists complain about the price of the tour. To them the price seems to be unjustified compared to what they might see. However, tourists are now more likely to stop and this not only to visit the local toilet block but also to be photographed by the roadside sign 'Welcome to Hobbiton'.

To give the locals an opportunity to see the former Hobbiton film set, which is on their doorstep, a one-off open day was held before the official tour started operation and 700 people visited the former film set without paying admission. Overall, the locals are proud that their town is now famous and even mentioned in papers overseas.

The mayor Hugh Vercoe wanted to change the name of Matamata permanently to Hobbiton when The Fellowship of the Ring was released (Whiting 2003). The local paper Matamata Chronicle published a special issue in December 2001 in which it changed its name to Hobbiton Chronicle. Matamata's public library is already renamed in 'Hobbiton Library'. Matamata changed its whole look for the premiere of the third film of the trilogy in December 2003 to celebrate the last film in which Hobbiton is again portrayed.

The Lord of the Rings film tourism in Matamata created direct economic benefits of NZ $\$ 102,000$ for the first three months Rings Scenic Tours were operating (Whiting 2003). Half of these benefits were generated by local businesses such as petrol stations, accommodation providers, cafés and particularly the local jewellers. The latter profited from tourists who bought copies of the 'one ring'. Also the Visitor Information Centre increased its income due to more people using it to book buses, accommodation or tours. 


\section{The Tour}

The tour operates three times daily in summer, and twice in winter, seven days a week. The duration of a tour is two hours. The tour starts and ends at the Visitor Information Centre in Matamata where the tickets can be purchased.

While they are driving to the farm the guides give the tourists information on Matamata and the region. This is important as the majority of tourists have never visited the region before and for others it is often their first contact with New Zealand's countryside. On the farm there are a number of gates to open and sheep to dodge; this provides a very authentic farm experience.

Before arriving at the former 'Hobbiton' film site a stop is made to point out where the facilities of the film crew, such as the technical car park, animal kingdom, costume, catering, make up facilities and of course the movie star caravans, were located while filming was in progress. A map is handed out during the tour as an official tour guide that shows the geography of the film set (Map 6.2).

Map 6.2: Map of former Hobbiton film set

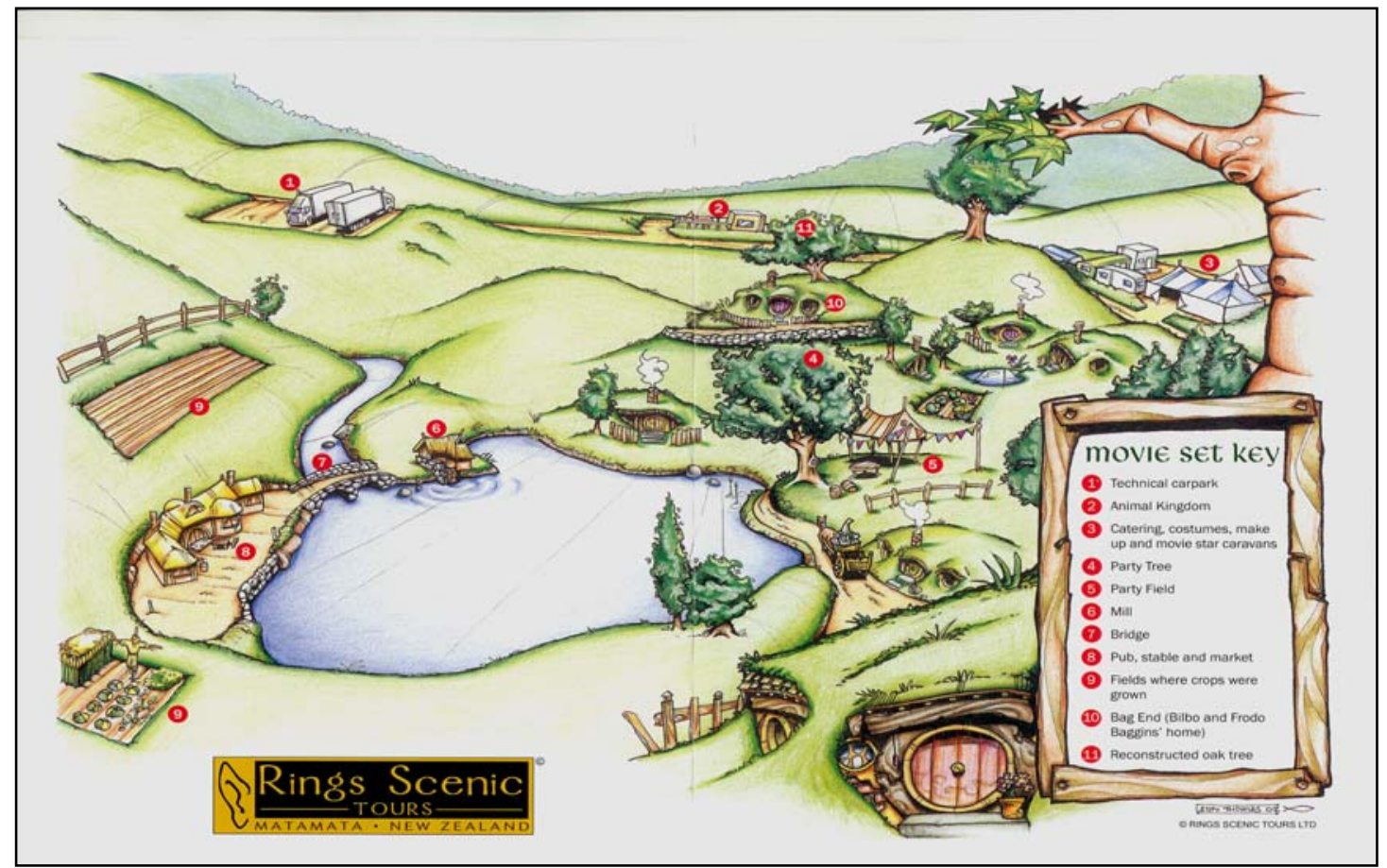

Source: Rings Scenic Tours Ltd. 2003

At the former film set picture boards are used to give a better understanding how the farm was transformed while filming (Pictures 6.2 and 6.3). In addition, different coloured poles show the dimension of buildings and features. 
Pictures 6.2 and 6.3: Guide using picture boards for demonstration

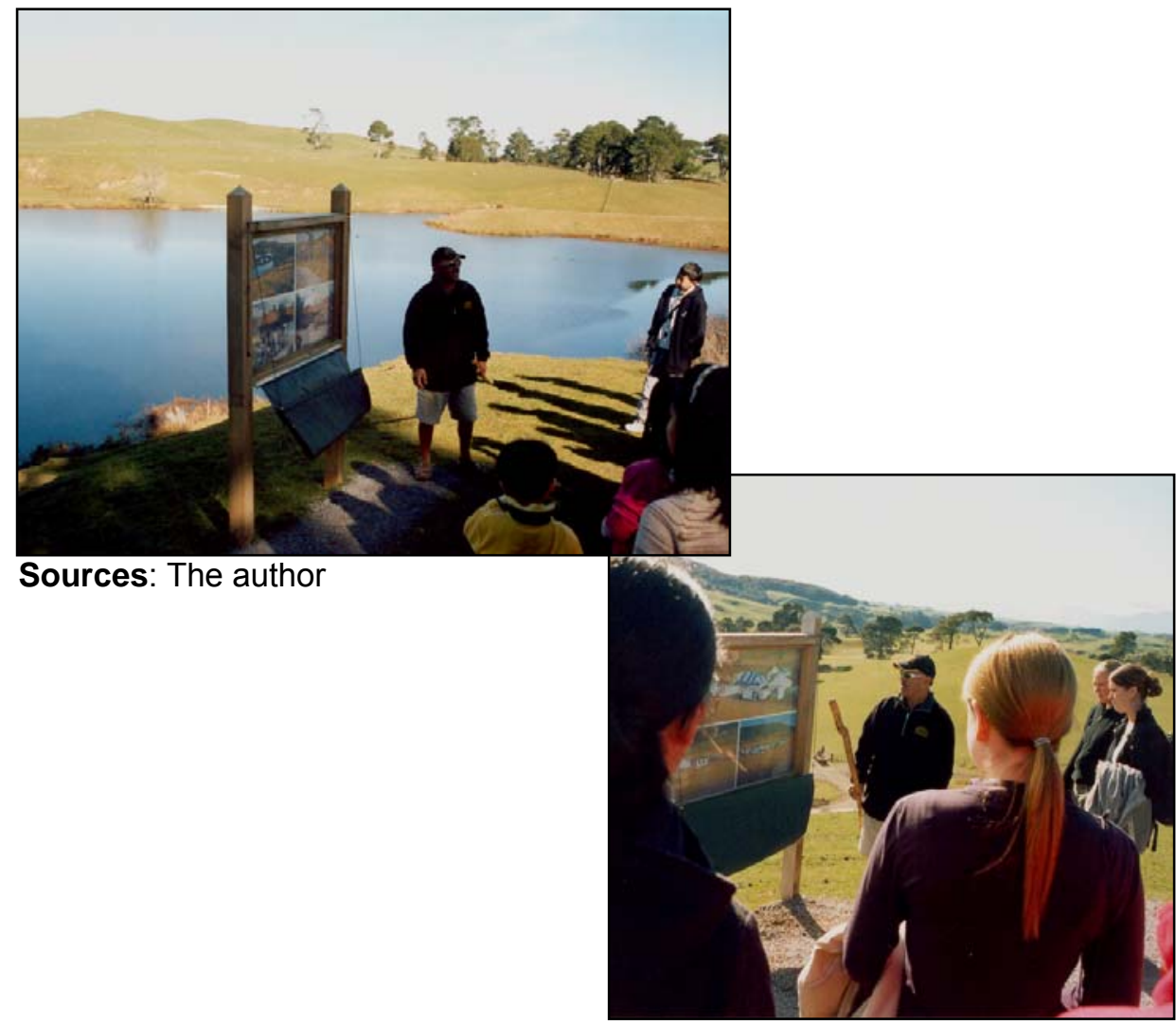

At the site the guides tell stories about events during the filming process as well as where scenes took place. The ways these stories are told depends very much on the personality of the tour guide. However, to ensure that all visitors get the same information no matter who their guide is, a script has to be studied closely by the guides before they conduct a tour. The order of this script is not so important but every tourist should get the same core information and stories.

Following, the findings of the survey $(n=97)$ and interviews $(n=3)$, which are more specific for the company, are discussed.

\section{Rings Scenic Tours respondents' travel patterns}

Visitors who are on a Rings Scenic Tour reach Matamata mostly by car, either private or rented. Although the town is on the main bus route only a few tourists get off the bus to join a tour to the former Hobbiton film set. This is because the journey by bus can only be continued after a tour when going on the 10 am or $12.30 \mathrm{pm}$ tours.

28.4 per cent stayed the night in Auckland before they went on a Rings Scenic Tour and 23.9 per cent stayed in Rotorua. Smaller numbers came via Katikati $(7.5 \%)$, 
Hamilton (6\%), and Waitomo Caves (6\%), Pahia, Otorohanga, or Taupo (each 4.5\%). They tended to stay with friends and relatives (22.4\%). Second favoured accommodation was backpackers/youth hostels (21.2\%). Motel accommodation ranked third $(18.8 \%)$.

On the day of the actual visit to the former Hobbiton film set, most tourists stayed in backpackers/youth hostels (23.4\%). Others stayed at friends and relatives (19.5\%) and hotels (14.3\%).

After the tour, the largest proportion of filmic tourists planned to spend the night in Rotorua (26.5\%) or in Auckland (17.6\%). 13.2 per cent of the respondents planned to stay in Matamata which confirms the positive impact film tourism has had for the accommodation providers in the town and in particular for local motels. Furthermore, visitors went to stay in Katikati $(7.4 \%)$, near the Waitomo Caves $(5.9 \%)$, or in Hamilton (5.9\%). A proportion of 5.9 per cent were not sure about their final destination of the day.

The planned accommodation for the day after the tourists had been to Matamata shows a significant change from the previous day. Most tourists planned to stay in hotel accommodation (26.6\%). Others planned to stay in backpacker/youth hostels (15.6\%), with friends and relatives (14.1\%), in motels $(10.9 \%)$, and on a holiday park or motor camp (3.1\%).

The day, after they had been in Matamata, 32.8 per cent of the respondents planned to stay in Rotorua and 18.8 per cent in Auckland. 10.9 per cent finished their visit to New Zealand and were going to spend the night either on a plane or overseas. 7.8 per cent were not sure or did not yet know where they were going to stay and 6.3 per cent planned to travel on to Wellington.

\section{Rings Scenic Tours respondents' information sources}

The investigation of a number of Visitor Information Centres on the North Island (Taupo, Turangi, Whakapapa, Otaki and Wellington) all potential destinations for The Lord of the Rings filmic tourists revealed that there was no promotional material available on Rings Scenic Tours, except Brodie's (2002) book in which the company and its tour is mentioned.

Figure 6.1 shows that 30.7 per cent of the respondents cited word of mouth as their information source for the Rings Scenic Tours. Respondents could indicate more than one information source. 67.9 per cent of these respondents indicated that they gained information about the tour within New Zealand, particularly in Auckland, which accounted for 32.1 per cent of all cases. Other word of mouth promotions for 
the tour were obtained in the USA (14.3\%), the U.K. (7.1\%), and Singapore, Australia and on a plane (each $3.6 \%$ ).

Figure 6.1: Information sources of respondents Rings Scenic Tours $(n=101)$

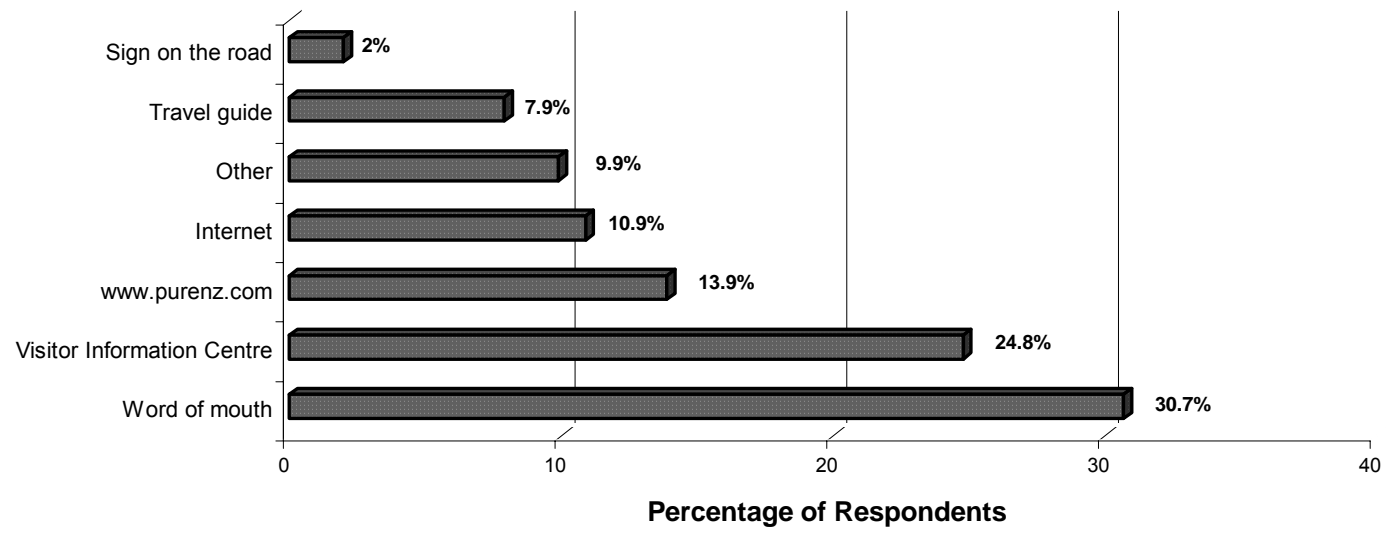

A Visitor Information Centre was the source of information for 24.8 per cent of the respondents. Here again Auckland was named by the most respondents (33.3 $\%)$, followed by Matamata's Visitor Information Centre (23.8\%) and Rotorua's Visitor Information Centre (14.3\%). This distribution corresponds with the main travel route of tourists while in New Zealand that goes from Auckland to Rotorua or vice versa.

Not surprisingly the Internet plays an important role as a source of information, particularly when research is undertaken overseas. 13.9 per cent found information for Rings Scenic Tours on the web page of Tourism New Zealand www.purenz.com. A further 10.9 per cent used a search engine, or Internet pages like www.tolkienonline.com, www.hobbitontours.com, www.nztours.co.nz or The Lord of the Rings fan community Internet page www.theonering.net.

Other information sources were named by 9.9 per cent of the respondents. These were specified as media, magazines and papers or lan Brodie's The Lord of the Rings Location Guidebook (2002). It can be assumed that the latter was also the source for some visitors who indicated a travel guide $(7.9 \%)$ as their source of information without specifying which one.

When this research was conducted, Ian Brodie's (2002) book was a main resource when looking for a guidebook to the former film sets and the researcher met a high number of tourists travelling with a copy of the book. However, a number of respondents criticised the book because of its complexity and the maps which were unhelpful especially for people who were not familiar with the regions.

Within the survey in Matamata only 2 per cent named a sign on the road as their information source. It can be assumed that this is the sign 'Welcome to Hobbiton' in Matamata. 


\section{Rings Scenic Tours respondents' suggestions for improvement}

The survey asked respondents to suggest any improvement for facilities for The Lord of the Rings film tourism. The majority with 54.7 per cent saw no reason for improvement whereas 45.3 per cent suggested improvements. The specific answers were categorised and put in groups for analysis.

Complaints related to the lack of information/advertisement of the former film site and offered tours were named by 41.2 per cent. This not only concerned Rings Scenic Tours and Matamata: it was cited as a general problem by all respondents who suggested improvements.

Suggestions for improvement of the former film set, such as to rebuild or at least maintain the hobbit holes, were named by 29.4 per cent of respondents. The lack of toilet facilities was cited as a fault by 8.8 per cent. On the other hand, the Visitor Information Centre staff does warn visitors in advance that within the two hours duration of the tour no toilet facilities will be available. However, for many people two hours can be a very long time without a chance to visit a toilet facility.

Criticism about the conditions of the paths, such as soft walking areas, mud particularly after rainfall and lack of facilities for disabled people were given by a further 8.8 per cent of the respondents.

Finally, suggestions to make the experience more perfect were to offer facilities where visitors could view the Hobbiton scenes from The Lord of the Rings after the tour or to provide opportunities for visitors to dress up and party around the tree as the hobbits in the film did.

The majority of the respondents $(54.7 \%)$ who did not see any need to improve the tour or the former film locations were mainly concerned that any improvement would spoil the natural environment and the appearance of the locations. In this group concerned was raised that more commercialisation and mass tourism would destroy the authenticity of the site. Selected comments against improvements are listed in Box 6.1. 
Box 6.1: Selected comments against improvement

\begin{tabular}{|l|}
\hline Comments \\
\hline You could see it all in its natural state. \\
\hline Fine as they are; don't want to make them too accessible \\
\hline I like natural and untouched viewing. \\
\hline With improvements it would lose authenticity. \\
\hline Keep it natural, NOT commercial! \\
\hline Leave it untouched. \\
\hline Leave something to imagination. \\
\hline Keep the natural environment. \\
\hline Become too touristy \\
\hline The natural content is what make's it. \\
\hline Based on possibilities and restrictions, I think the Hobbiton tour is run as well as possible \\
according to my knowledge. \\
\hline I like it the way it is: isolated, special, magical even! \\
\hline Because I wouldn't like NZ to become a Hollywood tour. \\
\hline It's ok as it is. Any development could spoil it. \\
\hline It's good as it is. No mass tourism please! \\
\hline
\end{tabular}

Source: Visitor survey Rings Scenic Tours

The next section gives information on the film tourism infrastructure, which includes a number of operators and their products in the Queenstown region. Nomad Safaris' Safari of the Rings tours are explained and the company-specific findings of the survey such as travel patterns, information source(s) of tourists as well as suggested improvement(s) are presented and discussed.

\subsubsection{Queenstown}

Safari of the Rings the second case study, is offered in Queenstown. Queenstown is "the self-styled adventure capital of the world" (Lonely Planet 2000: 61). It is located in the Southern Alps on the South Island (Map 6.1). Queenstown is doubtlessly one of the major tourist destinations in New Zealand, no matter what season (Hall and Kearsley 2001). Tourists get offered any imaginable kind of activity ranging from fun and adventure to extreme sport.

The magnificent mountain scenery in the Queenstown region is also popular for filming commercials, television series, documentaries, and feature films. Landscapes in the Queenstown Lakes District have been used to portray Canada, England, Tibet, Japan, the American Midwest and of course as embodying Tolkien's Middle-earth in the films of The Lord of the Rings (Queenstown Lakes District Film Office 2003).

The benefits and the potential of the film industry both during production, as well as post production, were recognised and acknowledged by the Queenstown Lakes District Council and a film office has been set up which operates under a film friendly policy to attract film companies from all over the world. 
Scenes for The Lord of the Rings were filmed on a variety of locations in the Queenstown region, such as on the shores of Lake Wakatipu, near Glenorchy and Paradise, at Deer Park Heights, on Arrow River near Arrowtown, on the Kawarau River and in Skippers Canyon. These sites are accessible to the public. Only one site near Closeburn on Lake Wakatipu is on private property and not accessible for the public.

According to David Kennedy, Destination Queenstown chief executive officer, Queenstown is benefiting from The Lord of the Rings film tourism (pers. comm., 27.08.03). However, no studies have been undertaken to measure the impact. Due to the variety of former film locations in the region a number of tourism operators are promoting their tours by linking them with the films of The Lord of the Rings. Because of budget restrictions, however, there is no existing marketing plan to combine these products. It is up to these individual operators to attract tourists (Kennedy 2003).

A number of tourism operators integrated the former film sites into their existing tours. The Lord of the Rings is used as a promotion instrument to distinguish the products of these operators from other operators' products. When research was undertaken (August/September 2003) only three established operators, Glenorchy Air, Heliworks Queenstown Helicopters and Nomad Safaris, designed new tours with a focus on The Lord of the Rings film sites. Overall, filmic tourists can choose from going by jet boat, on a horseback, with a jeep safari, by helicopter or on a bus tour to the former film sites in the Queenstown region.

Following operators in the Queenstown region and their The Lord of the Rings product(s) are briefly described.

\section{Glenorchy Air, Glenorchy}

Glenorchy Air operates in Glenorchy, which is a 45-minute drive from Queenstown. The company was involved in the making of the films by flying cast and crew to the film sets. Filmic tourists have the choice of two different flights called Trilogytrail, a five hours or a two and a half hour flight, to locations portrayed in the films.

Glenorchy Air uses a specially designed pamphlet to promote the Trilogytrail. The design of the pamphlet is interesting. Picture 6.4 shows the cover page of the pamphlet, which gives an image of the Dart River Valley that was used as backdrop for Isengard in the films. The landscape represented on the pamphlet was digitally altered, as is mentioned in white letters on the right side of the front page.

The inside of the pamphlet (Picture 6.5) shows images of four former film locations of The Lord of the Rings. The design and text gives the impression of a heritage tour. One would expect a trip back into history from the use of old runes and 
images of poles that seem to be Stone Age relicts. This confirms Rojek's argument (1993: 180) about tourism promotional publications that "seek to entice tourists with evocations of $(\ldots)$ 'worlds' which are presented as the opposite of the immediate conditions of "home'". In addition, this underlines the use of the film trilogy themes to portrayal New Zealand as the embodiment of where the mythical story was set.

Pictures 6.4 and 6.5: Glenorchy Air pamphlet (size changed) - Trilogytrail
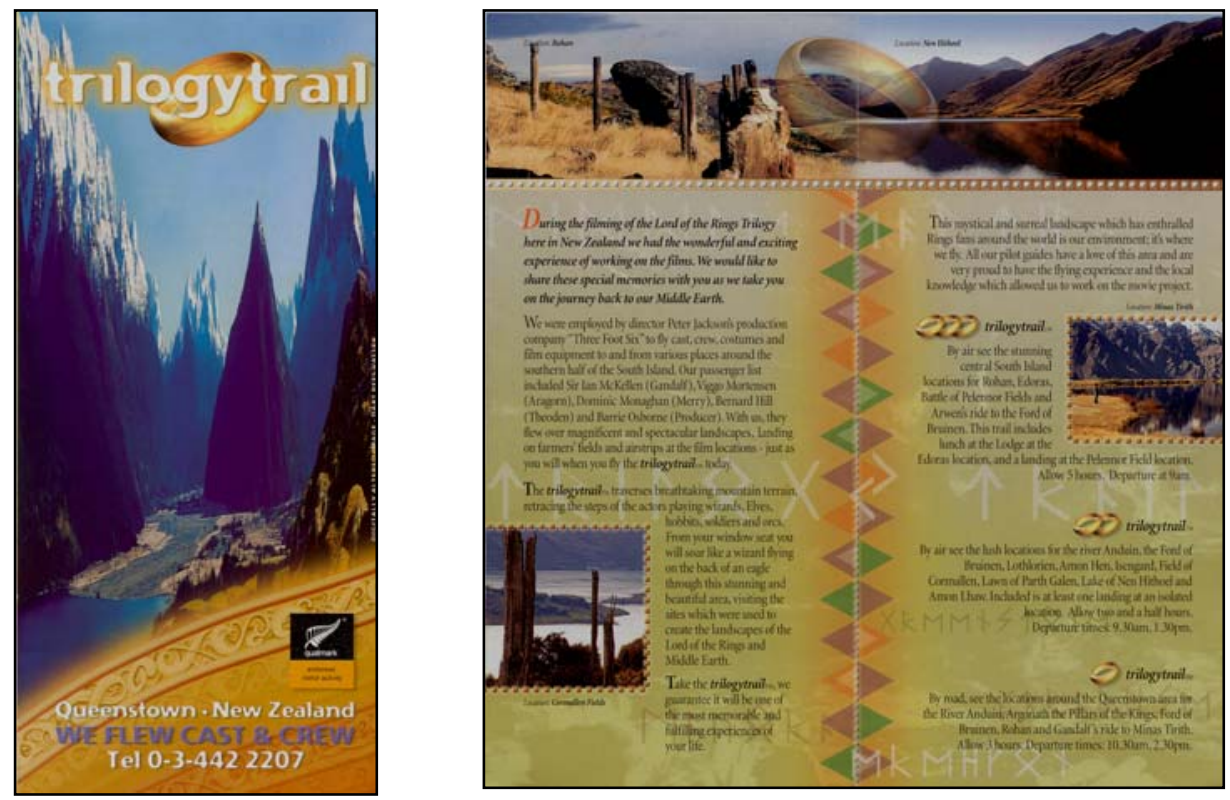

Source: Glenorchy Air Pamphlet 2003

\section{Dart Stables, Glenorchy}

Another operator located in Glenorchy is Dart Stables. It offers horse-riding tracks where tourists can "experience the exciting and splendour of riding through The Lord of the Rings country" (Dart Stables 2003). The horses of Dart Stables as well as some of the tour guides were involved in the filmmaking as extras.

Dart Stables does not offer a special tour to the former film sets. However, as filmed locations are on the route of the established horse tracks, the product is linked to the films of The Lord of the Rings. Owner operator, Peter Davis, feels confident that his clients are doing the horse ride because they love this activity and breathtaking landscapes. The former film sites are no more than an added bonus to them (Peter Davis, pers. comm., 22.08.03, Queenstown). This contrasts findings of two respondents within this research. These respondents went on a horse riding track of Dart Stables post a Safari of the Rings tour intending to visit The Lord of the Rings film location in a different way on the back of a horse. 


\section{Dart Wilderness Adventure, Glenorchy}

The third tourism operator in Glenorchy, which mentions former film sites in its pamphlet to attract tourists, is Dart Wilderness Adventure. Its pamphlet describes:

The majestic grandeur of Glenorchy and the Dart River valley, is a natural phenomena [sic] which will leave you awe inspired. Such an invoking tryst it is a must to be experienced. You can relive the magical aura of 'Middle Earth's' wild landscape as filmed in 'The Lord of the Rings' (Dart Wilderness Adventure 2003).

The company is offering jet boat trips along the Dart River, which are not newly designed tours to the former film sets of The Lord of the Rings. However, to justify promotion in the pamphlet, comments on the filming were included in the commentary.

\section{Dart River Safaris, Glenorchy}

Dart River Safari is the second jet boat operator in Glenorchy on the Dart River. Some of the former film locations were already included in their existing tours. In the company's pamphlet, the tour is promoted as an opportunity to "escape the crowds. (...), discover the magical wilderness of 'Lord of the Rings' (...) [and] jetboat to the edge of reality" (Dart River Safaris 2003).

According to Hilary Finnie, Dart River Safari's marketing manager, The Lord of the Rings film tourism had a huge impact on the company with a 25 per cent increase in visitor numbers and a growth rate of 30 to 40 per cent (sited in Tourism New Zealand 2003f).

\section{Air Fiordland, Te Anau}

Air Fiordland offers a The Lord of the Rings themed product called Wings over the Rings. The flight is offered only on demand. Although the office is based in Te Anau the locations visited on the tour are located in the Queenstown region. As with Glenorchy Air's newly composed tour, a pamphlet was designed using an ancient appearance (Picture 6.6 and 6.7). The inside presents a map styled as shown in Tolkien's books (Picture 6.7). It presents the film locations around Queenstown integrated in the flight. 
Pictures 6.6 and 6.7: Air Fiordland pamphlet (size changed) - Wings over the Rings

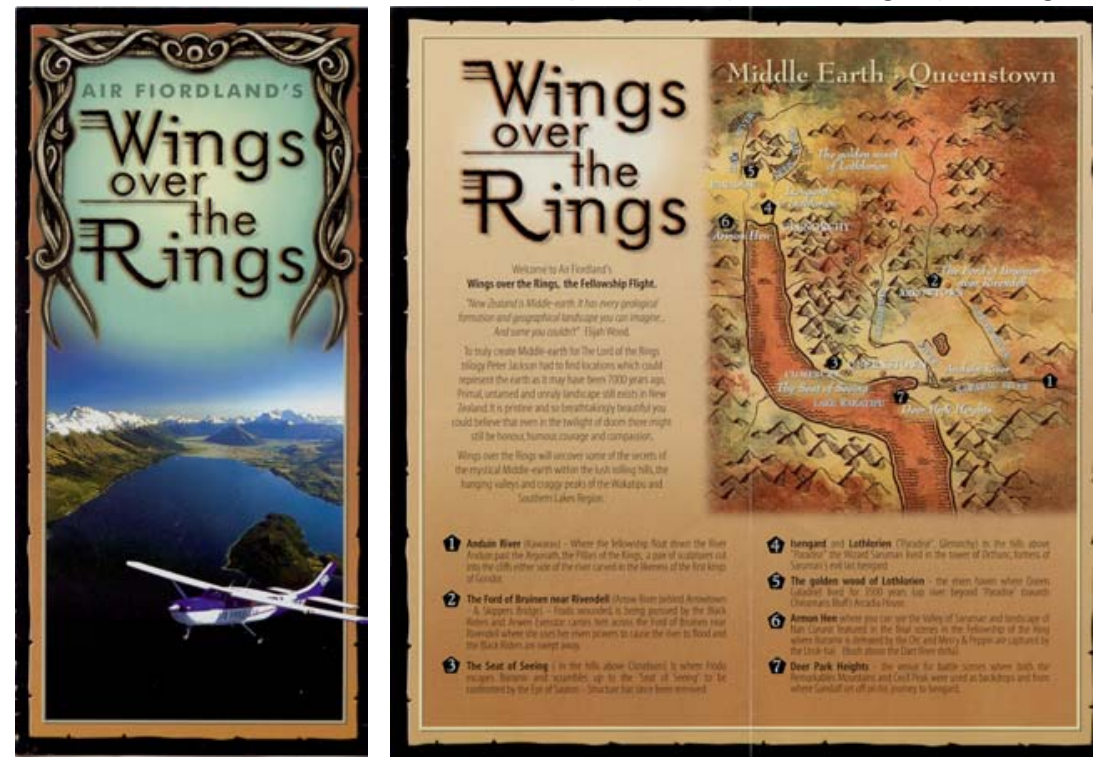

Source: Air Fiordland 2003

\section{Deer Park Heights, Queenstown}

Deer Park Heights is not in the first instance a tour operator but a privately owned alpine animal park. In the park, six film scenes of The Lord of the Rings, particularly film two, were depicted. The area was also used as backdrop for commercials and for an American Walt Disney Production The Rescue filmed in 1986. The owners of the deer park operate a two hour-long scenic tour twice a day, which integrates The Lord of the Rings film sites.

The park is situated on a hilltop above Kelvin Heights near Queenstown (Map 6.3). It is on private property and can be accessed by private motor vehicle by paying a fee of NZ \$20 per car at a tollgate. Buses, coaches or commercial mini vans are not permitted. The site can also be visited by bike or by people on foot, both of which are free of charge.

Map 6.3: Location of Deer Park Heights

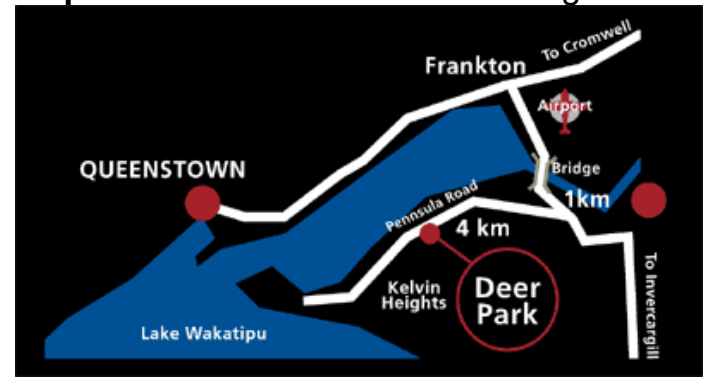

Source: The Deer Park Scenic Tours (2003)

Observations at the site revealed that the majority of visitors enter the park by private car. At the gate an information sheet is provided which shows where each 
type of animal can be found and more importantly where scenes of The Lord of the Rings were filmed. The locations are numbered in the map and also pointed out with signage (Pictures 6.8 and 6.9). Furthermore, to re-awaken the memory of visitors the scenes are briefly described in the information sheet.

Picture 6.8: Deer Park Heights sign to The Lord of the Rings (LOR) former film site

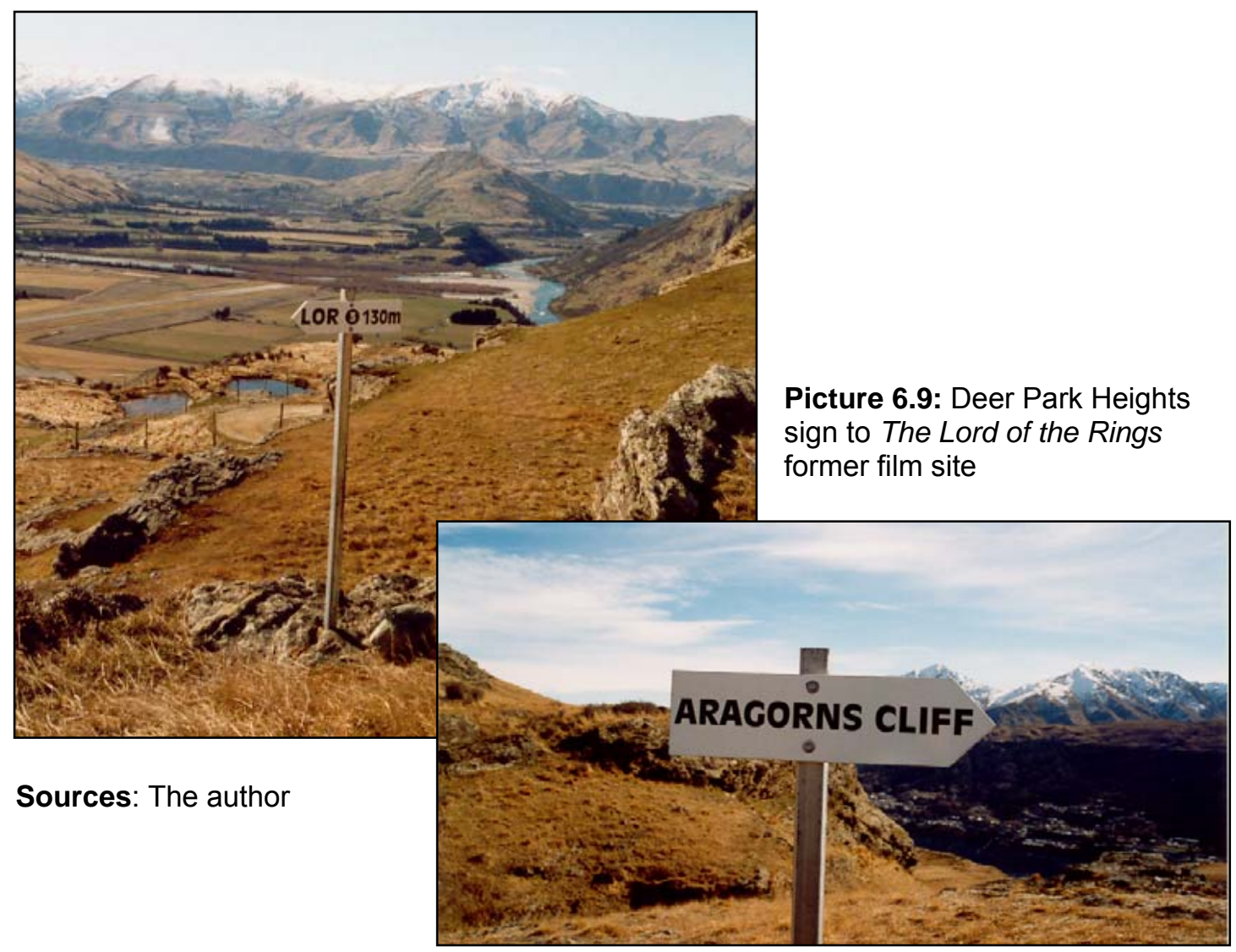

\section{Heliworks Queenstown Helicopters}

Heliworks Queenstown Helicopters is based at Queenstown airport, a ten-minute drive from the town centre. The company offers helicopter flights, such as scenic flights to the surrounding areas of Queenstown, heli-skiing flights, heli-lifting and transportation, film work and flights to The Lord of the Rings former film sites. According to Barbara Swan, operation coordinator, Heliworks is first and foremost working for film companies in the region and is a scenic flight operator secondarily (pers. comm., 20.08.03). The company was also involved in the films through enabling aerial filming as well as transportation of cast and crew.

Three The Lord of the Rings themed flights have been designed by Alfie Speight, the main filming pilot of Heliworks Queenstown Helicopters and lan Brodie, the author of The Lord of the Rings Location Guide Book (2002; 2003). The flights are The Flight to the Ford (40 min), The Great Forests (1h $15 \mathrm{~min}$ ) and The Middle 
Earth Explorer ( $2 \mathrm{~h} 30 \mathrm{~min})$. These flights are only available on demand. The programmes of a flight as well as the price are negotiable (Swan 2003). Thus, filmic tourists have the opportunity to compile their own special programme of flights to the locations they most like to visit.

The book by lan Brodie $(2002 ; 2003)$ is the main promotional tool for these flights. This was a clever choice due to its success that made it the second best selling book in New Zealand after the Bible (Cardy 2003).

The following section focuses on Nomad Safaris' The Lord of the Rings themed Safari of the Rings tours and the more company-specific findings of the survey such as travel patterns, information source(s) and suggested improvements named by respondents in the survey $(n=19)$ and interviews $(n=4)$.

\subsubsection{Case Study Safari of the Rings}

Before offering the Safari of the Rings, Nomad Safaris, which has been operating since 1992, was focusing on small group four-wheel-drive (4WD) adventure gold heritage tours in the Queenstown region. Off-road tours are offered to Macetown, Skippers Canyon and Seffertown. In addition, a half or full-day Land Rover 4WD Experience tour is offered where tourists have the opportunity to get behind the wheel and learn off-road driving skills with a trained instructor. These tours were the core business of Nomad Safaris and are still an integral part of the product range. The targeted clientele of these tours were mainly English-speaking Europeans, Australians, US-Americans, Dutch and Germans over 45 years of age (Helen Jansen, Business Development Manager, pers. comm., 01.09.03).

Soon after the first film of The Lord of the Rings-The Fellowship of the Ring was released, Jansen saw an opportunity in The Lord of the Rings film tourism. It took her further four months to convince the management that this might be a seller (Jansen 2003). Tours to the former film location were started in April/May 2002. Because some of the filmed locations were already integrated in the gold heritage tours the Safari of the Rings was designed by restructuring and expanding these existing tours.

Nomad Safaris started with a full-day Safari of the Rings tour because it was assumed that they would not get much demand by filmic tourists. It took only a couple of weeks of being on the market and the company received several enquiries for half-day tours (ibid). Thus, the full-day tour was simply separated in two half-day tours of four hours each, called tour A and tour B and priced with NZ $\$ 120$ per adult. 
These tours are attracting a broader group of clients than the gold heritage tours. Visitors of every age group and type seem to be interested (Jansen 2003). This increased the market in terms of age groups, backpackers and Free Independent Travellers (FIT's). The tours are also popular with older American coach tourists who have not seen the films of The Lord of the Rings but whose grandchildren have and so would like to visit the locations as well.

Yet, there are also tours were the majority or even the whole group has not watched the films or read the books. In this case there is no need to talk about the film scenes and former film sites. The tours are so designed that they are as much about the films as they are about the scenery.

Within each Safari of the Rings tour it is made as clear as possible that there are no sets left. In the pamphlet (Appendix 11) of the tours it is pointed out that:

[The tour] is based around several of the specific sites where filming took place. These are real places; there are no film sets [left]; they are areas of outstanding natural beauty that need no enhancement. Here it is possible to experience the magical atmosphere captured in the film (Safari of the Rings 2003).

In contrast to Rings Scenic Tours in Matamata, guides here are not following a script. The researcher's personal impression was that level of information given by guides varied highly. The requirements to conduct a tour as a guide are, beside knowledge of off road driving and the area, to be familiar with the books and the films. In addition, the guides are required to watch the appendices of the extended DVD versions of the films.

Of advantage is the fact that most of the guides were personally involved in the filming of The Lord of the Rings either as extras or, as in one case, as security guard. Tourists have even asked for autographs from these guides. As one participant stated about why she is satisfied with the tour experience: "It's fantastic and we got a 'real orc' as a tour guide!". One of the guides is also member of The Lord of the Rings fan club. Thus, he is enjoying challenging the knowledge on The Lord of the Rings of other fans on the tour.

\section{The Tours}

Tour A: 'Wakatipu Basin', which mainly goes to the same includes stops at the Remarkables (Misty Mountains), Kawarau River (River Anduin/The Argonath), Arrow River (Ford of Bruinen), and Skippers Canyon. The spot visited in Skippers Canyon was not used as a backdrop in The Lord of the Rings films. However, it is for David 
Gatward-Ferguson, owner of Nomad Safaris, the perfect representation of the road to Mordor. The tour also includes gold panning at the Arrow River.

Tour B: 'Glenorchy' goes along Lake Wakatipu to the Glenorchy area. It is focusing on former film locations at Twelve Mile Delta (Ithilien and the scene when Frodo, Sam and Gollum spot the army of Harad with their Olyphants), Dart River Valley (Isengard), Paradise (Lothlórien), and a number of other smaller scenes.

Within each tour refreshments are provided and one off-road experience is also included. A full-day tour, which includes locations visited in tour $A$ and $B$, is also offered on demand. According to the guides tour A seems to be slightly more popular than tour B.

In both tours long distances are covered. This makes it essential that guides have the ability and the knowledge to 'entertain' their passengers. Beside information on where certain scenes were filmed, tourists also receive information about the history and geography of the area. To illustrate as well as to re-awaken memories and to make it easier to recognise how particular landscapes were portrayed in the films, a folder with pictures and articles as well as lan Brodie's book (2002) is used.

The findings more specific to the company of the survey $(n=19)$ and interviews $(n=4)$ are presented and discussed below.

\section{Safari of the Rings respondents' travel patterns}

Queenstown as one of the most attractive destinations in New Zealand can be reached by air and on the road. The airport offers domestic as well as international flights and all main bus coach lines on the South Island stop and departure from here.

Respondents of the survey reached Queenstown by all three possible transport modes: plane, coach or car. In contrast to the Matamata case study none of the respondents was travelling with a campervan or motor home, which might be due to winter conditions when the survey was undertaken.

Queenstown offers a variety of accommodation types to suit every need from luxury hotel to budget accommodation. Respondents within the Queenstown case study survey stayed mainly either in hotel $(50 \%)$ or backpacker/youth hostel $(33.3 \%)$ accommodation. The distribution of accommodation types were nearly unchanged on the day before visiting the former film sets with a Safari of the Rings tour and the day of the actual visit. Changes occurred on the day after participating on a Safari of the Rings tour when 55.6 per cent of the respondents left Queenstown for another destination. On the day after the visit 33.3 per cent of the respondents stayed in hotel 
accommodation and 16.7 per cent in motels. 38.9 per cent of respondents were going to stay in backpackers or youth hostels.

All respondents within the survey stayed the day prior going on the tour to visit the former film locations as well as the actual day of the visit in Queenstown. On the day after the visit, 44.4 per cent stayed on in Queenstown, the rest travelled to Fox Glacier (27.8\%), Franz Josef Glacier (11.1\%), Dunedin (5.6\%), Christchurch (5.6\%), or Auckland (5.6\%).

\section{Safari of the Rings respondents' information sources}

Figure 6.2 gives the results of which information sources respondents used to find out about Nomad Safaris' Safari of the Rings tours.

Figure 6.2: Information sources of respondents Safari of the Rings $(n=24)$

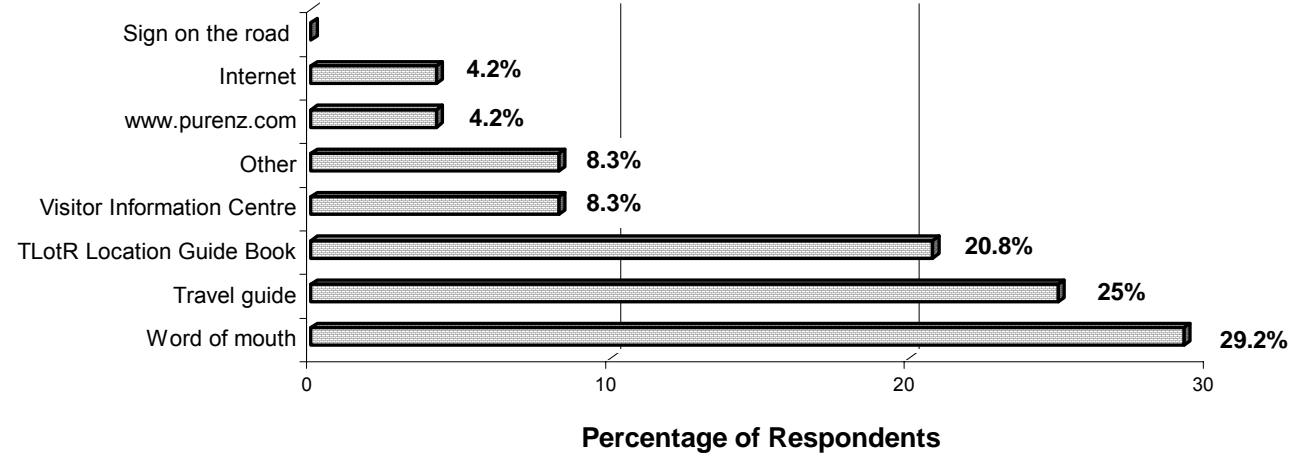

The results show that 29.2 per cent received information via word of mouth recommendations, 25 per cent used a travel guide and 20.8 per cent used lan Brodie's (2002) The Lord of the Rings Location Guide Book. This result is interesting given that the Safari of the Rings tours are not mentioned in Brodie's (2002) location guide book. A Visitor Information Centre gave information to 8.3 per cent of the respondents. Further 8.3 per cent named other information sources, which were brochures in the hotel. Only a low proportion (4.2\%) of respondents used the Internet or the webpage of Tourism New Zealand (www.purenz.com) as information sources.

Multiple nominations as information source were possible. One third of the respondents used more than one information source to find out about the Safari of the Rings tours.

\section{Safari of the Rings respondents suggested improvement}

When asking participants of a Safari of the Rings tour whether they would like to have facilities for The Lord of the Rings film tourism to be improved, more than half of 
them $(57.9 \%)$ expressed that no improvement was necessary. The statements made by respondents who did not want to have improvements are similar to those in Matamata. They appreciated the former film sites the way they are. In their opinion, improvements would spoil the nature and the authenticity of the landscapes.

Suggestions by respondents $(42.1 \%)$ who would appreciate improvements can be classified in two groups. The first group gave suggestions for material or practical improvement like better access, cheaper prices as well as establishing signboards, which show the scenes in the films and make it easier to recognise the former film sites. The second group respondents would like the sites to have actual props permanently on display or to have the former film sites transformed into a living theatre or a museum.

The third case study operator in this research is Red Carpet Tours. Its multi-day product and the more product-specific findings are shown and discussed in the next section.

\subsubsection{Case Study Red Carpet Tours}

Auckland-based Red Carpet Tours is a wholesale package tour operator. Each month it offers a 13-day The Lord of the Rings themed tour to former film locations of all three films in the North and South Island. The tour starts in Auckland and finishes in Christchurch. As the The Ultimate Fantasy name suggests, the tour promotes the fantasy of New Zealand as Middle-earth.

The idea of the company is to offer fans of Tolkien's work a tour to experience the film locations as part of a group of likeminded Tolkien fellow fans. Thus, the main promotional tool for Red Carpet Tours is the fan Internet page www.theonering.net. The strong connection between Red Carpet Tours and the Internet page is also due to personal connections since Red Carpet Tours director, Erica Challis, is also one of the founders of the theonering.net fan page.

The tourists can walk in the footsteps of the stars and relive the landscape journey as Tolkien has described it and as the actors experienced it while filming. Red Carpet Tours (2003a) goes as far as to say that it provides the "experience of a lifetime as we travel to Middle-earth". The main idea of Vic James, Red Carpet Tours managing director, was to offer The Lord of the Rings fans an exclusive film location tour as other film locations overseas have done successfully. The tours started in 2002 and according to $\mathrm{Mr}$ James, inquiries exist for as far as 2008 (e-mail correspondence, 29.01.04). 
Travellers on the tour stay in accommodation with The Lord of the Rings themes such as the 'Hobbit Lodge' in Ohakune or in a hotel where the main actors stayed in Methven 'The Sovereign Resort'. As stated on the Red Carpet Tours (2003a) Internet page, "many people have dreamed of walking on Middle-earth. Red Carpet Tours will take you into the dream".

Besides visiting the former film sites, the tour also occasionally incorporates talks by lan Brodie, the author of The Lord of the Rings Location Guide (2002; 2003) and himself a The Lord of the Rings enthusiast, as well as with extras who were involved in the films (Red Carpet Tours 2003a).

Two tour options are available depending upon demand. For smaller groups of up to 11 people a tailor-made mini-coach tour is available which can accommodate individual needs of tourists. A tour guide accompanies the tour. For groups, with a minimum of 25 tourists, a full coach tour is offered. The price of a mini-coach tour per person is between NZ $\$ 3,020$ and NZ $\$ 3,950$ depending on the accommodation type (ibid).

In the Red Carpet Tours itinerary (Box 6.2) destinations visited in the tours are described as sequences or landscapes portrayed in the films of The Lord of the Rings. The tours also include former film sites on privately-owned properties such as the Hobbiton film set in Matamata or the location where the main battle of the third film was filmed, Pelennor Fields, on the Ben Ohau Station in MacKenzie country.

\section{Box 6.2: Red Carpet Tours itinerary}

Day 1: Arrive in Auckland. Meet your fellow travellers. The 'Fellowship' begins.

Day 2: Auckland to Rotorua via Hobbiton.

Day 3: Rotorua to Ohakune via the Mount Ruapehu sites of Emyn Muil, Mordor and Gollum's fishing pool.

Day 4: Ohakune to Wellington via the Black Rider's ranch and the 'Get off the road' site.

Day 5: Today we take in the sites of Stone Street Studios, Helms Deep, Isengard and leaving Lothlórien

Day 6: Time to fly to Christchurch for the South Island portion of the tour.

Day 7: Christchurch to Twizel via the impressive site of Edoras. Be ready to ford some streams!

Day 8: Twizel to Alexandra via the remote sites of the Rohan village under siege.

Day 9: Alexandra to Te Anau via Nen Hithoel, the edge of Fangorn Forest and perhaps a jet boat trip down the River Anduin.

Day 10: Today you have a chance to take the optional trip to world famous Milford Sound. 
Day 11: From Te Anau we head to Queenstown via various sites used in the Two Towers. Can you find where Aragorn plunged over the cliff?

Day 12: Time for optional activities like rafting past the Pillars of Argonath or taking a helicopter flight to the 'Ford of Bruinen'.

Day 13: Time to depart- the tour ends.

Source: Red Carpet Tours 2003b

Demand for a tour was particularly high for the Return of the Ring tour in November/December 2003, which included the world premiere ceremony for the third film of the trilogy in Wellington. This tour also included a celebration of and for fans of J.R.R. Tolkien and his work, and fans of the films by Peter Jackson. The party, called Return of the Ringers, was jointly hosted and organised by Red Carpet Tours and theonering.net. As with the tours, the party was strongly The Lord of the Rings themed. The tour included musical entertainment by 'The Harp of Gondor' and by 'Lothlorien', a folklore band. The buffet offered 'Gimli's Favourite', red meat off the bone. Furthermore, as with other film theme parties, i.e. Star Trek/ Star Wars, fans had the opportunity to dress up and to participate in a costume contest or the Springle Ring Dancing Competition.

Red Carpet Tours future plans include setting up film locations tours to the sites of The Last Samurai in Taranaki as well as possibly to the former film sites of Whale Rider in the East Cape region (James 2004).

Following more company related findings of the survey $(n=16)$ are presented.

\section{Red Carpet Tour respondents' travel patterns}

As mentioned above, the Red Carpet Tours operates coach tours, which visit former film locations in the North and South Island (Map 6.1). The accommodation types provided for participants range from middle range to highly priced hotels and boutique lodges depending on tourist needs.

\section{$\underline{\text { Red Carpet Tour respondents' information sources }}$}

As the main promotional tool is the Internet the results for the information source are not surprising. Three-quarters of the respondents named the Internet and onequarter named word of mouth as their primary information source. In the dominant group of Internet users, respondents gained information from www.theonering.net, www.redcarpet-tours.com or by using a search engine. 
$\underline{\text { Red Carpet Tour respondents suggested improvements }}$

70 per cent of respondents within the Red Carpet Tours see a need for improvements. Their suggestions are for smoother pathways, better access and signs that indicate where cameras were located when shooting the films. Half of this group would like as part of the tour to have more contact with filmmakers and actors as well as the chance to visit the WETA workshops in Wellington.

The remaining 30 per cent who are against improvements enjoyed the remoteness of the sites and fear that improvement would result in increasing tourism at the sites and spoil the landscape.

This result is interesting when comparing with the results of the two half-day tour experiences in which over half of the respondents did not want to have any improvement. The different result may be explained by the fact that participants on Red Carpet Tours may originate from different groups than people on other tours and that the tour puts a very strong focus on The Lord of the Rings.

Beside the locally based case study operators in Matamata and Queenstown, other former film locations were also investigated. The emphasis was on what The Lord of the Rings themed products tourism operators offer and what information material is provided by Visitor Information Centres. Following these other sited locations and tourism operators are discussed.

\subsection{Other Film Site Locations and Tourism Operators}

A high number of New Zealand's landscapes were used in the films and tourism operators are realising the potential that The Lord of the Rings film tourism offers. The result is that an increasing number of operators setting up The Lord of the Rings themed tours. In the North Island the researcher visited the Tongariro National Park, Otaki and Wellington. In the South Island Canterbury and Central Otago were visited. In addition, a wholesale package operator, Tourmasters Southpacific NZ Ltd, was included in the research.

\subsubsection{Tongariro National Park}

Scenes of the prologue in the beginning of the first film, of Mordor and the Emyn Muil were filmed in the Tongariro National Park. It could be argued that Mordor and thus the Tongariro National Park can be seen as an iconic landscape due to the important events particularly in the third film and because it is the main destination of the quest (see chapter five, section 5.3). However, the Visitor Information Centre in both Turangi and Whakapapa provided no specific information on actual film locations of 
The Lord of the Rings. The staff only recommend buying Brodie's (2002) location guide book to interested tourists.

According to Pat Gregory of the Turangi Visitor Centre (Email correspondence, 23.07.03) "those [filmic tourists] interested seem to have an idea of the location of these [former film] sites". On the other hand she also acknowledges "there has been a lot of interest from visitors over the past couple years" (ibid).

When research in the area was conducted, in August 2003, only one operator, Mountain Air, related its product to the former film sites. Before they became film locations parts of the landscape were already flown over by the The Volcanic Explorer flight, which is 35 minutes long and costs NZ \$145 per person. According to Chris Morrisey (pilot of Mountain Air, Mount Ruapehu, pers. comm., 06.08.03) this company has not yet experienced specific demand from filmic tourists whose main interest is to visit former film locations.

\subsubsection{Otaki}

Scenes of 'Leaving The Shire' in the first film were shot near Otaki. No tourism operator offers tours to the site and the Visitor Information Centre only provides very vague information for filmic tourists. Brodie's book (2002) mentions the Otaki site, however, it cannot be purchased in the Visitor Information Centre.

\subsubsection{Wellington}

Wellington offers a variety of locations used as film sets for all three films. In addition to the film sets Wellington is also the production base, the director's hometown, and hosted The Lord of the Rings exhibition in 2001/2002 and the world premiere for the third film of the film trilogy in December 2003.

Positively Wellington Tourism, Wellington's official tourism organisation, is aware of the positive effect of film tourism. It provides information about relevant tour operators as well as two day self-organised itinerary recommendations on its Internet page (Positively Wellington Tourism 2003).

The film locations are all accessible to the public except for the Dry Creek Quarry in Lower Hutt where Minas Tirith and Helms Deep were filmed. However, none of the sets remained after filming.

Two tourism operators in Wellington offer The Lord of the Rings themed tours. The first is Flat Earth New Zealand Experience with a personalised three-hour luxury film location tour to all the locations in Wellington and the region. The tour costs NZ $\$ 300$ per car and is shared between the two to four tourists (Johnson 2004). The tour was launched in July 2003 and is offered on demand (ibid). 
Wellington Rover's Rover Rings Tour is the second organised tour option for filmic tourists in Wellington. Similar to Flat Earth, it offers a half-day tour designed for small groups. The tour is offered weekly as well as on demand and the tour admission is NZ \$150 per person. The newly designed The Lord of the Rings themed tour was started in July 2003 (Jason Bragg, owner operator Wellington Rover, pers. comm., 26.09.03). According to Mr Bragg filmic tourists on a Rover Rings Tour do not expect to see props (ibid). More important to them is to experience the atmosphere of the place where filming took place and anecdotes about the filming process. He is aware of the importance of stories that tourists like to hear and has integrated them in the tour (Bragg 2003).

While filming the trilogy, actor Sean Austin made his own short film which included some of his The Lord of the Rings colleagues including Peter Jackson in Wellington's suburb Kilbirnie. The film can be seen on the DVD of The Two Towers. Locations that were used in this short film will be included in the Rover Rings Tours in the future (ibid). Mr Bragg would be grateful if the WETA would allow visits to their studio, as filmic tourists would love to see 'behind-the-scenes'. However, currently there is no prospect that this will happen soon.

\subsubsection{Canterbury}

Christchurch is the hub of the Canterbury region and the main contact point for filmic tourists to get information about the region. It is also the second international gateway airport in New Zealand and thus the first destination for a number of filmic tourists. The Visitor Information Centre offers Brodie's (2002) book as well as a number of books about the filmmaking. Again, however, filmic tourists receive no helpful advice about where to go and what The Lord of the Rings themed products are offered. The staff of the centre only recommend buying Brodie's (2002) location guidebook.

Canterbury provided the film location for one of the iconic landscapes (see chapter seven, section 7.2) in the second film: Edoras. It was filmed in the Rangitata Valley on top of Mount Sunday. The valley is approximately an hour's drive from Christchurch. Mount Sunday itself is not easily accessible by road because three rivers have to be forded. However, according to Les Cain (owner and operator of $4 \times 4$ New Zealand Ltd., pers. comm., 10.09.03) this does not deter filmic tourists. He recalls that a filmic tourist from Israel even tried to cross the rivers with a Mitsubishi Mirage. This was because the Visitor Information Centre informed him, in his previous destination at Mount Cook, that there are no operators offering tours to the Edoras location (Cain, pers. comm. 10.09.03). This information was incorrect. An 
existing half or full-day tour is offered by $4 \times 4 \mathrm{New}$ Zealand Ltd, which is Geraldinebased. The company runs a wilderness tour to the area and ran it before filming took place. When filming started they integrated The Lord of the Rings theme into the existing tour. The owner and operator Mr Cain expected the interest by filmic tourists to drop off "but it's getting stronger and stronger and stronger" (Cain 2003) even although the tour is only locally advertised in Geraldine's Visitor Information Centre and via the company's Internet page.

The full-day tour costs NZ $\$ 120$ per person and is offered on demand. It visits the location where the film set of Edoras was built up and filmed as well as the valley where Helms Deep was digitally superimposed in post-production.

\subsubsection{Central Otago}

Within Central Otago, the Poolburn Dam in the Ida Valley provided the backdrop landscapes for Rohan in the second film. The main contact point for filmic tourists is the Visitor Information Centre in nearby Alexandra, which Brodie's book (2002) offers. The staff also refers inquirers to a local tour operator who runs a tour on his Ida Valley property.

\subsubsection{Tourmasters South Pacific NZ Ltd}

Tourmasters South Pacific NZ Ltd is a wholesale package operator based in Auckland. It created a The Lord of the Rings programme, which is based around tours offered by external suppliers and linked together in a package with transport and accommodation. The package tours began in May/June 2002. However, the first booking did not take place before November 2002. Since then bookings have increased (Anne-Marie Forsyth of Tourmasters South Pacific NZ Ltd, e-mail correspondence, 30.05.2003).

The company offers three different The Lord of the Rings themed tours: the North Island tour (9 days) ranges from NZ \$1,080-1,665, the South Island tour (15 days) ranges from NZ $\$ 2,425-3,415$ and a combination of both islands (22 days) ranges from NZ \$3,255-4,790 depending upon the accommodation and transport type (ibid).

The programme of the tours concentrates upon nature walks and other outdoor activities, which require a certain level of fitness. According to Ms Forsyth (2003) the received feedback of clients has been very positive and one client requested a repeat booking. 
The next section covers an overview of the filmic tourists sampled in this research. This includes respondents' country of origin, gender, age, purpose of travel, a possible influence of the films on the travel decision making, first or repeated visitation, returning plans, length of stay, and travelling companions.

\subsection{Overview of sample}

\section{Country of origin}

Among the respondents' country of origin, the USA (28\%) and the UK (26.5\%) comprised the two biggest groups. They were followed by Australia $(11.4 \%)$ and New Zealand $(9.8 \%)$ as explained in Figure 6.3. When considered in terms of continents, European respondents numbered 38.6 per cent, Americans (North and South) made up 31.1 per cent, Australia and New Zealand 21.2 per cent, and 9.1 per cent were Asians.

Figure 6.3: Country of origin of all respondents $(n=132)$

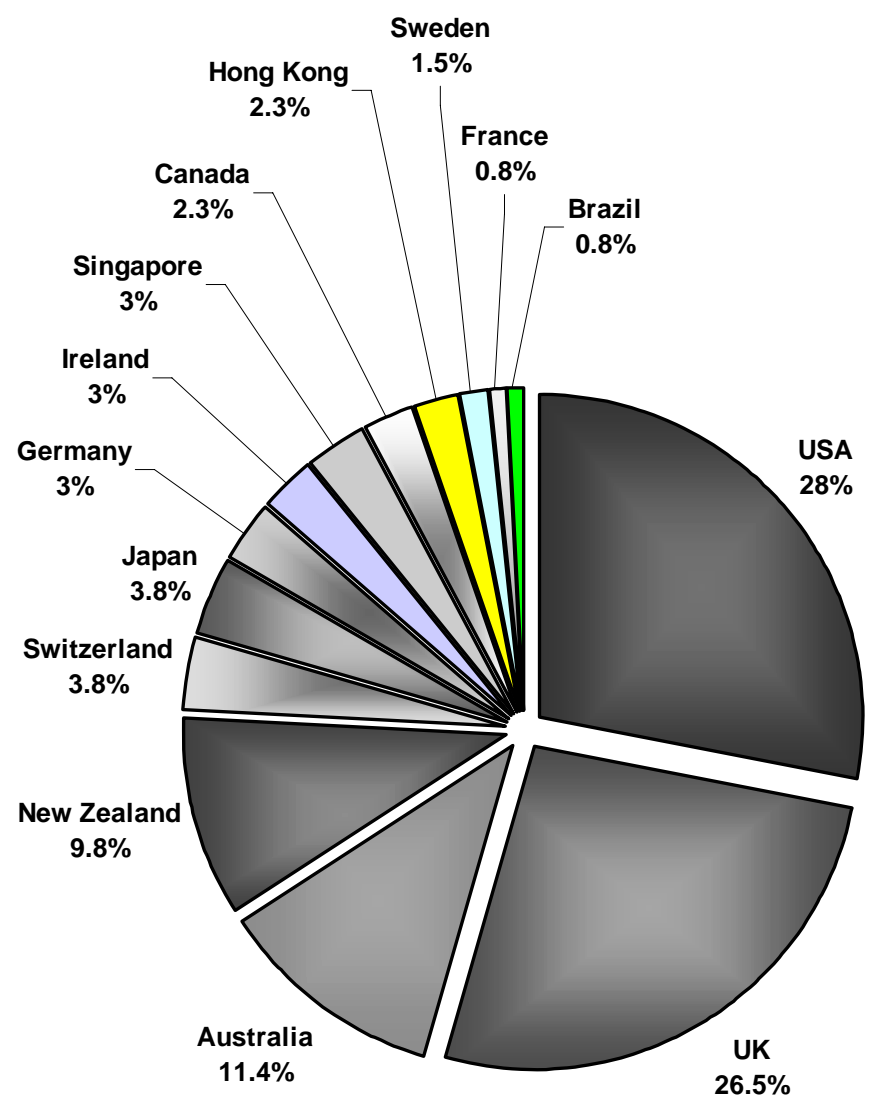

Statistical research by the Tourism Research Council New Zealand (2003a) looked at overseas visitor arrivals by country of origin for July 2003, when fieldwork for the present research was also undertaken. The statistics give the following results for the main countries from which participants of The Lord of the Rings themed tours came: Australia (36\%), the USA (10.5\%) and the UK (9.2\%). When comparing these 
figures it becomes clear that visitors from the USA and the UK are the main target groups for The Lord of the Rings film tourism.

When breaking the results down for each of the case studies, a noticeable difference in the proportion of respondents' country of origin can be seen (Figure 6.4). Of respondents within the Rings Scenic Tour, the highest proportions came from the UK $(28.9 \%)$, the USA $(24.7 \%)$, and New Zealand $(12.4 \%)$. However, respondents from ten other countries undertook a Rings Scenic Tour while research was conducted.

Figure 6.4: Country of origin of respondents within each case study

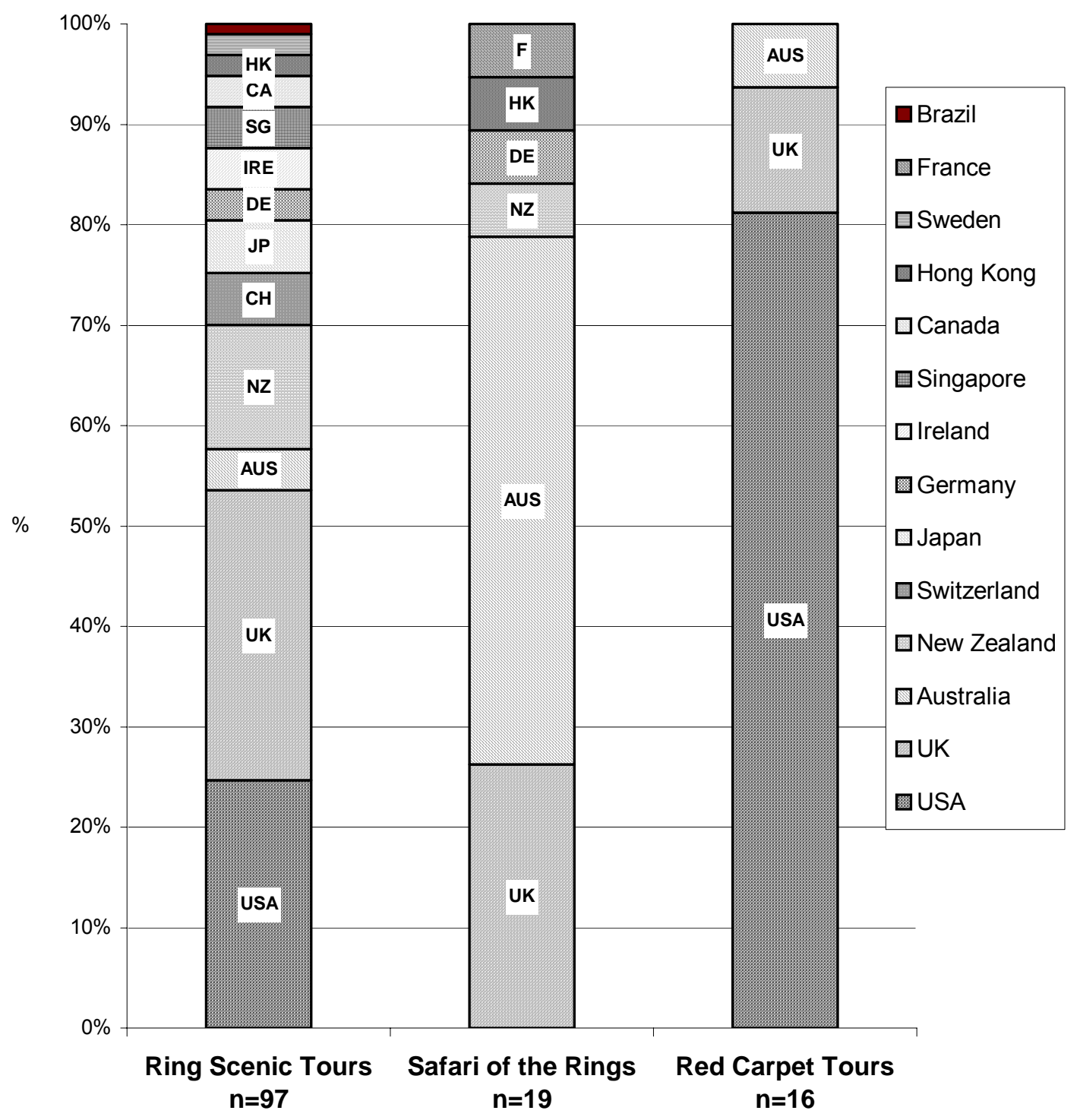


A different picture is seen for the Safari of the Rings groups, where over half of the respondents $(52.6 \%)$ came from Australia. Again, a high proportion also came from the UK (26.3\%).

For the Red Carpet Tours only three different nationalities were represented. The clear majority of respondents came from the USA (81.3\%). Filmic tourists from the UK (12.5\%) and Australia (6.3\%) made up the two other nationalities.

\section{Gender}

57.1 per cent of the respondents were female and 42.9 per cent male (Figure 6.5). The proportion of men to women on Rings Scenic Tours and Safari of the Rings tours is almost identical. Red Carpet Tours respondents show a slightly stronger proportion of female participants.

Figure 6.5: Gender representation within each case study

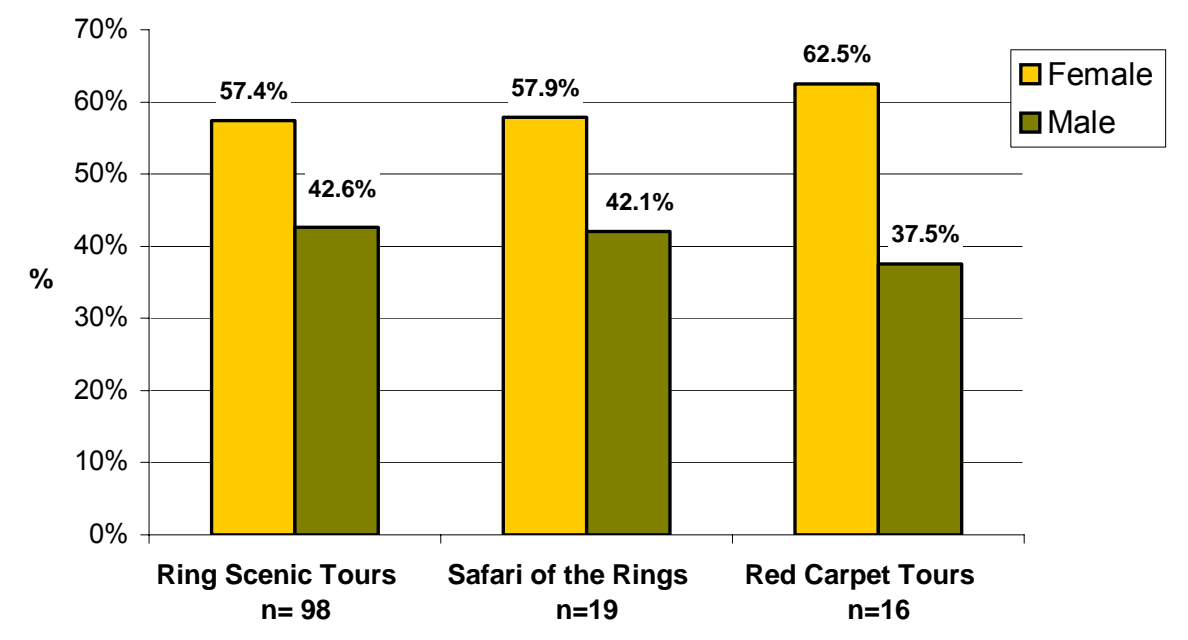

This confirms results in the Tourism New Zealand's Lord of the Rings Market Research Report (2003g), which shows that women in particular are motivated to come to New Zealand because of its connection with the film trilogy. This confirms also the fact that women are dominant in The Lord of the Rings fan Internet community (Tolkien Online 2004).

Interestingly, this does not correspond with the general gendered characteristics of visitors to New Zealand. According to an international visitor survey (Tourism Research Council 2003b) 55.5 per cent of all visitors to New Zealand in 2002 were male and 44.5 per cent female. 
$\underline{\text { Age }}$

Research conducted by Tourism New Zealand (2003f) on the influence of the film trilogy on visitors to New Zealand has shown that travellers under 34 years of age are the ones for whom the trilogy raised the most awareness of New Zealand, as well as most influenced their travel patterns. Thus, these age groups can be seen as target groups for The Lord of the Rings film tourism.

Results of all three case studies confirm the results of the above-mentioned market research of Tourism New Zealand (2003f) as Figure 6.6 points out: that most filmic tourists are aged between 16 and 34 years. These age groups form 49.9 per cent of all respondents in the research. The two largest groups are respondents aged between 25-29 years and 30-34 years, each with a proportion of 13.8 per cent.

This is, however, a slightly different result of age groups of tourists to New Zealand. According to these results visitors aged between 15 and 34 years made up only 33.7 per cent of the total proportion of visitors to New Zealand in 2003. (Tourism Research Council New Zealand 2003b).

Figure 6.6: Age groups within each case study and total proportion $(n=130)$

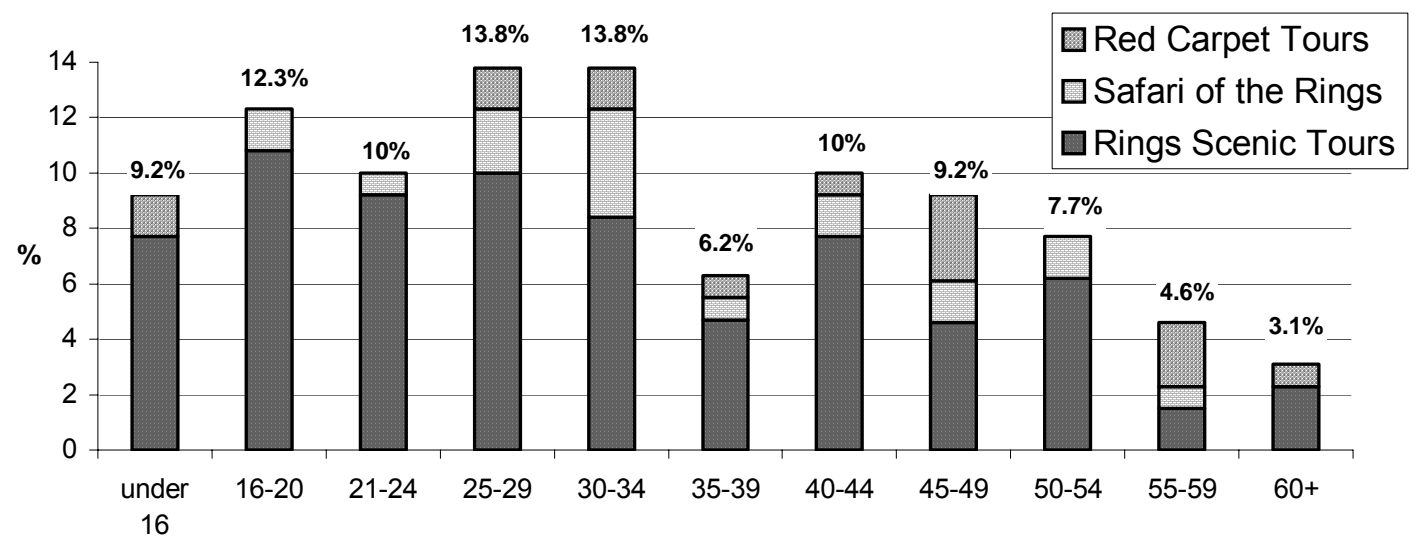

The distribution of age groups in each case study shows that respondents within the Ring Scenic Tours ranged over every age group. It is manifest that respondents who went on Rings Scenic Tours are generally younger than respondents of the other two case study groups. The largest number of respondents of Rings Scenic Tours was aged between 16 and 20 years. A possible explanation for the appeal of the former Hobbiton film set to a younger audience is that the images of Hobbiton, as portrayed in the films, are more suitable for children and a family attraction.

For the Safari of the Rings tours the largest proportion of respondents was aged between 30 and 34 years. The youngest tour respondent was 19 years old. This may be due to the nature of the tour, which includes off-road jeep experiences 
that can be quite rough and not suitable for small children. On the other hand, former film locations visited in the tour, such as Isengard or The Argonath might also be less attractive to younger groups of clients as well as to families with young children.

The distribution of age groups within the Red Carpet Tours respondents is uneven. Two explanations for a lack of participants aged between 16 and 24 years could be the high price of the tour and the fact that tourists in these age groups are generally less likely to participate in an organised coach tour (Cooper et al. 1998). The largest proportion of respondents within the Red Carpet Tours was aged between $45-49$ and 55-59 years.

\section{Purpose of travel}

According to the Tourism Research Council New Zealand (2003b), holidays/vacation is the main purpose of travel for 56.3 per cent of visitors to New Zealand. Visiting friends and relatives was the second reason given by 17.6 per cent of these respondents (ibid).

Respondents of The Lord of the Rings film location(s) tours were asked for the main reason for their visit to New Zealand (Figure 6.7). Results of all three case studies correspond with the above results. To specifically visit former film sites of The Lord of the Rings was the main motivation for only 8.9 per cent of the respondents.

Figure 6.7: Main purpose/motivation of all respondents to visit New Zealand $(n=123)$

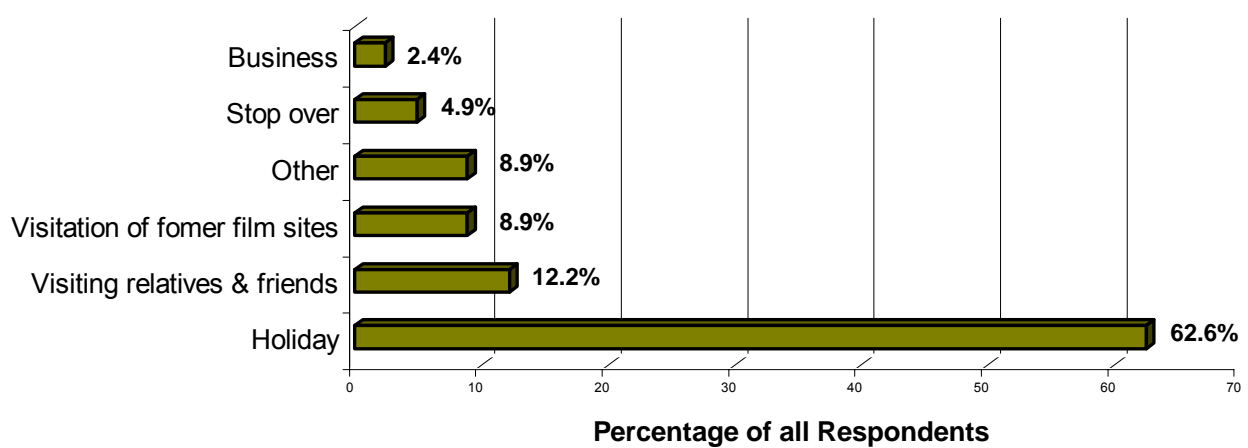

Influence of The Lord of the Rings on travel decision

In a survey by Tourism New Zealand (2003f) 93 per cent of international visitors were aware of the films. 9 per cent of these international visitors stated that the films of The Lord of the Rings were 'one reason but not the main reason' for visiting New Zealand. Another 0.3 per cent named it as 'the main reason' for coming to New Zealand (ibid).

Respondents in the present research were asked to rank the importance of New Zealand as the location where The Lord of the Rings was filmed in their decision 
to come here. Because of logistical problems, as mentioned in chapter two, this question was only included in questionnaires and interviews conducted in the Safari of the Rings tours. Figure 6.8 shows that for one third of the respondents of these tours the fact that the films of The Lord of the Ring were shot in New Zealand was very important for their decision to come here.

Figure 6.8: Importance of The Lord of the Rings films to visit New Zealand of Safari of the Rings respondents $(n=18)$

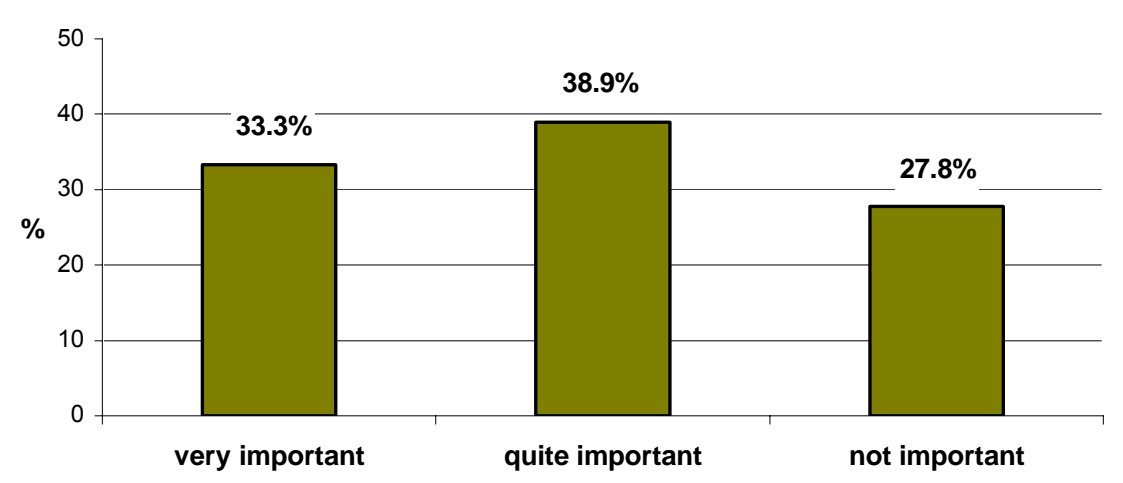

On the other hand when looking at the length of stay results of the Red Carpet Tours participants 68.8 per cent of them stayed less than 14 days in the country as the tour was of 13 days duration. Thus, for these respondents The Lord of the Rings significantly influenced their decision and reason for coming here.

\section{First time or repeated visit}

When looking at an international visitor survey of Tourism New Zealand (2003g) 55.9 per cent of the respondents were first time visitors to New Zealand and for 44.1 per cent of visitors it was their second or subsequent visit.

Results of The Lord of the Rings case study tours confirm that the majority of visitors are in New Zealand for the first time. However, the gap between first time and repeated visitors is more distinct (Figure 6.9). The proportion of respondents who were first time visitors is the highest within the Red Carpet Tours (87.5\%). The lowest number of first time visitors is within the Safari of the Rings tours $(77.8 \%)$. In the latter group, this might be explained by the high proportion of Australians within the groups (Figure 6.4) as New Zealand is a popular destination for Australians and they form the largest group of overseas tourists here (Tourism Research Council New Zealand 2003a). Overall, 84.2 per cent of all respondents were first time visitors to New Zealand. These numbers exclude New Zealand residents. 
Figure 6.9: Previous visit to New Zealand $(n=120)$

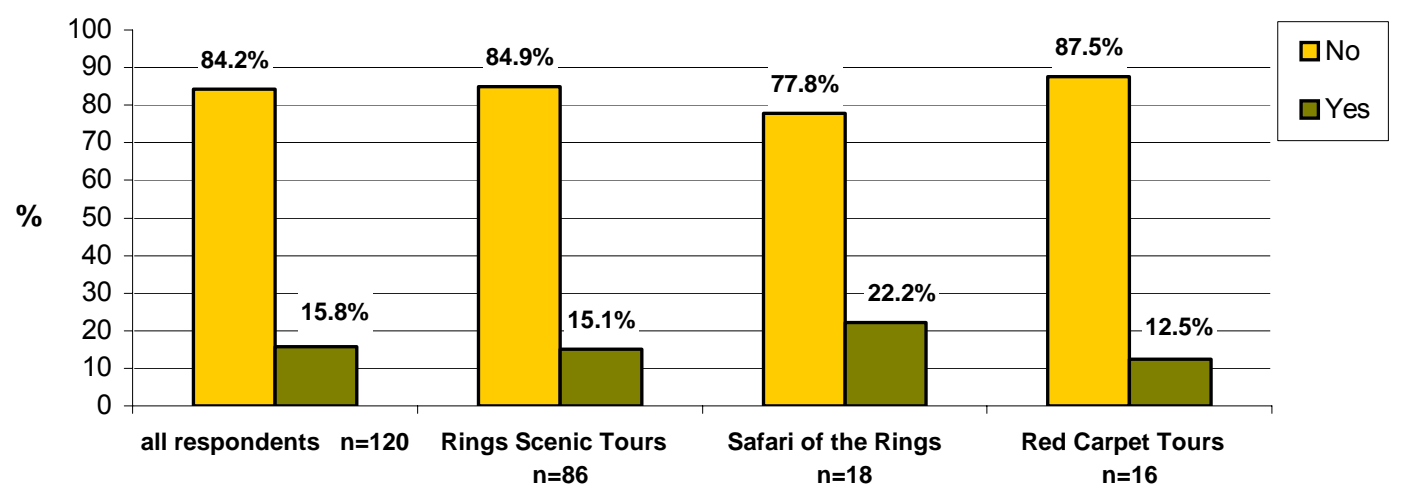

\section{Returning plans}

Of the respondents 59.8 per cent have plans to re-visit New Zealand (Figure 6.10). Respondents who indicated 'Yes' to repeat a visit to New Zealand were asked to specify when this would be. 20 per cent are planning to return next year and 80 per cent within the next five years. 38.5 per cent could foresee a possible return visit to New Zealand.

Figure 6.10: Plans to revisit New Zealand $(n=117)$

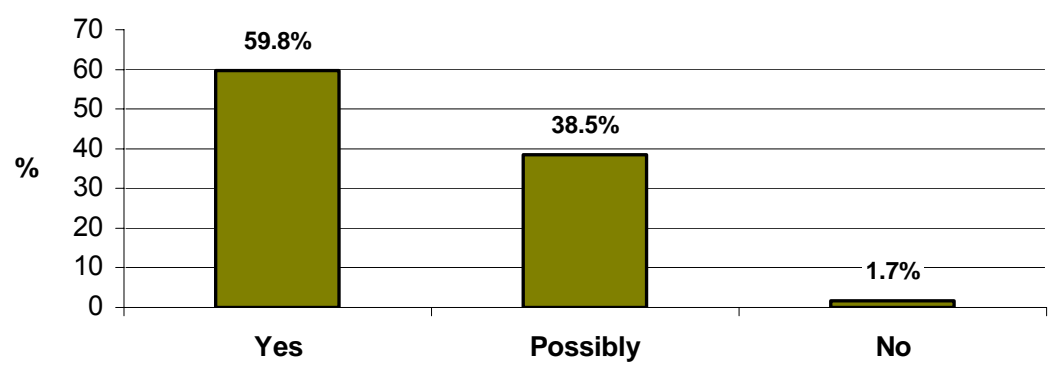

Only two respondents indicated that they do not want to revisit New Zealand. Their specified reasons for this were the costs of the airfare (visitor from the UK on Rings Scenic Tours) and an American tourist on a Red Carpet Tour stated that: "I have many travelling goals. I have seen enough of New Zealand!"

\section{Length of stay}

Figure 6.11 shows the findings for the question about the length of visitors' stay in New Zealand. New Zealand citizens and residents were filtered out of the analyses and only the data concerning non-New Zealanders were used. The classified time frame, which was used, is adapted by Tourism Research Council New Zealand (2003b). The findings show that the largest proportion of respondents (31.9\%) stayed 
between 20 and 29 days in the country. The second largest group (25.2\%) stayed between 14 and 16 days.

Figure 6.11: Length of stay in New Zealand of all respondents $(n=119)$

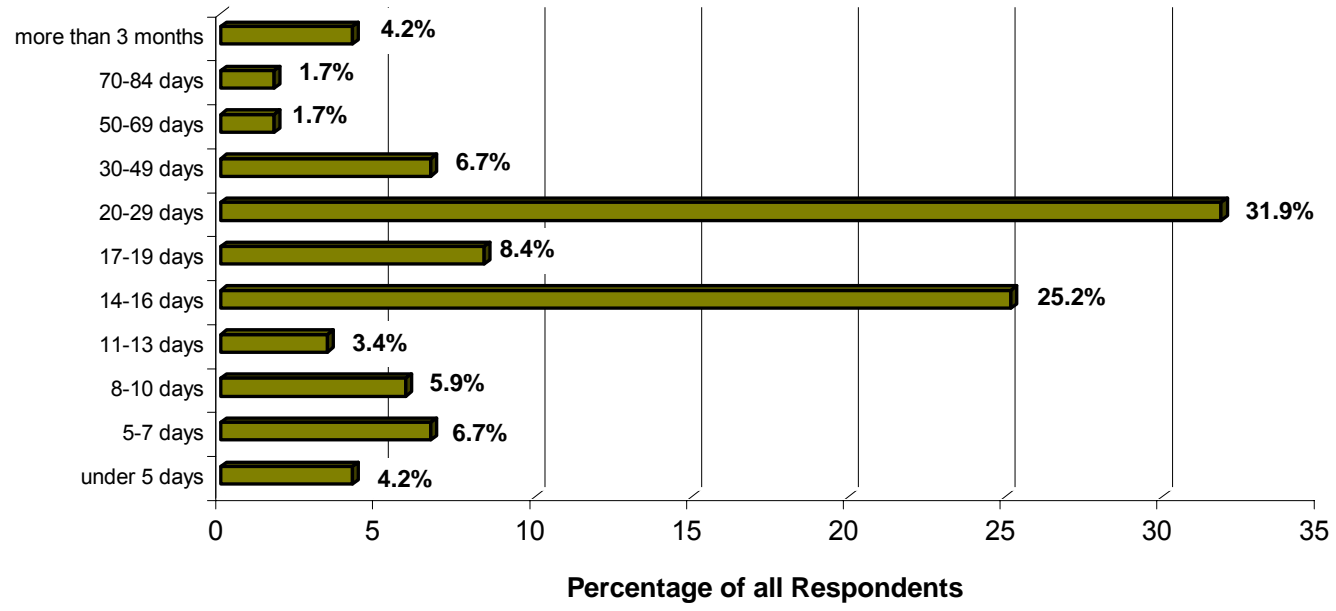

Table 6.1 shows the length of stay of respondents in the case studies in comparison to results of the Tourism Research Council New Zealand (TRCNZ) (2003b) international visitor survey. Thus, it becomes clear that on average filmic tourists stay longer in New Zealand than other tourists.

Table 6.1: Comparison length of stay per case study group and TRCNZ results

\begin{tabular}{|c|c|c|c|c|c|c|c|c|}
\hline Groups & $\begin{array}{l}\text { Under } 5 \\
\text { days }\end{array}$ & 5-7 days & $\begin{array}{l}8-10 \\
\text { days }\end{array}$ & $\begin{array}{l}11-13 \\
\text { days }\end{array}$ & $\begin{array}{l}14-16 \\
\text { days }\end{array}$ & $\begin{array}{l}17-19 \\
\text { days }\end{array}$ & $\begin{array}{l}20-29 \\
\text { days }\end{array}$ & $\begin{array}{l}30 \text { or } \\
\text { more } \\
\text { days }\end{array}$ \\
\hline $\begin{array}{l}\text { Rings } \\
\text { Scenic } \\
\text { Tours } \\
\text { respondents } \\
\text { (in \%) } \mathrm{n}=86\end{array}$ & $5.8 \%$ & $7 \%$ & $7 \%$ & $3.5 \%$ & $18.6 \%$ & $7 \%$ & $22.1 \%$ & $29.1 \%$ \\
\hline $\begin{array}{l}\text { Safari of the } \\
\text { Rings } \\
\text { respondents } \\
\text { (in \%) } n=17\end{array}$ & - & $11.8 \%$ & $5.9 \%$ & - & $11.8 \%$ & $17.6 \%$ & $47.1 \%$ & $5.9 \%$ \\
\hline $\begin{array}{l}\text { Red Carpet } \\
\text { Tours } \\
\text { respondents } \\
\text { (in \%) } n=16\end{array}$ & - & - & - & $6.3 \%$ & $75 \%$ & $6.3 \%$ & $12.5 \%$ & - \\
\hline $\begin{array}{l}\text { TRCNZ } \\
\text { respondents } \\
\text { (in \%) } \\
n=1,795,466\end{array}$ & $22.5 \%$ & $21.4 \%$ & $11.8 \%$ & $7.6 \%$ & $8.1 \%$ & $4.9 \%$ & $10.9 \%$ & $12.8 \%$ \\
\hline
\end{tabular}

\section{Travelling companions}

Findings of an international visitor survey of Tourism New Zealand (2003g), revealed that 34.8 per cent of visitors to New Zealand travelled alone, 28.5 per cent were 
couples, 11.3 per cent were family groups and 8.3 per cent were friends who travelled together.

Within this research, the largest proportion of respondents travelled with family (40\%) followed by couples (19.2\%) and groups of friends travelling together (17.7\%) (Figure 6.12).

Figure 6.12: Travelling companions of all respondents $(n=130)$

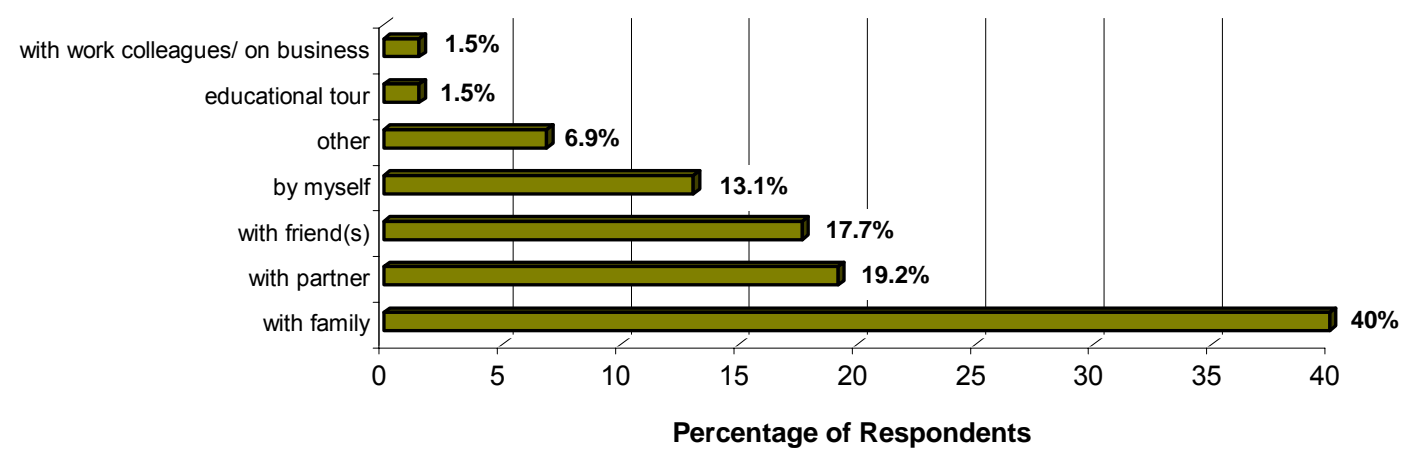

The high result of respondents travelling with family is due to the higher number of Ring Scenic Tours respondents as this tour attracts families more than both other tours. In detail 40.4 per cent of visitors to Hobbiton were travelling with family, 21.2 per cent with a partner and 17.2 per cent with a friend or friends. Interestingly, only 8.1 per cent were travelling by themselves.

These findings contrast results of respondents within Safari of the Rings tours who had the largest proportion of respondents travelling by themselves (33.3\%); 27.8 per cent were travelling in a group of friends or with a friend and 22.2 per cent were travelling with a partner.

56.3 per cent of respondents in Red Carpet Tours were travelling with family and 18.8 per cent by themselves or with a partner.

The next section gives the findings particularly concerned with the connection between filmic tourists and the films of The Lord of the Rings.

\section{5}

The Lord of the Rings Filmic Tourists

Who is and who is not a The Lord of the Rings filmic tourist? This question can be answered by defining anyone as a 'The Lord of the Rings filmic tourist' if he or she 'goes on a tour, which is based on the film locations of The Lord of the Rings'. However, there are also tourists who have not viewed the films but have read the 
books by Tolkien. These tourists may also like to visit the former film sets to decide whether these locations match with their personal images of Middle-earth.

The following analysis presents the research findings on the frequency of watching the films and whether filmic tourists had visited or were planning to visit more than one former film site.

\section{Frequency of watching the films}

The first question of the survey asked respondents whether they had watched the first and/or second film(s) of The Lord of the Rings and, if so, how many times (Figure 6.13).

Figure 6.13: Frequency of watching the $1^{\text {st }}$ and $2^{\text {nd }}$ films per case study group $(n=138)$

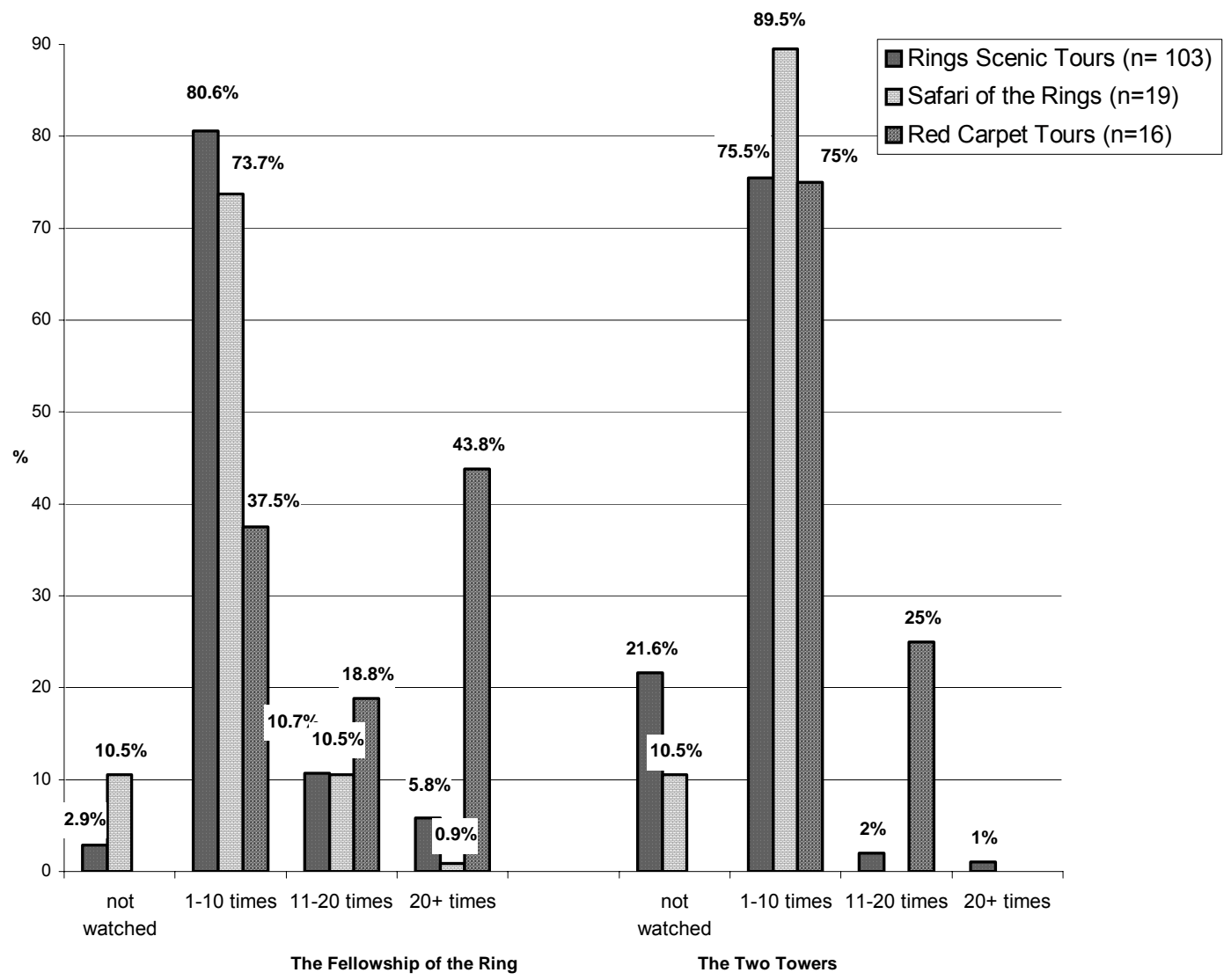

The results reveal that most of the respondents (74.6\%) had watched The Fellowship of the Ring, the first film of the trilogy, between one and ten times. There was a similar result for the second film, The Two Towers. This film was watched by 77.4 per cent between one and ten times. The fact that 21.7 per cent have watched the first film more than 11 times is due to its release on video in 2002. 
The 'front-runner' for the first film in watching times was an Australian female respondent in one of the Safari of the Rings tours in Queenstown who watched the first film 150 times. In general, the second film was watched less often. This might be because the second film had not been released on video at the time research was conducted. An American (USA) male respondent within a Rings Scenic Tours had watched the second film the greatest number of times when he viewed it more than 20 times.

The results for respondents who have not watched the films are interesting. Of the respondents 3.6 per cent have not watched the first film and the number increased to 17.5 per cent for the second film. The highest percentage of nonviewers of the second film went on Rings Scenic Tours. One reason for this result may be that Hobbiton did not appear in the second film and consequently visitors who liked the Hobbiton scenes may not necessarily have seen it.

\section{Visits to other The Lord of the Rings film sites}

Respondents of the half-day tour experiences, Rings Scenic Tours and Safari of the Rings, were asked whether they are travelling or planning to visit one or more other former film sets of The Lord of the Rings. The Red Carpet Tours groups were excluded from this question, as the locations they were visiting or about to visit were known.

The findings show that for nearly half of the respondents $(48.2 \%)$ The Lord of the Rings themed tour they were on was the only former film location tour they had experienced and they were planning to experience. Specifically, of the respondents in Matamata and Queenstown 19.1 per cent had been and 33.6 per cent were going to visit other The Lord of the Rings film locations while they were staying in New Zealand. Of the respondents who had been to other locations 27.3 per cent were planning to visit more former film locations after they had been on a tour in Matamata or Queenstown. Another 2.6 per cent would have liked to visit more locations but did not know where they are.

Filmic tourists who had been to other former film locations before participating in the survey had visited the following locations: Wellington (42.9\%), Queenstown region (28.6\%), Tongariro National Park (28.6\%), Fiordland (9.5\%), Mavora Lakes (9.5\%), Matamata (9.5\%) and Mount Sunday (4.8\%) (Map 6.4). Of the respondents who had been to other The Lord of the Rings film locations 23.8 per cent had already been to more than one before they went on a tour in Matamata or Queenstown. 
Map 6.4: Other former film sites visited or planned to visit by respondents

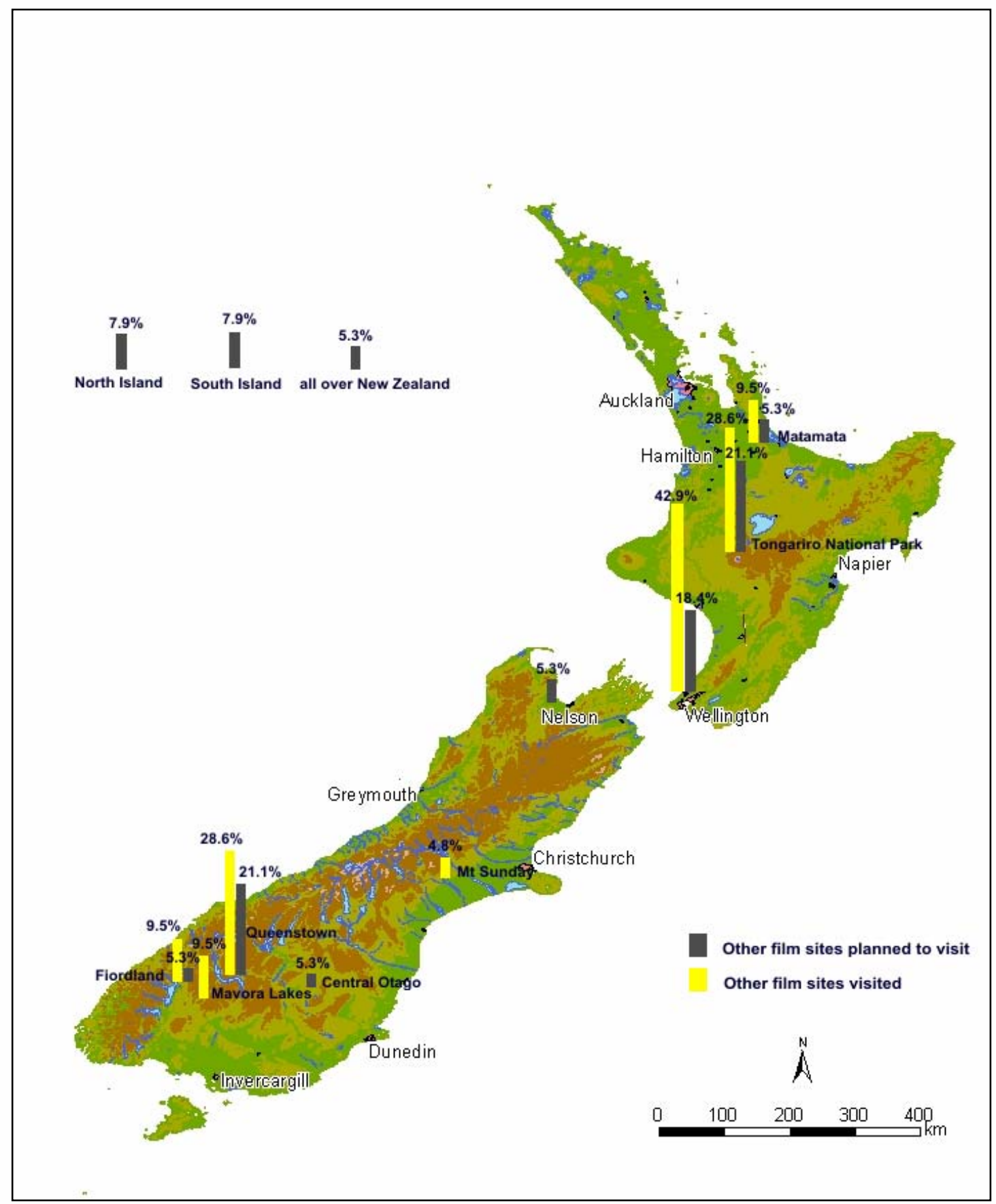

Map data source: adapted by the author from Maproom (2003)

Filmic tourists who were planning to visit other former film sites were going to do so in the Tongariro National Park (21.1\%), the Queenstown region $(21.1 \%)$, Wellington (18.4\%), Nelson (5.3\%), Matamata (5.3\%), Central Otago (2.6\%), and Fiordland (2.6\%). 21.1 per cent of filmic tourists were not specific about the locations. They said they would like to visit the locations on the South Island $(7.9 \%)$, the North Island (7.9\%) or even all over New Zealand (5.3\%) (Map 6.4). Overall, of the 
respondents who were planning to visit other former film locations, a proportion of 31.6 per cent were planning to visit more than one.

The main reasons given for not visiting other The Lord of the Rings film locations were time restraints because the tourists were towards the end of their holiday or because they had to take return flights within the next few days. Furthermore, the constraint was lack of knowledge about where the film sites were located and the belief that these places were inaccessible or too remote for most of the public. Only 5.2 per cent of the half-day tour respondents in the survey stated that they had no interest in visiting other film sites.

\subsection{Chapter Summary}

This chapter presented the findings obtained from visitor surveys and interviews at two locally based tourism companies in Matamata (Rings Scenic Tours) and Queenstown (Nomad Safaris' Safari of the Rings) and a package operator Red Carpet Tours. All three companies are offering The Lord of the Rings themed products.

Beside the chosen three case study operators other former film locations and operators were investigated in the Queenstown region, the Tongariro National Park, Otaki, Wellington, Canterbury, and Central Otago. In general findings show a variety of tours have been set up that are based upon or integrating The Lord of the Rings. In addition, the findings show that in most cases no appropriate information, such as how to reach the sites as well as which tours are offered is provided by Visitor Information Centres.

The different nature of the case study tours seems to attract different types of filmic tourists as well as to provide different experiences of the former film sites. The survey produced a profile of filmic tourists participating in The Lord of the Rings case study tours: 57 per cent of respondents were female, with half the visitors aged between 16-34 years of age. Three-quarters had watched the films between one and ten times, and two-thirds of respondents were staying in New Zealand for two to three weeks. The majority of the respondents was originated from other Englishspeaking countries ( $81 \%)$ and were first-time visitors to New Zealand $(84.2 \%)$ This is a longer total stay than the seven-night average for New Zealand but corresponds with visitor arrivals data on main countries of origin and age profile (Tourism Research Council New Zealand 2003b).

Two main types of filmic tourists, with different motives for travel, were identified. For those participating in the half-day tours (Rings Scenic Tours and Safari of the Rings), the primary motivation for travel was to experience New Zealand and a 
The Lord of the Rings trip was an interesting addition to their itinerary, particularly if they had already seen the films. In contrast, tourists travelling on a multi-day The Lord of the Rings tour (Red Carpet Tours) had travelled to New Zealand specifically for that purpose and returned home almost as soon as the tour was complete. For this group, their motive for travel was to experience 'New Zealand as Middle-earth' and had been fuelled by their passionate interest in the book and film trilogy.

The findings show that former The Lord of the Rings film sites in the Tongariro National Park, Wellington and the Queenstown region are the most attractive to respondents in the two half-day tours who had or wanted to experience more sites. However, for nearly half of the respondents in the two half-day tours this was the only former film site experience they had experienced and that they were planning to experience.

The following chapter focuses on the determined iconic landscapes of the films, 'New Zealand as Middle-earth', and filmic tourists' experiences of the former film sites. 


\section{Chapter seven}

\subsection{Introduction}

This chapter continues to present and discuss findings of the film analysis but also of the tourism research. It seeks to identify by content and analysis of the amount of screen time, on the one hand, and by respondents naming within the survey, on the other hand, which landscapes portrayed in the films, have a potential to attract filmic tourists. These landscapes could be seen as iconic landscapes within the films. For each iconic landscape identified, examples are given of how filmic tourists approach and experience them.

Other survey findings are also presented on how much filmic tourists related New Zealand's landscapes to the fantasy world of Middle-earth and, if so what, their reasons for doing this were.

Furthermore, the chapter gives results on how filmic tourists evaluated their experience of The Lord of the Rings former film sites. This includes the fulfilment of expectations and evaluation of the trip itself. Due to the different nature of the halfday and multi-day tour experiences filmic tourist expectations and satisfaction are separately presented and discussed. This is followed by the evaluation of whether or not the frequency of watching the films had impacted on filmic tourists' experiences of the landscape. Finally the chapter is summarised.

\subsection{Iconic Landscapes and Filmic Tourists' Experiences}

One of the aims of this research was to determine landscapes which had potential to act as icons in the films of The Lord of the Rings and, therefore, to become a tourist attraction. Iconic landscapes can be seen as "extraordinary or captivating" features, which viewers set in context with films they have watched (Riley et al. 1998: 924). These iconic landscapes awake the desire by filmic tourists to visit and experience the portrayed locations.

The criteria used to identify these iconic landscapes were: a) the length of time (the limit was set at 10 minutes) they were portrayed in both films (see Appendices 7 and 8); b) whether they contained a scene of primary importance in the films; and c) their unique appeal. Their unique appearance was defined in relation to architecture, design, the inspirational emotions, and landscape features. 
The method of triangulation was used, which combines the qualitative method of the textual analysis and interpretation with findings of the survey. Participants of The Lord of the Rings themed tours were asked to name the location/landscape in the films of The Lord of the Rings they remembered best or related the most. Respondents could name up to three landscapes/locations that lingered in their memory after they had seen the films. The 204 answers were analysed, categorised into themes, and evaluated. The most common themes by respondents are presented in Appendix 13.

Table 7.1 shows the criteria the landscapes were compared with. The analysis of the films discussed in chapter five and the results of naming by respondents $(\geq$ $5 \%$ ) in the survey (Appendix 13) resulted in the following potential iconic landscapes:

- Hobbiton

- Rivendell

- Edoras

The first film has a screening time of 171 minutes and the second film is 173 minutes long. This results in a total screen time for both films of 344 minutes. Table 7.1 shows the proportion each landscape portrayal had of the total screen time in both films.

Table 7.1: Landscapes in the $1^{\text {st }}$ and $2^{\text {nd }}$ films - comparison of the iconic value

\begin{tabular}{|c|c|c|c|c|c|}
\hline $\begin{array}{c}\text { Landscapel place } \\
\text { within } \\
\text { Middle-earth }\end{array}$ & $\begin{array}{c}\text { Screen } \\
\text { time }\end{array}$ & $\begin{array}{l}\text { Proportion of } \\
\text { scenes to } \\
\text { total film } \\
\text { length (in \%) }\end{array}$ & $\begin{array}{l}\text { Crucial } \\
\text { scene }\end{array}$ & $\begin{array}{c}\text { Extraordinary } \\
\text { appeal }\end{array}$ & $\begin{array}{l}\text { Naming by } \\
\text { respondents } \\
\text { (in \%) }\end{array}$ \\
\hline Edoras/ Rohan & $38: 47$ & $11.2 \%$ & yes & yes & $6.9 \%$ \\
\hline Helms Deep & $33: 54$ & $9.8 \%$ & yes & no & $1 \%$ \\
\hline Rivendell & $30: 10$ & $8.8 \%$ & yes & yes & $8.3 \%$ \\
\hline Moria & $27: 24$ & $7.9 \%$ & yes & no & $1 \%$ \\
\hline Hobbiton & $25: 31$ & $7.4 \%$ & yes & yes & $33.3 \%$ \\
\hline Isengard & $16: 35$ & $4.8 \%$ & yes & no & $2.5 \%$ \\
\hline $\begin{array}{l}\text { Path Galenll } \\
\text { Amon Hen }\end{array}$ & $16: 25$ & $4.7 \%$ & yes & no & $0.5 \%$ \\
\hline Fangorn Forest & $15: 45$ & $4.5 \%$ & yes & no & none \\
\hline Ithilien & $14: 46$ & $4.2 \%$ & no & no & none \\
\hline Lothlórien & $13: 30$ & $3.9 \%$ & no & yes & $2.5 \%$ \\
\hline Mordor & $12: 38$ & $3.6 \%$ & no & no & $6.9 \%$ \\
\hline Misty Mountains & $2: 45$ & $0.7 \%$ & no & no & $15.2 \%$ \\
\hline
\end{tabular}

These landscapes are now discussed in more detail and examples of filmic tourists' experiences are given. 


\section{Hobbiton:}

The scenes in Hobbiton were on screen for over 25 minutes. Of these, 18 minutes was of one particularly dominant block sequence at the beginning of the first film. Three main points make Hobbiton's appearance extraordinary. First, Hobbiton contrasted strongly with the dark and violent scenes of the first film's prologue. Second, the homely and peaceful atmosphere of The Shire was made to look similar to old England but is also fabulously unfamiliar. And finally, the positive appearance of the landscape provoked empathy in the viewer with the imperfect character of the hobbits. In addition, key plot elements were introduced, such as the appearance of the main protagonist, Frodo, first glimpses of the power of the ring and the subsequent mission to avert danger to the paradise of The Shire by evil forces.

The findings of the survey confirm the iconic status of Hobbiton, which was named by one third of the respondents (Appendix 13). This is, of course, in part because a high proportion of respondents were at the Hobbiton former film site (see Figure 6.4).

The former Hobbiton film set is now an integral part of Rings Scenic Tours, one of the case studies in this research. Filmic tourists participating in the tours can experience the only former film site of the trilogy that still has remnants of the film set.

\section{Rivendell:}

Rivendell is portrayed for 30 minutes and 10 seconds altogether in both films. Of these over 19 minutes are about the council when in the first film the good people of Middle-earth are debating over the ring. The unique appearance within the scenes in Rivendell is, without a doubt, because of the fantasy architecture and the setting within a beautiful and peaceful valley.

Key scenes are when Frodo is healed after he was fatally wounded and it was thought he had died at the Ford of Bruinen; the reunification with Gandalf and the meeting of the council where the good people of Middle-earth debate about who is able to fulfil this mission. Frodo, the hobbit, volunteers to carry and destroy the ring. This is the beginning of the fellowship of the ring and likewise the unity of the different races, such as hobbits, dwarfs, elves, and men.

Respondents in the survey also confirmed Rivendell as being an iconic landscape in the films and it was named by 8.3 per cent of them (Appendix 13).

At the former film site of Rivendell at Kaitoke Regional Park no sets remain. However, according to Johnson (2003) visitors on Rover Rings Tours or Flat Earth's The Lord of the Rings themed tours are not disappointed. On the contray, filmic tourists enjoy "soaking up the magical atmosphere" of the former film site (ibid: A10). 


\section{Edoras and Rohan:}

When combining screen times of Edoras and Rohan, as shown in the second film, these landscapes appear for over 38 minutes (Appendix 8). Edoras is shown in two sequences taking altogether over 20 minutes of screen time. The extraordinary aspects, here again, are the detail of props and architecture as well as the landscape settings.

A key scene that is the first turning point in the story is when Gandalf releases King Théoden from the spell and influence of Saruman. This signals the first victory over the evil allies. Also it is in Edoras where Éowyn experiences unrequited love for Aragorn and King Théoden decides to fight against the army that Saruman has sent to destroy Rohan.

Edoras because it is the capital of the Kingdom of Rohan was named by 7.8 per cent of the respondents as an iconic landscape (Appendix 13), which confirms the findings of the researcher's analysis.

The scenery of Mount Sunday in the Rangitata Valley near Methven, where the film set was erected, delights filmic tourists who visit the former film site because of its scenic appearance and even without the set it is easy to recognise (Walsh and Scottish tourist, pers. comm. 11.09.03, Rangitata Valley). However, only a few react to the extent as one of Cain's clients (the owner of $4 \times 4$ New Zealand Ltd) who wanted to stand where the steps of the Golden Hall of Edoras were in the film set so as to experience the landscape that Éowyn did (Picture 7.1). This British youth ignored Cain's warning about the cold and deep streams that had to be crossed to reach Mount Sunday and went to fulfil his vision. When he came back "he was absolutely blown away that he had accomplished his dream. He stood where the steps [in the film] were and he saw what she [Éowyn] saw" (Cain 2003).

According to Cain (ibid) only one or two people were disappointed that the buildings were not left at the former film site of Edoras. 


\section{Picture 7.1:}

Edoras- Éowyn standing in front of the Golden Hall overlooking Edoras (film image)

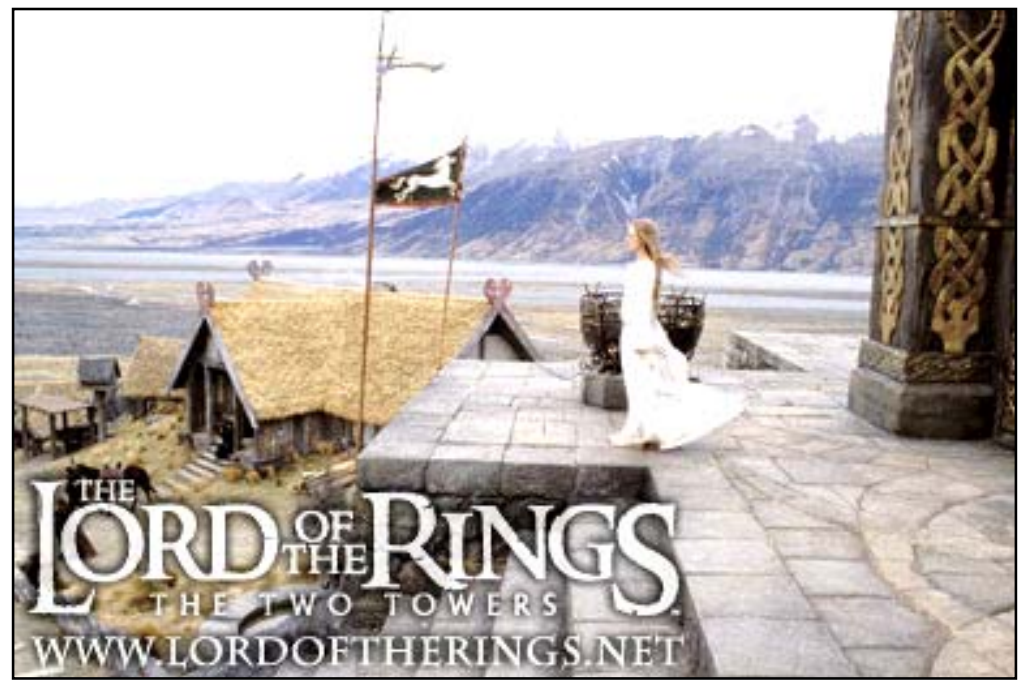

Source: Lord of the Rings Net 2004a

\section{New Zealand:}

Besides favouring these three landscapes in the first and second film 7.4 per cent of the respondents identified much or even all of New Zealand with the landscapes portrayed in the films of The Lord of the Rings (Appendix 13). This suggests that some imagined that in a sense New Zealand could be seen as an iconic location of the trilogy as a whole.

Picture 7.2: Tourism New Zealand advertisement

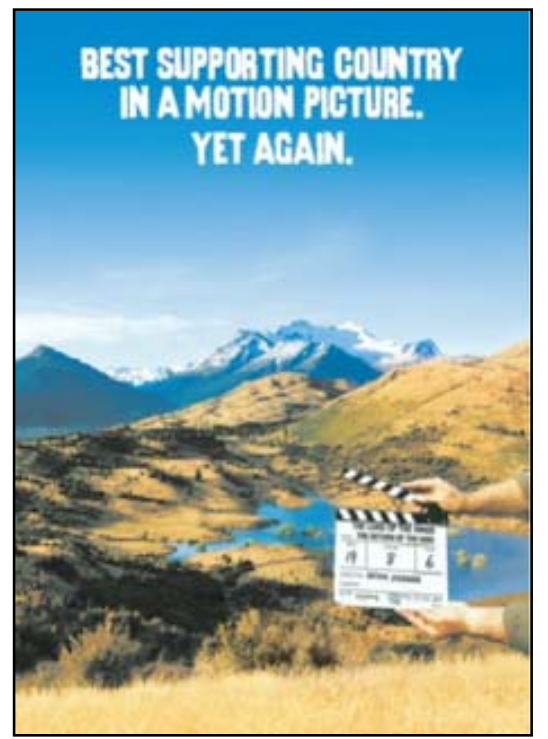

This is also reinforced by promotional campaigns that strongly emphasise the links between New Zealand and the films. For example, Tourism New Zealand reinforced the link between the film trilogy and New Zealand particularly after the overwhelming success at the 2004 Oscar Academy Award ceremony when it placed a full-page advertisement (Picture 7.2) in the Los Angeles Times and New York Times newspapers (The Dominion Post 2004).

Source: Tourism New Zealand 2004 


\section{Other iconic landscapes:}

In addition, the setting of two short sequences within The Fellowship of the Ring $\left(1^{\text {st }}\right.$ film) were assessed as having the potential to stay in the minds of viewers because they contain a key scene or some extraordinary features. The first is when the four hobbits are hiding from a Black Rider under the root of a tree (Picture 7.3). In this scene the hobbits have their first encounter with a Black Rider. It is when they realise that their quest will not be easy because of the power of the evil forces. It is also the first occasion when Frodo feels the desire to put the ring on his finger.

Picture 7.3: Hobbits hiding from Black Rider (film image)

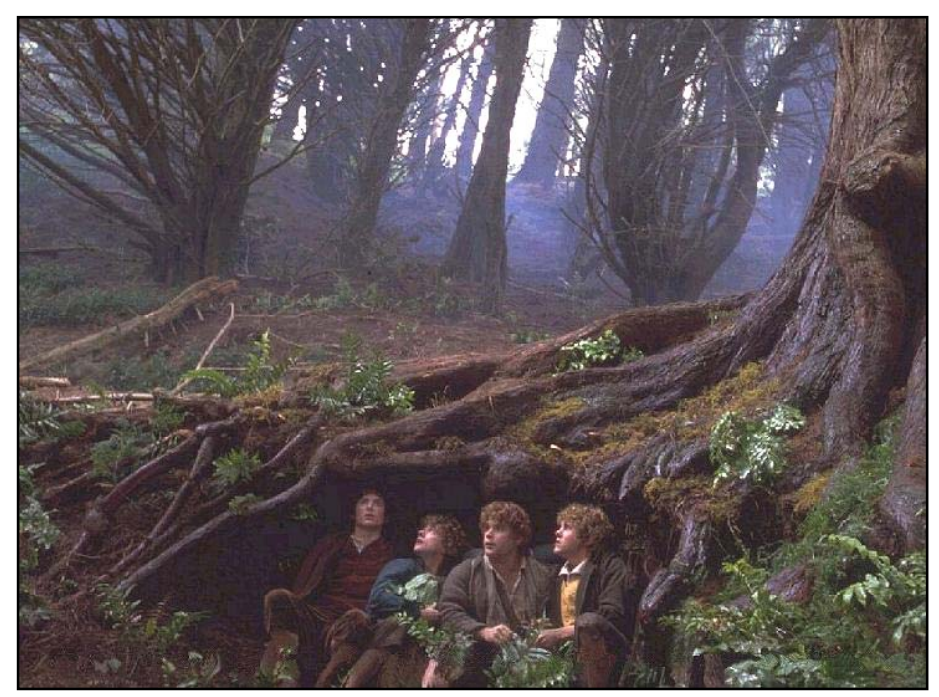

Source: Quintessential Lord of the Rings Movie Shots (2003)

This scene was filmed in a pine forest on Mount Victoria in Wellington. A typical pine tree, not native to New Zealand, was used for this scene and modified with an artificial trunk and root to emphasise the size differences of the hobbits, the tree and the Black Rider. Although there is nothing left of the set in the forest tourists still search for this particular tree so as to relive the scene.

Filmic tourists who went to Wellington to find this particular tree complained in informal conversations about their unsuccessful search for the tree (Swiss tourists, pers. comm. 07.09.03, Lake Tekapo). These two tourists mentioned that they in the end just wandered around and pretended that a nearby tree was 'the one'. It did not much matter to them in the end whether or not they found the right tree (ibid). More lucky filmic tourists were a group of Japanese tourists on their very special 'Hobbit holiday' where they re-enacted the key scene at the right tree as shown in Picture 7.4 . 
Picture 7.4: Hobbit holiday

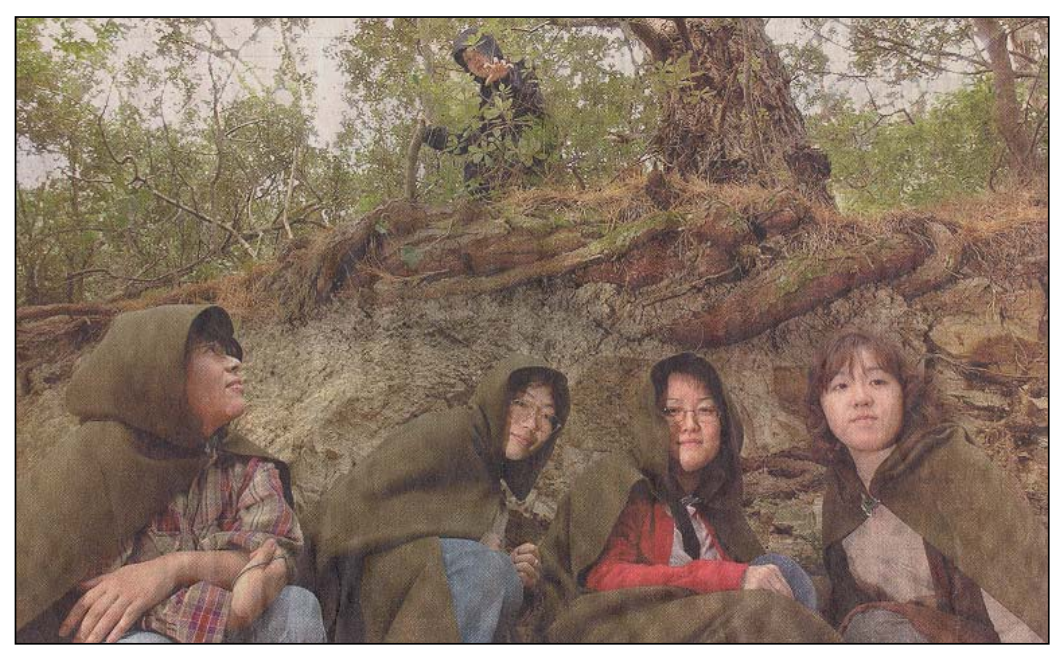

Source: The Dominion Post 2003b: B7

The second extraordinary landscape in the first film of The Lord of the Rings appears during the journey on the River Anduin when the fellowship is passing the Argonath. The Argonath, or Pillars of the Kings are two statues of ancient kings of men, Isildur and Anárion (Picture 7.5). The statues guard the entrance to Gondor. The design is extraordinary and even breathtaking because of the gigantic scale of the statues. We see, for example, a bird is flying up from its nest at the moment when the fellowship passes by the statues.

The New Zealand location portrayal was the Kawarau River near the Kawarau River Bridge, north of Queenstown (Picture 7.6). The rock faces on both sides are in reality approximately 30 metres high. However, the illusion of even steeper rock faces was created by means of a wide camera angle from close to the surface of the water. Finally, in post-production two statues approximately two metres high were digitally superimposed onto each side of the rock faces. 
Picture 7.5: The Argonath/Pillars of the Kings (film image)

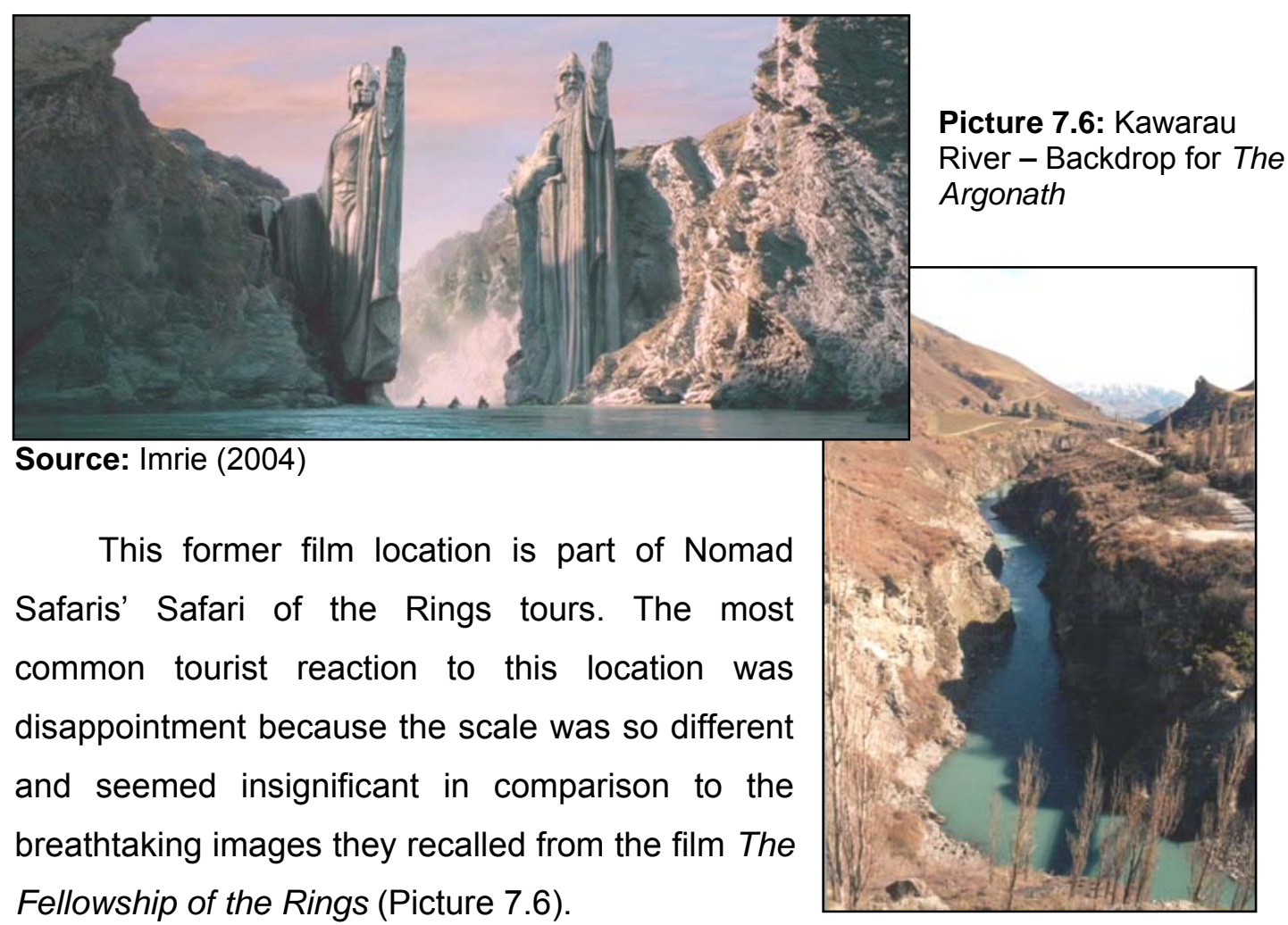

Source: The author

The second film of the trilogy contains one short sequence that can be seen as iconic, together with Edoras. This scene portrays the escape of the refugees of Rohan on their way to the fortress of Helms Deep (Picture 7.7).

Picture 7.7: Rohan refugees (film image)

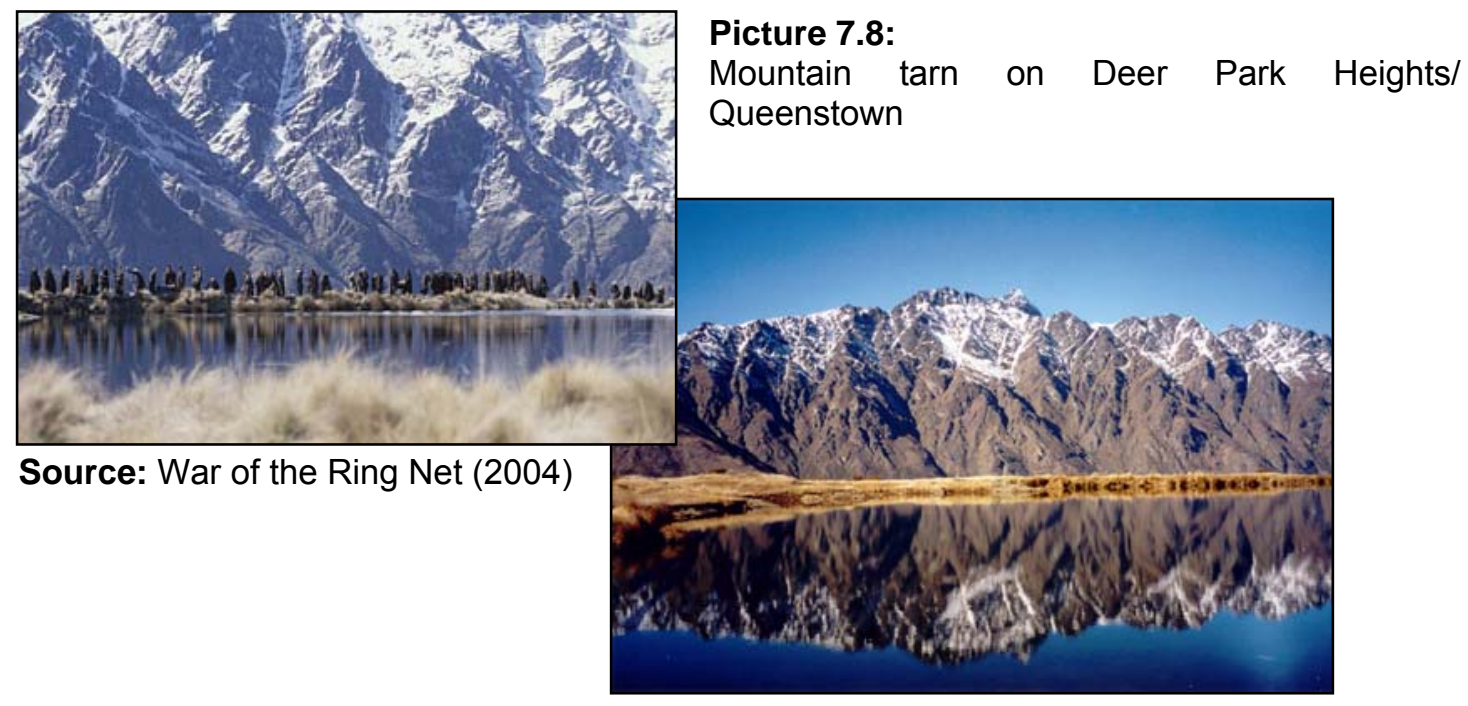

Source: The author 
The choice of this scene as iconic can neither be justified by its length of time on screen nor because it contains a key scene. It derives its iconic value because of its extraordinary setting on a tarn on top of Deer Park Heights with the unmistakable Remarkables Mountains in the background. The area is easily recognisable (Picture 7.8) and field observations at this particular location revealed that filmic tourists were particularly looking for this location on Deer Park Heights.

As Table 7.1 shows a number of other landscapes had longer screen times, key scenes or special appeal. However, the determining factor was the respondent rate (had to be $\geq 5 \%$ ) for a particular landscape to be classified as iconic.

Interestingly, it appears that the length of screen time is not the main reason why respondents perceived landscapes as remarkable. The best example is Helms Deep, as it appears in the second film. This is surprising, because it is the setting for the main battle in the two films. Remarkable is the screen time of more that 33 minutes. However, its appearance could not be regarded as unusual or unique and only 1 per cent of the respondents in the survey named it as an iconic landscape in the films (Appendix 13).

Another surprise concerns landscapes linked with Mordor. Scenes in Mordor are on screen for no more than 7 minutes in both films and were cited by 5.9 per cent of the respondents as iconic landscapes (Appendix 13). However, the researcher's analysis and interpretation did not consider Mordor as an iconic landscape in the first or second film of the trilogy because it does not contain main or key scenes and is not so extraordinary a landscape that tourists might want to see it for themselves. Furthermore, it is only present in short sequences in comparison to the other iconic landscapes. On the other hand, it may be fair to consider Mordor as an iconic landscape within the whole trilogy because it is the final destination of the journey, which is a theme of all three films.

Besides the specific iconic landscapes, such as Matamata (Hobbiton), Mount Sunday (Edoras) and the Kaitoke Regional Park near Wellington (Rivendell) discussed in detail above, it was also important to examine places that offered a variety of landscape features in the films of The Lord of the Rings. The contention is that places which offer a number of featured locations are more likely to become attractions to filmic tourists than locations which cannot be seen as iconic landscapes in the films and are spread over a wide number of places or are difficult for tourists to reach. 
There are two locations, which fit this category: Queenstown and Wellington. Respondents in the survey/interviews were asked to name their personal iconic landscapes in the first and second film. Locations related to the Queenstown region were named by 26 per cent of the respondents. Wellington and landscapes of its surrounding area, which hosted film sets, were named by 11.8 per cent of the respondents.

Other reasons why Queenstown and Wellington have the potential to act as main centres for The Lord of the Rings film tourism are that several scenes were filmed in the Queenstown region at Deer Park Heights; The Remarkables and Lake Alta; Glenorchy and Paradise; Closeburn; Twelve Mile Delta; Arrow River; Skippers Canyon; and Kawarau River. The landscapes of Middle-earth portrayed in these locations include Rohan; Ford of Bruinen; River Anduin/The Argonath; Lothlórien; Isengard; Misty Mountains; Amon Hen; Ithilien Camp; and Dimrill Dale.

In the Wellington region the following landscapes and scenes of Middle-earth were filmed: Bree; leaving The Shire (the scene when the hobbits are hiding under a tree root); the fortress of Helms Deep; Minas Tirith; River Anduin; Isengard; and Rivendell. In addition, Wellington can be seen as a main attraction for filmic tourists because it is the production base (WETA workshops in Miramar); home town of Peter Jackson; was the main base for the actors while filming and because the local Embassy theatre hosted the national premiere in 2001 and 2002 as well as the world premiere jointly with the Reading Cinema in 2003; and finally Te Papa hosted a special The Lord of the Rings exhibition between December 2002 and April 2003.

\section{3 'New Zealand as Middle-earth'}

On a larger scale than specific places and regions, since The Lord of the Rings, New Zealand itself has been promoted to iconic status as Middle-earth. "New Zealand has become the embodiment of Middle-earth to millions of moviegoers (...) the world over" (Brodie 2002: 98). For the purpose of tourism even the names of places have been paralleled with names used in the films. For example, Matamata markets itself as Hobbiton and at one point the mayor even planned to change the name permanently to Hobbiton (Whiting 2003). In addition, the names of places visited within The Lord of the Rings themed tours, such as Red Carpet Tours are replaced by Middle-earth names (see Box 6.2).

This also mirrors the association made by respondents when describing their experience (see section 7.4.1 and 7.4.2) by using place names of the films instead of the common New Zealand names. For example, as two respondents of Red Carpet Tours [RCT] described it: 
They [former film sites] were breathtaking-spectacular- especially Lothlorien and Fangorn Forest and the Misty Mountains. [RCT, male, under 16 years, USA, 1st time visitor]

The second comment suggests that a life-time dream to visit Middle-earth came true when the tourist visited New Zealand. Thus, there is no distinction made when she says:

This was the trip of a lifetime for me. I have loved Tolkien since 1967 (...). I would always say I wanted to visit Middle-earth. Well, now I have (...). This tour was a dream come true for me. [RCT, female, 55-59 years, USA, ${ }^{\text {st }}$ time visitor]

The marketing of New Zealand as Home of Middle-earth (Picture 7.9) or Middle-earth raised the question of how filmic tourists viewed the connection between Tolkien's fantasy world of Middle-earth and New Zealand. Filmic tourists were asked in the survey/interviews how much they related New Zealand's landscapes to Middle-earth.

Picture 7.9: Tourism New Zealand - Marketing of New Zealand as Home of Middle-earth

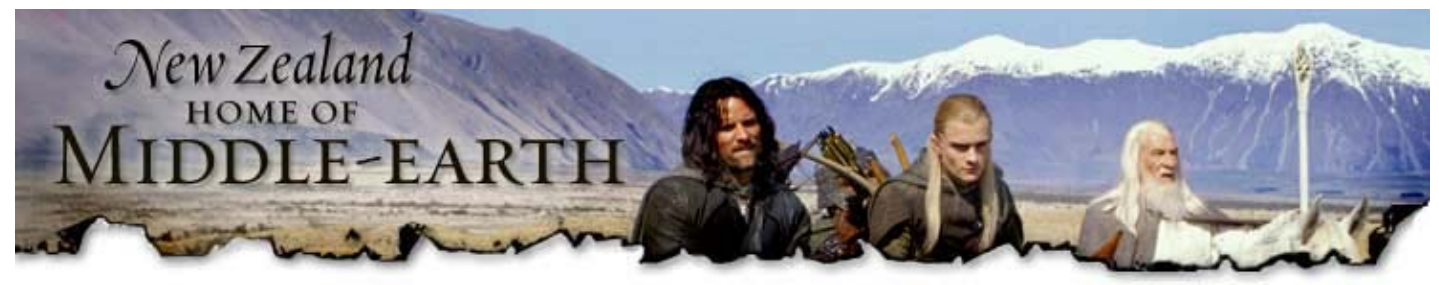

Source: Tourism New Zealand (2003e)

Respondents could use a ranking on a scale from (1) 'New Zealand is Middleearth' to (3) 'neutral' to (5) there are 'no similarities' between New Zealand and Middle-earth.

As Figure 7.1 shows the majority of respondents (49.2\%) expressed that New Zealand is Middle-earth, and 41.3 per cent of all respondents indicated that New Zealand's landscapes have some similarities to Middle-earth. 
Figure 7.1: Similarities of New Zealand's landscape and Middle-earth

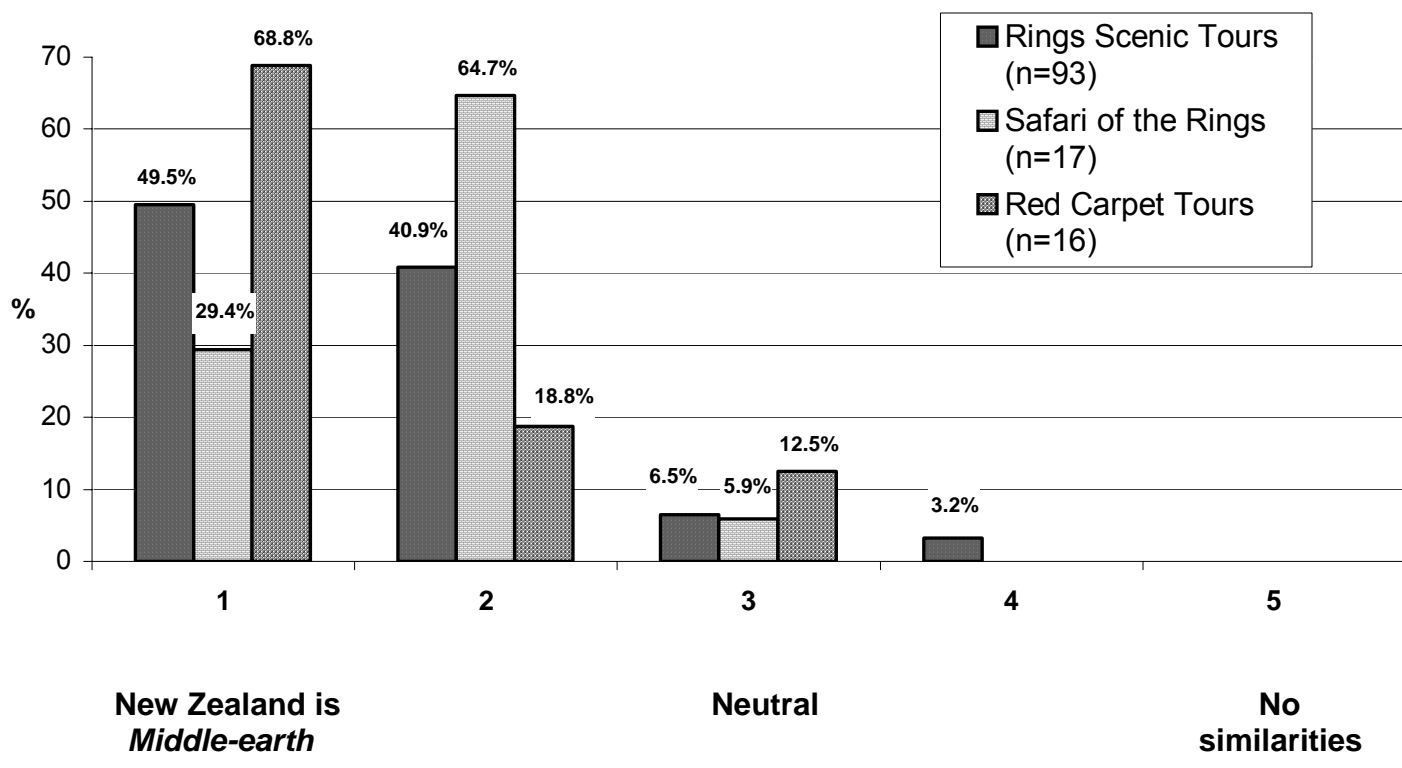

The highest proportion of respondents $(68.8 \%)$ who indicated that New Zealand is Middle-earth was within Red Carpet Tours (Figure 7.1). This may be related to the overall The Lord of the Rings theme of the tour (see section 6.2.3).

It was assumed that filmic tourists who had visited New Zealand before the films were released and New Zealand residents might be less likely to equate New Zealand with Middle-earth because of their prior or more detailed knowledge of the country. However, this assumption could not be proven. 53.8 per cent of all New Zealand resident respondents and 46.7 of respondents who had been to the country before echoed the sentiment that New Zealand is Middle-earth (Figure 7.2). 
Figure 7.2: Perceived similarities between New Zealand's landscape and Middle-earth

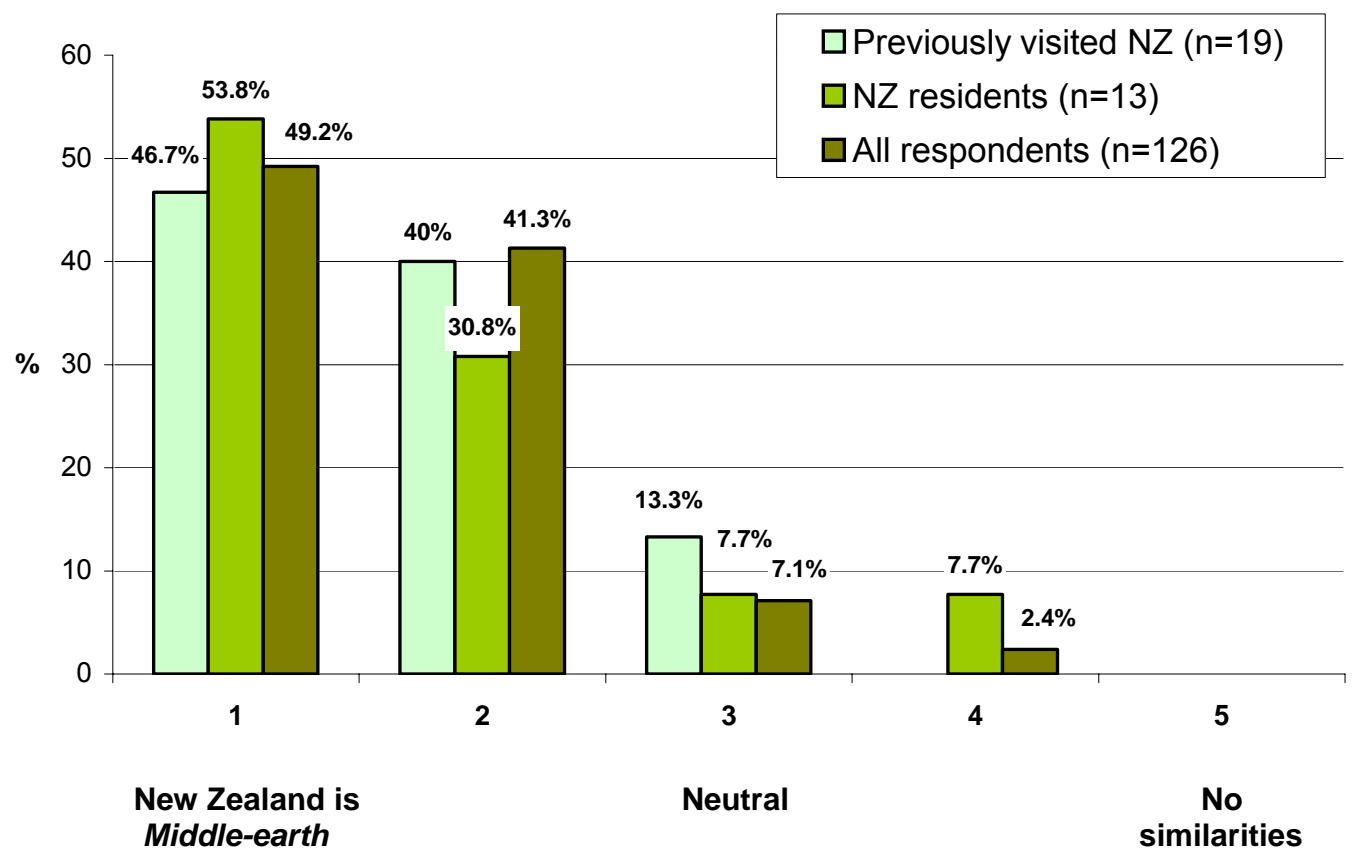

In addition to the above, respondents were asked to give reason(s) for their choice. A list with all answers is provided in Appendix 14. The answers were summarised into themed groups, which are described briefly below. The three case study tours are shortened in the following ways: Rings Scenic Tours [RST], Safari of the Rings tours [SotR] and Red Carpet Tours [RCT].

\section{- $\quad \mathrm{NZ}=$ Middle-earth (books)}

Similarities were perceived between New Zealand's landscapes and those described in Tolkien's books or how Middle-earth was imagined by respondents when they read the books, for example:

Having visited New Zealand 12 years ago and read the books, I thought then how suitable it [New Zealand] would be. [SotR, female, 45-49 years, UK, $1^{\text {st }}$ time visitor]

\section{- $\quad \mathrm{NZ}=$ Middle-earth (films)}

Similarities were seen between New Zealand's landscapes and the landscapes portrayed in the films by some respondents, for example:

Having seen New Zealand and The Lord of the Rings [films] I cannot imagine any other location of Middle-earth. [SotR, female, 55-59 years, Australia, previously visited NZ]

Flying into Queenstown is exactly like the mountain scenes in Lord of the Rings [films]. [SotR, male, 30-34 years, Australia, $1^{\text {st }}$ time visitor] 


\section{- Diversity of landscapes}

Some respondents cited the diversity of New Zealand's landscapes as the main parallel with Middle-earth, two examples:

I don't think there is another place on earth where the landscape varies as much as New Zealand does to be worthy of being called Middle-earth. [RST, female, 16-20 years, USA, $1^{\text {st }}$ time visitor]

So diverse! Jagged sunny mountains, unusual rock formations as seen in Rohan; crystal clear lakes like Mavora [Lakes]; rolling green hills like Hobbiton; volcanic boulders like Mordor - all on these islands! Where else would you find something like Mt Sunday? [RCT, female, 40-44 years, USA, $1^{\text {st }}$ time visitor]

\section{- $\quad \mathrm{NZ}=$ Middle-earth naturally}

Respondents expressed that New Zealand as Middle-earth existed naturally and had not required digital enhancement, for example:

It's all natural and not man-made. [RST, female, under 16 years, USA, $1^{\text {st }}$ time visitor]

The scenery and landscape represents medieval ages. Geographical formations are abundant and pure nature is at work! [RST, male, 25-29 years, Singapore, previously visited NZ]

\section{- $\mathrm{NZ} \neq$ Middle-earth}

Where respondents thought that New Zealand and Middle-earth were incomparable, the following reasons were given:

The two are not equitable- New Zealand is a country in it's own right. Bad question. [RST, male, 30-34 years, UK, $1^{\text {st }}$ time visitor]

Middle-earth wasn't tainted by humans, New Zealand's landscape had been. [RST, female, 30-34 years, UK, previously visited NZ]

I think Middle-earth is a marketing phrase. I am not a fanatic. [RST, female, 55-59 years, NZ]

\section{- $\quad \mathrm{NZ}=$ Middle-earth but only with the aid of computer wizardry}

According to some, only with digitally modifying New Zealand's landscapes could the Middle-earth portrayal be accurately portrayed, for example:

With a bit of imagination for the computer mastery- then it's Middle-earth. [SotR, female, 16-20 years, UK, $1^{\text {st }}$ time visitor]

\section{- NZ partially like Middle-earth}

New Zealand is only partially similar to Middle-earth, two examples:

Obviously certain aspects of landscape were quite like "Middle-earth" near the FILMING LOCATIONS. [RCT, male, 30-34 years, USA, $1^{\text {st }}$ time visitor]

Some sites reminded me of Middle-earth and some didn't. [RCT, male, under 16 years, USA, $1^{\text {st }}$ time visitor] 
Landscapes in the films and the reality of the former film site(s)

As one of the objectives of this research is to reveal how filmic tourists experience the former film sites and how this was informed by their previous watching of the films, two questions were designed within the survey to elicit this information. Respondents were asked to suggest adjectives to describe the landscape as portrayed and experienced in the films (question 2). In addition, a second question (question 5) asked them to suggest three adjectives to describe the actually visited landscape(s) of the former film site(s). The complete list with adjectives from all respondents is attached in Appendix 15. The intention of these questions was also to disclose whether filmic tourists distinguish between the landscape in the films and the real landscapes they have visited.

The most common adjectives used to describe the landscape shown in the film(s) were: beautiful, breathtaking, amazing, awesome, fantastic, green, magical, and spectacular. The most frequently used adjectives to describe the real landscapes at the former film site(s) were: green, beautiful, hilly/rolling, breathtaking, and fantastic.

The findings show that respondents in the different case study tours distinguish to a certain extent between the landscapes portrayed in the films and the real landscapes they had visited. More precisely, respondents within Rings Scenic Tours used the same adjectives to describe the landscapes in the films and the real experienced landscapes in 16.2 per cent of the cases. 34.8 per cent of Safari of the Rings' respondents used the same adjectives for the landscapes portrayed in the films and the real landscapes. The highest number (44.7\%) of similar words used was provided by respondents of Red Carpet Tours. In the latter, a common answer was that "the reality is not different from the fantasy".

\subsection{Filmic Tourists' Experiences of The Lord of the Rings Film Sites}

A very important matter for newly developed tourism companies such as Rings Scenic Tours, or newly developed tourism products of a company such as the Safari of the Rings tours and Red Carpet Tours is to know whether their product can satisfy the expectations of tourists as this will influence the long-term sustainability of their business.

This section explores how filmic tourists experienced the former film sites of The Lord of the Rings. Firstly, the fulfilment of expectations of filmic tourists participating in half-day tour experiences in Matamata and Queenstown are jointly 
discussed. Following the same is presented for the multi-day Red Carpet Tours as well as for independent travellers.

Secondly, also evaluated and discussed are the satisfaction levels of filmic tourists on the half-day tours, the multi-day experience as well as of those filmic tourists who travelled independently to the former film sites.

\subsubsection{Fulfilment of Expectations}

Before a person decides to visit the former film sites of The Lord of the Rings (s)he will build up expectations about what the place will be like. Particularly in the case of first-time visitors to New Zealand (Figure 6.9) the expectations might be very great due to their lack of previous experience. What filmic tourists expect from such a tour is essential knowledge for future management decisions because these perceptions can greatly differ from the ones that the tour operators have.

\section{Fulfilment of expectations: half-day tour experiences}

Participants of the two half-day tour experiences Rings Scenic Tours and Safari of the Rings were asked whether the location, the landscape of the former film site(s) and the tour experience were as they had expected. In other words, filmic tourists had to compare their expectations with their actual experience. They were given a choice of five options ranging from (1) 'much better than expected' to (5) 'much worse than expected'.

Figure 7.3 shows that almost two thirds (62.7\%) of Rings Scenic Tours' respondents felt their expectations had been exceeded. Their tour experience was either 'much better than expected' or 'better than expected'. Apparently due to the higher number of visitors on previous visits the proportion of the Safari of the Rings' respondents who indicated to they had a 'much better than expected' experience was lower. In this case however there were still over 41.2 per cent for whom the experience exceeded their expectations. The highest proportions $(58.8 \%)$ in the groups of Safari of the Rings tours had an experience as they expected it to be. None of the respondents within the Queenstown case study were disappointed with the former film sites experience. Within Rings Scenic Tours a few respondents (5.5\%) seem to have had very high expectations, which they felt were not rewarded. Thus, their experience was either 'worse than expected' or even 'much worse than expected'. 
Figure 7.3: Fulfilment of expectations (half-day tour experiences)

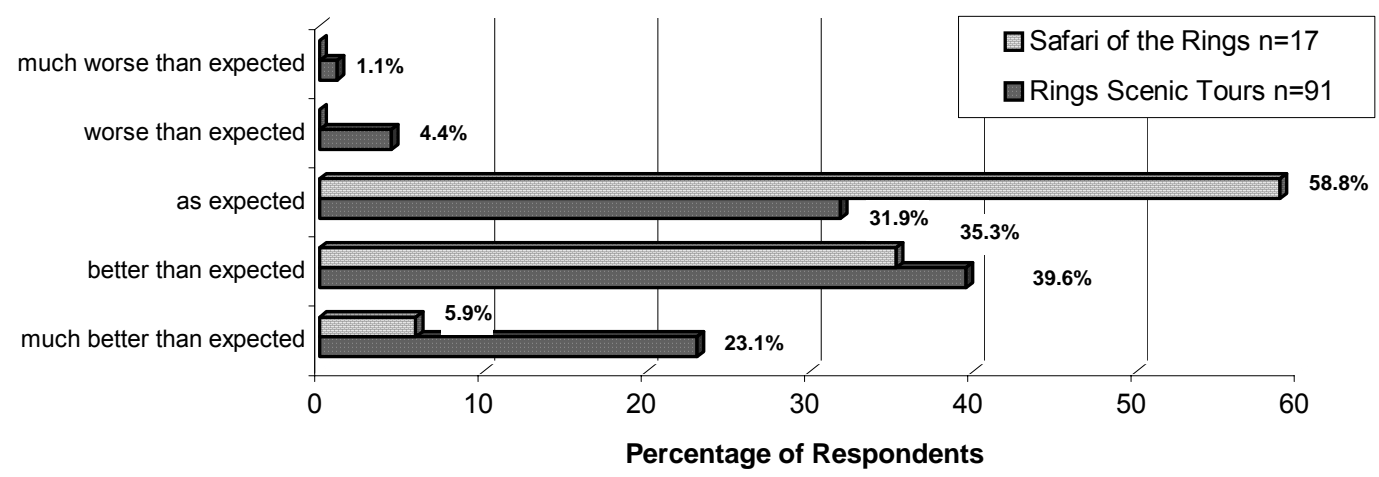

To actually reveal what filmic tourists expect from their tour experience an open-ended question was used to explore the reasons for respondents' rankings. The range of answers was widespread and the main reasons given are explored below under the following headings: expectations exceeded; expectations met; expectations not met; and no expectations. A complete list with all explanations is presented in Appendix 16.

\section{Expectations exceeded}

\section{i) Positively surprised}

Three different types of reasons why visitors were positively surprised were named. Firstly, respondents did not expect to see remnants of the former film sets on site, particularly the Hobbiton film set remnants. As these visitors had low expectations they were positively surprised and had their expectations exceeded. For example one person stated:

I had heard that everything was gone and there was more there than I expected. [RST, female, 30-34 years, NZ]

Secondly, some respondents were positively surprised that the natural landscape already had similar features needed for the portrayal of Middle-earth. These respondents showed they had appreciated the landscape by saying:

I was surprised and delighted that the set was actually built around the natural beauty and landscape, such as the lake and the party tree. And that the scenery that I had seen in the film actually did exist in its natural state and wasn't man made or computer enhanced. [RST, female, 25-29 years, UK, $1^{\text {st }}$ time visitor]

In the case of the Safari of the Rings respondents' statements tended to be more general about the beauty of the Queenstown landscape, for example:

The mountains of Queenstown were absolutely believable, spectacular! [SotR, male, 30-34 years, Australia, $1^{\text {st }}$ time visitor] 
Thirdly some respondents did not expect to receive as much interesting information as guides had provided and appreciated being given a closer insight into the filming process. Their expectations were exceeded; for example, one respondent commented:

A lot more detail- a must to see the movie again as [to] appreciate the attention to detail that was achieved so well. [RST, female, 40-44 years, NZ]

ii) Excited about opportunity to visit a film set

Respondents who said they were excided to experience landscapes where filming took place are summarised in this group. These respondents had their expectations exceeded. Two examples:

I was able to see the inside of the holes. [RST, female, 16-20 years, NZ]

Never been on a 'film set' before; imagination runs riot. [RST, female, 60+ years, UK, NZ previously visited]

\section{iii) General expressions of enjoyment}

Respondents who generally expressed having enjoyed the tour or the former film sites indicated that the experience within the tour was 'better' or 'much better than expected'. Therefore, these respondents could exceed their expectations.

\section{Expectations met}

\section{i) Research prior trip}

Respondents who previewed the landscape from research on the Internet, brochures and pictures prior to their visit stated that the experience of the former film sites was as they expected it to be. One commented that:

I've seen brochures so knew what to expect [RST, female, 25-29 years, Ireland, $1^{\text {st }}$ time visitor]

\section{ii) Could recognise film site(s)}

Some respondents stated that they could recognise the former film sets because they appeared as portrayed in the films. For example two people said:

Left a lot to the imagination but allowed you to visualize scenes from the movie.

[RST, female, 25-29 years, UK, $1^{\text {st }}$ time visitor]

I recognised most of them immediately and even taking film limitations into account, they were as they appeared on screen. [SotR, female, 45-49 years, UK, previously visited NZ]

To be able to recognise the former film sites is without a doubt a main expectation filmic tourists have when they visit places they previously saw in a film. Thus, it is not surprising that half of the respondents in this group indicated their experience was 'as 
expected'. The other half of the respondents had either an experience that was 'much better than expected' or 'better than expected'.

iii) Did not expect the set as it was in the film

These respondents experienced the landscapes as they expected them to be and did not expect the former film sites to appear as they were portrayed in the films, for example.

I expected the set not to be in the same state as in the movie. [RST, male, 21-24 years, UK, $1^{\text {st }}$ time visitor]

\section{Expectations not met}

i) Expected more to be left or in better condition/ expected film locations to look more like in the films

By contrast some respondents had high expectations and the reality could not do justice to them. These filmic tourists expected to find more left on site and in better condition, for example a couple of people commented:

They [the hobbit holes] didn't look as similar the movie as I thought they might" [RST, female, 16-20 years, USA, $1^{\text {st }}$ time visitor]

I thought the hobbit houses would still be complete. In fact it is a ruined town, a ghost town. [RST, female, 55-59 years, NZ]

Some respondents of the Safari of the Rings tours also expected the former film sites to look more similar to the way they appeared in the films, for example:

There's no evidence of the film or Middle-earth. The sets added to the landscape to create the illusion of Middle-earth. [SotR, male, 25-29 years, Australia, $1^{\text {st }}$ time visitor]

\section{ii) Wanted more natural experience}

Although respondents in this group were more critical, half also stated that their experience had been 'better than expected'. However, in this group was also one respondent who could not satisfy his expectations and indicated the film site experience was 'worse than expected'. Two statements clarifying these perspectives are:

[Preferring] natural area instead of being built up like a film set. [RST, female, 30-34 years, UK, previously visited NZ]

Landscape is perfect but Hobbiton was rebuilt. [RST, male, 40-44 years, Germany, $1^{\text {st }}$ time visitor]

\section{No Expectations}

Respondents, who declared that they had no real expectation prior the tour, did not know what to expect or did not expect much, experienced the former film sites as 
better than they had assumed they would be. One respondent's experience was 'as expected', which is a contradiction given that he stated he had no expectations.

In summary, half-day tour respondents exceeded their expectations mainly because they did not expect to find parts of the film set still on view; the similarities of New Zealand's landscapes with the Middle-earth portrayal; the richness of information given by the tour guides; and the opportunity to visit a former film site.

Expectations were met due to research undertaken prior the tour; the recognition of the former film site as it was portrayed in the films; and the assumption that no film sets remained.

Respondents did not met their expectations because of disappointment about the condition of the film set remnants; expectations that the landscapes would look more as they appeared in the film; and their need for a more natural experience. Finally, some respondents had no expectations prior to the tour.

\section{Fulfilment of expectations: multi-day tour experience}

Participants of Red Carpet Tours are generally enthusiasts of Tolkien's work and The Lord of the Rings films. This could be proven by the great frequency with which they had watched the films (Figure 6.13) as well as their decision to tour New Zealand almost solely to visit the former film sites. For instance, over two-thirds $(68.8 \%)$ of the Red Carpet Tours' respondents stayed in New Zealand for only one day longer than the tour.

Red Carpet Tours' participants had high expectations as they were thoroughly conversant with the films and Tolkien's books. The majority $(87.6 \%)$ had their expectations exceeded (Figure 7.4). For the remaining proportion (12.4\%) the experience was as they expected it to be. When comparing these figures with results of the two half-day tours in Matamata and Queenstown (Figure 7.3) we see that a greater proportion of respondents in the Red Carpet Tours felt their expectations had been exceeded. 
Figure 7.4: Fulfilment of expectations (multi-day tour experience) $(n=16)$

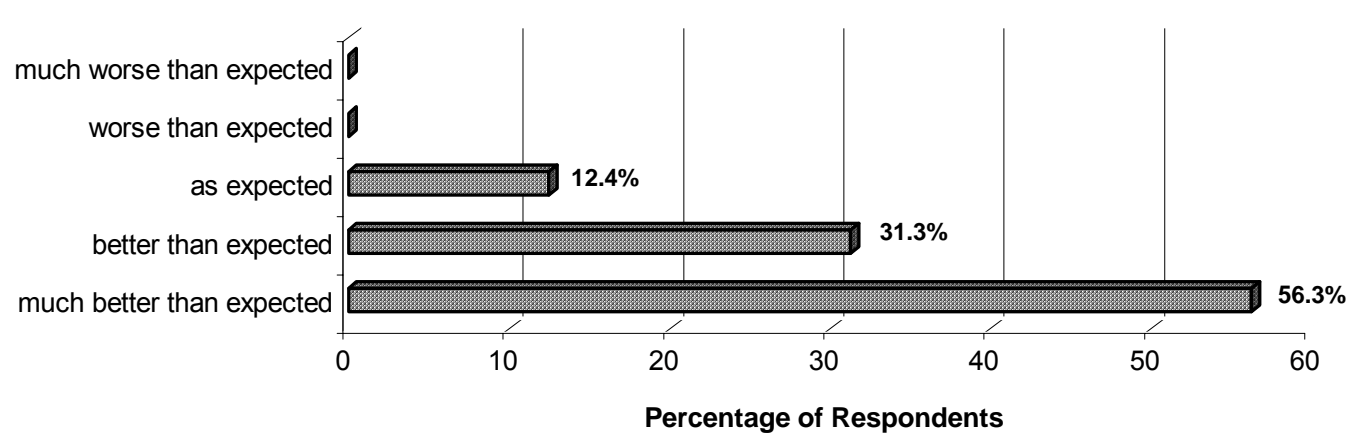

There were three main reasons for the fulfilment of expectations cited by respondents who had been on the Red Carpet Tours and these are summarised below. A complete list with all answers is presented in Appendix 16.

\section{Expectations exceeded}

ii) General expressions of enjoyment

One respondent explained the former film sites were very interesting and his experience was 'better than expected'.

\section{ii) Positively surprised about landscapes}

All respondents in this group had an experience that was 'much better than expected'. According to their explanations this was mainly due to the beauty of the former film landscapes. For example one person said:

They were breathtaking-spectacular- especially Lothlorien and Fangorn Forest and the Misty Mountains. [RCT, male, under 16 years, USA, $1^{\text {st }}$ time visitor]

\section{iii) Experience of former film sites}

This third group comprises answers that explain that the fulfilment of expectations was mainly due to the experience of the actual former film sites. Respondents declared they were amazed when they visited sites where filming took place, for example:

(...) There is something magical about touching the same rocks, feeling the wind. Grounding experience. [RCT, female, 40-44 years, USA, $1^{\text {st }}$ time visitor]

\section{Expectations not met}

i) Expected film location to look more like in the films

Respondents did not exceed their expectations when they could not recognise the former film landscapes they had seen in the films or see the expected film sets. For example, one person commented:

(...) We did see some physical evidence of film sites but I was hoping to see more of film sites! [RCT, female, 30-34 years, USA, $1^{\text {st }}$ time visitor] 


\section{Fulfilment of expectations: independent travellers' experiences}

Filmic tourists who were experiencing the former film sites by themselves had slightly different expectations of these landscapes in contrast to filmic tourists who were on an organised tour. Informal conversations exposed that the former type of tourist was not aiming to find, for example, the exact spots where camera had filmed. They preferred to experience just the greater landscapes where filming generally took place. In other words they were looking for the 'Middle-earth feeling' and to experience landscapes that could have been portrayed as Middle-earth.

\subsubsection{Tour Satisfaction}

The satisfaction level of filmic tourists after visiting The Lord of the Rings film sites on an organised tour is another key element in this research. This is due to the assumption that filmic tourists could form the wrong impression New Zealand's landscapes after they had watched the highly computer technical modified films of The Lord of the Rings. Filmic tourists in the case study tours were asked to evaluate their tour experience on a ranking scale from (1) 'very satisfied' via (3) 'neutral' to (5) 'very dissatisfied'. The findings are summarised below.

\section{Tour satisfaction: half-day tour experiences}

In both half-day tour experiences, the majority of respondents indicated they were 'very satisfied' or 'satisfied'. Besides the high proportion of very satisfied respondents on Rings Scenic Tours, a small number of people ranked their satisfaction level as 'neutral' or even 'dissatisfied' (Figure 7.5). Only one of these respondents gave a reason for the ranking. She said:

"(...) I just wish that it had looked more like the movie" [RST, female, 16-20 years, USA, $1^{\text {st }}$ time visitor]. 
Figure 7.5: Satisfaction with tour experience (half-day tour experiences)

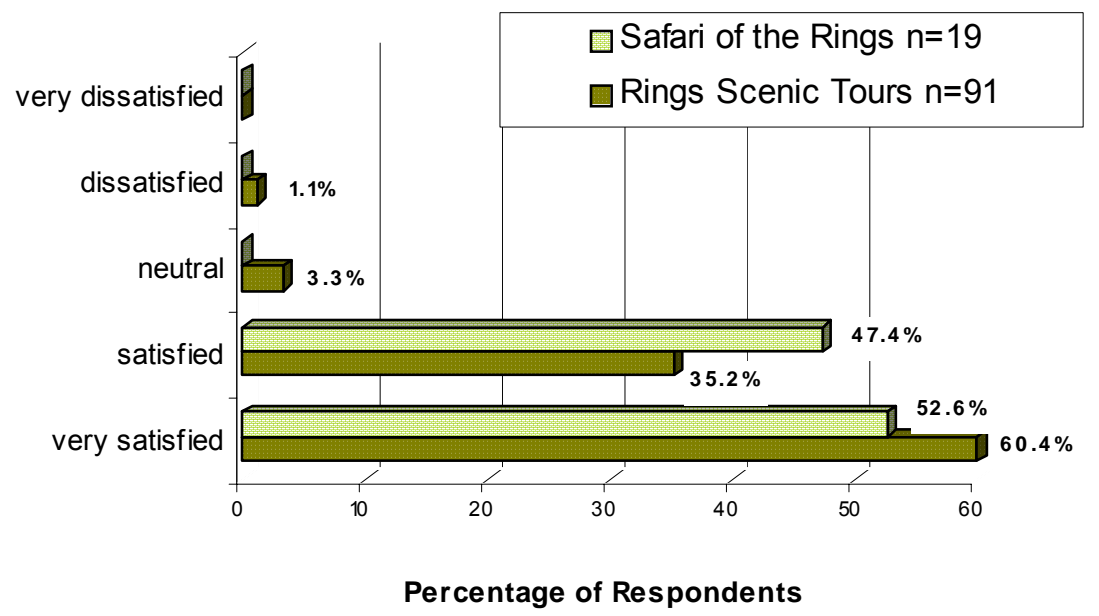

As with the question on visitors' expectations, respondents were asked to explain why they indicated a particular level of satisfaction. The answers were more complex and suggested often a number of themes. However, they could be summarised under four main themes: general comments and the quality of the tour and guides; the landscape of the former film sites and the general area; the experience of visiting a former film set; and critique of the film set remains. These themes are listed and described below. A complete list of answers is presented in Appendix 17.

\section{ii) General comments and quality of the tour and guides}

The highest proportion of respondents who had a 'very satisfying' or 'satisfying' tour experience cited the quality of the tour and the information given by guides as the main reason for their level of satisfaction. Some typical statements are:

This has been a wonderful way to see NZ at its best. [SotR, female, 25-29 years, Australia, $1^{\text {st }}$ time visitor]

The tour is worthwhile and well managed. It is a good "spin off" from the films. I'm a Kiwi and enjoying exploring my own country. [RST, female, 55-59 years, NZ]

The tour guides were fantastic. They brought a brilliant blend of knowledge and enthusiasm. [RST, female, 35-39 years, UK, $1^{\text {st }}$ time visitor]

\section{ii) Landscape of the former film sites/general area}

Many filmic tourists were amazed by the natural landscape of the film set as well as the farm landscape such as they saw on the former Hobbiton film set, or the landscapes in the Queenstown area visited in the Safari of the Rings tours. Comments included were:

I thought it was a great opportunity to see the landscape and it gave me a good insight into the amount of time, work and expenses it took to make the film perfection. 
It was amazing to gain insight into how they created such a fantasy world. [RST, female, 21-24 years, Ireland, $1^{\text {st }}$ time visitor]

The farm is the Shire, the location is Hobbiton. [RST, male, under 16 years, UK, $1^{\text {st }}$ time visitor]

I was amazed by the scenery here in Queenstown. You had to come here to see it. [SotR, male, 30-34 years, Australia, $1^{\text {st }}$ time visitor]

Respondents in this group, therefore, had a 'very satisfying' or 'satisfying' tour experience.

\section{iii) Experience of visiting a former film set}

In this group respondents were 'very satisfied' or 'satisfied' with the tour experience. Statements of respondents were:

I have been to Hobbiton that makes me satisfied. [RST, male, under 16 years, Hong Kong, $1^{\text {st }}$ time visitor]

Amazing to say 'l've been there!' [RST, female, 25-29 years, Ireland, $1^{\text {st }}$ time visitor]

\section{iv) Critique on film set remnants}

Surprisingly, when taking into account the conditions of the set remnants, only a small proportion of all respondents were critical that the remnants were all that survived of the Hobbiton film set. However, these respondents indicated that they had a 'satisfying' tour experience, for example:

Didn't realise that the set would look so different. [RST, female, 21-24 years, UK, $1^{\text {st }}$ time visitor]

Shame that the set is slowly deteriorating. What about future visitors? [RST, male, 30-34 years, UK, $1^{\text {st }}$ time visitor]

Yet again no evidence of the illusion of Middle-earth. [SotR, male, 25-29 years, Australia, $1^{\text {st }}$ time visitor]

\section{Tour satisfaction: multi-day tour experience}

Respondents of the Red Carpet Tours were asked how satisfied they were with the tour experience once it was completed. The results show clearly that all the respondents had enjoyed a satisfying tour experience (Figure 7.6). Notable was the high proportion of 'very satisfied' respondents (87.5\%) in the Red Carpet Tours. These figures are higher than of respondents within the two half-day tour experiences (Figure 7.5). One explanation may be the creation of the illusion of Middle-earth in the course of the Red Carpet Tours. Therefore, Mitchell's (1998) experimental model is confirmed in which he asserts that when the hyper-real experience is met filmic tourists are more satisfied. This is in contrast to tourists who only have a 'real' experience and are more likely to remain unsatisfied (see Box 4.1). 
Figure 7.6: Satisfaction with tour experience (multi-day tour experience) $(n=16)$

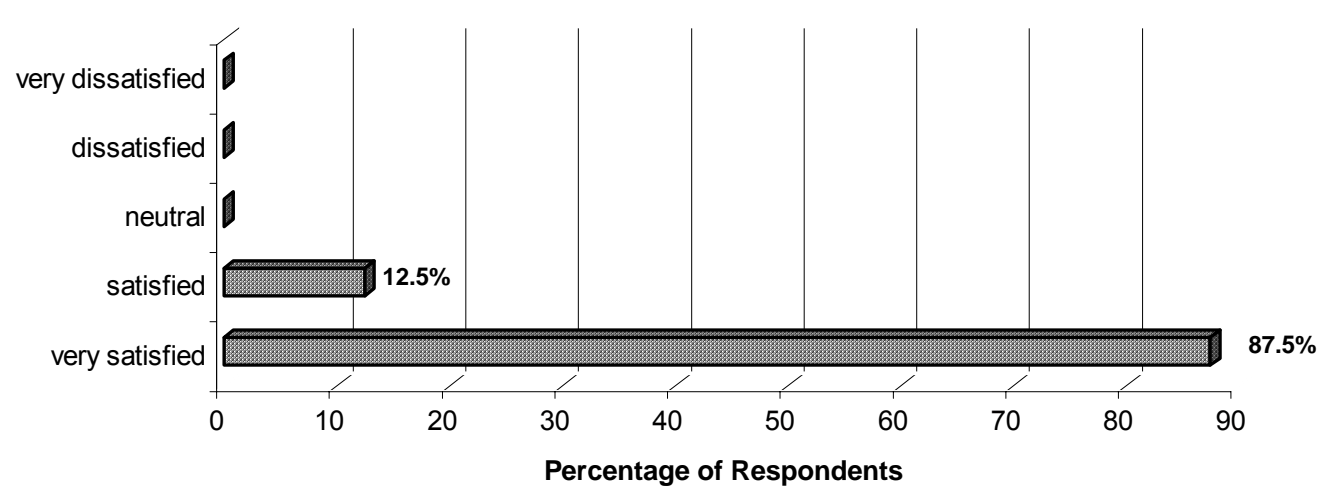

Explanations given by the Red Carpet Tours' respondents were very detailed. However, two main themes could be found in the replies. The complete list of replies can be found in Appendix 17.

\section{i) New Zealand \& New Zealanders}

Local people were a reason for a 'satisfying' tour experience, for example:

New Zealanders are a diverse cultural group anyway and they seem to welcome all. No one was rude. Kiwis are very down to earth (...)." [RCT, female, 40-44 years, USA, $1^{\text {st }}$ time visitor]

\section{ii) Guides, organisation and composition of the tour}

The guides, the tour organiser and the composition of the tour attractions were often mentioned reasons for having enjoyed the tour. This is confirmed with these two statements:

Wonderful tour-so much care and research gone into this. Vic James [Red Carpet Tours Managing Director] cares about LotR and it shows. [RCT, female, 45-49 years, UK, $1^{\text {st }}$ time visitor]

Great way to see NZ especially because some sights were "off the beaten paths" taken by tourists. [RCT, male, 30-34 years, USA, $1^{\text {st }}$ time visitor]

Beside these two main themes, the statement of a female respondent provided one example of having her personal dream fulfilled. She was overwhelmed by the experience, which can be seen, in her ranking of the satisfaction level with 1 plus 10. She explained:

This was the trip of a lifetime for me. I have loved Tolkien since 1967,and when people would ask me if I were to go to Fantasy Island (an old US TV series where people's dreams can come true) I would always say I wanted to visit Middle-earth. Well, now I have, and if I can get the money together again by next year I'm going again next summer. This tour was a dream come true for me- it's impossible for me to express in words how very much I was overwhelmed by New Zealand. [RCT, female, 55-59 years, USA, $1^{\text {st }}$ time visitor] 


\section{Satisfaction: independent travellers' experiences}

Informal conversations with filmic tourists who independently visited the former film sites revealed a different pattern of satisfaction. Here the proportion of filmic tourists who were dissatisfied with their experience was higher than of those on an organised tour. This is because a number of these independently travelling filmic tourists were not familiar with New Zealand and at the same time they had high expectations. This made them more likely to be unsatisfied with their experience of the former film sites. Reasons given for this dissatisfaction were problems with locating the sites, with recognising them as well as not having background information available, for example, about the filmmaking.

The more satisfied independent tourists were all familiar with New Zealand because they had previously visited or had long been interested in the country. These tourists stated that although often they could not recognise the locations when they were searching for the former film sites, their experience had not been spoiled. In contrast the desire to recognise the former film set was not as important as the beauty of the landscape.

Thus, filmic tourists who took part in organised The Lord of the Rings theme tours are more likely to be satisfied. To increase the satisfaction level of the independently travelling filmic tourists, better location guides are needed. lan Brodie's (2002) location guidebook was not seen as a helpful tool for trying to locate the film sites. Guidebooks need to include background information about what parts of the films were shot at a particular site and interesting stories and anecdotes about the filming process to improve the experience for filmic tourists and this all in an easily understandable way with clear maps.

\subsubsection{Impact of Film Watching on the Experience}

One assumption within this research was that the frequency with which the films were viewed would impact considerably upon the expectations and finally the satisfaction of filmic tourists with the experience. In other words, it was assumed that a person who watched the films, for example, 30 times would have very high expectations about how the landscape will look. In reality this could lead to disappointment and dissatisfaction as no sets as portrayed in the films can be seen.

Data analysis (by employing chi-square tests and regression) revealed that there was no significant relationship between the frequencies with which the films were watched, and the expectations and satisfaction level. However, a significant relationship between expectations and satisfaction level existed. That means that 
filmic tourists whose expectations were exceeded also had a satisfying tour experience, which is, of course, scarcely surprising.

\subsection{Chapter Summary}

This chapter has examined iconic landscapes by using Riley et al.'s (1998) approach that considers the plot which contains a key scene, the landscape having extraordinary appearance, analysis of screen time and information by respondents within the survey. Hobbiton, Rivendell and Edoras were taken as the main icon sites of the films. In addition, three short sequences investigated as having iconic status within the films. Moreover, it was argued that those locations, which offer a number of main former filmsets have the potential to act as iconic landscapes of the films, too. This is the case for Wellington and Queenstown.

The research attempted to reveal whether or not the branding of New Zealand as Middle-earth is justified. The survey findings clarified that nearly half $(49.2 \%)$ of the respondents agreed that New Zealand is Middle-earth. Explanations given for filmic tourists' responses were mainly concerned with the variety and similarities of New Zealand's landscapes to how they were used on film. However, more critical comments declare that New Zealand did not accord with the fantasy world of Middleearth and the portrayal of Middle-earth had only been achieved by modifying the landscapes with computer technology.

For the majority of tourists on all three tours, expectations concerning the landscapes had been met or exceeded and they departed satisfied with their experiences; and this was particularly the case with the multi-day tour participants. In general, respondents' expectations were exceeded because of their low expectation, the beauty of the landscape, and the film set experience. Rather than being exceeded, some tourists' expectations were broadly met. This was attributed to research they had done prior the tour which gave them informed knowledge of how the landscape would look; the comparability of the natural/real landscape with the imaginary landscape portrayed in the films; or the fact that tourists did not expect to find the natural landscapes exactly as they appeared in the films. Where expectations were not met, tourists had expected more to have remained of former film sets or felt that the landscapes did not match the grandeur of those featured in the films (which were often digitally enhanced). Conversely, other respondents did not have their expectations met, even when there were film set remains: these tourists would have preferred to have had a solely natural landscape experience.

The majority of tourists were satisfied with their film tourism experience. Respondents identified three main factors contributing to their satisfaction: an 
appreciation of New Zealanders, particularly the guides and tour operators, for their hospitality, knowledge and behind-the-scenes insights; an appreciation of the natural landscapes of New Zealand; and a delight at being immersed in Middle-earth.

Respondents with a low satisfaction level named as the main reason the poor condition of the film set remnants (particularly in the case of the former Hobbiton film set on the Rings Scenic Tours or just the lack of film set remnants, as in the case of the Safari of the Rings tours. This confirms research by Aitken and Zonn (1994) that filmic tourists judge the real landscapes against the film landscapes. In contrast, it seems that the closer the real landscapes approximate the hyper-real landscapes of the films, the more expectations are met or exceeded and the greater the satisfaction of the tourists with their tour experience. This, in turn, verifies Mitchell's (1998) model and demonstrates that most filmic tourists want the absolute unreality of the film landscapes offered as 'real' presence (Eco 1986), through the tangibility of film sets and other forms of interpretation.

Closely associated with this point, it seems that the degree of satisfaction when visiting a former film set in an organised tour depends significantly upon the ability of guides to interpret the landscapes for tourists. This may include explaining the locations and angles from which the film was shot, or providing behind-the-scenes' insights which further enhance tourists' reading of the 'real' landscapes. The better these explanations and the re-awakening of memories of the films, the greater the satisfaction of filmic tourists, and the greater their desire to watch the films again to see them all from a new perspective. As such, tour guides, like the windows of the tour buses studied by Schofield (1996), are critically important mediators of film landscapes and tourist experience and satisfaction.

It was argued that the frequency of watching the films could impact on filmic tourists' experience in the sense that the more the films were watched the higher the expectations and the less likely they were to have a satisfying experience because the real landscapes do not provided the features of the film portrayal. However, this assumption could not be proven.

The following and final chapter of this thesis presents the final discussions, draws final conclusions, and gives the implications of the findings. 


\section{Chapter eight Final Discussion and Recommendations}

\subsection{Introduction}

This research was designed to gain an understanding of how New Zealand's landscapes were portrayed in the first two films of The Lord of the Rings, and how this impacts on filmic tourists' experiences and, more generally, The Lord of the Rings film tourism in New Zealand.

This chapter provides a final discussion of the findings and answers to the research questions/objectives. This chapter seeks also to question the importance of The Lord of the Rings films and film tourism for New Zealand. New Zealand is currently using The Lord of the Rings as a myth to promote the country and to attract tourists, as well as an instrument of national pride. The findings resulted in a number of implications for film tourism management, which are highlighted here, along with recommendations. In addition, the chapter provides recommendations for further research in the field.

\subsection{Research Evaluation}

Four specific objectives were formulated for the investigation of this research:

1) to analyse how New Zealand's landscapes are portrayed in the films of The Lord of the Rings;

2) to evaluate how filmic tourists' experience the landscapes of New Zealand and how their experiences are related to The Lord of the Rings films;

3) to determine landscapes shown in the films which have a potential to attract filmic tourists and act as icons; and

4) to discuss the implications for The Lord of the Rings film tourism and New Zealand more generally.

An interpretive multi-method approach, which combined quantitative and qualitative methods, was used. By combining the findings of qualitative and quantitative methods (textual analysis, survey, interviews, observations and the researcher's own response) rich findings were gained. More precisely, the method of closed textual reading and interpretation was employed for the analysis of the New Zealand landscapes' portrayal in the films. Empirical research included surveys and semi-structured interviews to reveal how filmic tourists on three organised case study tours experience the former film landscapes. In addition, informal conversations with 
filmic tourists who independently visited the former film sites were used to gain a better understanding of their landscape experience. Furthermore, semi-structured interviews were conducted with film tourism operators, local tourism bodies, and locals in Matamata and Queenstown to reveal their experiences with The Lord of the Rings film tourism and filmic tourists.

The employed methods were seen as the most appropriate for the investigation of the study in order to provide rich results. Beside the strengths of the chosen methods (as discussed in chapter two) limitations must be acknowledged, which are mainly concerned with the small (survey $n=132$; tourists interviews $n=7$ ) as well as unequal sample size (Rings Scenic Tours $n=97$; Safari of the Rings $n=19$; Red Carpet Tours $n=16$ ).

\subsection{Findings}

This study investigated the previously listed four objectives. Following this, the findings of the representation of New Zealand's landscapes, filmic tourists' experiences of these landscapes, the examined iconic landscapes and the implications of The Lord of the Rings film tourism are summarised and discussed.

\subsubsection{Representation of New Zealand's Landscapes in the Films}

Tolkien's books, as well as Jackson's filmic translation, belong to the genre of fantasy literature/film. This genre integrates elements of fairytales in which symbolic landscapes are used to transport moods, boost our emotions and enhance the drama of the story. In The Lord of the Rings this can be seen in the use of bush/forest as a metaphor for aspects of the unknown and its potential danger, and the symbolic use of rivers and their associated landscapes representing change or a journey to the viewer.

When employing Lukinbeal's (1995) categorisation of the geography in film it can be said that New Zealand's landscapes in The Lord of the Rings films are portrayed in three ways: as geography, metaphor and spectacle. In detail, the landscape is portrayed as geography in which the story is set and, thus, landscape is an active character in the narrative of the films. Landscape is also used as metaphor that gives meaning to a place and the state of mind of the protagonist while on the journey. In The Lord of the Rings Frodo's quest begins in green hilly landscapes but the final 'destination' is Mordor, which is dark and rocky. It is not only the landscape that changes but also the protagonist who seems to age on his journey. Thirdly, landscapes are portrayed as spectacles of beauty in fantastical places such as Rivendell or Lothlórien. 
Through the films of The Lord of the Rings New Zealand's cultural landscape was transformed into Tolkien's mythical world of Middle-earth. The Middle-earth representation portrayed the social structures of the story interwoven with actors' performances, narrative elements, and film sets made of built set constructions or computer-generated images superimposed in post-production or a combination of both. These layers were then imposed on the real New Zealand landscapes to create the cultural landscape of Middle-earth. By doing so New Zealand is presented as a place faraway in time and space, as a representation of a European fairytale Dark Age with a mixture of familiar landscapes, such as the English inspired Hobbiton or fantastical landscapes such as Lothlórien.

As the non-modern is viewed as authentic in today's modern society (Meethan 2001) (see chapter four, section 4.4.3) Middle-earth might appear authentic, a real historical place. This is, of course, a contradiction due to, on one hand, Middle-earth as a created fantasy-world is not based on real history and, on the other hand, the filmic representation that has no relation to local New Zealand history and culture.

The landscape portrayal in the films provides little hint of the real cultural landscapes of New Zealand. This is due to the position of layers of different cultural histories, and ruins of ancient societies, on top of the manipulated or camouflaged real New Zealand landscapes.

\subsubsection{Filmic Tourists' Experiences}

Chapter four clarified that little academic research on filmic tourists' experiences of former film sites has been done. Available case studies are limited to Europe, the USA and Australia.

As argued in chapter three (section 3.2.3), film manipulates reality. The use of digital and set modifications in film makes it hard for the audience to perceive a realistic sense of place. The landscapes portrayed in The Lord of the Rings films are a mixture of set constructions and computer digital images. The experience of the real landscapes provides few features of the hyper-real landscape as experienced when watching the films. This, of course, impacts on filmic tourists' experiences of the former film sites when "the real is judged against the staged" (Aitken and Zonn 1994b: 7).

Organised film location tours, therefore, use illustrations of the film portrayal to make it easier for tourists to recognise the real New Zealand landscapes used in the films. In addition, stories about the challenge of filmmaking are integrated into the tours, and therefore become a part of the fascination of a visit to the former film locations, particularly because the film sets have been removed or demolished. This 
and, in some cases, guides who were involved in the filming as extras, provide a kind of behind-the-scenes experience. Part of the filmic tourists' experience is also to reenact scenes in the films at the particular sites and thus to perform and create their own individual texts.

The research showed that there are two main groups of filmic tourists participating on organised tours. First, there are tourists who participate on the halfday tour as a diversified addition to their holidays in New Zealand. In the case of Matamata (Hobbiton), its handy location, half way between Rotorua and Auckland, is also seen as a good reason to have a travel break and visit the former film set. The second group, participants on the multi-day tour, came here specifically to experience 'New Zealand as Middle-earth'. These filmic tourists have a passionate interest in Tolkien's work as well as in the film trilogy. Their main motivation to become a filmic tourist is what Riley and Van Doren (1992) clarified as pilgrimage (see chapter four, section 4.4.4).

Box 8.1 displays the reasons identified by case studies' respondents for having their expectations exceeded, met or not met. In detail, respondents' expectations were generally exceeded because of initial low expectations of the natural landscape's similarities with the film portrayal or the tour in general. Expectations were also exceeded due to the beauty of New Zealand's landscapes, which was not expected by many tourists. Furthermore, filmic tourists were amazed by the film set experience and their expectations were exceeded because of the set remains (on the former Hobbiton film site) and the informative tour. 
Box 8.1: Reasons for expectation fulfilment/disappointment

Low expectations

Beauty of landscape

Film set experience

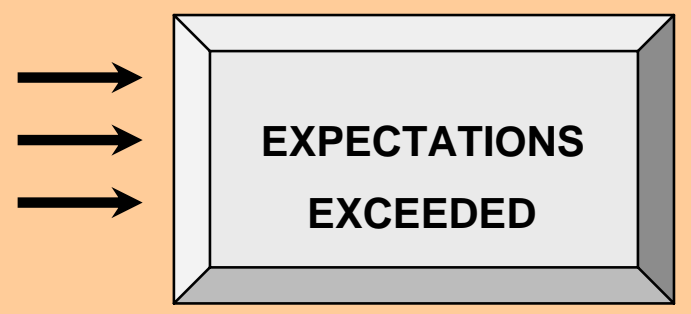

Research prior to trip

Natural landscape matches film portrayal

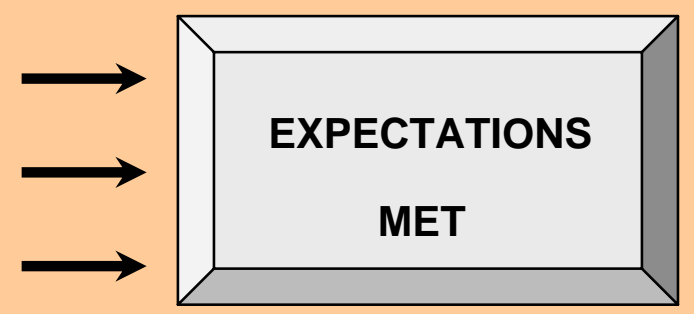

Moderate expectations of landscape

Natural landscape did not match film portrayal

Film set remains

(too few or too many)

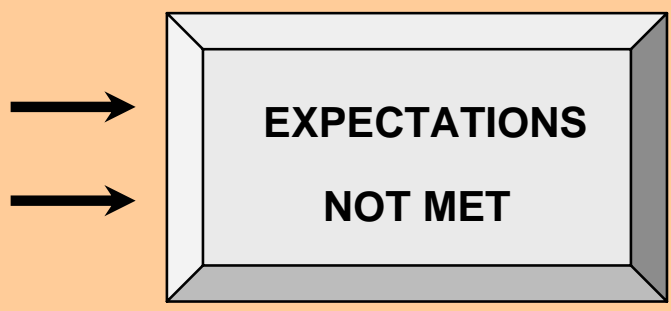

Expectations were met due to tourist's personal research done prior to the tour that informed their knowledge of how the landscape would look, the comparability of the natural landscape with the imaginary landscape portrayed in the films, or the fact that tourists did not expect to have the natural landscapes appear as in the films.

Reasons for expectations not being met were when filmic tourists expected more to be left of the former film sets. On the other hand, other filmic tourists did not have their expectations met when there were film set remains. More precisely, these tourists would have preferred to have a solely natural landscape experience.

Box 8.2 summarises the reasons named for having had a satisfying tour experience. Respondents with a low satisfaction level named as the main reason the condition of the film set remains (particularly in the case of the "Rings Scenic Tours" and the Hobbiton former film set) or simply the lack of film set remnants as in the case of "Safari of the Rings" tours. In the latter, this confirms Aitken and Zonn's (1994b) findings that filmic tourists judge the film landscapes against the real landscape. 
Box 8.2: Reasons for tour satisfaction

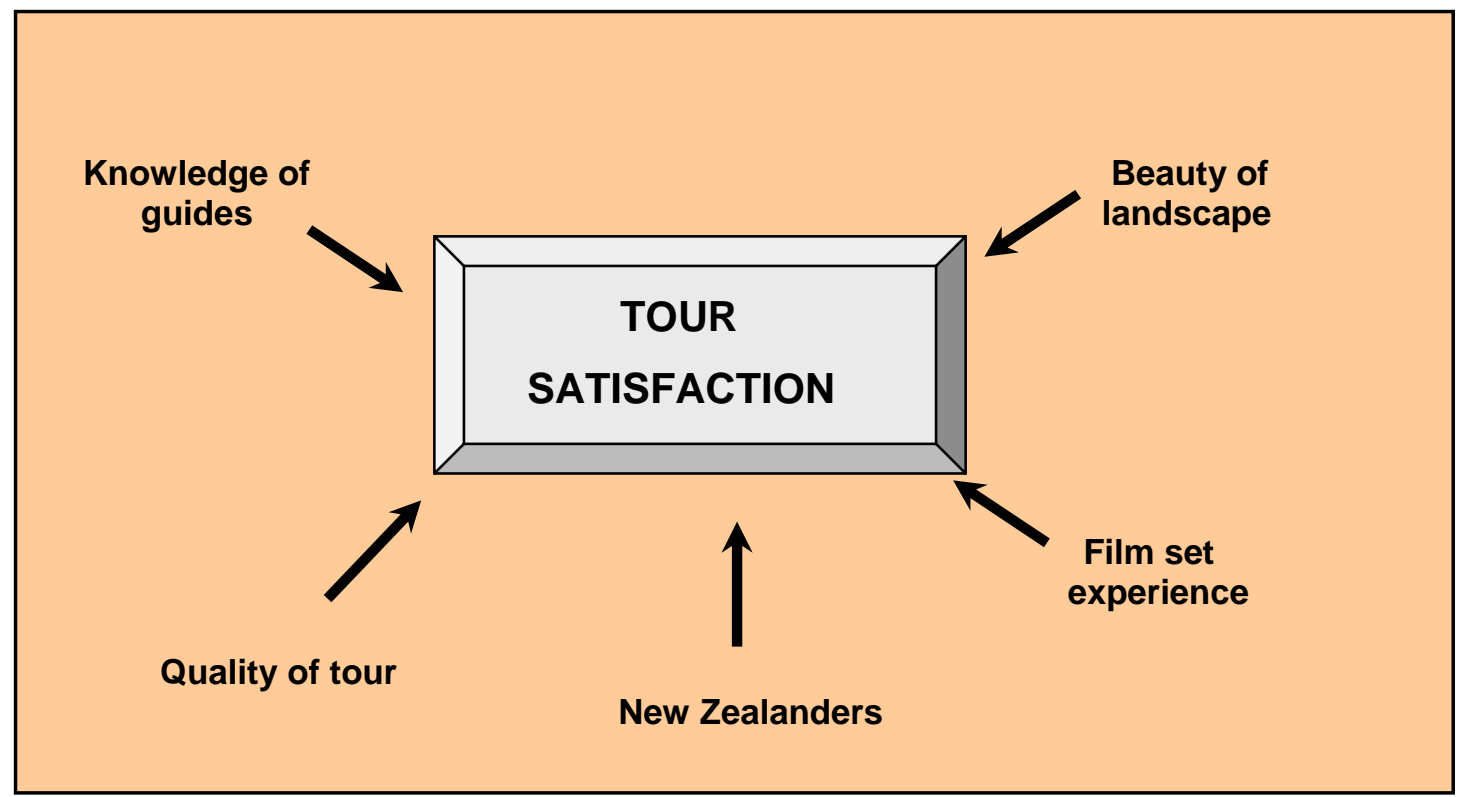

Where satisfaction was achieved it was often due to the beauty of the landscapes, particularly those perceived to be off the beaten tourist tracks, the film set experience that immersed them within Middle-earth, an appreciation of the New Zealand people, and/or the quality of the tour and the knowledgeable guiding.

It seems that the degree of satisfaction when visiting former film sets in an organised tour depends highly on the ability of the guides to explain the landscapes people see and identify which shots were taken where. The better these explanations and the re-awakening of film memories, the higher the satisfaction of filmic tourists. These findings support Mitchell's (1998) model whereby the closer the real landscape experience matches the hyper-real landscape experience of the film(s), the greater the satisfaction of filmic tourists with their tour experience. If the guides are able to re-awaken these images of the films, filmic tourists then want to watch the film again to see it all from a new perspective after having been there.

Furthermore, the findings show that there is no significant relationship between the frequency the film(s) were watched and the filmic tourists' satisfaction level of the landscape experience.

\subsubsection{Iconic Landscapes}

Riley et al. (1998: 924) suggested that landscapes portrayed in films, which capture the viewer due to their "extraordinary or captivating" features, can act as iconic landscapes and film tourism attractions. By employing this approach the research identified the iconic landscapes of the films by: a) analysing their length of screen time, which had to be at least 10 minutes; b) content analysis in the context of crucial 
scenes; c) judgement of their extraordinary or captivating appearance; and d) respondents naming within the survey, which had to be at least 5 per cent (see chapter seven, section 7.2). These established criteria resulted in the following iconic landscapes of the first and second film:

- Hobbiton - mainly filmed in the Hinuera Valley/Matamata

- Rivendell - portrayed in the Kaitoke Regional Park/Wellington

- Edoras - filmed on Mount Sunday/Rangitata Valley

In addition, three short sequences in the films were seen as having iconic status:

- Hiding scene - filmed at Mount Victoria/Wellington

- The Argonath/Pillars of the Kings - the Kawarau River/near Queenstown was used as the backdrop

- Rohirrim refugees scene - portrayed at Deer Park Heights/near Queenstown

These iconic landscapes/scenes in the films hold the most attraction for filmic tourists and scenes are re-performed as they were seen in the films (see chapter seven, section 7.2). Filmic tourists, thus, step into the particular film set, and produce and perform their own personal texts. This is done on tours by forming interpretive communities, which confirms the findings of Aden et al. (1995) as shown in chapter four (section 4.4.4).

By examining these iconic landscapes, which have a potential to attract filmic tourists, Wellington and Queenstown were seen as main centres for The Lord of the Rings film tourism and, thus, are iconic locations as well. This is due to the variety of former film sites in Wellington and Queenstown, and the nearby areas. The importance of both cities for The Lord of the Rings film tourism/filmic tourists was also confirmed by the findings of the survey.

\subsubsection{Implications}

The portrayal of New Zealand's landscapes as the embodiment of Tolkien's fantasy world Middle-earth impacts on filmic tourists' experience. This is due to the different appearance of the real landscapes, which lack props and the superimposed features of the film portrayal. Thus, the sustainability of The Lord of the Rings tourism has to be questioned, taking a variety of aspects into account. Sustainability of film tourism involves a discussion of whether tourism is able to benefit a region for a long time after a film has been released.

Completed research does not give a definitive timeframe for the lasting effects of film tourism or reasons for a prolonged impact (for example Riley et al. 1998). To 
ensure future benefits many factors must be considered, including visitors' satisfaction, tourism operators' prospects, impacts on locals, tourism planning policies and environmental issues.

As discussed in chapter seven (section 7.4.2), the findings of the three main case studies show that the clear majority $(96.8 \%)$ of respondents were 'very satisfied' or 'satisfied' with their tour experience. The small proportion of less satisfied respondents had different expectations of the former film sites. They expected them to be more like the portrayal in the films or at least easily recognisable.

Filmic tourists' satisfaction, which is related to the fulfilment of expectations, particularly when the location does not appear in reality as portrayed in the films, is most important for long-term sustainability. In the context of lasting benefits, it must be kept in mind that a dissatisfied tourist will not provide positive word-of-mouth promotion.

Also important, in relation to the sustainability of film tourism, is how tourism operators judge their prospects. This is crucial for future investments. The eight operators of The Lord of the Rings themed tours, interviewed about how long their company might benefit from The Lord of the Rings film tourism, as well as how long they assume the phenomenon will last in general, named varied timeframes. Some operators and tourism managers judge The Lord of the Rings film tourism will only last up to two years after the third film is released. For example, Anne-Marie Forsyth of Tourmasters South Pacific NZ Ltd (e-mail correspondence, 30.05.2003) expects:

interest to wane within a year or two after the release of the last movie. (...) travellers will move on to the next fad fairly quickly.

Operators with a similar appraisal are careful not to risk too much investment in this as they see it as an ephemeral tourist demand.

On the other hand some operators are more positive about the lasting effects. As Helen Jansen (pers. comm., 01.09.03, Queenstown) of Nomad Safaris, which offers the Safari of the Rings explains:

Certainly it will outlive me. The Lord of the Rings is going to be one of those movies that people watch. I think it will become, I wouldn't say a cult movie because I think it is bigger than that. But I think it will stimulate and it will motivate people to come to New Zealand for a long time. (...) Is it ten years ago since The Piano was made? And there are still tourists to a beach north of Auckland. So I think it's going to last a long long time.

Recently growing numbers of tourism operators with The Lord of the Rings themed products indicate that film tourism providers needed time to realise the opportunities 
this film tourism offers. However, as always in business, latecomers are likely to miss out on benefits, for example when their product is not visible in time on the market for the season $2003 / 2004$ or even prior to this.

In the context of sustainability, social impacts on locals have also to be taken into account. An extreme case mentioned by Sterry (1998) is the small Pennine town of Holmfirth in which the popular series of Last of the Summer Wine was set. Sterry (1998: 368) examined that:

Holmfirth appears to have lost its own identity, to have been in a way devalued as it is mobbed by pilgrims searching and hoping for a glimpse of their favourite characters from the series, rather than simply enjoying the intrinsic beauty of the town.

The town centre is transformed into a kind of theme park with the familiar signs and buildings as portrayed in the series. Souvenir shops offer memorabilia and in a café, which acts as a setting in the series, tourists can get a certificate that proves that they have been there (Sterry 1998). Other village communities that provided film sets and experienced film tourism spin-off effects also endured negative impacts on the socio-cultural balance of the communities (for example Beeton 2001; O'Connor 2001).

Interestingly, there are varied statements received from locals in The Lord of the Rings film tourism destinations of Matamata and Queenstown. To date in Matamata locals are positive about film tourism, which boosts the local economy financially. Locals are benefiting which enables them to "[eat] out more and [take] previously unaffordable holidays" (Huffstutter 2003: B5). Secondly, the pride factor associated with locals' participation as extras in the films or their ability to say 'this is where I am from' and have people know, should not be undervalued.

Conversations with locals in Queenstown showed that they are not yet suffering from the flood of The Lord of the Rings filmic tourists, although their reaction was different than in the Matamata case. They find it hard to relate to the fascination of filmic tourists with "these mountains out there (...) I see them every day (...). These tourists get so obsessed with it." (Queenstown local, pers. comm., 29.08.03, Queenstown). This more moderate reaction is not surprising, due to Queenstown's strongly tourism-based economy, which has completely opposite pre-conditions to Matamata.

In regards to tourism planning, very little has been achieved so far due to local tourism bodies' financial restraints. This is almost a contradiction when looking at the strong promotion done by Tourism New Zealand. According to David Kennedy (2003), Destination Queenstown Chief Executive Officer, in Queenstown there is also 
no plan to create one tool for promoting The Lord of the Rings film sites, including all the companies that offer such themed tours. A tool like this would improve the situation of filmic tourists who visit the locations independently, as well as create one marketing tool for all The Lord of the Rings themed tours operators, which in return would decrease their promotional costs.

As the findings show, The Lord of the Rings film tourism destinations are diverse in their tourism infrastructural conditions. This must also be taken into account when planning for the future and in achieving sustainability.

The original idea of environmental sustainability prescribed "development that meets the needs of the present without compromising the ability of future generations to meet their own needs" (World Commission on Environment and Development 1987 cited in McManus 2000: 812). In the context of The Lord of the Rings, the environmental capacity of the former film locations is unquestionably an issue. This is because a number of the locations are in fragile environments, which experienced flocks of tourists after the release of the films. For example, the beach forest in Paradise, near Glenorchy, which is part of the Mount Aspiring National Park is experiencing an increase in visitor numbers, according to locals and tour guides of the Safari of the Rings. But how much tourism is sustainable and how much is not in these regions? When filming took place, filmmakers' intention was to leave only footprints but how about filmic tourists? Local policy makers should recognise these issues and integrate solutions in resource as well as tourism management plans.

When asking about the longitude of benefits caused by film tourism, operators and tourism officials often mentioned The Sound of Music filmed in 1965, which still attracts filmic tourists to Salzburg in Austria to experience the images portrayed in the film. Other examples such as Close Encounters of the Third Kind (1977), which was filmed in the Devil's Tower National Monument, Wyoming, or Field of Dreams (1989), a baseball field on a former cornfield in lowa, tell a similar but more dramatic story (Tooke and Baker 1996, Mitchell 1998 and Riley et al. 1998). These two examples experienced a tremendous growth in visitor numbers after the films were released and filmic tourists are still going to experience the locations (Riley et al. 1998).

The question is, how can benefits from film tourism be sustained? Certainly on one hand, it is the repeated viewing which brings the message to potential filmic tourists. This can be achieved, as in The Lord of the Rings, through the clever idea of releasing the trilogy over three years instead of simultaneously. Furthermore, DVD releases, extended DVD and video releases and, in future, occasional television broadcasting, will also extend the interest in the locations and the desire to visit them. 
This study is the first academic research concerned with landscape portrayal in The Lord of the Rings films and its implications for film tourism in New Zealand. Thus, it contributes and adds to the understanding of previous research on the representation of landscapes in film, as well as filmic tourists' experiences.

In The Lord of the Rings films, New Zealand's cultural landscapes were layered with the cultural landscape of mythical Middle-earth. Landscapes in the films were used as geography, metaphor and spectacle as part of the narrative to set the story.

The real New Zealand landscapes that remain after filming barely provide elements of the film portrayal due to film sets and computer generated images used in the films. This disjunction between the real and the hyper-real portrayed in the films then impacts on filmic tourists' experience and the sustainability of film tourism in New Zealand. The findings seem to confirm Mitchell's (1998) model by showing that the more perfect the representation of hyper-reality in the tours, the higher the satisfaction and thus the more enhanced the tourist's experience. This is particularly the case in the multi-day 'New Zealand as Middle-earth' experience within Red Carpet Tours.

Filmic tourists desire to step into the film set and to be part of the film through re-enacting film scenes; whether it be to stand on top of the hill where Edoras was filmed and act like Éowyn, or to dance like the hobbits under the party tree in Hobbiton. This confirms Aden et al.'s (1995) findings at a former film site on which filmic tourists form interpretive communities to produce and perform individualised texts when re-performing the action of the film (see chapter four, section 4.4.4).

When employing Riley and Van Doren's (1992: 269) three qualities that a film must have to create a potential for inducing tourism, "uniqueness, status or timely significance", to analyse the films of The Lord of the Rings it becomes clear that these films have, without a doubt, potential to induce tourism. This is already obvious.

The films of The Lord of the Rings are unique as it was long believed that Tolkien's work was "not translatable into a popular dramatic art", such as film (Reed 1984: 139). Furthermore, filming took place in one major project with at least three sets simultaneously operating over only 18 months of filming. The films were released in a unique strategy over three years, which has not been done before. Moreover, the films are strongly tied to the whole country, both through the films and tourism promotion. This sets The Lord of the Rings apart from other previous productions. 
The Lord of the Rings has a huge fan base even before the films were released, which is organised in a broad network mainly over the Internet. This could also be a disadvantage due to high expectations of the final film by these 'experts'. However, when examining the online fan networks, such as www.theonering.net and www.tolkienonline.com, it becomes clear that the community appreciates the visual portrayal of Tolkien's books by Jackson. In addition, the films appear as epic, both in the story and the filmmaking process.

The films were timed well, coinciding with a general interest in historical costume films, grounded particularly in societies such as the USA. In addition, the portrayal offers an escape from daily life, and moreover, the political situation when the first and the second films were released. The 'war on terrorism' marred the world after the September $11^{\text {th }} 2001$ attacks, as did the following war on Iraq. In this environment the films, which were dealing with friendship and a quest to rescue the world of evil forces, were released and could 'preach to the converted'.

Furthermore, the films are landscape dominated and the film promotion strongly emphasises New Zealand as the film location. This makes it easier for filmic tourists to trace the former film locations despite the fact that there are no connections to the author Tolkien or landscapes he might have imagined when writing the books.

The first two films of the trilogy were huge box office success. The Fellowship of the Ring reached US $\$ 862$ million in revenue. This places it at number seven in the top ten grossing films of all times. However, The Two Towers topped this result with US $\$ 889$ million, and is currently fifth position in the list of the most successful films (Tourism New Zealand 2003e).

This research has revealed that a myth has been created for the purpose of stimulating tourism. It is the myth tourist guides tell filmic tourists about the filming process which was assumed to be impossible. Furthermore, the unconventional and sometimes unorthodox production techniques are celebrated as examples of the "can do' mentality of New Zealanders. In particular, the work of the WETA departments (WETA Workshop and Digital) and their introduction of new techniques resulted in a kind of realism, even an art history, for every set, in order to make the landscapes of Middle-earth believable (Taylor 2003).

Previous research (for example Riley et al. 1998) has shown that the long-term benefit of filmic tourists' demands is hard to predict. Aspects such as filmic tourists' satisfaction, the number of tourists, the judgement of success by tourism operators, local impacts and environmental aspects have to be taken into account when questioning the sustainability of this newly developing film tourism in New Zealand. 
Local, or even the national tourism body, can improve independent filmic tourists' experiences by providing information material.

The Lord of the Rings films and their main visual icon New Zealand are presented as the embodiment of a myth. This is done in two ways: first, with the story of The Lord of the Rings as a mystical fairytale; second, with the myth of the challenging filmmaking process, which was for years thought to be impossible due to Tolkien's fantastical descriptive world. This is what makes filmic tourists' experiences in New Zealand unique as it is based on both the anecdotes about the filmmaking as well as the former film set experience.

\subsection{Film Tourism Management Recommendations}

It was discovered that filmic tourists on organised The Lord of the Rings former film location tours were generally very satisfied $(62.7 \%)$ with the tour experience. However, this research also identified improvements suggested by respondents. Acting on these suggestions would create a more satisfying experience, therefore potentially sustaining the benefits of The Lord of the Rings film tourism in New Zealand, particularly in regards to independent filmic tourists.

Recommendations are given for different levels of the tourism industry in New Zealand, ranging from Tourism New Zealand to local tourism bodies and The Lord of the Rings film tourism operators.

\section{Tourism New Zealand}

Tourism New Zealand has the role of developing, implementing and promoting New Zealand's tourism internationally. Since the release of the film trilogy this is done by strongly linking New Zealand to The Lord of the Rings. Tourism New Zealand is packaging and promoting the country as the Home of Middle-earth. However, when taking into account that the former film locations offer few features of the cultural landscapes of the Middle-earth portrayal as experienced while watching the films, more realism in the tourism promotion is appropriate and necessary. This means clear statements have to be made to inform potential filmic tourists that no sets, as seen in the films, remain.

A second recommendation, based on complaints by a number of respondents in the research, is the improvement of appropriate information material. This could be done by designing a former film location map (as successfully done by the British Tourism Authority), which combines information on New Zealand generally, the films, anecdotes about the filmmaking, main locations used for filming, and what tours are offered for filmic tourists with contact details. Clear and simple formatting would 
enable even first time visitors to experience the former film sites by themselves. The Lord of the Rings film map should be available in Visitor Information Centres on the main tourist route (Auckland-Rotorua-Wellington-Christchurch-Queenstown-Nelson) as well as at former film locations. Such a map could also combine marketing efforts by local tourism operators and thus decrease promotional costs for them, as they are in most cases, newly established tourism companies.

\section{Local tourism bodies}

Local Visitor Information Centres in former film locations should offer information on The Lord of the Rings themed tours offered and locations where filming took place. Furthermore, other sightseeing options should be mentioned to visitors to keep them longer in the town/region and, thus, increase tourist spending. Another recommendation is to establish better access to the sites, as well as signposts pointing out the exact position and camera angles of a particular scene.

The Queenstown region, particularly, due to the number of scenes portrayed there, could produce its own guide, giving filmic tourists an overview of what was filmed there, the location, what options are offered by film location tourism operators. as well as anecdotal stories about the filmmaking. Furthermore, signboards could be set up, which display the scenes of the films and highlight camera angles. This would make the landscapes more easily recognisable.

Wellington, as the second main centre for The Lord of the Rings film tourism, could design a similar guide integrating film sites in the region. In addition, the WETA workshop could be consulted to arrange monthly tours for interested filmic tourists to gain an opportunity to look behind the scenes of the filmmaking.

\section{Regional Councils/ Department of Conservation (DOC)}

Filming took place in some of the most remote and fragile environments in New Zealand. Prior to filming these areas did not, or only to a low degree, experience tourism. Therefore local Regional Councils and DOC offices need to consider the possible increase in visitor numbers and include these in their resource management planning to guarantee sustainability of these environments.

\section{The Lord of the Rings film tourism case study operators}

A general recommendation, not only for the particular case study operators, is to set up a knowledge base for tour guides within companies. Such a tool could then be used to refresh guides' knowledge about the filmmaking and other behind-thescenes anecdotes for filmic tourists on their tours. Furthermore, operators should aim 
to make it as clear as possible to tourists, such as in their pamphlets, that the sites do not provide sets as seen in the films.

\section{Rings Scenic Tours}

The case study operator Ring Scenic Tours in Matamata should continue negotiations with New Line Cinemas to get approval to rebuild, or at least to maintain, the holes. This is necessary to provide Hobbiton film set tours for future filmic tourists.

At the former film site, toilet facilities should be provided. The security and condition of the walkways at the site should be improved in a way that also allows disabled visitors to enter the area on a tour.

As a number of visitors indicated a desire to watch the Hobbiton scenes after the tour experience, a viewing facility could be set up once the screening rights have been negotiated with New Line Cinema. Moreover, the management could organise special theme events. For example, an annual celebration party could be held in style of the film portrayal where staff dress up, possibly tourists as well, and re-enact the party scene at the beginning of the first film. This could be done on Bilbo and Frodo's birthday, the $22^{\text {nd }}$ of September, each year.

However, as slightly more than half of respondents (54.7\%) did not see a need for any improvements, and would prefer to keep the former set as it is, changes should be moderate, not overdone resulting in a Disney-like theme park.

\section{Safari of the Rings}

The conditions of the former film sets in the Queenstown region visited on Safari of the Rings tours are slightly different to Matamata. No parts of the sets remain and the landscapes were digitally modified to a high degree in post-production. Also the areas visited are not the property of the company. The emphasis should be placed upon reawakening filmic tourists' memories of the film portrayal by, for example, using signboards that make it easier to recognise the landscapes as portrayed in the films.

The company could also establish a knowledge base for guides to refresh film and filmmaking facts. Furthermore, due to the variations in information given by guides, a script could be written which includes information on the region, information about the filming process, as well as anecdotes relating to the main actors.

In addition, Nomad Safari should consider the use of microphones in the jeeps, particularly on fully booked tours, to guarantee that the information given by guides reaches all passengers. 


\section{Red Carpet Tours}

As the researcher did not personally participate on a Red Carpet Tour, recommendations can only be based on suggestions made by Red Carpet Tour participants in the survey.

A recommendation for the Red Carpet Tours management would be to liaise with the WETA workshops in Wellington and arrange visitation opportunities as part of the tours.

\subsection{Suggestions for Further Research}

There is varied and numerous opportunities for further research on this topic. Economic post-production impacts of The Lord of the Rings on New Zealand in general could be analysed. A broader study could also be undertaken, analysing The Lord of the Rings film tourism in New Zealand as a whole, or the impact on communities like Matamata, Wellington or Queenstown. This could also integrate impacts on the social-cultural balance and everyday life in former film location communities. In particular, Matamata is an interesting study area in this regard as it was a formerly non-tourism destination that is now experiencing tourist waves.

The Lord of the Rings myth creation for the purpose of tourism, as well as economic promotion of the whole country, could be investigated in more detail. This could also integrate the impacts of this myth, or myth creation, on society in New Zealand.

Another potential area of study is analysing how the tourism industry, as well as policy makers, react to both positive and negative spin-off effects of the films. Furthermore, qualitative approaches could be employed in a study to reveal the impact of the films on visitors' perception of New Zealand. A final research recommendation would be to apply the findings and recommendations of this study to other film destinations overseas. 


\section{Bibliography}

A

Adams, P. (1992) Television as Gathering Place. In Annals of the Association of American Geographers. Vol. 82. No. 1. pp.117-135.

Aden, R.C., Rahoi, R.L. and Beck, C.S (1995) "Dreams are born on places like this": The process of interpretive community formation at the Field of Dreams site. In Communication Quarterly. University Park: Fall 1995. Vol. 43. Issue 4. pp. 368-403.

Air Fiordland (2003) Wings over the Rings. Pamphlet. Te Anau.

Air New Zealand (2003) Media Releases [Online].

Available:http://www.airnz.co.nz/aboutus/mediacentre/pressreleases/default.htm. [23.03.2003].

Aitken, S. C. (1991) A transactional geography of the image-event: the films of Scottish director Bill Forsyth. In Transactions: Institute of British Geographers. Vol.16. No. 1. pp.105-118.

Aitken, S. C. and Zonn, L.E. (1993) Weir(d) Sex: Representation of Gender-Environment Relations in Peter Weir's Picnic at Hanging Rock and Gallipoli. In Environment and Planning D: Society and Space. Vol.11. pp.191-212.

Aitken, S. C. and Zonn, L.E. (eds) (1994a) Place, Power, Situation, and Spectacle. A Geography of Film. Rowan \& Littlefield Publishers Inc. Totowa.

Aitken, S. C. and Zonn, L.E. (1994b) Re-Presenting the Place Pastiche. In Aitken , S. C. and Zonn, L.E. (eds) Place, Power, Situation, and Spectacle. A Geography of Film. Rowan \& Littlefield Publishers Inc. Totowa. pp. 3-26.

Aitken, S. C. (1997) Analysis of Texts: Armchair Theory and Couch-Potato Geography. In Flowerdew, R. and Martin, D. (eds) Methods in Human Geography. Longman. London. pp. 197-212.

B

Bakhtin, M. (1981) The Dialogic Imagination: Four Essays, translated by Caryl Emerson and Michael Holquist. University of Texas Press. Austin.

Barnes, T.J. (2000) Social construction. In Johnston, R.J., Gregory, D. Pratt, G., and Watts, M. (eds) $4^{\text {th }}$ ed. The Dictionary of Human Geography. Blackwell Publishers Ltd. Oxford. pp. 747-748.

Barnes, T. J. and Duncan, J.S. (eds) (1992) Writing Worlds. Discourse, text \& metaphor in the representation of landscape. Routledge. London.

Baudrillard, J. (1983) Simulations. Translated by Foss, P., Patton, P. and Beitchman, P. New York: Semiotext[e]. 
Beattie, S. (1998) Jackson Lands \$264m Film Deal. In Evening Post. 25 August 1998. p. 1.

Beeton, S. (2001) Smiling for the camera: The influence of film audience on a budget tourism destination. In Tourism, Culture \& Communication, Vol. 3. pp. 15-25.

Bell, C. and Lyall, J. (2002) The Accelerated Sublime. Thrill-Seeking Heroes in the Commodified Landscape. In Coleman, S. and Crang, M. (eds) Tourism Between Place and Performance. Berghahn Books. New York. pp. 21-37.

Boorstin, D. (1972) The Image: A Guide to Pseudo-Events in America. Atheneum. New York.

Brodie, I. (2002) The Lord of the Rings Location Guidebook. HarperCollins Publishers. Auckland.

Brodie, I. (2003) $2^{\text {nd }}$ ed. The Lord of the Rings Location Guidebook. HarperCollins Publishers. Auckland.

Brook, R. (2001) Welcome to Middle Earth.Telegraph.co.uk [Online]. Available:

http://www.portal.telegraph.co.uk/core/Content/displayPrintable.jhtml;\$sessionid\$M3ZJ. html. [12.02.2003].

Brooker-Gross, S. R. (1985) The Changing Concept of Place in the News. In Burgess, J. and Gold, J.R. (eds) Geography The Media \& Popular Culture. Croom Helm Ltd. London. pp. 63-85.

Burgess, J. and Gold, J.R. (eds) (1985) Geography The Media \& Popular Culture. Croom Helm Ltd. London.

Burgess, J. (1985) News from Nowhere: The Press, the Riots and the Myth of the Inner City. In Burgess, J. and Gold, J.R. (eds) Geography The Media \& Popular Culture. Croom Helm Ltd. London. pp. 192-228.

Burgees, J. (1987) Landscape in the Living Room: Television and Landscape Research. In Landscape Research. Vol. 12. No.3. pp. 1-7.

Burns, R.B. (1998) $3^{\text {rd }}$ ed. Introduction to Research Methods. Addison Wesley Longman Australia Pty Limited. South Melbourne.

Butler, R. (1990) The Influence of Media in shaping International Tourism Patterns. In Tourism Recreation Research. Vol. 15. No. 2 pp. 46-55.

C

Cairns, B. and Martin, H. (1994) Shadows on the Wall. A study on seven New Zealand feature films. Longman Paul Ltd. Auckland.

Cardy, T. (2003) Rings locator. In The Dominion Post. Wellington. 12.11.2003. p. B7.

Carney, G. (ed) (1994) The sounds of people and places: a geography of American folk and popular music. $3^{\text {rd }}$ ed. Rowman and Littlefield Lanham.

Chapple, G. (1995) Gone, Not Forgotten. In Listener. 25. November 1995. Vol. 151. No. 2901. p. 16. 
Clark, H. (2001) Maximising spin-offs from The Lord of The Rings

Questions and answers. New Zealand government announcement. [Online]. Available: http://www.executive.govt.nz/minister/clark/lor/qa.htm [15.11.03].

Clarke, A. (2001) Research and the policy-making process. In Gilbert, N. (ed) $2^{\text {nd }}$ ed. Researching Social Life. Sage Publications. London. pp. 28-42.

Cohen, E. (1988) Authenticity and Commoditization in Tourism. In Annals of Tourism Research. Vol. 15. pp. 371-386.

Cohen, E. (1996) A Phenomenology of Tourist Experiences. In Apostolopoulos, Y., Leivadi, S. and Yiannakis, A. (eds) The Sociology of Tourism. Theoretical and empirical investigations. Routledge. London.

Cohen, S. and Taylor, L. (1976) Escape Attempts: The Theory and Practice of Resistance in Everyday Life. Penguin. Harmondsworth.

Conrich, I. and Woods, D. (2000) Introduction. In Conrich, I. and Woods, D. (eds) New Zealand- A Pastoral Paradise? Studies in New Zealand Culture No. 6. Kakapo Books. Clifton Village. pp. 8-10.

Cooper, C., Fletcher, J., Wanhill, S., Gilbert, D. and Stepherd, R. (1998) $2^{\text {nd }}$ ed. Tourism. Principles and Practice. Longman Limited. Harlow. pp. 278-79.

Corrigan, T. (1998) $3^{\text {rd }}$ ed. A Short Guide to Writing about Film. Longman. New York.

Cosgrove, D. (1984) Social Formation and Symbolic Landscape. Croom Helm. London.

Cosgrove, D. and Daniels, S. (1988) The Iconography of Landscape; Essays on the symbolic representation, design and use of past environments. Cambridge University Press. Cambridge.

Cosgrove, D. (1989) Geography is Everywhere: Culture and Symbolism in Human Landscapes. In Gregory, D. and Walford, R. (eds) Horizons in Human Geography. Macmillan Education Ltd. London. pp. 118-135.

Cosgrove, D. (1994a) Cultural Geography. In Johnston, R. J., Gregory, D. and Smith, D.M. (eds) The Dictionary of Human Geography. $3^{\text {rd }}$ ed. Blackwell Ltd. Oxford. pp. 111-113.

Cosgrove, D. (1994b) Culture. In Johnston, R. J., Gregory, D. and Smith, D.M. (eds) The Dictionary of Human Geography. $3^{\text {rd }}$ ed. Blackwell Ltd. Oxford. pp. 116-117.

Cosgrove, D. (2000) Iconography. In Johnston, R. J., Gregory, D. and Smith, D.M. (eds) The Dictionary of Human Geography. $4^{\text {th }}$ ed. Blackwell Ltd. Oxford. p. 366.

Couldry, N. (1998) The view from the inside the 'simulacrum': visitors' tales from the set of Coronation Street. In Leisure Studies. Vol. 17. pp. 94-107.

Coventry, N. (2003) TRENZ report-2. In Inside Tourism. Issue 455. Taumarunui.

Crompton, J.L. (1979) Motivations for Pleasure Vacation. In Annals of Tourism Research. Vol. 6, pp. 408-424.

Croy, G. and Walker, R. (2003) Imaging and Branding the Destination. In Hall, C.M. (ed) Introduction to Tourism: Dimensions and Issues. 4th ed. Hospitality Press. Frenchs Forest. pp.105-125.

Curtis, J. (1976) Woody Guthrie and the Dust Bowl. In Places. Vol.3. pp. 12-18. 
Dart River Safaris (2003) Dart River Safaris. Pamphlet. Glenorchy.

Dart Stables (2003) Horse Riding Dart Stables. Pamphlet. Glenorchy.

Dart Wilderness Adventure (2003) Jetboat the Dart River. Pamphlet. Glenorchy.

Deer Park Scenic Tours (2003) Private Access. [Online] Available: http://www.thedeerpark.co.nz/private_access.html [10.10.03].

Denzin, N. (1991) Images of Postmodern Society: Social Theory and Contemporary Society. Sage Publications. Newbury Park.

Duncan, J. and Duncan, N. (1988) (Re) reading the landscape. In Environment and Planning D: Society and Space. Vol.6. pp.117-126.

Duncan, J. (1990) The City as Text: The politics of landscape interpretation in the Kandyan Kingdom. Cambridge University Press. Cambridge.

Duncan, J. and Gregory, D. (eds) (1999) Writes of Passage. Reading travel writing. Routledge. London.

Duriez, C. (2001) Tolkien and The Lord of the Rings. A guide to Middle-earth. Philip Garside. Publishing Ltd. Wellington.

$E$

Eco, U. (1986) Travels in Hyperreality. Essays. Translated from the Italian by Weaver, W. Harcourt Brace \& Company. San Diego.

Ellis, J. (1991) Visible Fictions. Cinema: television: video. Routledge. London.

Errigo, A. (2003) The Rough Guide to The Lord of the Rings. Penguin Books Ltd. London.

$\mathrm{F}$

Fernside (2003) Tariffs and Bookings [Online]. Available: http://www.fernside.co.nz/tariffsand.html [22.09.03].

Film New Zealand (1999) The Production Guide to the World in One Country. Film New Zealand. Wellington.

Film New Zealand (2001) filmNZnews "the world in one country". The official newsletter of Film New Zealand. June 2001. Vol. 1. Issue 2.

Film New Zealand (2003) New Zealand Home of Middle-earth [Online]. Available: http://www.filmnz.com/middleearth/locations/index.html [16.12.03].

Fitzpartrick, J., Secrist, J. and Wright, D.J. (1998) Secrets for a successful dissertation. Sage Publications. London.

Ford, L. (1971) Geographic factors in the origin, evolution and diffusion of rock and roll music. In Journal of Geography. Vol. 70. pp. 455- 464.

Ford, L. and Henderson, F. (1974) The Image of Place in American Popular Music. In Places. Vol. 1 no.1. pp. 31-37. 
Foucault, M. (1972) The Archaeology of Knowledge and the Discourse on Language. Tavistock Publishing. New York.

Foucault, M. (1977) Discipline and Punish: The Birth of the Prison. Translated by A. Sheridan. Allen Lane. London.

\section{G}

Gill, W. (1993) Region, agency and popular music: the northwest sound, 1958- 66. In Canadian Geographer. Vol. 37. No. 2. pp. 120- 131.

Glenorchy Air (2003) Trilogytrail. Pamphlet. Queenstown.

Gold, J., Haigh, M. and Jenkins, A. (1993) Ways of Seeing: Exploring Media Landscapes Through a Field-Based Simulation. In Journal of Geography. Vol. 92. No..5. pp. 213216.

Goldberg, M. (2000) Some suggestions on "how to read a film". [Online]. Available: http://www.bothell.washington.edu/faculty/mgoldberg/students/readafilm.htm. [08.06.2003].

Gould, P. and Lyew-Ayee, A. (1985) Television in the Third World: A High Wind on Jamaica. In Burgess, J. and Gold, J.R. (eds) Geography The Media \& Popular Culture. Croom Helm Ltd. London. pp. 33-62.

$\mathrm{H}$

Hall, C. M. and Kearsley, G. (2001) Tourism in New Zealand. An introduction. Oxford University Press. Oxford.

Hall, S. (ed) (2002) Representation: Cultural Representations and Signifying Practices. Culture, Media and Identities. Sage Publications. London.

Herbert, D.T. (1996) Artistic and literary places in France as tourist attractions. In Tourism Management. Vol.17.No.2. pp. 77-85.

Herendeen, W. H. (1986) From Landscape to Literature. The River and the Myth of Geography. Duquesne University Press. Pittsburgh.

Hickethier, K. (1993) Film- und Fernsehanalyse. J.B. Metzlerische Verlagsbuchhandlung. Stuttgart.

Higson, A. (1984) Space, Place, Spectacle: Landscape and Townscape in the "Kitchen Sink" Film. In Incorporating Screen Education. Vol. 25. pp. 2-21.

Higson, A. (1987) The Landscape of Television. In Landscape Research. Vol.12. No. 3. pp.8-13.

Hilty, A. (1996) Tourism and Literary Connection: How to Manage the Image Created. In Robinson, M., Evans, N. and Callaghan, P. (eds.) Culture as the Tourist Product. Centre of Travel and Tourism in association with Business Education Publishers Ltd. Sunderland. pp.185- 198. 
Holloway, J.C. (2002) $6^{\text {th }}$ ed. Business of Tourism. Pearson Education. New York.

Hopkins, J. (1994) A Mapping of Cinematic Places: Icons, Ideology, and the Power of (Mis)representation. In Aitken , S. C. and Zonn, L.E. (eds) Place, Power, Situation, and Spectacle. A Geography of Film. Rowan \& Littlefield Publishers Inc. Totowa. pp. 47-68.

Huffstutter, P.J. (2003) The Frodo Economy. In The Dominion Post. Wellington. 31.10.2003. p. B 5.

Imrie, D. (2004) David Imrie Figure Painting. Lord of the Rings. [Online] Available: http://www.davidimrie.pwp.blueyonder.co.uk/lotr.htm [10.01.2004].

Iso-Ahola, S.E. (1982) Towards a Social Psychological Theory of Tourism Motivations: A Rejoinder. In Annals of Tourism Research. Vol. 9, pp. 256-262.

Jackson, P. (1995) Maps of Meaning. Routledge. London.

Jackson, P. (2001) Making sense of qualitative data. In Limb, M. and Dwyer, C. (eds) Qualitative Methodologies for Geographers. Issues and Debates. Arnold. London. pp. 199-214.

Jarvis, B. (1985) The Truth is only known by Guttersnipes. In Burgess, J. and Gold, J.R. (eds) Geography The Media \& Popular Culture. Croom Helm Ltd. London. pp. 96-122.

Jay, M. (1986) In the empire of the gaze: Foucault and the denigration of vision in the twentieth century French thought. In Hoy, D.C. (ed) Foucault: A critical reader. Basil Blackwell. New York. pp. 175- 204.

Jenkins, A. (1990) A View of Contemporary China: A Production Study of a Documentary Film. In Zonn, L. (ed) Place Images in Media: portrayal, experience and meaning. Rowan and Littlefield Publishers. Savage. pp. 207-229.

Johnson, A.-M. (2003) Rings magic casts a spell on visitors. In The Dominion Post. Wellington. 05.11.2003. p. A10.

Johnson, A.-M. (2004) Tourist tempted by a touch of class. In The Dominion Post. Wellington. 07.02.2004. p. A12.

Jones, S. (1999) Projecting a nation. New Zealand film and its perception in Germany. In Conrich, I. (ed) Studies in New Zealand Culture. No.3. pp. 1-28.

K

Kennedy, C. (1994) The Myth of Heroism: Man and Desert in Laurence of Arabia. In Aitken , S. C. and Zonn, L.E. (eds) (1994a) Place, Power, Situation, and Spectacle. A Geography of Film. Rowan \& Littlefield Publishers Inc. Totowa. pp. 161-182. 
Kennedy, C. and Lukinbeal, C. (1997) Towards a holistic approach to geographic research on film. In Progress in Human Geography. Vol.21. No.1. pp. 33-50.

Kitchin, R. and Tate, N. J. (2000) Conducting Research in Human Geography. Theory, Methodology and Practice. Prentice Hall. Harlow.

Kim, H. and Richardson, S.L. (2003) Motion pictures impacts on destination images. In Annals of Tourism Research. Vol.30. No.1 pp. 216-237.

Kozak, M. (2001) A Critical Review of Approaches to Measure Satisfaction with Tourist Destinations. In Mazanec, J.A., Crouch, G.I., Brent Ritchie, J.R. and Woodside, A.G. (eds) Consumer Psychology of Tourism, Hospitality and Leisure. Volume 2. CAB International. Oxon. pp. 303-320.

LeHéron, E.J. (2002) Translating Place: landscape, film and film landscape. Unpublished thesis in partial fulfilment of the requirements for the degree of Master of arts in Geography. University of Auckland. Auckland.

Leyshon, A., Matless, D. and Revill, G. (1995) The place of music. In Transactions of the Institute of British Geographers. Vol. 20. No. 4. pp. 423- 433.

Lickorish, L. (1991) Developing Tourism Destinations. Longman Ltd. London.

Lonely Planet $(2000) 10^{\text {th }}$ ed. New Zealand. Lonely Planet Publications Pty Ltd. Footscray.

Lord of the Rings Net (2004a) Rivendell [Online]. Available: http://www.lordoftherings.net/legend/gallery/ [07.01.2004].

Lord of the Rings Net (2004b) Edoras. [Online] Available: http://www.lordoftherings.net/index_explore_edoras_set.html [10.02.2004].

Lord of the Rings Net (2004c) The Dead Marshes. [Online] Available: http://www.lordoftherings.net/index_explore_deadmarsh.html [10.02.2004].

Lord of the Rings Net (2004d) Fangorn Forest. [Online] Available: http://www.lordoftherings.net/index_explore_fangorntaylor.html [10.02.2004].

Lukinbeal, C. (1995) A Geography in Film, A Geography of Film. Unpublished Masters Thesis. California State University. Hayward.

\section{M}

MacCannell, D. (1976) The Tourist. A new theory of the leisure class. Schocken Books. New York.

Mallory, W. and Simpson-Housley, P. (eds) (1987) Geography and Literature: a meeting of disciplines. Syracuse University Press. Syracuse.

Mannel, R.C. and Iso-Ahola, S.E. (1987) Psychological Nature of Leisure and Tourism Experience. In Annals of Tourism Research. Vol. 14. pp. 314-331.

Mannell, R.C. (1989) Leisure Satisfaction. In Jackson, E.L. and Burton, T.L. (eds) 
Understanding Leisure and Recreation: Mapping the Past, Charting the Future. Venture Publishing Inc. Philadelphia.

Mansvelt, J. (1999) Consuming Spaces. In Le Heron, R., Murphy, L., Forer, P. and Goldstone, M. (eds) Explorations in Human Geography: Encountering Places. Oxford University Press. Oxford. pp.318-344.

Manvell, R. (1956) Geography and the documentary film. In The Geographical Magazine. Vol. 29. pp. 491-500.

Maproom (2003) Data NZ. [Online]. Available: http://www.maproom.psu.edu/dcw/.[10.11.03].

McDowell, L. (1994) The Transformation of Cultural Geography. In Gregory, D., Martin, R. and Smith, G. (eds) Human Geography. Society, Space and Social Science. Macmillan Press Ltd. London. pp. 146- 173.

McManus, P. (2000) Sustainable Development. In Johnston, J. et al. (eds) The Dictionary of Human Geography. $4^{\text {th }}$ ed. Blackwell Publishers Ltd. Oxford. pp. 812-816.

McNamara, M. (2001) Lord of literature. In Tolkien Online [Online] Available: http://www.tolkienonline.com/docs/4821.html [15.01.03].

Meethan, K. (2001) Tourism in Global Society. Place, Culture, Consumption. Palgrave. New York.

Middleton, V.T.C. and Clarke, J. (2001) $3^{\text {rd }}$ ed. Marketing in Travel and Tourism. Butterworth Heinemann. Oxford.

Mitchell, R. (1998) Field of Dreams. An experiential perspective on the influence of major motion pictures on perceptions of destination and tourist experiences. Unpublished paper.

Morgan, N. and Pritchard, A. (1998) Tourism Promotion and Power; Creating Images, Creating Identities. Chichester. New York.

\section{$\mathrm{N}$}

National Geographic (2001) Lord of the Rings: Magic for New Zealand Tourism? [Online]. Available: http://www.nationalgeographic.com/news/2001/12/1218_wirenewzearing.html. [12.02.2003].

Newby, P. T. (1981) Literature and the Fashioning of Tourist Taste. In Pocock, D.C.D. (ed) Humanistic Geography and Literature. Essays on the Experience of Place. Croom Helm Ltd. London. pp. 130-141.

New Zealand Institute of Economic Research (2002) Scoping the Lasting Effects of the Lord of the Rings: Report to The New Zealand Film Commission. New Zealand Institute of Economic Research. Wellington.

Nicholson, D. (1991) Images of Reality. In Geographical Magazine. Vol. LXIII. No. 4. pp. 2832. 
O'Brien, M. (2003) Ghost in the Machine. The Dual layers of Fictional Reality. [Online]. Available: http://www.crossoveruniverse.com/layers.html [25.09.03].

O'Connor, N. (2001) The Effect Of Television Induced Tourism on the Village of Avoca, Country Wicklow. Presented at the $10^{\text {th }}$ Atlas Annual Conference: Innovation, Tourism and Regional Development. 4-5 October 2001. Dublin, Ireland.

O'Hehir, A. (2002) The Lord of the Rings The Fellowship of the Ring. In Sight and Sound. Vol. 12. No. 2. February 2002. pp. 49-52.

\section{P}

Page, S.J, Brunt, P., Busby, G. and Connel, J. (2001) Tourism: A Modern Synthesis. Thomson Learning. London.

Pizam, A., Neumann, Y. and Reichel, A. (1978) Dimensions of tourist satisfaction area. In Annals of Tourism Research. Vol. 5. pp. 314-322.

Plimoth Plantation (2004) What to see \& do [Online] Available: http://www.plimoth.org/visit/what/1627.asp. [02.01.04].

Pocock, D.C.D. (ed) (1981) Humanistic Geography and Literature. Croom Helm. London.

Pocock, D.C.D. (1992) Catherine Cookson Country: Tourist Expectation and Experience. In Geography. Vol. 77. pp. 236-243.

Porteous, J.D. (1975) A Preliminary landscape Analysis of Middle-Earth during its Third Age. In Landscape. Vol. 19. pp. 33-38.

Porteous, J.D. (1990) Landscapes of the Mind. Worlds of sense and metaphor. University of Toronto Press. Toronto.

Positively Wellington Tourism (2003) The Lord of the Rings Locations Itinerary. [Online] Available: $\quad$ http://www.wellingtonnz.com/SightsAndActivities/Lordoftherings.htm [11.11.03].

Potter, W.J. (1996) An Analysis of Thinking and Research about Qualitative Methods. Lawrence Erlbaum Associates, Inc. Publishers. Mahwah.

Prince, S. (2001) $2^{\text {nd }}$ ed. Movies and Meaning. An introduction to film. Allyn \& Bacon. Needham Heights.

Pringle, T. (1988) The privation of history: Landseer, Victoria and the Highland myth. In Cosgrove, D. and Daniels, S. (eds) The Iconography of Landscape: essays on the symbolic representation, design and use of past environments. Cambridge University Press. Cambridge. pp. 142- 160.

Q

Queenstown Lakes District Office (2003) Queenstown Lakes District Film. [Online]. 
Available: http://www.filmqueenstown.com/default.asp [12.12.03].

Quintessential Lord of the Rings Movie Shots (2003) Four hobbits hiding from the Black Rider. [Online] Available:

http://www.quintessentialwebsites.com/lordoftherings/movieshots/Book1_Chapter03.ht $\mathrm{m}$ [11.12.2003].

$\mathrm{R}$

Red Carpet Tours (2003a) Lord of the Rings - Visit Middle-earth with Red Carpet Tours. [Online] Available: http://www.redcarpet-tours.com/index.cfm [08.10.03].

Red Carpet Tours (2003b) Tour options. [Online]. Available: http://www.redcarpettours.com/itinerary.cfm [08.10.03].

Reed, A.K. (1984) The Greatest Adventure is What Lies Ahead: Problems in Media and Mythodology- An Analysis of the Rankin/ Bass Production of Tolkien's The Hobbit. In Journal of Popular Culture. No. 4. pp. 138-146.

Riley, R. and Van Doren, C.S. (1992) Movies as tourism promotion: a 'pull' factor in a 'push' location. In Tourism Management. Vol. 13. No.3. pp. 267-274.

Riley, R., Baker, D. and Van Doren, C.S. (1998) Movie induced tourism. In Annals of Tourism Research. Vol.25, No.4.pp. 919-935.

Rings Scenic Tours Ltd. (2003) Official Tour Guide. Matamata.

Robertson, I. and Richards, P. (2003) Introduction. In Robertson, I. and Richards, P. (eds) Studying Cultural Landscapes. Arnold. London. pp. 1-18

Rojek, C. (1990) Baudrillard and leisure. In Leisure Studies. Vol.9. pp. 7-20.

Rojek, C. (1993) Ways of Escape. Modern transformations in leisure and travel. Macmillan Press Ltd. London.

Rose, G. (1994) The cultural politics of place: local representation and oppositional discourse in two films. In Transactions: Institute of British Geographers. Vol. 19. No. 1. pp. 46-60.

Rose, G. (2001) Visual Methodologies. An introduction to the interpretation of visual material. Sage Publications. London.

Ryan, C. (1995) Researching Tourist Satisfaction. Issues, Concepts, Problems. Routledge. London.

Ryan, C. (1997) The Tourist Experience. Continuum. London.

Ryan, C. (2002) $2^{\text {nd }}$ ed. The Tourist Experience. Continuum. London.

S

Sack, R. (1992) Place, Modernity, and the Consumer's World. John Hopkins University Press. Baltimore.

Safari of the Rings (2003) Safari of the Rings. Pamphlet. Queenstown.

Sauer, C. (1925) The Morphology of Landscape. University of California Publications in 
Geography. Vol. 2. pp.19-54.

Schmidhauser, H. (1989) Tourist needs and motivations. In Witt, S.F. and Moutinho, L. (eds) Tourism Marketing and Management. Prentice-Hall. Hemel Hempstead.

Schofield, P. (1996) Cinematographic images of a city. Alternative heritage tourism in Manchester. In Tourism Management. Vol.17. No.5. pp. 330-340.

Scottish Tourist Board (2003) National Wallace Monument [Online]

Available:

http://search.visitscotland.com/sitemakescotland.asp?userid=DIFRPUMYPL\&executep age=ProviderInfo/VSTproviderpage. asp\&providerid=3128429\&survivallevel=2\&templat eextension=VST\&sortorder $=$ [02.01.04].

Seamon, D. (1990) Awareness and reunion: a phenomenology of the person-world relationship as portrayed in the New York photographs of André Kertész. In Zonn, L.E. (ed) Place Images in the Media: portrayal, experience and meaning. Rowman and Littlefield. Savage. pp. 31- 62.

Selwyn, T. (1996) Introduction. In Selwyn, T. (ed) The Tourist Image. Myths and Myth Making in Tourism. John Wiley \& Son. Chichester.

Shaw, G. and Williams, A.M. (2002) $2^{\text {nd }}$ ed. Critical Issues in Tourism. A geographical perspective. Blackwell Publishers. Oxford.

Shurmer-Smith, P. and Hannam, K. (1994) Worlds of Desire, Realms of Power. A cultural geography. Edward Arnold. London

Sibley, B. (2002) The Lord of the Rings: The making of the trilogy. HarperCollins. London.

Singh, K. (2003) Film-Induced Tourism: Motivations of Visitors to the Hobbiton Movie Set as Featured in The Lord of the Rings. Unpublished Thesis submitted in partial fulfilment for the degree of Bachelor of Business (Tourism and Hospitality) LaTrobe University. Melbourne.

Squire, S J. (1996) Literary Tourism and Sustainable Tourism: Promoting 'Anne of Green Gables' in Prince Edward Island. In Journal of Sustainable Tourism. Vol.4, No. 3. pp. 119-134.

Statistics New Zealand (2000) New Zealand official Year book. Wellington. p.4.

Statistics New Zealand (2001) 2001 Census: Ethnic Groups. [Online]. Available: http://www.stats.govt.nz/domino/external/pasfull/pasfull.nsf/7cf46ae26dcb6800cc256a6 2000a2248/4c2567ef00247c6acc256bf9000ef41b?OpenDocument [30.01.04].

Sterry, P. (1998) Serial soap addiction. From screen viewing to pilgrimage. In Fladmark, J.M. (ed) In Search of Heritage as Pilgrim or Tourists? Downhead Publishing Limited. Shaftsbury. pp. 363-373.

Stewart, M. (1997) The Impact of films in the Sterling Area. Scottish Tourist Board Research Newsletter.

Suvantola, J. (2002) Tourist's Experience of Place. Ashgate Publishing Ltd. Aldershot. 
Taylor, J. (1998) Consuming Identity: Modernity and Tourism in New Zealand. Research in Anthropology \& Linguistics. Number 2. Department of Anthropology. University of Auckland. Auckland.

Taylor, R. (2003) Reaching the Grey Havens. Seminar at Victoria University of Wellington. 22.10.03.

Te Papa (2002) The Lord of the Rings Motion Picture Trilogy- The Exhibition [Online]. Available: http://www.tepapa.govt.nz/rings/overview.htm. [10.04.2003].

The Dominion Post (2003a) 'Where can I find a hobbit?' In The Dominion Post. 10.11.2003. [Online] Available: http://www.stuff.co.nz/stuff/0,2106,2720866a2202,00.html [12.12.03].

The Dominion Post (2003b) Rings Locator. In The Dominion Post. 12.11.2003. p. B7.

The Dominion Post (2004) Spotlight falls on New Zealand. In The Dominion Post. 03.03.2004. p. A1.

TNT Magazine New Zealand (2002) Rings a bell. Vol. April - May 2002. Issue 35. pp. 12-13.

Tolkien, J.R.R. (1994) The Lord of the Rings. Houghton Mifflin Company. Boston.

Tolkien Online (2004) I am a women, hear me think. [Online]. Available: http://www.tolkienonline.com/docs/14941.html [30.01.04].

Tooke, N. and Baker, M. (1996) Seeing is believing: the effect of film on visitor numbers to screened locations. In Tourism Management. Vol.17.No.2. pp. 87- 94.

Tourism New Zealand (2001) New Zealand Film Locations attract global audience. [Online]. Available: http://media.purenz.com//index.cfm/purenz_page/75BC2267-88F3-44A1BO5B-OAA2955B5490/context/print.html. [12.03.2003].

Tourism New Zealand (2002a) Tourism New Zealand Annual Report 2001-2002.[Online].

Available: http://www.tourisminfo.co.nz/cir_pub/annual_report/ceos_report.html. [23.09.2003].

Tourism New Zealand (2002b) Airline to Middle-earth Unveils Tourism's Biggest Flying Billboard [Online]. Available:

http:// media.purenz.com//index.cfm/purenz_page/BDF72693-A704-432E-9FA3C3BF398B6711/context/print/page_id/9827/topic/1518.html. [23.03.2003].

Tourism New Zealand (2002c) Tourism News September 2002. Wellington.

Tourism New Zealand (2003a) Tourism News November 2003. Wellington.

Tourism New Zealand (2003b) Tourism News January 2003. Wellington.

Tourism New Zealand (2003c) Featured Driving Routes [Online]. Available: http://www.newzealand.com/index.cfm/purenz_page/01D07FC2-C58B4AED-A653-0DD8FCCCAC16.html [05.05.2003].

Tourism New Zealand (2003d) Tourism News May 2003. Wellington.

Tourism New Zealand (2003e) New Zealand Home of Middle Earth [Online]. Available: http://travel.newzealand.com/homeofmiddleearth/ [06.11.03]. 
Tourism New Zealand (2003f) Lord of the Rings Market Research Summary Report. Wellington.

Tourism New Zealand (2003g) International Visitor Survey [Online] Available: http://www.tourisminfo.govt.nz/cir_randd/index.cfm?fuseaction=Survey\&subaction=Nati onalOnly\&item=DisplayReport [25.10.03].

Tourism New Zealand (2004) Best Supporting Country in a Motion Picture- Yet Again! [Online] Available:

http://www.tourisminfo.govt.nz/cir_news/index.cfm?fuseaction=newscentre\&subaction= news\&article_id=595 [12.03.04].

Tourism Research Council New Zealand (2003a) Arrival by country of origin monthly [Online] Available:

http://www.trcnz.govt.nz/Surveys/International+Visitor+Arrivals/Data+and+Analysis/Tabl e-Arrivals-by-Country-of-Origin-Monthly.htm [04.11.03].

Tourism Research Council New Zealand (2003b) Total arrival by gender and age in 2003 [Online] Available:

http://www.trcnz.govt.nz/Surveys/International+Visitor+Arrivals/Data+and+Analysis/Tabl e-Total-Arrivals-by-Gender-and-Age-Annual.htm [24.02.04].

Tourism Research Council New Zealand (2003b) International Visitor Survey Age, Gender, Origin \& Purpose. Year ended December 2002 [Online].

Available:

http://www.trcnz.govt.nz/Surveys/International+Visitor+Survey/Data+and+Analysis/Tabl e-Age-Gender-Origin-Purpose.htm [15.10.03].

Tourism Waikato (2004) Waikato...where the grass is greener. [Online]. Available: http://www.waikatonz.co.nz/. [01.03.04].

Tuan, Y.-F. (1978) Literature and Geography: Implications for Geographical Research. In Ley, D. and Samuels, M.S. (eds) Humanistic Geography. Prospects and Problems. Maaroufa Press. Chicago. pp. 194- 206.

Tuan, Y.-F. (1990) Realism and Fantasy in Art, History, and Geography. In Annals of the Association of American Geographers. Vol. 80. No. 3. pp. 435-446.

Turner, G. (1988) Film as Social Practice. Studies in Communication. Routledge. London.

\section{U}

Urry, J. (1990) The Tourist Gaze. Sage. London

Urry, J. (2002) $2^{\text {nd }}$ ed. The Tourist Gaze. Sage. London.

\section{V}

Valentine, G. (1995) Creating transcressive space: the music of kd lang. In Transactions of the Institute of British Geographers. Vol. 20. No. 4. pp. 474- 485. 
Valentine, G. (2001) At the drawing board: developing a research design. In Limb, M. and Dwyer, C. (eds) Qualitative Methodologies for Geographers. Issues and Debates. Arnold. London. pp. 41-54.

W

Walker, R. D. (2001) Film friendly Queenstown: tourism, film, local government and the community. A thesis submitted for the degree of Master of Tourism. University of Otago. Dunedin.

Wall, M. (2000) The popular and geography: Music and racialized identities in Aotearoa/ New Zealand. In Cook, I., Crouch, D., Naylor, S. and Ryan, J.R. (eds) Cultural Turns/ Geographical Turns. Pearson Education Ltd. Harlow. pp. 75-87.

Wang, N. (1999) Rethinking Authenticity in Tourism Experience. In Annals of Tourism Research. Vol. 26. No. 2. pp. 349-370.

War of the Ring Net (2004) Photo Gallery. [Online]. Available: http://www.warofthering.net/movies/photos/ttt/places/rohangeneral/imagepages/image8 .shtml [03.01.2004].

Westbrook, R.A. and Oliver, R.L. (1991) The dimensionality of consumption emotion patterns and consumer satisfaction. In Journal of Consumer Research. Vol. 18. pp. 8491.

Williams, K. (1998) Jackson Project May Give \$200m Boost to Economy. In The Dominion Post. 26.08.1998. p. 1.

Williams, R. (1982) The Sociology of Culture. Schocken Books. New York.

World Commission on Environment and Development (1987) Our common future. Oxford University Press. Oxford.

Wright, A. (2000) Realms of Enchantment: New Zealand Landscape as Tolkienesque. In Conrich, I. And Woods, D. (eds) New Zealand - A Pastoral Paradise? Studies in New Zealand Culture No.6. Kakapo Books. Clifton Village. pp. 52- 59.

Wright, J.B. (1993) The Real River That Runs Through It: Montana's Imperilled Blackfoot. In Focus. Vol. 43. No.1. pp. 18- 21.

Y

Youngs, M.J. (1985) The English Television Landscape Documentary: A Look at Granada. In Burgess, J. and Gold, J.R. (eds) Geography The Media \& Popular Culture. Croom Helm Ltd. London. pp. 144-164. 
Zonn, L. (1984) Landscape Depiction and Perception: A Transactional Approach. In Landscape Journal. Vol.3. No. 2. pp. 144-150.

Zonn, L. (1985) Images of place: a geography of the media. In Royal Geographical Society of Australia. Vol.84. pp. 35-45.

Zonn, L. (ed) (1990a) Place Images in Media: portrayal, experience and meaning. Savage. Maryland: Rowan and Littlefield Publishers.

Zonn, L. (1990b) Tusayan, the traveller, and the Imax theatre: an introduction to place images in media. In Zonn, L. (ed) Place Images in Media: portrayal, experience and meaning. Savage. Maryland: Rowan and Littlefield Publishers. pp. 1-5.

Zube, E. and Kennedy, C. (1990) Changing Images of the Arizona Environment. In Zonn, L. (ed) Place Images in Media: portrayal, experience and meaning. Savage, Maryland: Rowan and Littlefield Publishers, Inc. pp. 183-203.

\section{Video Source}

Sadovichikoff, V. and Macdonald, R. (1997) Moving pictures as text: an introduction to the language of film and television. [VHS]. Video Education Australia.

\section{Films Cited}

Osborne, B.M., Jackson, P., and Walsh, F. (Producers) \& Walsh, F., Boyens, P., Sinclair, S., and Jackson, P. (Screenplay) \& Jackson, P. (Director). (1999-2001). The Lord of the Rings: The Fellowship of the Ring [DVD]. New Line Production Inc., New Zealand/ USA. Released: December 2001.

Osborne, B.M., Jackson, P., and Walsh, F. (Producers) \& Walsh, F., Boyens, P., Sinclair, S., and Jackson, P. (Screenplay) \& Jackson, P. (Director). (1999-2001). The Lord of the Rings: The Two Towers [DVD]. New Line Production Inc., New Zealand/ USA. Released: December 2002.

\section{Personal Communications}

Alexander, R. (01.08.03) Rings Scenic Tours. personal communication. Matamata.

Bragg, J. (26.09.03) Wellington Rover. personal communication. Wellington.

Cain, L. (10.09.03) 4x4 New Zealand Ltd. personal communication. Geraldine.

Davis, P. (22.08.03) Dart Stables. personal communication. Queenstown.

Forsyth, A.-M. (30.05.03) Tourmasters South Pacific NZ Ltd. e-mail correspondents.

Gregory, P. (23.07.03) Visitor Information Centre Turangi. e-mail correspondents. 
Horne, H. (25.07.03) Rings Scenic Tours. personal communication. Matamata.

James, V. (29.01.04) Red Carpet Tours. e-mail correspondents.

Jansen, H. (01.09.03) Safari of the Rings. personal communication. Queenstown.

Kennedy, D. (27.08.03) Destination Queenstown. personal communication. Queenstown.

Matamata local (01.08.03) personal communication. Matamata.

Morrisey, C. (06.08.03) Mountain Air. personal communication. Mount Ruapehu.

Queenstown local (29.08.03) personal communication. Queenstown.

Swan, B. (20.08.03) Heliworks Queenstown Helicopters. personal communication.

Queenstown.

Swiss tourists (07.09.03) personal communications. Lake Tekapo.

Whiting, S. (01.08.03) Visitor Information Matamata. personal communication. Matamata. 


\section{VICTORIA UNIVERSITY OF WELLINGTON \\ Te Whare Wananga o te Upoko o te Ika a Maui}

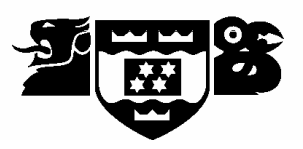

\section{Dear Visitor}

Thank you for volunteering to participate in my research project. My name is Daniela S. Carl and I am a postgraduate student doing a Masters of Science (Geography) at Victoria University of Wellington, New Zealand/ Aotearoa. This research attempts to understand tourists' experiences of New Zealand's landscapes featured in the films of The Lord of the Rings.

The Human Ethics Committee of Victoria University has approved this research project. This questionnaire is completely anonymous and does not identify you in any way!

The completion of this questionnaire should take only a few minutes of your time. Please complete the questionnaire after you have visited the sites. The questionnaire will be collected at the end of this tour.

\section{Thank you!}

If you have any questions, wish further information or feedback, please contact me or my supervisors:

\section{Daniela S. Carl}

Institute of Geography - School of Earth Sciences

Victoria University of Wellington

P.O. Box 600

Wellington

Phone: (0)4- 4635493

New Zealand/ Aotearoa

E-mail: carldani@scs.vuw.ac.nz

\section{Supervisor}

Sara Kindon

Senior Lecturer Institute of Geography

School of Earth Sciences

Victoria University of Wellington

Phone: (0)4- 4636194

Co-Supervisor
Dr Karen Smith
Senior Lecturer Tourism Management
School
Victoria Management School
Victoria University of Wellington
Phone: (0)4- 4635721
E-Mail: Karen.Smith@vuw.ac.nz

E-mail: Sara.Kindon@vuw.ac.nz 
The Lord of the Rings film locations visitor survey

Date 12003

A 1. Have you watched the film(s) of The Lord of the Rings?

First film: The Fellowship of the Ring

$\square \quad$ No $\quad \square$ Yes How many times?

Second film: The Two Towers

$\square \quad$ No $\quad \square$ Yes How many times?

2. In your opinion which three words best describe the landscapes shown in the film(s) of The Lord of the Rings? (Please use adjectives)

1

2

3

3. Which locations/ landscapes do you remember best from the film(s) of The Lord of the Rings? (Please name or describe at least two)

1

2 
4. On a scale of 1-5, please tell me how much you relate New Zealand's landscape to Middle-earth? (Please circle number)

1

New Zealand

is Middle-earth
2

3

neutral
4

5

no similarities

Please explain your answer!

B 5. Which three words best describe the actual landscapes of the former film location you have visited? (Please use adjectives!)

1

2

3

6. Were the film locations/ landscapes you have visited as you expected them to be? (Please circle number)

1

much better than expected

2 better than expected
3

as expected

as expected

4

worse than much worse

expected than expected

Please explain your answer! 


\section{How did you find out about this tourl former film location?}

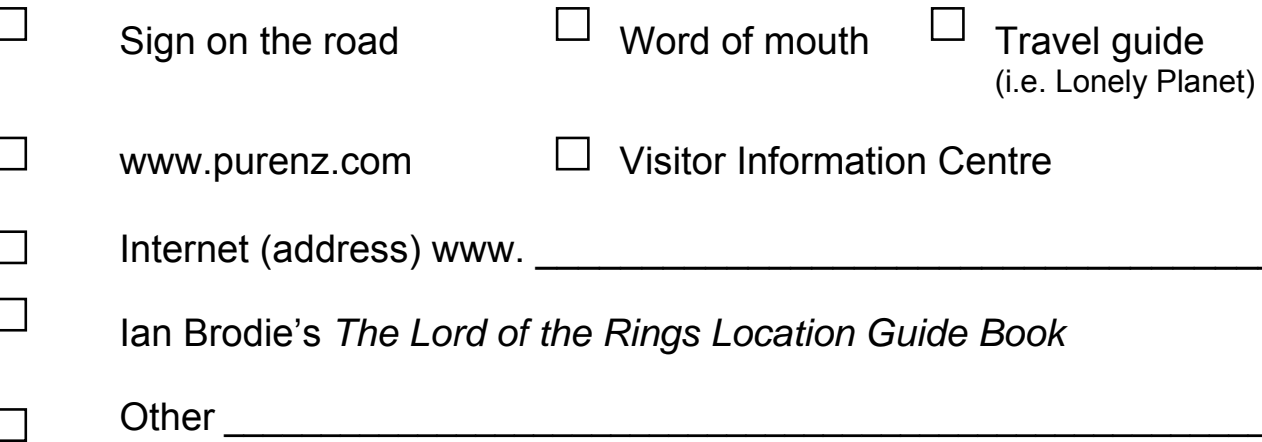

Where was that?

(i.e. in your home country, Auckland Airport,...)

\section{Who made the decision to visit this film location(s)?}
Myself
Partner
Friend(s)
Other

When and where did you make this decision?

(i.e. today/ Queenstown, 2 months ago/ Glasgow)

9. Overall, how satisfied are you with this tour experience here? (Please circle number)

$\begin{array}{ccccc}\mathbf{1} & \mathbf{2} & \mathbf{3} & \mathbf{4} & \mathbf{5} \\ \text { very satisfied } & \text { satisfied } & \text { neutral } & \text { dissatisfied } & \begin{array}{c}\text { very } \\ \text { dissatisfied }\end{array}\end{array}$

Please explain your answer! 
10. Have you been to other film locations of The Lord of the Rings?

$\square \quad$ No $\quad \square$ Yes Where?

When?

11. Are you planning to visit other film locations of The Lord of the Rings?

No Why?

Possibly

$\square \quad$ Yes Where?

Why?

12. Would you like facilities for The Lord of the Rings film tourism to be improved in any way? (i.e. better access to sites, closer accommodations, etc.)

$\square \quad$ Yes $\quad$ In what way?

$\square$ No Please explain why not:

C 13. What was your main motivation to visit New Zealand? (tick only one)

$\square \quad$ Holiday $\square$ Business $\square$ Visiting relatives \& friends

$\square \quad$ Stop over to/ from

$\square \quad$ Visitation of former film set

Other

14. How important was the fact that The Lord of the Rings was filmed in New Zealand for your decision to come here?

$\square \quad$ Very important $\square$ Less important $\quad \square$ Not important 
15. Have you been to New Zealand before?

16. Are you planning to visit New Zealand again in the future?

$\square \quad$ Yes

When? $\quad \square \quad$ Next year $\quad \square \quad$ Within next 5 years

Possibly

No Please explain why not:

17. How long are you staying in New Zealand?

Days —Weeks $\square$ Live here

18. How are you travelling? (more than one possible answer)

$\square \quad$ By myself $\quad \square \quad$ With partner $\quad \square$ With friends $\quad \square$ With family

$\square \quad$ Educational tour $\square \quad$ With work colleagues/ on business

$\square \quad$ Other

19. What is your preferred type of accommodation while staying in New Zealand?

$\square \quad$ Hotel (1)

(1) $\square$ Motel (2)

Backpacker/ Youth Hostel (3)

$\square \quad$ Farm Stay/ Bed \& Breakfast

(4) $\square$ Holiday Park/ Motor Camp (5)

Friends/ Relatives/ Home stay (6)

Tent / Camp Ground (7)

Campervan/ Motor Home

(8)

Other

Where did you stay last night?

(i.e. Auckland) 
What kind of accommodation was it?

Number:

(Use numbers given above!)

Other:

Where are you staying tonight?

(i.e. Rotorua)

What kind type of accommodation is it? Number:

(Use numbers given above!)

Other:

Where are you going

to stay tomorrow?

(i.e. Christchurch)

What kind of accommodation will it be? Number:

(Use numbers given above!)

Other:

D 20. Please give me a brief description of yourself!

- $1 . \quad$ Country of origin

- 2. Sex

Female

Male

- 3. Age (circle age group)

under 16

$16-20$

21-24

25-29

30-34

35-39

$40-44$

45-49

$50-54$

$55-59$

$60+$

\section{Comments or suggestions?}

Thank you very much for your help, it is appreciated! 


\section{VICTORIA UNIVERSITY OF WELLINGTON \\ Te Whare Wananga o te Upoko o te Ika a Maui}

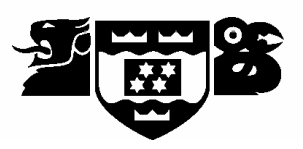

\section{Dear Participant}

Thank you for volunteering to participate in my research project. My name is Daniela S. Carl and I am a postgraduate student doing a Masters of Science (Geography) at Victoria University of Wellington, New Zealand/ Aotearoa. This research attempts to understand tourists' experiences of New Zealand's landscapes featured in the films of The Lord of the Rings. The information you provide in your interview with me will be most helpful and will complement information I gather from other film tourists within a questionnaire survey. The anticipated duration of this interview is between five and ten minutes.

Your information will be treated confidentially and only used for the purposes of this research project. You also have the right to withdraw any information you provide (prior to data analysis and writing) without having to give reasons.

Your responses within this interview will be taped and be put into a written report (thesis), which will be lodged in the university library. It is also intended that one or more articles from the research will be submitted for publications in scholarly journals.

\section{Thank you!}

If you have any questions, wish further information or feedback, please contact me or my supervisors:

Daniela S. Carl

Institute of Geography - School of Earth Sciences

Victoria University of Wellington

P.O. Box 600

Wellington

Phone: (0)4- 4635493

New Zealand/ Aotearoa

E-mail: carldani@scs.vuw.ac.nz

\section{Supervisor}

Sara Kindon

Co-Supervisor

Dr Karen Smith

Senior Lecturer Institute of Geography

School of Earth Sciences

Victoria University of Wellington

Phone: (0)4- 4636194

Senior Lecturer Tourism Management

School

Victoria Management School

Victoria University of Wellington

E-mail: Sara.Kindon@vuw.ac.nz 
Title of project: Cultural Representation of New Zealand's Landscapes in the Films of The Lord of the Rings and its Implications for Tourism

Researcher: Daniela S. Carl

Research Institute: Institute of Geography,

Victoria University of Wellington

I have been given and understood an explanation of this research project. I have had an opportunity to ask questions and have them answered to my satisfaction. I understand that I may withdraw myself (or any information I have provided) from this project (before data collection and analysis is completed) without having to give reasons. I agree to a taped interview.

I acknowledge that the information that is given may be used for publication. I understand that I will have an opportunity to check the transcript of the interview before publications.

I give my consent to participate in this project. 
VICTORIA UNIVERSITY OF WELLINGTON

Te Whare Wananga o te Upoko o te Ika a Maui

\section{Dear Participant}

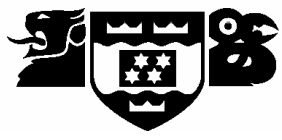

Thank you for volunteering to participate in my research project. My name is Daniela S. Carl and I am a postgraduate student doing a Masters of Science (Geography) at Victoria University of Wellington, New Zealand/ Aotearoa. This research attempts to understand tourists' experiences of New Zealand's landscapes featured in the films of The Lord of the Rings. The information you provide in your interview with me will be most helpful and will complement information I gather from tourists themselves.

Due the fact of a very limited number of tourism enterprises operating at locations featured in the films of The Lord of the Rings it is impossible to guarantee your anonymity. However, your information will be treated confidentially and only used for the purposes of this research project. You also have the right to withdraw any information you provide (prior to data analysis and writing) without having to give reasons.

Your responses within this interview will be taped and be put into a written report (thesis), which will be lodged in the university library. It is also intended that one or more articles from the research will be submitted for publications in scholarly journals.

\section{Thank you!}

If you have any questions, wish further information or feedback, please contact me or my supervisors:

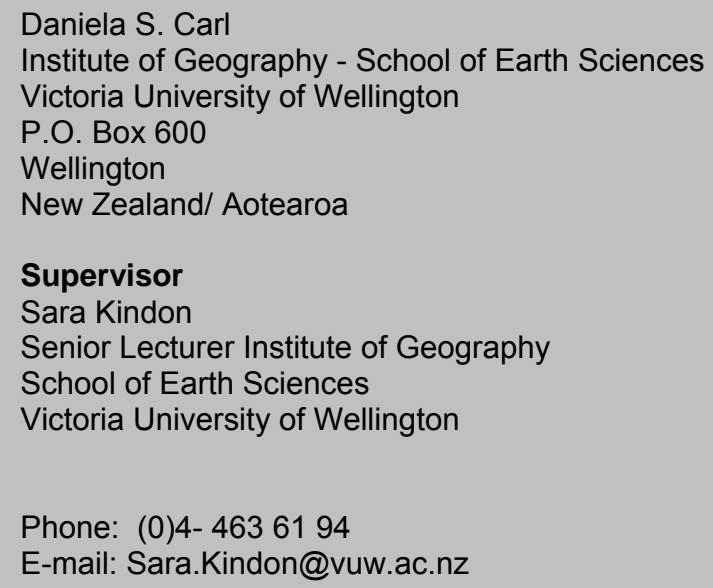

Phone: (0)4- 4635493

E-mail: carldani@scs.vuw.ac.nz

\section{Co-Supervisor}

Dr Karen Smith

Senior Lecturer Tourism Management School

Victoria Management School Victoria University of Wellington

Phone: (0)4- 4635721

E-Mail: Karen.Smith@vuw.ac.nz 
Title of project: $\quad$ Cultural Representation of New Zealand's Landscapes in the Films of The Lord of the Rings and its Implications for Tourism

Researcher: Daniela S. Carl

Research Institute: Institute of Geography, Victoria University of Wellington

I have been given and understood an explanation of this research project. I have had an opportunity to ask questions and have them answered to my satisfaction. I understand that I may withdraw myself (or any information I have provided) from this project (before data collection and analysis is completed) without having to give reasons. I agree to a tape interview.

I acknowledge that the information that is given may be used for publication. I understand that I will have an opportunity to check the transcript of the interview before publications.

I give my consent to participate in this project. 


\begin{tabular}{|c|c|c|}
\hline $\begin{array}{l}\text { Screen } \\
\text { time } \\
\text { (in minutes) }\end{array}$ & $\begin{array}{l}\text { Landscape/place } \\
\text { within Middle-earth }\end{array}$ & $\begin{array}{l}\text { Main film location } \\
\text { in New Zealand }\end{array}$ \\
\hline $6: 32$ & Mordor & $\begin{array}{l}\text { Iwikau Village/ Tongariro National Park, } \\
\text { Rees River Valley }\end{array}$ \\
\hline $18: 24$ & The Shire/ Hobbiton & $\begin{array}{l}\text { Hinuera Valley/ Matamata, Wellington } \\
\text { (studio), Miramar peninsula }\end{array}$ \\
\hline $0: 36$ & Mordor & Wellington (studio set) \\
\hline $1: 30$ & Minas Tirith & $\begin{array}{l}\text { Wellington (studio set), The Remarkables/ } \\
\text { Queenstown, Lower Hutt }\end{array}$ \\
\hline $0: 28$ & The Shire & Hinuera Valley/ Matamata \\
\hline $3: 55$ & Bilbo's House & Wellington (studio set) \\
\hline $0: 11$ & Mordor & Wellington (studio set) \\
\hline $0: 06$ & Bilbo's House & Wellington (studio set) \\
\hline $0: 05$ & The Shire & Hinuera Valley/ Matamata \\
\hline $2: 33$ & Bilbo's House & Wellington (studio set) \\
\hline 1:55 & Leaving the Shire & Otaki, Hinuera Valley/ Matamata \\
\hline $4: 26$ & Isengard & $\begin{array}{l}\text { Dart River Valley/ Glenorchy, Harcourt } \\
\text { Park/ Upper Hutt, Wellington (studio set) }\end{array}$ \\
\hline $5: 54$ & Leaving the Shire & $\begin{array}{l}\text { Otaki, Wellington/ Mount Victoria, Hinuera } \\
\text { Valley/ Matamata }\end{array}$ \\
\hline 7:35 & Bree & $\begin{array}{l}\text { Wellington (studio set), Fort Dorset/ } \\
\text { Wellington }\end{array}$ \\
\hline 1:20 & Way to Rivendell & Takaka Hill \\
\hline 1:39 & Isengard & $\begin{array}{l}\text { Wellington (studio set), Harcourt Park/ } \\
\text { Upper Hutt }\end{array}$ \\
\hline $4: 28$ & Watchtower of Amon Sûl & Port Waikato, Wellington (studio set) \\
\hline $2: 24$ & Isengard & Wellington (studio set) \\
\hline $2: 31$ & Way to Rivendell & Wellington (studio \& outdoor set) \\
\hline $1: 32$ & Horse ride to Rivendell & Waitarer Forest, Tarras \\
\hline $1: 41$ & Ford of Bruinen & Arrow River/ Arrowtown, Skippers Canyon \\
\hline 1:10 & Rivendell & $\begin{array}{l}\text { Kaitoke Regional Park, Southern Alps, } \\
\text { Wellington (studio set) }\end{array}$ \\
\hline $0: 50$ & Isengard & Wellington (studio set) \\
\hline 19:20 & Rivendell & $\begin{array}{l}\text { Kaitoke Regional Park, Wellington (studio } \\
\text { set) }\end{array}$ \\
\hline $5: 15$ & $\begin{array}{l}\text { South of Rivendell, Misty } \\
\text { Mountains, Pass of Caradhras }\end{array}$ & $\begin{array}{l}\text { Southern Alps, Mt Olympus, Treble Cone/ } \\
\text { Wanaka }\end{array}$ \\
\hline $0: 15$ & Isengard & Wellington (studio set) \\
\hline 1:45 & Misty Mountains & $\begin{array}{l}\text { Southern Alps, Lake Manapouri/ Fiordland, } \\
\text { Paradise/ Glenorchy }\end{array}$ \\
\hline \multirow[t]{2}{*}{$25: 25$} & Mines of Moria & Wellington (studio set), \\
\hline & Way out of Moria & Mt Owen \\
\hline $12: 40$ & Woods of Lothlórien & Paradise beech forest/ Glenorchy \\
\hline $1: 35$ & Isengard & Wellington (studio set) \\
\hline $0: 50$ & Lothlórien & Fernside Lodge Park/ Fetherston \\
\hline $2: 45$ & River Anduin & $\begin{array}{l}\text { Hutt River, Queenstown/ Kawarau River, } \\
\text { Rangitikei River Gorge, Moawhango River }\end{array}$ \\
\hline $16: 25$ & Path Galen / Am & $\begin{array}{l}\text { Mavora Lakes, Paradise Forest/ Glenorchy, } \\
\text { Lake Wakatipu/ Closeburn }\end{array}$ \\
\hline
\end{tabular}




\begin{tabular}{|lll|}
\hline $2: 30$ & River Anduin & Lake Wakatipu/ Queenstown \\
\hline $1: 04$ & $\begin{array}{l}\text { Edge of mountain range - > view } \\
\text { to Mordor }\end{array}$ & Tongariro National Park \\
\hline
\end{tabular}

The Fellowship of the Ring- main landscapes/places and their screen time

\begin{tabular}{|rl|}
\hline $\begin{array}{l}\text { Screen } \\
\text { time } \\
\text { (in minutes) }\end{array}$ & $\begin{array}{l}\text { Landscape/place } \\
\text { within Middle-earth }\end{array}$ \\
\hline $25: 31$ & The Shire/ Hobbiton \\
\hline $25: 25$ & Mines of Moria \\
\hline $20: 30$ & Rivendell \\
\hline $16: 25$ & Path Galen/ Amon Hen \\
\hline $13: 30$ & Lothlórien \\
\hline $11: 09$ & Isengard \\
\hline $7: 49$ & Leaving the Shire \\
\hline $7: 35$ & Bree \\
\hline $7: 19$ & Mordor \\
\hline $6: 00$ & Misty Mountains \\
\hline & \\
\hline
\end{tabular}




\begin{tabular}{|c|c|c|}
\hline $\begin{array}{l}\text { Screen } \\
\text { time } \\
\text { (in minutes) }\end{array}$ & $\begin{array}{l}\text { Landscape/place } \\
\text { within Middle-earth }\end{array}$ & $\begin{array}{l}\text { Main film location } \\
\text { in New Zealand }\end{array}$ \\
\hline $1: 00$ & Misty Mountains & Southern Alps \\
\hline $1: 59$ & Mines of Moria & Wellington (studio set) \\
\hline $7: 21$ & Emyn Muil & $\begin{array}{l}\text { Tongariro National Park, Wellington (studio } \\
\text { set) }\end{array}$ \\
\hline $1: 45$ & Way to Rohan & Deer Park Heights, Poolburn/ Ida Valley \\
\hline 1:00 & Plains of Rohan & Poolburn/Ida Valley \\
\hline $1: 47$ & Isengard & Wellington (studio set) \\
\hline $1: 02$ & Rohirrim village & Poolburn/Ida Valley \\
\hline $2: 42$ & Edoras & Mt Sunday/ Rangitata Valley \\
\hline $1: 43$ & Edge of Fangorn Forest & Paradise Forest, Wellington (studio set) \\
\hline $6: 27$ & Plains of Rohan & Poolburn/ Ida Valley \\
\hline $3: 22$ & Fangorn Forest & Wellington (studio set) \\
\hline $6: 43$ & Dead Marshes & Te Anau, Wellington (studio \&outdoor set) \\
\hline $2: 30$ & Fangorn Forest & Wellington (studio set) \\
\hline 1:02 & Abyss of Moria & Wellington (studio set) \\
\hline $0: 46$ & Fangorn Forest & Wellington (studio set) \\
\hline $0: 50$ & Edge of Fangorn Forest & Paradise area \\
\hline $0: 12$ & Plains of Rohan & Poolburn/ Ida Valley, Rangitata Valley \\
\hline $0: 37$ & Fangorn Forest & Wellington (studio set), Paradise Forest \\
\hline $5: 03$ & Opposite Black Gate/ Mordor & Wellington (studio set) \\
\hline 17:39 & Edoras & $\begin{array}{l}\text { Mt Sunday/ Rangitata Valley, wellington } \\
\text { (studio set) }\end{array}$ \\
\hline $0: 13$ & Isengard & $\begin{array}{l}\text { Dart River Valley/ Glenorchy, Wellington } \\
\text { (studio set) }\end{array}$ \\
\hline 0:08 & $\begin{array}{l}\text { Way to Helms Deep- Lake with } \\
\text { refugees/ Rohan }\end{array}$ & Deer Park Heights/ Queenstown \\
\hline $0: 15$ & Isengard & $\begin{array}{l}\text { Dart River Valley/ Glenorchy, Wellington } \\
\text { (studio set) }\end{array}$ \\
\hline 4:56 & Ithilien & $\begin{array}{l}\text { Tongariro National Park, Wellington (studio } \\
\text { set), Paradise Forest, Twelve Mile Delta/ } \\
\text { Lake Wakatipu }\end{array}$ \\
\hline $0: 44$ & Way to Helms Deep/ Rohan & Deer Park Heights/ Queenstown \\
\hline $2: 32$ & Rivendell & Wellington (studio set) \\
\hline $0: 16$ & Way to Helms Deep/ Rohan & Rangitata Valley \\
\hline $1: 14$ & Rivendell & Wellington (studio set) \\
\hline $6: 36$ & Way to Helms Deep/ Rohan & Deer Park Heights/ Queenstown \\
\hline $2: 33$ & Helm Deep & $\begin{array}{l}\text { Valley near Mt Sunday, Lower Hutt (Dry } \\
\text { Creek Quarry) }\end{array}$ \\
\hline 1:27 & Isengard & $\begin{array}{l}\text { Dart River Valley/ Glenorchy, Wellington } \\
\text { (studio set) }\end{array}$ \\
\hline $0: 50$ & Fangorn Forest & Wellington (studio set) \\
\hline $1: 31$ & $\begin{array}{l}\text { Shores of River Anduin + Plains } \\
\text { of Rohan }\end{array}$ & Poolburn/ Ida Valley \\
\hline $5: 54$ & Rivendell & Wellington (studio), Mt Victoria/ Wellington \\
\hline $9: 50$ & Ithilien Camp & Paradise Forest, Wellington (studio set) \\
\hline $0: 59$ & Way to Helms Deep & Poolburn/ Ida Valley, Rangitata Valley \\
\hline $4: 21$ & Helms Deep & Lower Hutt (Dry Creek Quarry) \\
\hline $1: 16$ & Fangorn Forest & Wellington (studio set) \\
\hline $12: 57$ & Helms Deep & Lower Hutt (Dry Creek Quarry) \\
\hline $1: 35$ & Fangorn Forest & Wellington (studio set) \\
\hline
\end{tabular}




\begin{tabular}{|lll|}
\hline $3: 17$ & Helms Deep & Lower Hutt (Dry Creek Quarry) \\
\hline $1: 41$ & Fangorn Forest & Wellington (studio set) \\
\hline $5: 42$ & Helms Deep & Lower Hutt (Dry Creek Quarry) \\
\hline $1: 20$ & Fangorn Forest & Wellington (studio set) \\
\hline $0: 34$ & Near Osgiliath & Twelve Mile Delta \\
\hline $2: 11$ & Fangorn Forest/ Edge of Forest & Wellington (studio set) \\
\hline $2: 25$ & Osgiliath & Wellington (studio set) \\
\hline $4: 27$ & Helms Deep & Lower Hutt (Dry Creek Quarry) \\
\hline $2: 21$ & Isengard & $\begin{array}{l}\text { Dart River Valley/ Glenorchy, Wellington } \\
\text { (studio set) }\end{array}$ \\
\hline $2: 26$ & Osgiliath & Wellington (studio set) \\
\hline $0: 22$ & Helms Deep & Lower Hutt (Dry Creek Quarry) \\
\hline $0: 23$ & Isengard & $\begin{array}{l}\text { Dart River Valley/ Glenorchy, Wellington } \\
\text { (studio set) }\end{array}$ \\
\hline $1: 57$ & Osgiliath, Isengard, Helms Deep & $\begin{array}{l}\text { Wellington (studio set), Dart River Valley/ } \\
\text { Glenorchy }\end{array}$ \\
\hline $3: 03$ & Leaving Osgiliath & Mt Victoria/ Wellington \\
\hline $0: 16$ & Mordor & Wellington (studio set) \\
\hline & &
\end{tabular}

The Two Towers- main landscapes/places and their screen time

\begin{tabular}{|rl|}
\hline $\begin{array}{l}\text { Screen } \\
\text { time } \\
\text { (in minutes) }\end{array}$ & $\begin{array}{l}\text { Landscape/place } \\
\text { within Middle-earth }\end{array}$ \\
\hline $38: 47$ & Rohan/ Edoras \\
\hline $33: 54$ & Helms Deep \\
\hline $15: 48$ & Fangorn Forest \\
\hline $14: 46$ & Ithilien Camp \\
\hline $9: 40$ & Rivendell \\
\hline $7: 21$ & Emyn Muil \\
\hline $6: 48$ & Osgiliath \\
\hline $6: 43$ & Dead Marshes \\
\hline $5: 26$ & Isengard \\
\hline
\end{tabular}




\section{Plot summaries of the $1^{\text {st }}$ and the $2^{\text {nd }}$ films of The Lord of the Rings}

These plot summaries were determined by watching the films. Information on responsibilities is adapted from O'Hehir's article in Sight and Sound (2002). The locations where the films were set were gathered from Brodie's (2002; 2003) The Lord of the Rings Location Guidebook, information given by guides of Rings Scenic Tours and the Safari of the Rings tours, as well as by the researcher's own fieldwork on locations.

\section{Plot Summary of The Lord of the Rings}

$\begin{array}{ll}\text { Director: } & \text { Peter Jackson } \\ \text { Director of Photography: } & \text { Andrew Lesnie } \\ \text { Conceptual Design: } & \text { Alan Lee, John Dowe }\end{array}$

Co-production USA/ New Zealand by New Line Productions, Inc.

North Island locations: Hinuera Valley/Matamata, Tongariro National Park, Ohakune, Rangitikei River Gorge, Waitarere Forest, Otaki Gorge, Fernside/Featherston, Upper Hutt, Kaitoke Regional Park, Harcourt Park, Hutt River, Wellington

South Island locations: Takaka Hill, Mount Olympus, Mount Owen, Mount Sunday, Tarras, Wanaka, Kawarau River, Queenstown, Arrowtown, Skippers Canyon, Closeburn, Twelve Mile Delta, Dart River Valley, Paradise, Mavora Lakes, Mararoa River, Takaro Road, Waiau River, Northwest Lakes, Ida Valley

$1^{\text {st }}$ Film

The Fellowship of the Ring (2001)

The first film of the trilogy begins with a retrospective view of the happenings around the one ring 2500 years before the main story of The Fellowship of the Ring takes place.

Accidentally the ring was found by a hobbit, Bilbo Baggins. The power of the ring gave Bilbo an unusually long life. His friend, the wizard Gandalf, asserted that the ring Bilbo owns is the ring, forged by Sauron, the Dark Lord of Mordor, to rule over Middle-earth. However, on his $111^{\text {th }}$ birthday Bilbo decides to give the ring away and disappears out of The Shire. The ring and the burden to save his people from Sauron's power are inherited by Bilbo's nephew Frodo.

Suddenly Frodo is pushed into a treacherous mission. Frodo and his friends Samwise, Merry and Pippin leave The Shire to bring the ring to the village of Bree 
were they would meet Gandalf again. On their way the hobbits are attacked by Sauron's Black Riders. In Bree the group meet a human named Strider who subsequently leads them on. They are again attacked by the Black Riders. To escape the situation Frodo puts the ring on and becomes invisible. He is seriously wounded in the fight. Strider, also known as Aragorn, calls for help from Arwen, an elf and his love, to carry Frodo to a secure place, Rivendell. In Rivendell the hobbits meet Bilbo and Gandalf again. Gandalf been prevented from meeting the hobbits at Bree by a fight against his wizard colleague Saruman, who is collaborating with Sauron.

Representatives of the people of Middle-earth, who are threatened by Sauron and his allies, come together in Rivendell, the home of the Elves, to talk about the danger of the ring and how it can be destroyed in order to save their world. Before it falls into the wrong hands they agree to carry the ring to Mordor, to Mount Doom, the only place where it can be destroyed. Frodo volunteers for this mission. Eight others accompany him: Sam, Merry, and Pippin, his hobbit friends; Legolas, an elf; Gimli, a dwarf; the humans Boromir and Aragorn; and Gandalf the wizard. This is the beginning of the fellowship of the ring.

The fellowship travels under the Misty Mountains through the mines of Moria, which were created by the dwarves. However, they are not alone. Gollum, the miserable former owner of the ring, is following to get his 'precious' ring back. However, this is not the only danger in the mines. A tremendous number of orcs and the balrog, a gigantic evil fire creature, are attacking them. Gandalf fights against the balrog. When it looks as Gandalf has won the battle, the fire tail of the balrog pulls Gandalf with it, into the abyss.

The others escape and find a secure refuge in the woods of Lóthlorien, which is ruled by Galadriel, an elf queen. Afterwards they continue their journey to the south along the Great River. Boromir tries to snatch the ring off Frodo. Again, Frodo puts the ring on and escapes. Merry and Pippin are attacked and kidnapped by uruk-hais. Boromir is trying to save them but is mortally wounded. Meanwhile, Frodo and Sam break away from the group and continue travelling eastwards to Mordor. The reminder of the fellowship, Legolas, Gimli and Aragorn, decide to follow the uruk-hais to rescue Merry and Pippin. 
$2^{\text {nd }}$ Film

The Two Towers (2002)

The quest to destroy the Ring and to save Middle-earth continues as the powerful wizard Saruman and the dark lord Sauron are continuing to transform Middle-earth into a dark and unfriendly place.

The Two Towers begins were The Fellowship of the Ring finished. The fellowship has been splintered. Gimli, Legolas and Aragorn are trying to rescue the hobbits Merry and Pippin who have been taken by Saruman's army of uruk-hais. Meanwhile, Frodo and Sam continue their journey to Mordor. Frodo and Sam get lost in the hills of the Emyn Muil. It is here that they meet Gollum, the former owner of the ring who is attacking them to get his 'precious' back. Gollum promises to lead them to Mordor. Although Sam does not trust the creature, Frodo forms an odd attachment to Gollum.

Elsewhere the kidnapped hobbits, Merry and Pippin, are able to escape while the uruk-hais and orcs are fighting against each other and are minutes later attacked by an army of riders from Rohan. Merry and Pippin escape into the dark and ancient Fangorn Forest where they meet Treebeard, a walking and talking ent who is the shepherd of the forest.

Meanwhile the other fellows, led by Aragorn, discover that Gandalf is alive and stronger than ever before. Gandalf tells them that Pippin and Merry are safe in the hands of Treebeard, the leader of the ents. However, Saruman and his armies are attacking Rohan. Gandalf urges Legolas, Gimli and Aragorn to fight alongside Rohan's king Théoden and his people at the fortress of Helms Deep.

Merry and Pippin convince the ents to march against Isengard the home of the evil wizard Saruman. Frodo and Sam have to face the realisation that they cannot enter Mordor through the Black Gate. They decide to follow Gollum to a back entrance into Mordor. On their way the three are captured by Faromir, the brother of Boromir, and his troops. Faramir decides to hand the ring of power to his father in Gondor so he can use it to fight the enemies. However, confronted with the real story about his brother's death, he releases the hobbits so they can fulfil their mission.

At the two battlefields, Isengard and Helms Deep, the good forces are victorious. Saruman is defeated as is the superior army of tens of thousands of bloodthirsty creatures sent by Saruman to destroy Helms Deep and Rohan. 


\section{Pamphlet Rings Scenic Tours/ Matamata}

Front-page

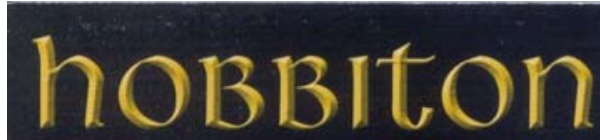

movie set

welcome to the

midole-edrth movie set

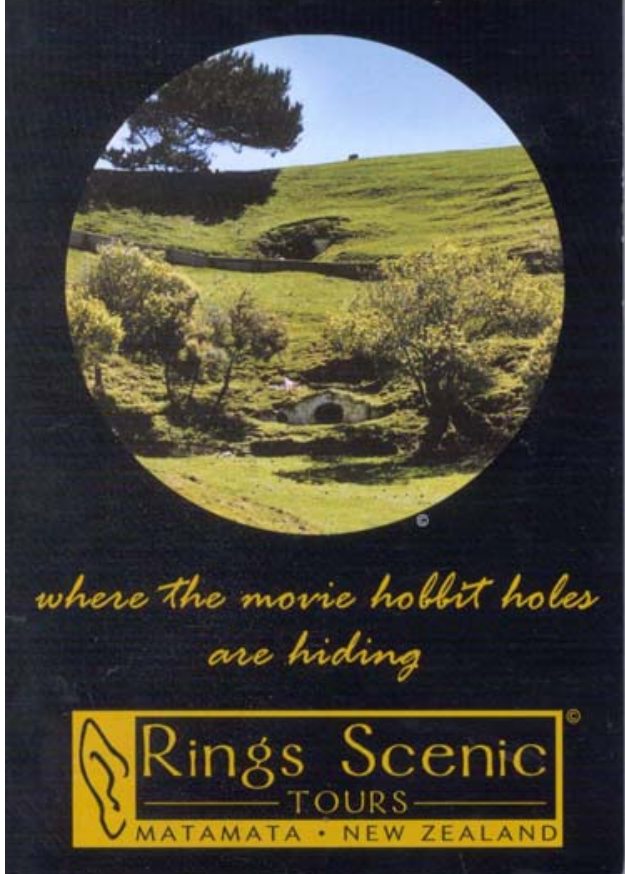

Back-page

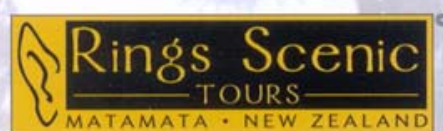

Daily tours are now available to visit the original Hobbiton village set from The Lord of the Rings movie trilogy.

Your tour starts with a drive

through a picturesque working sheep farm with spectacular views across to the Kaimai Ranges.

The Hobbiton movie set has been returned to its natural state,

however hobbit holes and some structures from the film set are still present.

Your tour guide will escort you through the ten acre site recounting fascinating details on how the Hobbiton set was created.

TOURS OPERATE DAILY BOOKINGS ARE ESSENTIAL

A free courtesy van departs daily from the Matamata Information Centre 45 Broadway Matamata.
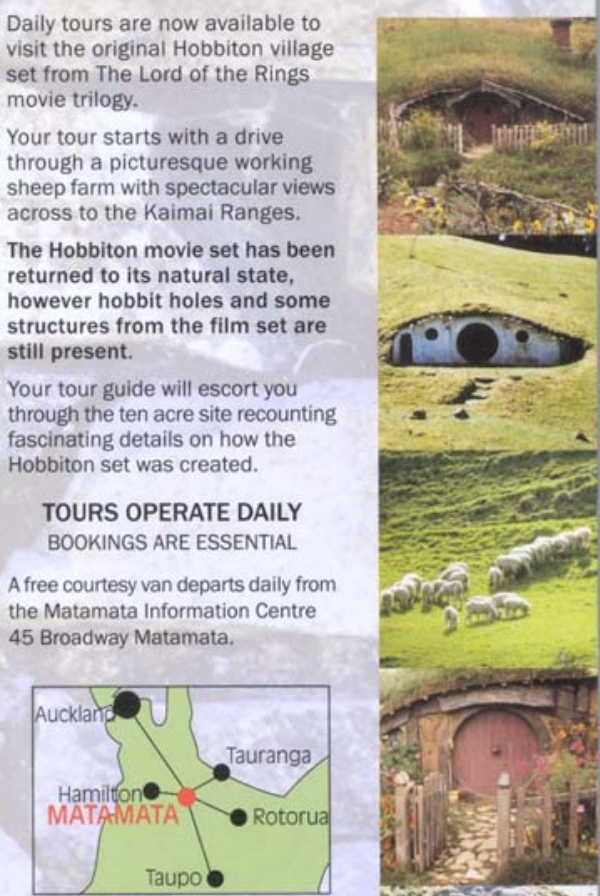

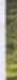
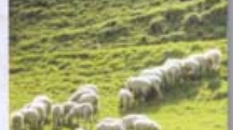

yonim

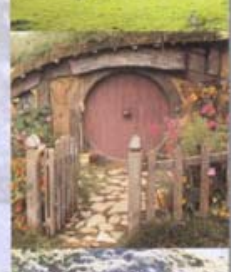

FOR BOOKINGS AND PRICES CONTACT

Rings Scenic Tours 45 Broadway Matamata phone 078886838 • fax 078885653 e-mail info@hobbitontours.com www.hobbitontours.com

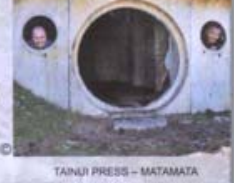


Front and back page

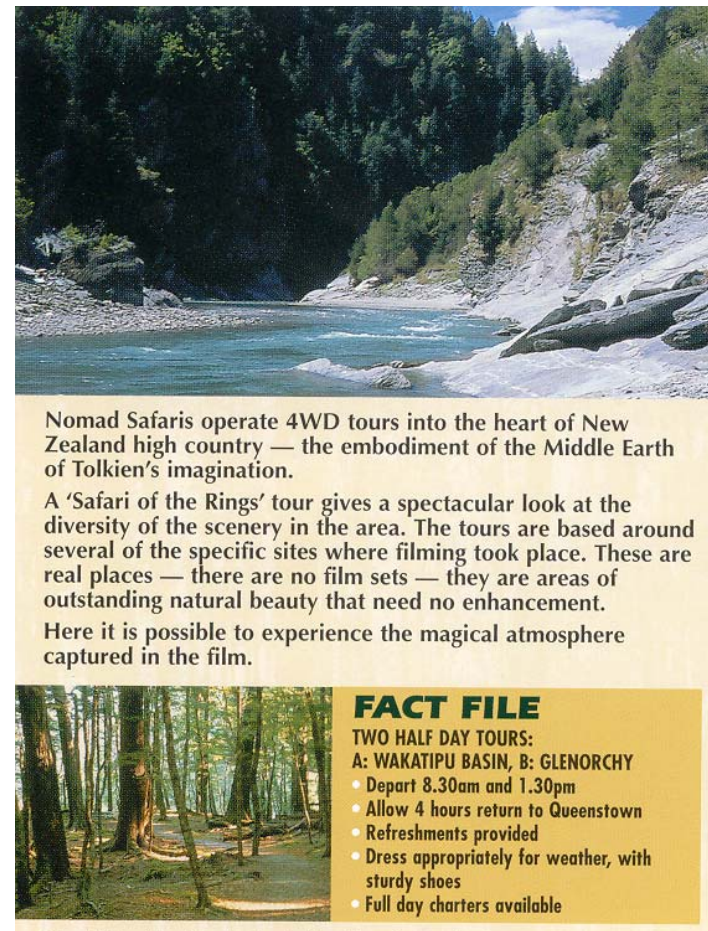

The Wakatipu Basin includes the sites of 'The Ford of Bruinen', 'The Road to Mordor' and 'The Pillars of the Kings'.

Locations in the Glenorchy area include 'The Seat of Seeing', the elfin forest of 'Lothlorien' and 'Isengard'.

Other half day tours available with Nomad Safaris, all showcase landscapes used in 'The Lord of the Rings': SIKIPPERS CANYON Follow the Shotover River on this hand-hewn mountain road. SEFFERTOWN 4 WD at its best - many river MACETOWIN crossings and spectacular scenery Rugged tours to the remains of an original gold rush settlement.

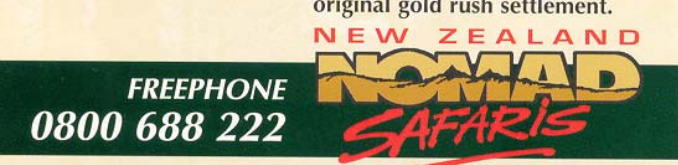

PO BOX 341 QUEENSTOWN NEW ZEALAND

PH $6 4 \longdiv { 3 4 4 2 6 6 9 9 }$ FAX 6434427346 EMAIL safari@outback.net.nz WEB www.outhark.net.n7

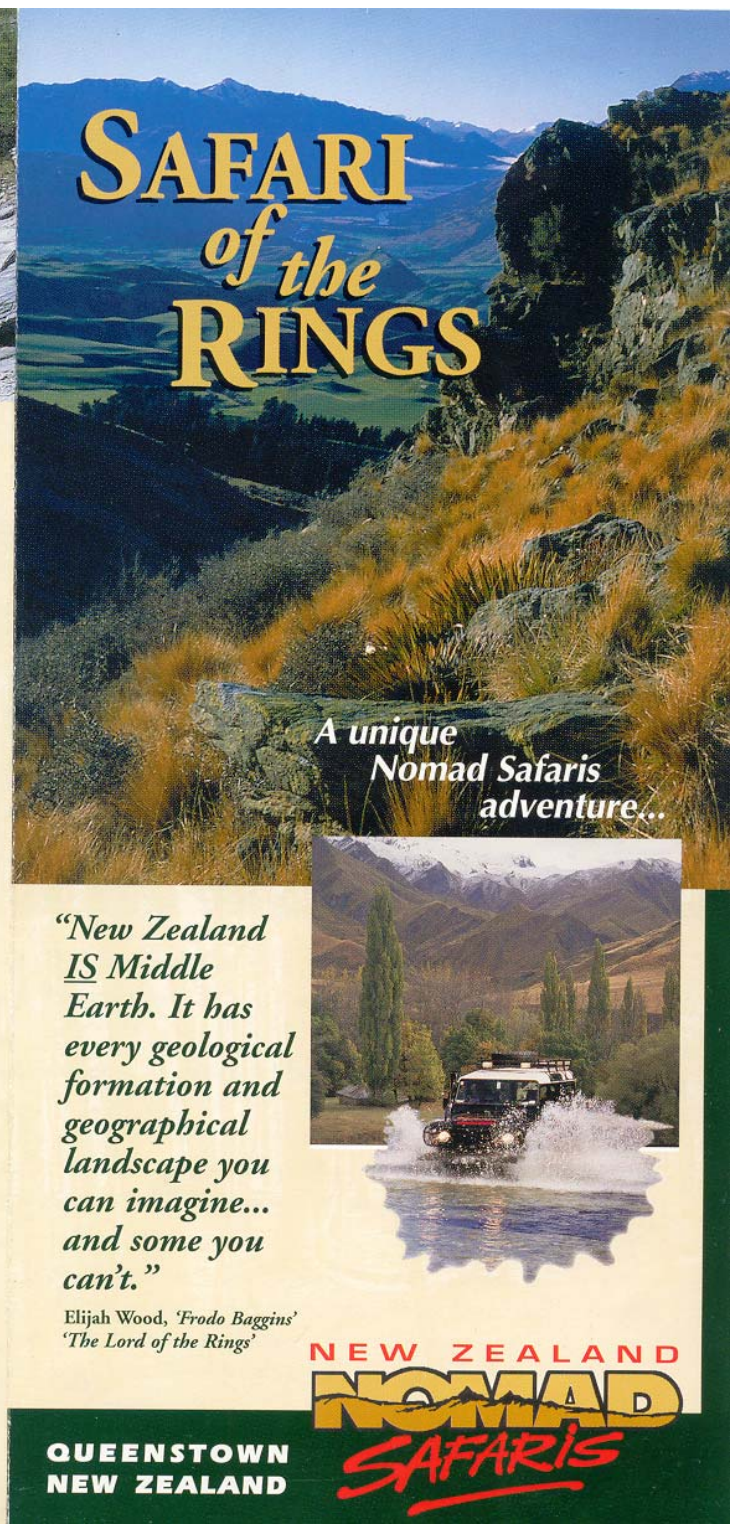


Inside

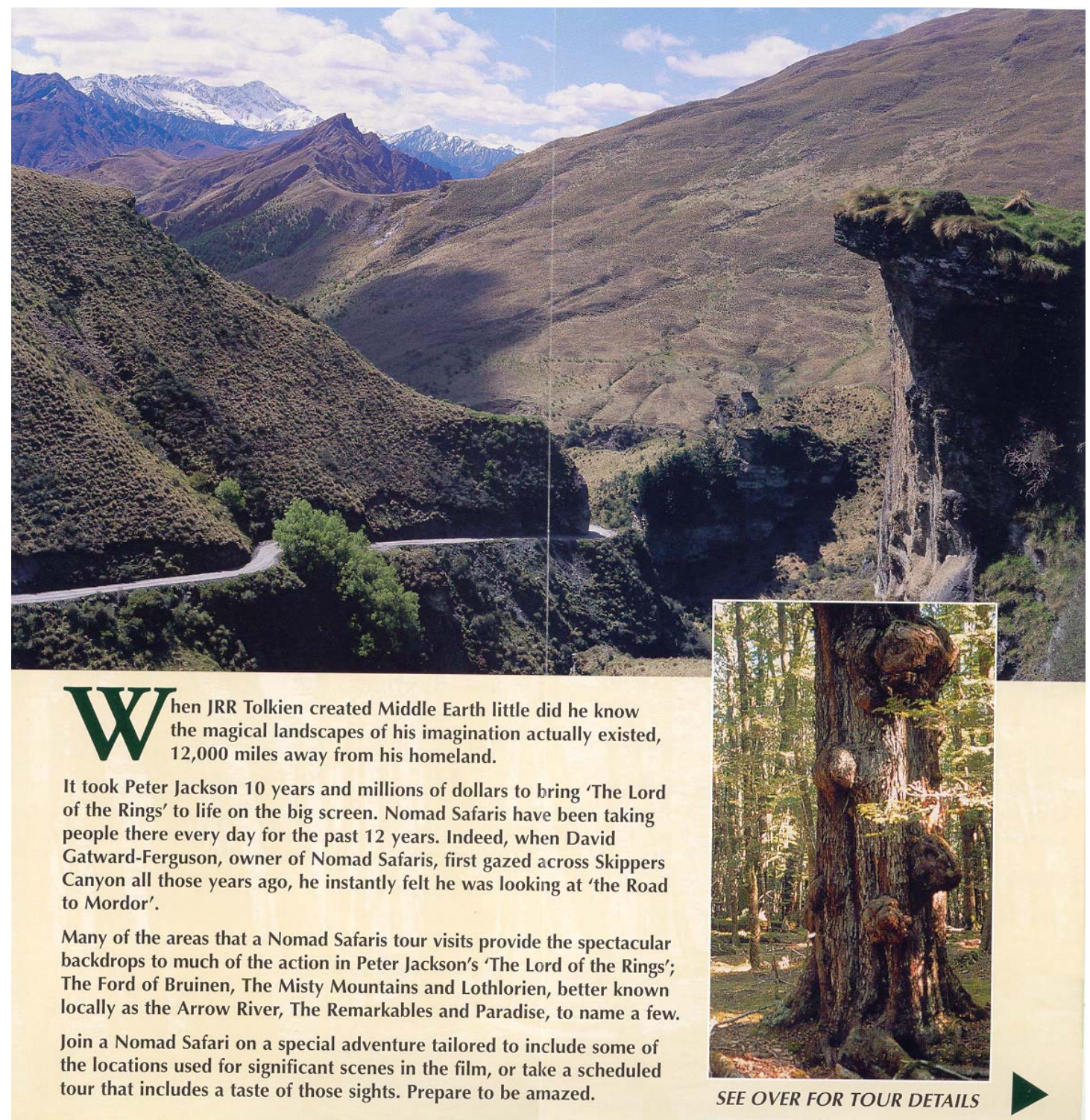




\section{Postcards of Rings Scenic Tours and Hobbiton site near Matamata}
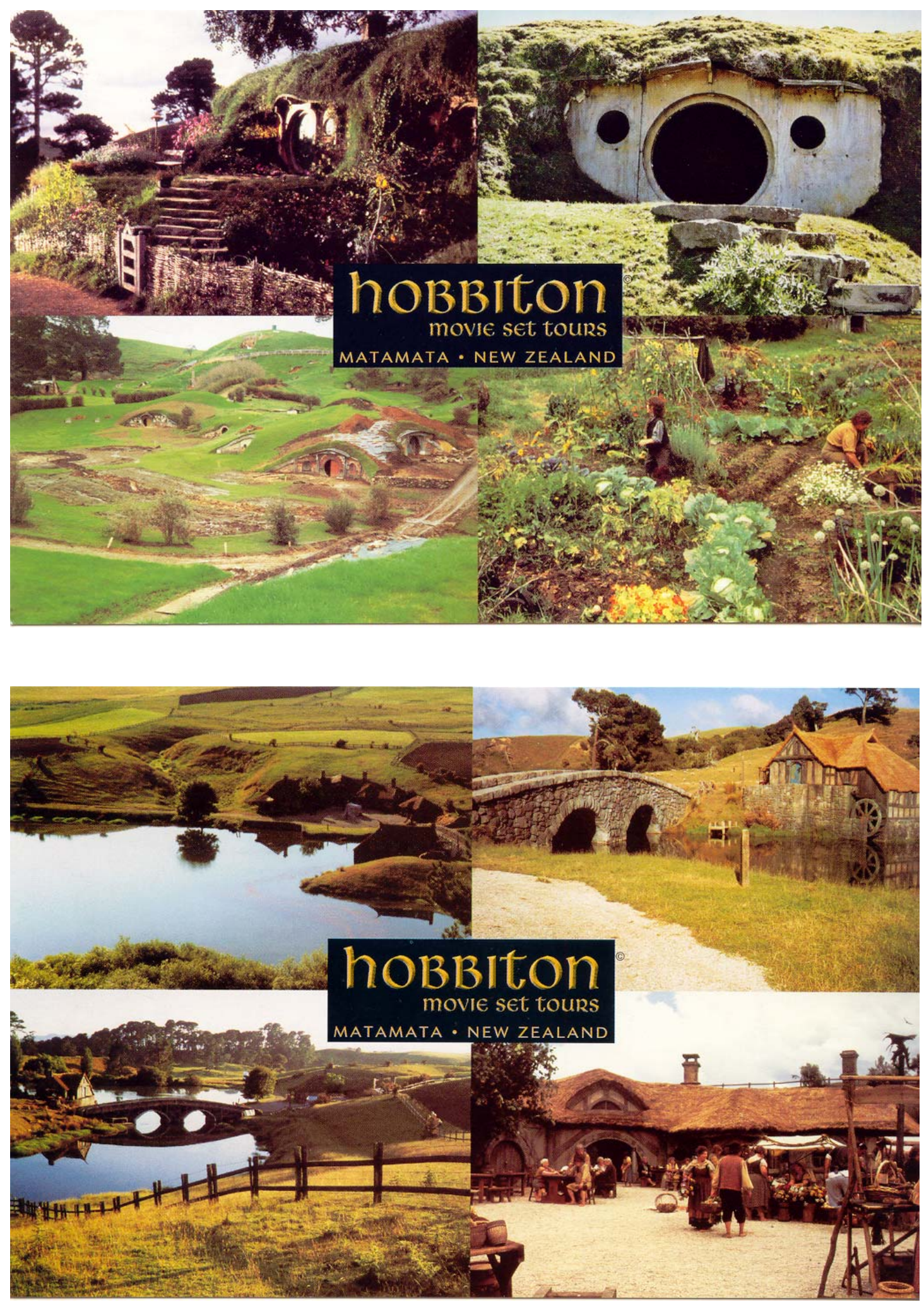
Iconic Landscapes named by all respondents

\begin{tabular}{|c|c|c|}
\hline $\begin{array}{l}\text { Landscapes } \\
\text { named }\end{array}$ & Theme & $\begin{array}{l}\text { Naming (in \%) } \\
\mathrm{n}=204\end{array}$ \\
\hline $\begin{array}{l}\text { The Shire/ Hobbiton - } \\
\text { Matamata }\end{array}$ & Hobbiton & 33.3 \\
\hline $\begin{array}{l}\text { Misty Mountains/ } \\
\text { Mountains of Moria - } \\
\text { Southern Alps/ snow- } \\
\text { capped mountains/ } \\
\text { mountains/ mountain } \\
\text { ranges/ snow/ } \\
\text { Queenstown/ The } \\
\text { Remarkables }\end{array}$ & The Remarkables & 15.2 \\
\hline Rivendell & Rivendell & 8.3 \\
\hline $\begin{array}{l}\text { Edoras/ Rohan - } \\
\text { Mt Sunday/Mt Pott } \\
\text { Station }\end{array}$ & Edoras & 7.8 \\
\hline $\begin{array}{l}\text { Mordor/ Mt Doom - } \\
\text { Tongariro National } \\
\text { Park/ Iwikau Village/ } \\
\text { Whakapapa Ski field/ } \\
\text { Taupo/ Mt Ruapehu }\end{array}$ & Mordor & 5.9 \\
\hline Isengard & Isengard & 2.5 \\
\hline Lothlórien & Lothlórien & 2.5 \\
\hline $\begin{array}{l}\text { River Anduin/ } \\
\text { Argonath - } \\
\text { rivers/ canoeing down } \\
\text { the fiords }\end{array}$ & River Anduin & 2 \\
\hline $\begin{array}{l}\text { Moria/ Bridge of } \\
\text { Khazad-dûm }\end{array}$ & Moria & 1 \\
\hline Helms Deep & Helms Deep & 1 \\
\hline $\begin{array}{l}\mathrm{NZ} \text { countryside/ much } \\
\text { of NZ/ all of NZI } \\
\text { Everywhere! }\end{array}$ & New Zealand & 7.4 \\
\hline
\end{tabular}


New Zealand's landscapes and Middle-earth similarities named by respondents

\section{Question 4}

On a scale of 1-5, please tell me how much you relate New Zealand's landscape to Middle-earth? (Please circle number)

1

New Zealand

is Middle-earth
2

neutral
4

5

no similarities

\section{Please explain your answer!}

Themed groups of explanations (all respondents)

$\mathrm{NZ}=$ Middle-earth $($ books)

\begin{tabular}{|ll|}
$\begin{array}{l}\text { Number } \\
\text { indicated } \\
\text { on scale }\end{array}$ & Explanation \\
\hline 2 & Landscapes similar to those described by Tolkien \\
\hline 1 & $\begin{array}{l}\text { Having travelled a fair amount of the world NZ most closely represents landscapes I } \\
\text { visualised whilst reading Tolkien. }\end{array}$ \\
\hline 2 & NZ had lakes, mountains, volcanoes and lowland in just an island same as Middle-earth. \\
\hline 1 & $\begin{array}{l}\text { The geographical locations match the ones from the book. NZ's incredible geographic } \\
\text { diversity truly makes it seem like its own compact little universe. }\end{array}$ \\
\hline 1 & Because it is Middle-earth. \\
\hline 1 & Because it looks like Middle-earth. \\
\hline 1 & As I imagined it after reading the book. \\
\hline 2 & Of all the places I have been, NZ most is like how I picture it. \\
\hline 2 & Many locations are as I would imagine in the book. \\
\hline 1 & Such exact picture of the ones described in the books. \\
\hline 1 & Everything is exactly as l'd imagined. \\
\hline 2 & Seeing the film was like my images from the book. \\
\hline 2 & The breathtaking beauty of NZ fulfils the imagined image of Middle-earth. \\
\hline 1 & It is so close to the descriptions Tolkien described! \\
\hline 1 & The look and feel are both right. I agree with Sean Austin: 'It's as though JRR Tolkien \\
& walked through NZ and then wrote the book". \\
\hline 1 & The places in the film are very much like that described in the book. \\
\hline 1 & Fantastic range of landscape types match perfectly with imaginary lands of the storyline. \\
\hline 1 & NZ's remote wilderness is just what JRR Tolkien had in mind! \\
\hline 1 & Tolkien could have written LOTR as being in New Zealand. \\
\hline 1 & NZ has all the landscapes described by Tolkien. \\
\hline & Can see scenes of The Lost Tales of Numenor and The Simarillion here. \\
\hline 1 & The landscape is uncanny to Middle-earth. \\
\hline 1 &
\end{tabular}




\section{NZ = Middle-earth (films)}

\begin{tabular}{|ll|}
\hline $\begin{array}{l}\text { Number } \\
\text { indicated } \\
\text { on scale }\end{array}$ & Explanation \\
\hline 1 & It was all filmed here. \\
\hline 1 & NZ has the magesticness of the movie scenery. \\
\hline 2 & It is the only visual representation there is! \\
\hline 1 & A lot of similarities between the film and the description of Tolkien. \\
\hline 1 & It was very much like it was in the movie. \\
\hline 1 & $\begin{array}{l}\text { Having seen New Zealand and LotR 1\&2 I cannot imagine any other location for Middle- } \\
\text { earth. }\end{array}$ \\
\hline 2 & Perfect location for the movie. \\
\hline 2 & The depicted landscapes matches well with NZ. \\
\hline
\end{tabular}

\section{Diversity of landscapes}

\begin{tabular}{|ll|}
\hline $\begin{array}{l}\text { Number } \\
\text { indicated } \\
\text { on scale }\end{array}$ & Explanation \\
\hline 1 & Landscape life nowhere else in a small area. \\
\hline 1 & $\begin{array}{l}\text { Because NZ has rugged and unspoiled views and undeveloped and unpolluted } \\
\text { landscape which to me is Middle-earth. }\end{array}$ \\
\hline 1 & $\begin{array}{l}\text { Well this is a country which is relatively small which has a rugged landscape and such a } \\
\text { great variation of climate, for example sun, rain, snow. }\end{array}$ \\
\hline 1 & $\begin{array}{l}\text { Idon't think there is another place on earth where the landscape varies as much as NZ } \\
\text { does to be worthy of being called Middle-earth. }\end{array}$ \\
\hline 1 & I've seen nowhere else on earth like it! \\
\hline 1 & We have such a wonderful contrast in our landscape to capture it all. \\
\hline 1 & $\begin{array}{l}\text { The variety of landscapes in NZ changes so much in a short time: Mountains, farmlands, } \\
\text { deserts, coastlines. }\end{array}$ \\
\hline 2 & Couldn't imagine it in any other country. \\
\hline 1 & $\begin{array}{l}\text { NZ offers a wonderful mix of landscapes, but, naturally, not in the same patterns as } \\
\text { Tolkien's Middle-earth. }\end{array}$ \\
\hline 1 & $\begin{array}{l}\text { So diverse! Jagged sunny mountains, unusual rock formations as seen in Rohan; crystal } \\
\text { clear lakes like Mavora; rolling green hills like Hobbiton; volcanic boulders like Mordor - } \\
\text { all on these islands! Where else would you find something like Mt Sunday? }\end{array}$ \\
\hline 2 & $\begin{array}{l}\text { The different landscapes often in a very short space of time, strange rock formations, } \\
\text { plant life all lending to the sense of 'another world'. Plus the lack of people/ traffic etc. }\end{array}$ \\
\hline & Such a varied landscape it can well accommodate the features of Middle-earth. \\
\hline
\end{tabular}

\section{$\mathrm{NZ}=$ Middle-earth naturally}

\begin{tabular}{|ll|}
\hline $\begin{array}{l}\text { Number } \\
\text { indicated } \\
\text { on scale }\end{array}$ & Explanation \\
\hline 1 & All is very magical, mystical, unspoiled \\
\hline 2 & NZ has the unspoiled and beautiful landscape that is in the film. \\
\hline 2 & Unspoiled nature; beautiful landscape \\
\hline 1 & $\begin{array}{l}\text { The scenery and landscape represents medieval ages. Geographical formations are } \\
\text { abundant and pure nature is at work! }\end{array}$ \\
\hline 2 & New Zealand has natural beauty \\
\hline 2 & Looks the same- rainy and gloomy. \\
\hline
\end{tabular}




\begin{tabular}{|ll|}
\hline 2 & Rolling green hills to flat desolate rocks. Exactly the same. \\
\hline 1 & Looks so natural \\
\hline 1 & Landscape unaltered in filming. \\
\hline 1 & So rustic and untouched. \\
\hline 1 & It's all natural \\
\hline 2 & Very similar; easy to see why they picked it; remote. \\
\hline 1 & Because it is just so specific and perfect. \\
\hline 1 & Green, beautiful, be wilding landscape. \\
\hline 1 & Most natural and not man made. \\
\hline 1 & It's more than just topography though that's magically ME, there's a magical feeling here. \\
\hline 1 & I told Vic James that ME has been the home in my dreams for over 35 years, and now I \\
\hline
\end{tabular}

\section{$\mathrm{NZ} \neq$ Middle-earth}

\begin{tabular}{|ll|}
\hline $\begin{array}{l}\text { Number } \\
\text { indicated } \\
\text { on scale }\end{array}$ & Explanation \\
\hline- & The two are not equitable. NZ is a country in it's own right. Bad question. \\
\hline- & Don't know never been to Middle-earth. \\
\hline 2 & Middle-earth wasn't tainted by humans, NZ landscape had been. \\
\hline 3 & I think Middle-earth is a marketing phrase. I'm not a fanatic. \\
\hline 2 & In the back of my mind I remember it is a European based saga. \\
\hline 2 & Stupid question. \\
\hline
\end{tabular}

\section{$\mathrm{NZ}=$ Middle-earth but only with the aid of computer wizardry}

\begin{tabular}{|ll|}
\hline $\begin{array}{l}\text { Number } \\
\text { indicated } \\
\text { on scale }\end{array}$ & Explanation \\
\hline 2 & $\begin{array}{l}\text { NZ's incredible geographic diversity truly makes it seem like its own compact little } \\
\text { universe (but it still takes a bit digital doctoring to make it seem like Middle-earth) }\end{array}$ \\
\hline 3 & $\begin{array}{l}\text { As I understand, a lot of the film featured digitally enhanced landscapes, so upon viewing } \\
\text { the scenery, didn't connect with the films. }\end{array}$ \\
\hline 2 & $\begin{array}{l}\text { The way it is depicted in the film is spot on, real life is fantastic but the extra "glame" } \\
\text { makes it. }\end{array}$ \\
\hline 2 & With a bit of imagination for the computer mastery-then it's Middle-earth! \\
\hline
\end{tabular}

\section{NZ partial like Middle-earth}

\begin{tabular}{|ll|}
\hline $\begin{array}{l}\text { Number } \\
\text { indicated } \\
\text { on scale }\end{array}$ & Explanation \\
\hline 2 & Very similar to Middle-earth, but not quite 'wild' enough. \\
\hline 2 & So similar with only minute differences \\
\hline 1 & Hobbiton fits the image. \\
\hline 2 & All the countryside is just as you imagine Middle-earth. \\
\hline 2 & Out of town areas and mountains \\
\hline 2 & Certain things remind me of a few parts: cornfields, mountains, etc. \\
\hline 2 & NZ is Middle-earth but is also still simply NZ with beautiful and unique landscape and \\
\hline
\end{tabular}




\begin{tabular}{|ll|}
\hline \multicolumn{2}{|c|}{ nature :-) } \\
\hline 3 & Some did some didn't \\
\hline 2 & $\begin{array}{l}\text { Obviously certain aspects of landscapes were quite lie "Middle-earth" near the FILMING } \\
\text { LOCATIONS. }\end{array}$ \\
\hline 3 & Some sites reminded me of Middle-earth and some didn't. \\
\hline 1 & Expected a few less pine trees in Middle-earth- but it was Middle-earth. \\
\hline 2 & It is Middle-earth with a bit of Europe and a bit of Aussie in. \\
\hline 3 & It has similarities but it is more developed then shown in the film. \\
\hline
\end{tabular}


Adjectives for the landscapes in the films and the real landscapes named by all respondents

\begin{tabular}{|c|c|c|c|c|}
\hline $\begin{array}{l}\text { Landscapes } \\
\text { in the film(s) }\end{array}$ & $\begin{array}{l}\text { Rings } \\
\text { Scenic } \\
\text { Tours } \\
\text { naming }\end{array}$ & $\begin{array}{l}\text { Red Carpet } \\
\text { Tours } \\
\text { naming }\end{array}$ & $\begin{array}{l}\text { Safari of the } \\
\text { Rings } \\
\text { naming }\end{array}$ & Sum of naming \\
\hline Amazing & & 12 & 1 & 4 \\
\hline Ancient & & 1 & & \\
\hline Authentic & & 1 & & \\
\hline Awe-inspiring & & 1 & 2 & 2 \\
\hline Awesome & & 7 & 3 & 4 \\
\hline Barren & & 1 & & \\
\hline Beautiful & & 31 & 4 & 4 \\
\hline Bewildering & & 1 & & \\
\hline Big & & & 1 & \\
\hline Breathtaking & & 19 & 7 & 2 \\
\hline Bright & & 1 & & \\
\hline Bucolic & & 1 & & \\
\hline Captivating & & 1 & 1 & 1 \\
\hline Contrasting & & 1 & & \\
\hline Cool & & 2 & & \\
\hline Different, varied, diverse & & 3 & 2 & \\
\hline Dramatic & & 5 & 1 & 1 \\
\hline Dreary & & 1 & & \\
\hline Elegant & & 1 & & \\
\hline Evocative & & & 1 & \\
\hline Exciting & & 2 & 1 & \\
\hline Expansive & & & 1 & \\
\hline Extraordinary & & & 1 & \\
\hline Extravagant & & 1 & & \\
\hline Fantastic & & 9 & 1 & 2 \\
\hline Farmland & & 1 & & \\
\hline Fascinating & & 1 & & \\
\hline Fictional & & & 1 & 1 \\
\hline Foreboding & & 3 & & \\
\hline Fresh & & & 1 & \\
\hline Grandeur & & 2 & 1 & \\
\hline Great & & 1 & & \\
\hline Green & & 10 & 1 & \\
\hline Heaven & & 1 & & \\
\hline
\end{tabular}




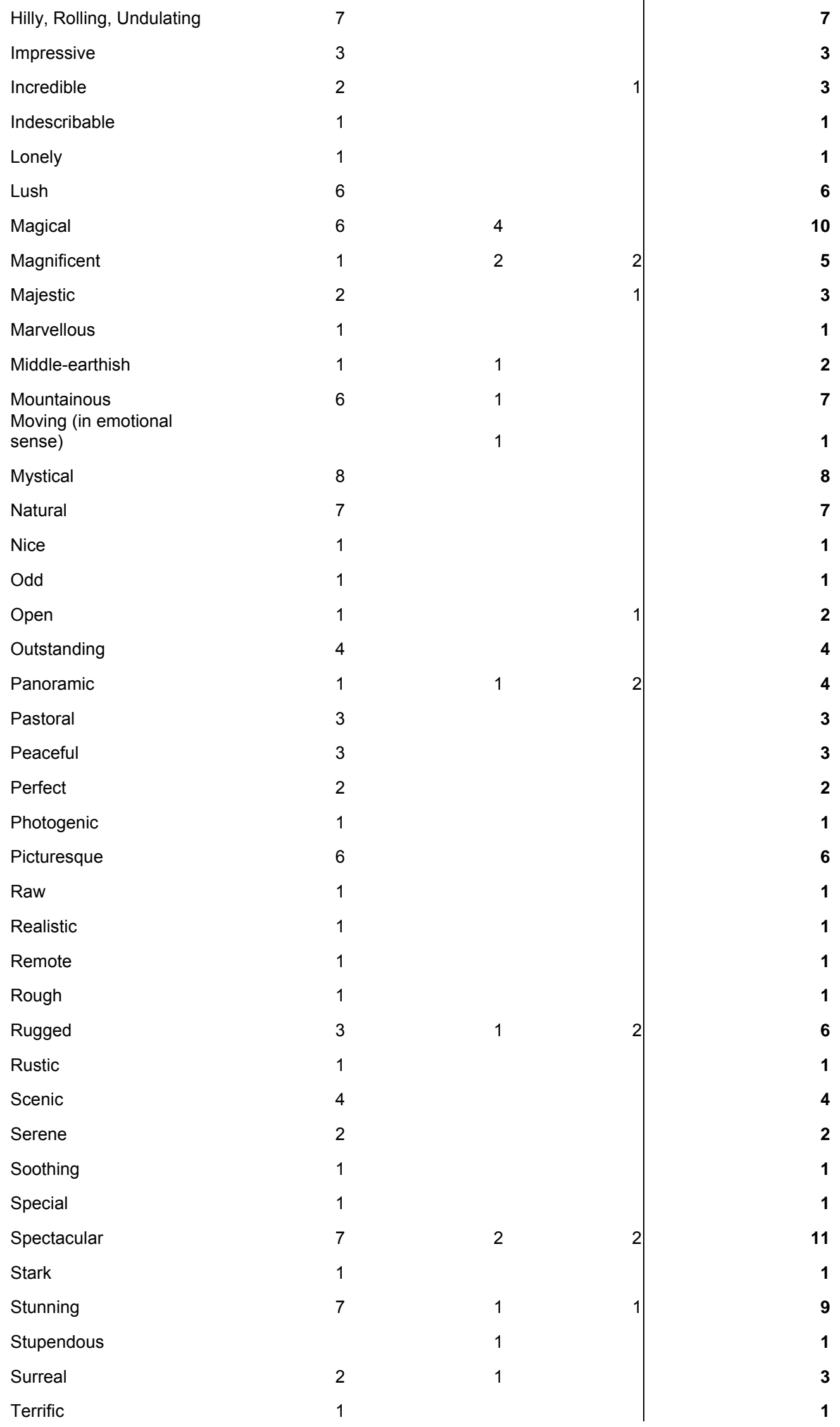




$\begin{array}{ll}\text { Therapeutic } & 1 \\ \text { Timeless } & 3 \\ \text { Tranquil } & 2 \\ \text { Unbelievable } & 2 \\ \text { Unique } & \\ \text { Unreal } & 5 \\ \text { Untouched, Unspoiled } & 1 \\ \text { Vast } & 1 \\ \text { Vibrant } & 1 \\ \text { Vivid } & 1 \\ \text { Volcanic } & 1 \\ \text { Well chosen } & 4 \\ \text { Wild, Untamed } & \\ \text { Wonderful } & \end{array}$

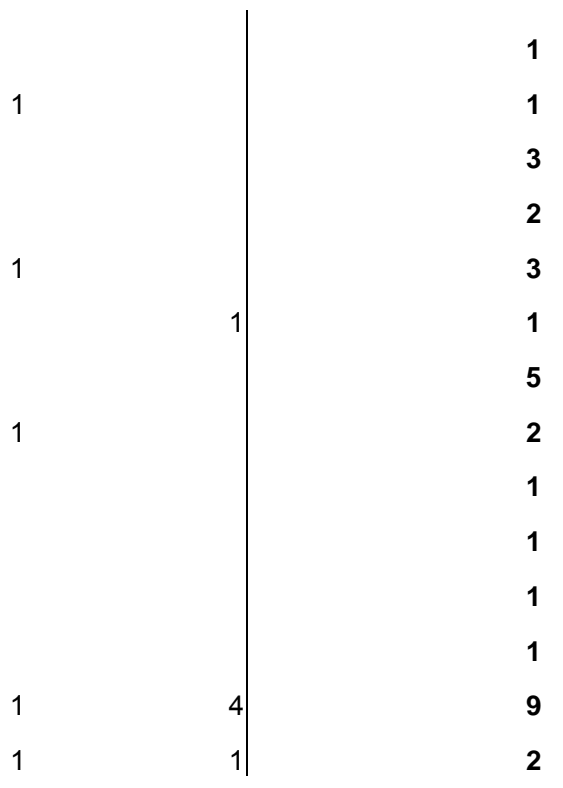

Real landscapes Rings of the former film Scenic site(s)

Tours

Red Carpet

Safari of the naming naming Rings

naming

Sum of naming

Adventurous

1

Alive

1

Amazing

5

Authentic

1

Awe-inspiring

Awesome

Barren

2

Beautiful

1

Believable

12

1

1

3

2

3

1

5

2

1

1

1

1

9

2

Big

Breathtaking

Bushy

Calm, quiet

Charming

1

Clean

Cold

Cool

Cute

1

Déjà-vu

Empty

English

4

Evocative

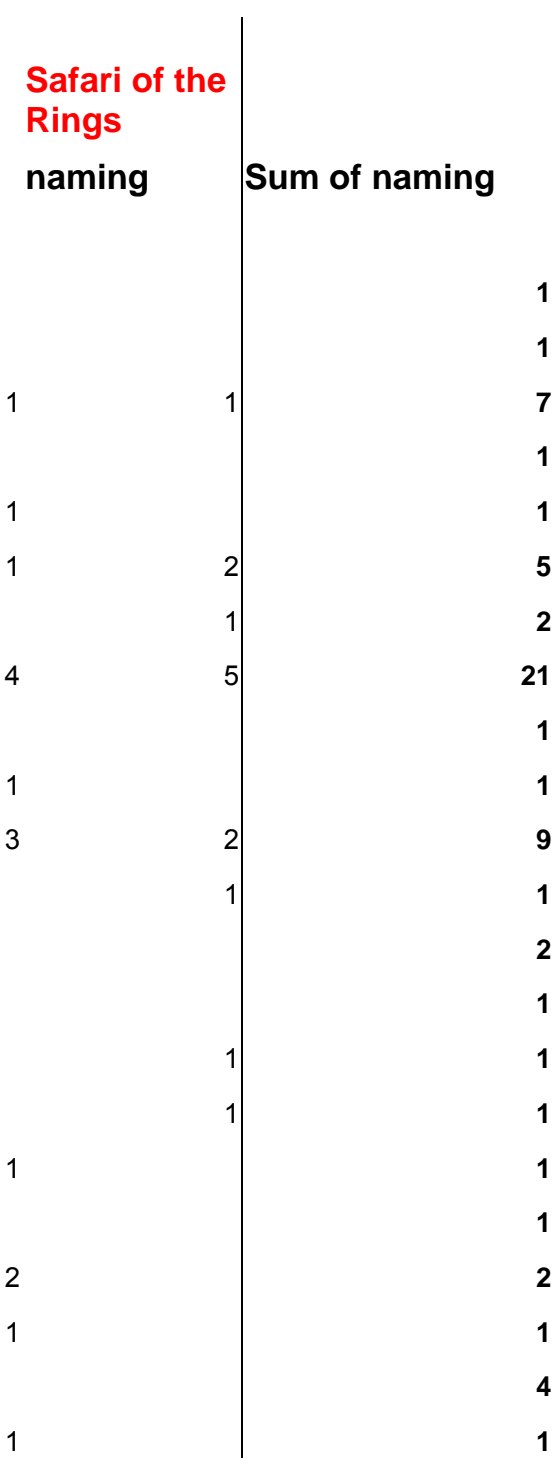




\begin{tabular}{|c|c|c|c|c|}
\hline Exciting & 1 & & & 1 \\
\hline Extraordinary & & 1 & & 1 \\
\hline Fantastic & 6 & 1 & 1 & 8 \\
\hline Farmland & 1 & & & 1 \\
\hline Friendly & 1 & & & 1 \\
\hline Good & 2 & & & 2 \\
\hline Gorgeous & 2 & 1 & 1 & 4 \\
\hline Grandeur & 1 & & & 1 \\
\hline Great & 2 & & & 2 \\
\hline Green & 23 & 1 & & 24 \\
\hline Hilly, Rolling, Bumpy & 18 & & & 18 \\
\hline Impressive & 2 & & & 2 \\
\hline Incredible & & 1 & & 1 \\
\hline Less dramatic & & & 1 & 1 \\
\hline Lovely & 1 & 1 & & 2 \\
\hline Lush & 7 & & & 7 \\
\hline Magical & 1 & 3 & & 4 \\
\hline Magnificent & & 2 & & 2 \\
\hline Met expectations & & & 1 & 1 \\
\hline More commercial & & & 1 & 1 \\
\hline Muddy & 1 & & & 1 \\
\hline Mystical & 1 & 1 & & 2 \\
\hline Natural & 5 & & 2 & 7 \\
\hline Nice & 1 & & & 1 \\
\hline Panoramic & 2 & & 1 & 3 \\
\hline Pastoral & 5 & & & 5 \\
\hline Peaceful & 6 & & 1 & 7 \\
\hline Perfect & 3 & & & 3 \\
\hline Picturesque & 4 & & & 4 \\
\hline Pretty & 1 & & & 1 \\
\hline Pristine & 1 & 1 & & 2 \\
\hline Pure & 1 & & & 1 \\
\hline Quiet & & & 1 & 1 \\
\hline Real ME & 1 & & & 1 \\
\hline Realistic & 1 & & 1 & 2 \\
\hline Remarkable & 1 & & & 1 \\
\hline Remote & 2 & 1 & & 3 \\
\hline Rocky & & & 1 & 1 \\
\hline Rugged & 4 & 3 & 1 & 8 \\
\hline Rustic & 1 & & & 1 \\
\hline Scenic & 3 & 1 & & 4 \\
\hline Serene & 2 & & 1 & 3 \\
\hline
\end{tabular}




\begin{tabular}{|c|c|c|c|}
\hline $\begin{array}{l}\text { Sheepy, lots of sheep, } \\
\text { sheep poo }\end{array}$ & 7 & & 7 \\
\hline Spacy & 1 & & 1 \\
\hline Spectacular & 3 & 3 & 6 \\
\hline Stunning & 2 & 2 & 4 \\
\hline Stupendous & & 1 & 1 \\
\hline Surreal & & 2 & 2 \\
\hline Tranquil & 2 & & 2 \\
\hline Unbelievable & 1 & & 1 \\
\hline Undulating beauty & 1 & & 1 \\
\hline Unique & 1 & & 1 \\
\hline Unseen & 1 & & 1 \\
\hline Untouched, Unspoiled & 2 & 2 & 5 \\
\hline Varied & & 1 & 1 \\
\hline Vast & 2 & 1 & 3 \\
\hline Verdant & 1 & & 1 \\
\hline Visual & & 1 & 1 \\
\hline Well chosen & 1 & & 1 \\
\hline Wide & 1 & & 1 \\
\hline Wild, Untamed & 1 & 1 & 3 \\
\hline Wonderful & 2 & 1 & 3 \\
\hline
\end{tabular}




\section{Expectations}

\section{Question 6}

Were the film locations/ landscapes you have visited as you expected them to be? (Please circle number)

1

much better than expected
2 better than expected
3

as expected
4

worse than expected
5

much worse

than expected

Please explain your answer!

\section{Expectation specifications two half-day tour experiences}

\section{Expectations exceeded}

\section{$>$ Positively surprised}

\begin{tabular}{|c|c|}
\hline \multicolumn{2}{|c|}{ Rings Scenic Tours/ Matamata } \\
\hline $\begin{array}{l}\text { Number } \\
\text { indicated } \\
\text { on scale }\end{array}$ & Explanation \\
\hline 2 & It has more houses than I expected. \\
\hline 2 & There were more holes still there than expected. \\
\hline 1 & I wasn't getting my hopes up and I was pleasantly surprised. \\
\hline 1 & I didn't realise that as much as the set was left as it was. \\
\hline 1 & I didn't expect the hobbit holes to be in so good condition. \\
\hline 1 & $\begin{array}{l}\text { I did not think here would be as much retained set and the description from the tour } \\
\text { guides just made it come alive. }\end{array}$ \\
\hline 1 & Good explained. Houses better than expected. \\
\hline 1 & More was left than I thought. \\
\hline 2 & I had heard that everything was gone and there was more there than I expected. \\
\hline 2 & $\begin{array}{l}\text { No amount of photography or film can show adequately the beauty of the landscape in } \\
\text { NZ. }\end{array}$ \\
\hline 1 & Mountains and hills were so beautiful \\
\hline 2 & $\begin{array}{l}\text { I was surprised and delighted that the set was actually built around the natural beauty } \\
\text { and landscape, such as the lake and the party tree. And that the scenery that I had seen } \\
\text { in the film actually did exist in its natural state and wasn't man made or computer } \\
\text { enhanced. }\end{array}$ \\
\hline 1 & $\begin{array}{l}\text { Because I thought it was going to be totally man made but from what I seen it could have } \\
\text { been filmed any place on the farm. }\end{array}$ \\
\hline 3 & $\begin{array}{l}\text { I was not sure if the company that produced the movie to enhance the colour. I } \\
\text { suspected so, although I knew the land must be beautiful to start. }\end{array}$ \\
\hline 3 & They don't look exactly the same but one doesn't expect them to. They're very beautiful \\
\hline
\end{tabular}




\begin{tabular}{|c|c|}
\hline & $\begin{array}{l}\text { and it's good to see there are real places that can so inspire a filmmaker (not just artificial } \\
\text { landscapes). [did the tour the second time] }\end{array}$ \\
\hline 1 & Much more thorough tours than expected \\
\hline 1 & $\begin{array}{l}\text { A lot more detail- a must to see the movie again as appreciate the attention to detail that } \\
\text { was achieved so well. }\end{array}$ \\
\hline 2 & It gave an insight into the movie. \\
\hline \multicolumn{2}{|c|}{ Safari of the Rings/ Queenstown } \\
\hline $\begin{array}{l}\text { Number } \\
\text { indicated } \\
\text { on scale }\end{array}$ & Explanation \\
\hline 3 & $\begin{array}{l}\text { The filming obviously made the landscape more that it would appear naturally, but the } \\
\text { essential beauty at the locations was still evident }\end{array}$ \\
\hline 1 & The mountains of QT were absolutely believable, spectacular! \\
\hline
\end{tabular}

$>$ Excited about opportunity to visit a film set

\begin{tabular}{|ll|}
\hline \multicolumn{2}{|l|}{ Rings Scenic Tours/ Matamata } \\
\hline $\begin{array}{l}\text { Number } \\
\text { indicated } \\
\text { on scale }\end{array}$ & Explanation \\
\hline 1 & I was able to see the inside of the holes \\
\hline 1 & Never been on a 'film set' before; imagination runs riots \\
\hline 2 & Being allowed in them and close made it better \\
\hline
\end{tabular}

$>$ General expressions of enjoyment

\begin{tabular}{|c|c|c|c|}
\hline & ic Tours/ Matamata & Rings Scen & c Tours/ Matamata \\
\hline & & $\begin{array}{l}\text { Number } \\
\text { indicated on } \\
\text { scale }\end{array}$ & Explanation \\
\hline & & 1 & It's cool \\
\hline & & 2 & It was pretty good \\
\hline & & 1 & Very beautiful and handsome. Good tour guide \\
\hline & & 2 & Seeing the reality of hobbiton is super \\
\hline & Rings/ Queenstown & Safari of the & Rings/ Queenstown \\
\hline & & $\begin{array}{l}\text { Number } \\
\text { indicated } \\
\text { on scale }\end{array}$ & Explanation \\
\hline & & 2 & Great to see locations in real life \\
\hline & & 2 & Fantastic! \\
\hline
\end{tabular}




\section{Expectations met}

$>$ Research prior trip

\begin{tabular}{|ll|}
\hline \multicolumn{2}{|l|}{ Rings Scenic Tours/ Matamata } \\
\hline $\begin{array}{l}\text { Number } \\
\text { indicated } \\
\text { on scale }\end{array}$ & Explanation \\
\hline 3 & Similar to what I had read about. \\
\hline 3 & Seen previous visitor photos \\
\hline 3 & $\begin{array}{l}\text { I knew most of the set had been returned to original state. The best thing about the tour } \\
\text { was information given by guides. }\end{array}$ \\
\hline 3 & $\begin{array}{l}\text { I'd seen pictures on the hobbitontours.com website, and knew what to expect as far as } \\
\text { the conditions of the site. }\end{array}$ \\
\hline 3 & $\begin{array}{l}\text { I would have been number 4 (worse than expected) if I hadn't seen the photo on the } \\
\text { brochure (present day). }\end{array}$ \\
\hline 3 & I've seen brochures so knew what to expect. \\
\hline Safari of the Rings/ Queenstown \\
\hline $\begin{array}{l}\text { Number } \\
\text { indicated } \\
\text { on scale }\end{array}$ & Explanation \\
\hline 3 & I had done a bit of research on the net prior my trip. \\
\hline
\end{tabular}

$>$ Could recognise film site(s)

\begin{tabular}{|ll|}
\hline \multicolumn{2}{|l|}{ Rings Scenic Tours/ Matamata } \\
\hline $\begin{array}{l}\text { Number } \\
\text { indicated } \\
\text { on scale }\end{array}$ & Explanation \\
\hline 1 & Left a lot to the imagination but allowed you to visualize scenes from the movie. \\
\hline 3 & Nearly just like the movie. \\
\hline 2 & Seemed so real untouched. \\
\hline 2 & Could relate to the actual film. \\
\hline 3 & Looked just as I remembered it pictured in the film. \\
\hline 2 & I can relate all the things to the movie \\
\hline 3 & $\begin{array}{l}\text { Much of the set was still like the movie, the terrain and trees. However, it would be nice } \\
\text { to have intact like the original set. }\end{array}$ \\
\hline Safari of the Rings/ Queenstown \\
\hline $\begin{array}{l}\text { Number } \\
\text { indicated } \\
\text { on scale }\end{array}$ & Explanation \\
\hline 3 & $\begin{array}{l}\text { I recognised most of them immediately and even taking film limitations into account, } \\
\text { they were as they appeared on screen. }\end{array}$ \\
\hline
\end{tabular}


$>$ Did not expect the set as it was in the film

\begin{tabular}{|ll|}
\hline Rings Scenic Tours/ Matamata \\
\hline $\begin{array}{l}\text { Number } \\
\text { indicated } \\
\text { on scale }\end{array}$ \\
\hline 3 & Explanation \\
\hline 3 & Didn't think they'd be like the films \\
\hline
\end{tabular}

\section{Expectations not met}

$>$ Expected more to be left and in better conditions/ expected film locations to look more like in the films

\begin{tabular}{|c|c|}
\hline \multicolumn{2}{|c|}{ Rings Scenic Tours/ Matamata } \\
\hline $\begin{array}{l}\text { Number } \\
\text { indicated } \\
\text { on scale }\end{array}$ & Explanation \\
\hline 3 & It's the ghost of a movie set! What else can you say? \\
\hline 4 & Would have liked the set more intact. \\
\hline 2 & Wished that they had not demolished the original ones around. \\
\hline 4 & They didn't look as similar to the movie as I thought they might. \\
\hline 3 & $\begin{array}{l}\text { I thought the hobbit houses would still be complete. In fact it is a ruined town, a ghost } \\
\text { town. }\end{array}$ \\
\hline 3 & I have seen them in the films and obviously time will take its roll over the years. \\
\hline \multicolumn{2}{|c|}{ Safari of the Rings/ Queenstown } \\
\hline $\begin{array}{l}\text { Number } \\
\text { indicated } \\
\text { on scale }\end{array}$ & Explanation \\
\hline 3 & The real difference is that they are smaller than expected. \\
\hline 3 & $\begin{array}{l}\text { There's no evidence of the film or Middle-earth. The sets added to the landscape to } \\
\text { create the illusion of Middle-earth. }\end{array}$ \\
\hline
\end{tabular}

$>$ Wanted more natural experience

Rings Scenic Tours/ Matamata

Number Explanation

indicated

on scale 


\begin{tabular}{|ll|}
\hline 2 & Natural area instead of being built up like a film set \\
\hline 4 & Landscape is perfect but hobbiton was rebuilt \\
\hline
\end{tabular}

\section{No Expectations}

\begin{tabular}{|c|c|}
\hline \multicolumn{2}{|c|}{ Rings Scenic Tours/ Matamata } \\
\hline $\begin{array}{l}\text { Number } \\
\text { indicated } \\
\text { on scale }\end{array}$ & Explanation \\
\hline 3 & Had no expectations \\
\hline 2 & Didn't know what to expect \\
\hline 2 & Unsure what to expect \\
\hline 2 & $\begin{array}{l}\text { Having no real expectations of the Shire, I was pleasantly surprised to see how like the } \\
\text { movie the actual area already is. }\end{array}$ \\
\hline 2 & Didn't expect much \\
\hline \multicolumn{2}{|c|}{ Safari of the Rings/ Queenstown } \\
\hline $\begin{array}{l}\text { Number } \\
\text { indicated } \\
\text { on scale }\end{array}$ & Explanation \\
\hline 2 & I had no idea what to expect. \\
\hline
\end{tabular}

\section{Other film sites visited}

Rings Scenic Tours/ Matamata

Number Explanation

indicated

on scale

$2 \quad$ hobbiton $=2 /$ rivendell=4 because not much instruction, no part of set left to see

3 I have only visited Mt Ruapehu, where I believed some of the Mordor battle scenes were filmed, and thus was barren as expected

Expectation specifications multi-day tour experience

\section{Expectations exceeded}

$>$ General expressions of enjoyment
Number
Explanation

indicated 
Positively surprised about landscapes

\begin{tabular}{|ll|}
\hline $\begin{array}{l}\text { Number } \\
\text { indicated } \\
\text { on scale }\end{array}$ & Explanation \\
\hline 1 & $\begin{array}{l}\text { They were breathtaking-spectacular- especially Lothlorien and Fangorn Forest and the } \\
\text { Misty Mountains }\end{array}$ \\
\hline 1 & The small screen does not do justice to the vast beauty of the NZ landscapes. \\
\hline 1 & They are mainly unchanged untouched and not commercialised. \\
\hline 1 & $\begin{array}{l}\text { Even more raw and unspoiled in reality. Get an even better sense of the vastness of the } \\
\text { landscapes, scale of mountains, and quietness of outer country. }\end{array}$ \\
\hline
\end{tabular}

\section{$>$ Experience of former film sites}

\begin{tabular}{|ll|}
\hline $\begin{array}{l}\text { Number } \\
\text { indicated } \\
\text { on scale }\end{array}$ & Explanation \\
\hline & $\begin{array}{l}\text { My expectations were high, but they were beaten because of their pristine beauty, } \\
\text { cleanliness. There is something magical about touching the same rocks, feeling the wind. } \\
\text { Grounding experience. }\end{array}$ \\
\hline 1 & $\begin{array}{l}\text { Much better to be experienced in person than on screen. The vast distances (esp. in } \\
\text { mountains) are much more appreciated during visits to the film sites. }\end{array}$ \\
\hline 1 & $\begin{array}{l}\text { I didn't think they would be as recognisable. I feel like I have not only visited NZ, but } \\
\text { Middle-earth as well. }\end{array}$ \\
\hline 2 & $\begin{array}{l}\text { Edoras was breathtaking, even through the movie set was long gone. The plundered } \\
\text { Rohan village location was wonderful because artefacts were still there. }\end{array}$ \\
\hline 3 & $\begin{array}{l}\text { It was exiting when you could see some of the shots that were in the movie and } \\
\text { recognise them. Others were a bit disappointing as we could not recognise them. }\end{array}$ \\
\hline
\end{tabular}

\section{Expectations not met}

Expected film locations to look more like in the films

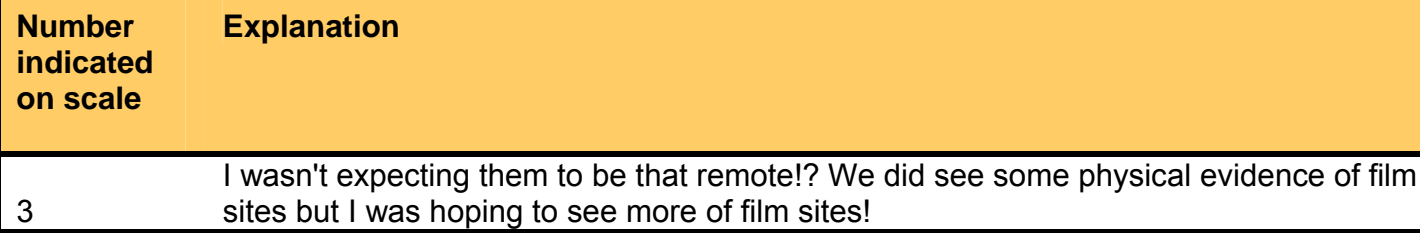




\section{Specifications for tour satisfaction}

\section{Question 9}

Overall, how satisfied are you with this tour experience here? (Please circle number)

$\begin{array}{ccccc}\mathbf{1} & \mathbf{2} & \mathbf{3} & \mathbf{4} & \mathbf{5} \\ \text { very satisfied } & \text { satisfied } & \text { neutral } & \text { dissatisfied } & \begin{array}{c}\text { very } \\ \text { dissatisfied }\end{array}\end{array}$

Please explain your answer!

$\underline{\text { Specifications for tour satisfaction two half-day tour experiences }}$

$>$ General comments and quality of the tour and guides

\begin{tabular}{|c|c|}
\hline \multicolumn{2}{|c|}{ Rings Scenic Tours/ Matamata } \\
\hline $\begin{array}{l}\text { Number } \\
\text { indicated } \\
\text { on scale }\end{array}$ & Explanation \\
\hline 2 & Good tour \\
\hline 2 & It was pretty good \\
\hline 1 & $\begin{array}{l}\text { In depth and comprehensive tour. All explained very concisely and plenty of time to take } \\
\text { it all in. }\end{array}$ \\
\hline 1 & Very informative. Well worth the money. \\
\hline 2 & It was really cool but too many annoying tourists. \\
\hline 1 & Very good guiding; landscape just as expected; good timing (2h) \\
\hline 2 & About what I bargain for! \\
\hline 2 & Was impressed \\
\hline 1 & That how satisfied; fantastic \\
\hline 2 & Expensive \\
\hline 2 & Tour excellent; weather lousy \\
\hline 2 & $\begin{array}{l}\text { 1. It was wet and they supplied umbrellas-it's the small things that count } \\
\text { 2. the tour guide had good knowledge } \\
\text { 3. Van was o.k. }\end{array}$ \\
\hline 1 & Highlight so far of our trip \\
\hline 1 & $\begin{array}{l}\text { Much better than I imagined. The price was somewhat daunting but in the end well worth } \\
\text { it! Fantastic tour guide (Amber). Home grown! }\end{array}$ \\
\hline 1 & Brought my imagination alive! \\
\hline 1 & Better than I expected \\
\hline 2 & Saw what I expected to see \\
\hline 2 & It was basically how I picture it. I found out many different things. \\
\hline 1 & We've seen much of Hobbiton and know more than before. \\
\hline 1 & It was a unique experience \\
\hline 3 & It was pretty good. I just it had looked more like the movie. \\
\hline
\end{tabular}




\begin{tabular}{|c|c|}
\hline 1 & It has helped make my visit to NZ very satisfying. \\
\hline 1 & $\begin{array}{l}\text { The tour is worthwhile and well managed. It is a good "spin off" from the films. I'm a Kiwi } \\
\text { and enjoying exploring my own country. }\end{array}$ \\
\hline 2 & Worth the money \\
\hline 1 & Definitely made fun and real to the full extent it could have been \\
\hline 2 & It was good \\
\hline 2 & Good explanation on details (tree, party field) \\
\hline 1 & Very thorough and informative (maybe a bit too thorough for young ones) \\
\hline 1 & Much fact and many stories \\
\hline 1 & I got answers to all my questions \\
\hline 2 & $\begin{array}{l}\text { Good tour guides. Lot of usual and interesting information. } \\
\text { Shame the set isn't in a very well look after state. }\end{array}$ \\
\hline 1 & Guides were excellent and property magnificent \\
\hline 2 & Very thorough, entertaining, interesting \\
\hline 1 & Excellent tour guide gave lots of details \\
\hline & $\begin{array}{l}\text { Excellent tour guide, very enthusiastic and knowledgeable. Shame more of the original } \\
\text { set not there. }\end{array}$ \\
\hline 2 & Humorous and informative \\
\hline 1 & Wealth of details. Enthusiasm \\
\hline 1 & $\begin{array}{l}\text { The tour guides were fantastic. They brought a brilliant blend of knowledge and } \\
\text { enthusiasm. }\end{array}$ \\
\hline 1 & Much more in depth information about scenes and locations they were filmed. \\
\hline 1 & $\begin{array}{l}\text { Guides are friendly and helpful; allow us to wander around and take pictures freely. Site } \\
\text { is wonderful! }\end{array}$ \\
\hline 1 & Fun+ informative and guide knew all that we wanted to know. \\
\hline 1 & Excellent explanations of where everything was filmed. \\
\hline 1 & Very informative, very friendly guides and a beautiful movie set! \\
\hline \multicolumn{2}{|c|}{ Safari of the Rings/ Queenstown } \\
\hline $\begin{array}{l}\text { Number } \\
\text { indicated } \\
\text { on scale }\end{array}$ & Explanation \\
\hline 1 & Excellent tour with interesting info and experienced driver-many thanks Tony \\
\hline 1 & Good fun, Good info, Friendly guide \\
\hline 1 & Great fun- Great driver \\
\hline 1 & Great driver \& well informed \\
\hline 1 & Good guide, nice people, excellent weather conditions \\
\hline 1 & It's been fantastic- a brilliant experience. \\
\hline 2 & This has been a wonderful way to see NZ at its best. \\
\hline 1 & It's fantastic and we got a "real orc" as a tour guide! \\
\hline 2 & $\begin{array}{l}\text { More information about the filming etc would have been nice, but it was still an enjoyable } \\
\text { experience. }\end{array}$ \\
\hline
\end{tabular}

\section{Landscape of the former film sites/general area}

\begin{tabular}{|ll|}
\hline \multicolumn{2}{|l|}{ Rings Scenic Tours/ Matamata } \\
\hline $\begin{array}{l}\text { Number } \\
\text { indicated } \\
\text { on scale }\end{array}$ & Explanation \\
\hline 1 & $\begin{array}{l}\text { I thought it was a great opportunity to see the landscape and it gave me a good inside } \\
\text { into the amount of time, work and expenses it took to make the film perfection. It was } \\
\text { amazing to gain inside into how they created such a fantasy world. }\end{array}$ \\
\hline 2 & $\begin{array}{l}\text { A great experience to be able to see NZ's countryside and small towns and e this } \\
\text { fantastic movie was created }\end{array}$ \\
\hline
\end{tabular}




\begin{tabular}{|ll|}
\hline 1 & The farm is the Shire, the location is Hobbiton \\
\hline 1 & $\begin{array}{l}\text { The farm is wonderful enough to tour on its own merits, and the set still being here } \\
\text { makes it really special. }\end{array}$ \\
\hline 2 & With the conditions of the set, I couldn't say "very satisfied" but the landscape is stunning. \\
\hline Safari of the Rings/ Queenstown \\
\hline $\begin{array}{l}\text { Number } \\
\text { indicated } \\
\text { on scale }\end{array}$ & Explanation \\
\hline 2 & Amazing views of landscapes. \\
\hline 1 & I was amazed by the scenery here in Queenstown. You had to come here to see it. \\
\hline
\end{tabular}

$>$ Experience of visiting a former film set

\begin{tabular}{|ll|}
\hline \multicolumn{2}{|l|}{ Rings Scenic Tours/ Matamata } \\
\hline $\begin{array}{l}\text { Number } \\
\text { indicated } \\
\text { on scale }\end{array}$ & Explanation \\
\hline 2 & I have been to Hobbiton that makes me satisfied. \\
\hline 1 & $\begin{array}{l}\text { I was so thrilled to see it; not a huge LotR enthusiast but loved every minute and movie } \\
\text { making facts. }\end{array}$ \\
\hline 1 & It was really neat to see an actual partial movie set: the tree and the field was the best \\
\hline 1 & So great opportunity o match the movie with the actual location \\
\hline 1 & I loved the chance to be on an actual film set. \\
\hline 1 & $\begin{array}{l}\text { Totally brilliant- sometimes when you see where a film was made or how it can be } \\
\text { disappointing- this exhilarating! }\end{array}$ \\
\hline 1 & It was amazing to see the location! \\
\hline 1 & Just what I hoped for. Whole family was excited to visit Hobbiton and Bag End. \\
\hline 1 & I loved LotR and like seeing the scenes \\
\hline 1 & Amazing to say “'ve been there!". \\
\hline
\end{tabular}

$>$ Critique on film set remains

\begin{tabular}{|ll|}
\hline \multicolumn{2}{|l|}{ Rings Scenic Tours/ Matamata } \\
\hline $\begin{array}{l}\text { Number } \\
\text { indicated } \\
\text { on scale }\end{array}$ & Explanation \\
\hline 2 & Didn't realise that the set would look so different \\
\hline 2 & Shame that the set is slowly deteriorating. What about future visitors? \\
\hline $\begin{array}{l}\text { Safari of the Rings/ Queenstown } \\
\text { Number }\end{array}$ & Explanation \\
indicated \\
on scale
\end{tabular}




\section{$\underline{\text { Specifications for tour satisfaction multi-day tour experience }}$}

New Zealand and New Zealanders

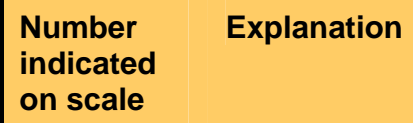

New Zealanders are a diverse cultural group anyway and they seem to welcome all. No one was rude. Kiwis are very down to earth. Tom was great! Great way to see so much in 1 a short time.

$2 \quad$ The landscape was very nice.

$>$ Guides, organisation and composition of the tour

\begin{tabular}{|c|c|}
\hline $\begin{array}{l}\text { Number } \\
\text { indicated } \\
\text { on scale }\end{array}$ & Explanation \\
\hline 1 & Tour guide was very knowledgeable of $\mathrm{NZ}$ and sites \\
\hline 1 & $\begin{array}{l}\text { Even better in reality than expected. Landscapes even more beautiful in reality, } \\
\text { excellent tour guide (Vic James), gorgeous country and lovely people of NZ (very } \\
\text { friendly!). Saw places we would NEVER otherwise get to see! }\end{array}$ \\
\hline 1 & $\begin{array}{l}\text { Great way to see NZ especially because some sights were "off the beaten paths" taken } \\
\text { by tourists. }\end{array}$ \\
\hline 1 & Better than imagined! Tom, Vic + Red Carpet did an amazing job! \\
\hline 2 & $\begin{array}{l}\text { It was rough going-I had a lot of luggage due to travelling for } 8 \text { weeks. I also travelled } \\
\text { alone with my teenage son-it was very challenging to handle all that plus pack and } \\
\text { unpack each night! Seeing lan Brodie was wonderful! }\end{array}$ \\
\hline 1 & $\begin{array}{l}\text { Wonderful tour-so much care and research gone into this. Vic James cares about LotR } \\
\text { and it shows. }\end{array}$ \\
\hline 1 & I only wish we stayed in Wellington longer. \\
\hline $1+10$ & $\begin{array}{l}\text { This was the trip of a lifetime for me. I have loved Tolkien since 1967, } \\
\text { and when people would ask me if I were to go to Fantasy Island (an old US TV series } \\
\text { where people's dreams can come true) I would always say I wanted to visit Middle-earth. } \\
\text { Well, now I have, and if I can get the money together again by next year I'm going again } \\
\text { next summer. This tour was a dream come true for me- it's impossible for me to express } \\
\text { in words how very much I was overwhelmed by New Zealand. }\end{array}$ \\
\hline
\end{tabular}

